Hyenas of the Limpopo 



\title{
Hyenas of the Limpopo
}

\section{The Social Politics of Undocumented Movement across South Africa's Border with Zimbabwe}

\author{
Xolani Tshabalala
}

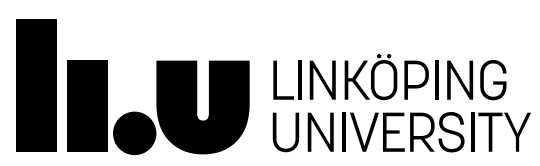

Linköping Studies in Arts and Science No. 729

Faculty of Arts and Sciences

Linköping 2017 
Linköping Studies in Arts and Science • No. 729

At the Faculty of Arts and Sciences at Linköping University, research and doctoral studies are carried out within broad problem areas. Research is organized in interdisciplinary research environments and doctoral studies mainly in graduate schools. Jointly, they publish the series Linköping Studies in Arts and Science. This thesis comes from Institute for Research on Migration, Ethnicity and Society (REMESO) at the Department of Social and Welfare Studies.

Distributed by:

Department of Social and Welfare Studies

Linköping University

58183 Linköping

Xolani Tshabalala

Hyenas of the Limpopo: The Social Politics of Undocumented Movement across South Africa's Border with Zimbabwe

Edition 1:1

ISBN 978-91-7685-408-2

ISSN 0282-9800

(C) Xolani Tshabalala

Department of Social and Welfare Studies 2017

Typesetting and cover by Merima Mešić

Printed by: LiU-Tryck, Linköping 2017 




\section{Acknowledgements}

The decision to pursue $\mathrm{PhD}$ level studies at what in the beginning seemed like a faraway place represented a leap into the unknown. Along the winding journey that has brought me to this point, I have accumulated many debts. I will never be able to recall or pay them all, and in explicitly acknowledging the help of some people here, I remain equally indebted, in the spirit of the gift, to many others whose generosity is all the more appreciated in its namelessness.

I give thanks to the almighty God for holding me up constantly, and I make mention of Him always in my prayers.

I thank the many people who participated in this study, in Zimbabwe, South Africa, and at the Beitbridge border, without whose insights and experiences I could not have been able to put together this thesis. Special thanks go to Msholozi, a key participant who allowed me into his world, and put up with a lot of hours I spent prying into his life and secrets. I also thank all other participants in Zimbabwe and South Africa, in Beitbridge and in Musina towns, and many fellow travellers, migrants, and facilitators, for being generous hosts. Ukwanda kwaliwa ngabathakathi. Lingadinwa lakusasa!

The privilege to rub shoulders with researchers at, and to be part of a stimulating research environment that is REMESO is an experience I treasure well. But this experience has both a beginning and some defining moments.

When I first arrived in Stockholm in early September of 2012, at night, Stefan Jonsson was there to pick me up in a rather old car. I believe he replaced it not long afterwards. That night, Stefan drove with me to his apartment in Norrköping, from where I began to learn and experience, step by step, everything that 
has placed me in a position to complete this thesis. I mention this in recognition of how Stefan has been more than a research supervisor to me. At the very foundation of the many ways in which he has supported me, Stefan has retained belief in my abilities even when I have been beset with self-doubt, which seems to happen often. But he has also, while guiding me along the way, allowed me to discover things for myself. For the many troubles he has gone through on my behalf, and for taking the time to comment on the many ideas I have been experimenting with over the years, I offer my humble thanks.

I also wish to thank Carl-Ulrik Schierup, my other supervisor, for inspired conversations about 'reading' social texts, and situations, and not least for his excellent understanding of the politics and economies of labour migration in South Africa. His insights throughout my studies, and particularly towards the completion of this manuscript, have been indispensable. Carl, I am grateful for your enthusiasm in going through the drafts I have been sending your way, and in providing helpful critique of the theory and methods of studying everyday social situations that are taking place halfway around the globe. Thank you also for your help with life outside the institute.

Zoran Slavnic deserves mention for his helpful interventions at important stages of this process. I have likewise been able to draw inspiration from seemingly mundane conversations with Peo Hansen, Branka Likic-Brboric, Anna Bredström, Magnus Dahlstedt, Patricia Lorenzoni and Anders Neergaard. I offer my thanks to them all. More thanks go to Simone Scarpa, who could not tire in reflecting on the possible directions my research was taking. I thank Aleksandra Ålund too, for insisting that there was a positive end to my PhD journey.

Iz'bongo kuwe Sara Ahlstedt, Viktor Vesterberg, Jennie K. Larsson, Christophe Foultier, Indre Genelyte, Olav Nygård, Andrey Tibajev, Lisa Karlsson Blom, and Ayşegül Kayagil, my 
former and current $\mathrm{PhD}$ colleagues at the institute. Through your reflections and support, I have been able to benefit in writing this thesis as well as in being part of a familiar circle that is connected by a common purpose. Thank you, Julia Willén, for your enthusiasm regarding my research episteme. Special mention goes to Karin Krifors, who, on a particular day along the disserted corridors of REMESO in the summer of 2016, convinced me of the value in not postponing my studies when I had accepted to do just that. Thank you, Karin, for showing me the value you place in life itself. I must mention Nedžad Mešić, whose help at and outside the institute has been altogether immeasurable. Among the countless favours Nedžad has extended my way, he supported me as I carried the burden of mourning my late mother. I can never be grateful enough for that. Nedžad and I have also had innumerable conversations over bad coffee as we burnt the midnight oil at REMESO, conversations that kept the belief in me that 'it can be done'.

Along the way, I have also benefitted from scholars based at different stations, who took the time to read earlier and different drafts of this text. I wish to mention Anja Karlsson Franck, Lisa Åkesson, Khalid Khayati, Cristina Udelsmann-Rodrigues, and Jesper Bjanersen, who gave thorough and precise feedback on what was inevitably rough drafts of this thesis. Special thanks to Anja, who helped me situate my research more clearly, and to Cristina, who suggested a more holistic approach to addressing Southern African 'informality'. I acknowledge Jesper's plea for me to carry through with the ideas I may have, and to not fizzle out like a 'fireworks malfunction'. Can I also thank Joost Fontein, whose passion for writing and research is infectious? Joost advised me to write as often as it is possible. Needless to say, that craft is still coming to me.

In South Africa, my former institute, the African Centre for Migration and Society (ACMS) deserves mention. I have been able to continue to interact with and find a temporary home among 
former colleagues while on fieldwork and other exchanges. I wish to thank Loren Landau, Ingrid Palmary, Jo Vearey, and JeanPierre Misago for their time, resources and critical comments on seminar presentations I have held there. Darshan Vigneswaran made it all happen for me. Thank you Darshan, you have been immense. I must also thank Khangelani Moyo, umasaka olefocus! Khangelani facilitated my fieldwork at the University of the Witwatersrand's School of Architecture and Planning, among many other experiences he shared with me.

I also thank Stanford Mahati, who suggested useful contacts in Musina Town, on the border of South Africa and Zimbabwe. Partly as a result of his contacts, I was able to spend a considerable amount of time conducting fieldwork across the border.

Thank you to Freedom Mazwi and Tonderai Sichone, from the Agrarian Institute in Harare, for helping me access the National Archives of Zimbabwe, and for knowing where to look for specific documents in such a big place. I should also mention Rwayi at the National Archives in Bulawayo, whose help and suggestions on colonial documents was pivotal for the continuation of the archival part of my research work in Zimbabwe.

Special mention goes Eva Rehnholm, Anita Andersson and Bitte Palmqvist, who have helped with the often complex and dense administration terrain at Linköping University. Leanne Johnstone took the trouble to proofread my text, and to suggest solutions to the many problems that come with mobilizing a second language as a writing and communication medium. The inconsistencies that remain in the text are, without doubt, altogether mine. I also thank Merima Mešić, for her patient generosity with the final text adjustments. One could only imagine that it runs in the family.

I have great gratitude for Forte (FAS), who supported my PhD studies while at REMESO. I also wish to thank the Nordic Africa Institute (NAI), for funding my fieldwork in Zimbabwe and 
South Africa, and for hosting me as a visiting PhD researcher in October of 2016. Victor Adetula, the (then) head of research at NAI, deserves a mention for his piercing insights into the challenges that confront contemporary Africa, and for asking direct questions about the substance of my research questions. I reserve special mention for Marie Karlsson, who made sure I found my way around the Institute, and around Uppsala. Through the many interactions I have had with her, Marie has shown me that it is possible to combine studies, family, and floorball. And for that, I am very grateful.

Further gratitude goes to Sparbanksstiftelsens Alfas internationella stipendiefond för LiU Norrköping, through whose generosity I could carry out some of the fieldwork for this study.

There are many other people who have contributed to this journey. I wish to thank Ana Irene Rovetta Cortes, whose passion for research meant that she could share with me ways of troubleshooting through the many obstacles that confront broke PhD students. I also thank the following people, for their company and encouragement in the face of challenging academic tasks. Dion Nkomo, the late Gugulethu Siziba, Sehlaphi Sibanda, Mbuso Moyo, Duduzile Ndlovu, Reason Beremauro, Glen Ncube, Shepherd Mpofu, Fortune Nleya, Sigwabusuku Mafu, Nkululeko Mafu and Noluthando Ncube. These comrades have in their own different ways kept suggesting to me that academic freedom is a pursuit worth following.

To my family in Zimbabwe, South Africa and Sweden, thank you all for putting up with me, for comfort, and for encouraging and giving me things to look forward to. My dad, thank you for never doubting me, even when both of us were not sure where I was headed. Sabelo Tshabalala, Thulani Tshabalala, Phathisani Tshabalala and Makhosana Tshabalala, Salome Ndlovu, Sindiso Ncube, Bekithemba Zikhali, Vusa Chamboko, Mrapper, Mavusana, Layani, Colbert Ndlovu, Mnqobi, Nobukhosi and 
Sindi, thank you for the laughs, and the memories. To my other cousins, nieces and nephews, ngiyabonga kini lonke for being such a happy group.

My friends, Kwanele Mkandla and Ibrahim Jallow, thank you for being there to advise, listen and complain about things. Through our safe conversations, I am often able to regain perspective when issues appear clouded. Thank you kaMkandla for the company over the years. Sphuma kude fanakithi. And then, utsho uliphinde elithi; impilo iyahanjelwa. Jimmy, thank you for placing value in our friendship through thick and thin.

Two women have contributed immensely to this journey, and this season of thanks would be pointless without mentioning them by name. I wish to thank Ayanda Mabhena, the mother of my two sons Khusi and Thobi, for her strength, dedication, and devotion in raising them the way she has. Ayanda, you have done a lot for us. This thesis is dedicated to my mother, who saw its early beginnings, but is not here to share in its end. For all that she was, I could never thank MaKhumalo enough.

Finally, I wish to thank all the anonymous reviewers who read sections of this text, some of which eventually got published as journal articles. I am compelled to note that parts of the Introduction and Chapter Four of this thesis have appeared in the (2017) Journal of Borderlands Studies (DOI: 10.1080/08865655.2017.1348910) under the title; 'Hyenas of the Limpopo: "Illicit Labour Recruiting", Assisted Border Crossings, and the Social Politics of Movement Across South Africa's Border with Zimbabwe'. Chapter Seven has also appeared in the (2016) Journal of Trafficking, Organised Crime and Human Security, 2 (2), under the title; 'Brokerage economies: Crisis, cultural acts, and contested subjectivities at the Beitbridge border of South Africa and Zimbabwe'. 




\section{Acronyms}

$\begin{array}{ll}\text { AAA } & \text { American Anthropological Association } \\ \text { ANC } & \text { African National Congress } \\ \text { BBC } & \text { British Broadcasting Corporation } \\ \text { BSAC } & \text { British South Africa Company } \\ \text { BSAP } & \text { British South Africa Police } \\ \text { CAC } & \text { Central African Council } \\ \text { CBRTA } & \text { Cross-Border Road Transport Agency } \\ \text { CIO } & \text { Central Intelligence Organisation } \\ \text { CNC } & \text { Chief Native Commissioner } \\ \text { CODESA } & \text { Convention for a Democratic South Africa } \\ \text { CoRMSA } & \text { Consortium for Refugees and Migrants in South Africa } \\ \text { DHA } & \text { Department of Home Affairs } \\ \text { CPI } & \text { Corruption Perception Index } \\ \text { ESAP } & \text { Economic Structural Adjustment Programme } \\ \text { ILO } & \text { International Labour Organisation } \\ \text { NAZ } & \text { National Archives of Zimbabwe } \\ \text { NAD } & \text { Native Affairs Department } \\ \text { NP } & \text { National Party } \\ \text { NRC } & \text { Native Recruitment Corporation } \\ \text { SACP } & \text { South African Communist Party } \\ \text { SADC } & \text { Southern African Development Community } \\ \text { SANA } & \text { South African National Archives } \\ \text { SAMP } & \text { Southern African Migration Project } \\ \text { SAPS } & \text { South African Police Service } \\ \text { SARS } & \text { South African Revenue Services } \\ \text { SNA } & \text { Secretary for Native Affairs } \\ \text { SW Zimbabwe } & \text { Southwestern Zimbabwe } \\ \text { TEBA } & \text { The Employment Bureau of Africa } \\ \text { TI } & \text { Transparency International } \\ \text { TTL } & \text { Tribal Trust Land } \\ \text { UNHRC } & \text { United Nations Human Rights Commission } \\ \text { WNLA (Wenela) } & \text { Witwatersrand Native Labour Association } \\ \text { ZIMRA } & \text { Zimbabwe Revenue Authority } \\ \text { ZSDP } & \text { Zimbabweans' Special Dispensation Project } \\ & \end{array}$





\section{Contents}

\section{CHAPTER 1}

INTRODUCTION: Braving the Limpopo 1

A social situation of the borderland 1

Say'wel' iNgulukudela - An analysis

of the social politics of border crossings $\quad 7$

Thesis outline $\quad 13$

The political economy of migrant labour: a regional overview 15

Colonial encroachment and land dispossession 17

Black labour in the capitalist economy 20

Great apartheid $\quad 23$

Settler colonialism and apartheid as strategies of bordering $\quad 26$

'No black in the rainbow'

The role of migration in regional capitalism 31

Precarious labour 31

Dispossession and exploitation 33

Struggles around borders $\quad 35$

Borders, borderlands and frontiers $\quad 35$

The border as a site of struggle $\quad 38$

The Beitbridge border $\quad 39$

Assisted border crossings $\quad 42$

Hyenas, assisted border crossings and ukulayitsha 47

The rise of ukulayitsha 48

Cross-border informality, remittances and ukulayitsha 51 
Framing the problem $\quad 56$

Labour $\quad 56$

Migration 58

$\begin{array}{ll}\text { Borders } & 60\end{array}$

Analytical concepts: articulation and the hyena 62

Hyenas of the Limpopo and the materiality of articulation 64

Border practice $\quad 65$

\section{CHAPTER 2}

METHODS AND METHODOLOGY:

Social history and mobile phenomenology 67

$\begin{array}{ll}\text { Entry points } & 67\end{array}$

Interviews and hangouts with undocumented migrants 68

Ride-alongs with omalayitsha $\quad 69$

$\begin{array}{ll}\text { Mapping the border } & 71\end{array}$

$\begin{array}{ll}\text { A social history and phenomenology } & 73\end{array}$

$\begin{array}{ll}\text { of assisted border crossings } & 73\end{array}$

$\begin{array}{ll}\text { Social history } & 73\end{array}$

Mobile phenomenology $\quad 75$

$\begin{array}{ll}\text { Researcher positionality } & 77\end{array}$

$\begin{array}{ll}\text { A brief note on ethics } & 79\end{array}$

\section{CHAPTER 3}

THEORETICAL FRAMEWORK: Locating border practices in the political economy of migrant labour 85

$\begin{array}{ll}\text { Introduction } & 85\end{array}$

$\begin{array}{lr}\text { 'Pay forward' } & 85\end{array}$

Speaking one's way through the border 88 
Passing for a documented traveller

The motions of border crossings

Border struggles $\quad 94$

Performances and ethics of illegibility 96

Assisted border crossings as practices of proximity 101

Delimiting border struggles at Beitbridge 102

Facilitation: the politics of informality and morphogenesis 103

$\begin{array}{ll}\text { Facilitation } & 104\end{array}$

$\begin{array}{ll}\text { Political and migrant subjectivities } & 105\end{array}$

Banal corruption and the informalisation of border crossings 106

Morphogenesis and subjectivities of transition 113

Dispossession, frontiers of capital and surplus movement $\quad 117$

$\begin{array}{ll}\text { Dispossession } & 117\end{array}$

$\begin{array}{ll}\text { State borders as frontiers of capital } & 119\end{array}$

A case for surplus movement? 123

$\begin{array}{ll}\text { Conclusion } & 127\end{array}$

\section{CHAPTER 4}

SURPLUS MOVEMENT AND ITS FACILITATION:

Border struggles in colonial Limpopo 131

$\begin{array}{ll}\text { Introduction } & 131\end{array}$

Encounters in the Limpopo Valley 135

$\begin{array}{ll}\text { Finding Gatsheni } & 135\end{array}$

The other side of the beckon 139

Surplus labour in the Limpopo Valley 143

On surplus labour $\quad 143$

Mobility and the internal mechanics of surplus labour 146 
'Embarrassing numbers'

$\begin{array}{ll}\text { Building an economy with } & 157\end{array}$

'employed prohibited natives' 157

Phantoms, guns and farms 157

$\begin{array}{ll}\text { Agrarian capitalism and colonial governmentality } & 161\end{array}$

Border farms, border enforcement and precarious labour 161

African nationalist movements, $\quad 165$

border security and migrant labour $\quad 165$

Illicit labour recruiting in colonial Limpopo 167

A territory swarming with recruiting agents $\quad 167$

$\begin{array}{ll}\text { Highway robbery } & 170\end{array}$

$\begin{array}{ll}\text { Policing illicit recruiting } & 171\end{array}$

$\begin{array}{ll}\text { Placating border enforcement } & 173\end{array}$

$\begin{array}{ll}\text { 'Assisted border crossings' } & 176\end{array}$

in post-apartheid Limpopo 176

$\begin{array}{ll}\text { Contesting colonial borders } & 176\end{array}$

$\begin{array}{ll}\text { The multiplication of labour } & 179\end{array}$

Irregular migrant labour, assisted 182

border crossings and frontiers of capital 182

The 'episodic' border $\quad 185$

$\begin{array}{ll}\text { Conclusion } & 186\end{array}$ 


\section{CHAPTER 5}

A HYENA ECONOMY: The embodiment

and sociality of assisted border crossings

Introduction

Hyena-name, practice, or both, or none?

The hyena concept as identity and practice

Hyenas and the social politics of ukulayitsha 202

Hyena in African mythology and folklore 203

Hyenas and ukulayitsha in the Limpopo Valley today 205

Identity, boundary-marking and categories of meaning 210

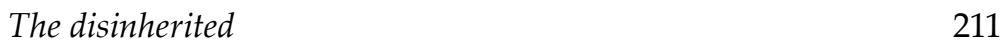

Subverting the symbolic order 213

Risk, obligation and reciprocity 215

$\begin{array}{ll}\text { in assisted border crossings } & 215\end{array}$

On obligation, reciprocity and ukutshokotsha 217

Conviviality and deference in exchange 220

Ukutshokotsha as gift exchange $\quad 222$

'Eating': commensality, social 224

proximity and access to resources $\quad 224$

$\begin{array}{ll}\text { To eat } & 225\end{array}$

When compliance pronounces hunger 227

$\begin{array}{ll}\text { Bureaucratic socialities } & 228\end{array}$

Crossing the border as a motif $\quad 229$

for passing through social categories $\quad 229$

Performing hope 233

$\begin{array}{ll}\text { Conclusion } & 234\end{array}$ 


\section{CHAPTER 6}

'GHOST PASSPORTS': Disembodiment, illegibility and the negotiation of undocumented border crossings

Introduction

The ethics of illegibility

Ghost passports and make-belief

'Documents help, but we're not waiting'

A slap in the face

Illegibility, precarious living labour and dire life 264

Dire life 265

The ambivalence of enforcement $\quad 267$

$\begin{array}{ll}\text { Flight } & 270\end{array}$

Conclusion: Make-belief as appeasement 273

\section{CHAPTER 7}

CONTESTING MIGRANT SUBJECTIVITIES:

Crisis, ambivalence and political identities of transition 277

When fear visits 277

Subjectivities of transition $\quad 279$

'On the subject of crisis' and 'the crisis of the subject' 279

Ambivalence, ritual and subjectivities of liminality 281

Subjectivities of transition 283

Temporal multiple subjectivities of the border 285

Waiting on the move 289

Contesting everyday border subjectivities 296

Crisis, social practices and subjectivities of transition 302

Conclusion 305 


\section{CHAPTER 8}

CONCLUSION 309

Introduction 309

When a good day's work means starvation 310

The social situation of undocumented movement 315

Irregularity as informal politics 316

Vestiges of the past and continuities of the present 317

A bus-full of hyenas $\quad 319$

Paying one's way in $\quad 320$

One eats, the other starves 322

Towards a new conception of the politics of undocumented movement 



\section{Figures}

Fig. 1.1 Msholozi, getting ready to leave Hillbrow, South Africa, to Zimbabwe, March 2014

Fig. 1.2 The Limpopo Valley, shared among four Southern African Countries. Map courtesy of Francis Musoni (2012).

Fig. 1.3 A panoramic view looking towards Zimbabwe (Rhodesia) from South Africa. The Limpopo River can be seen in the middle ground. (Picture borrowed from Trollip, 2013).

Fig. 1.4 The iconic Alfred Beit Bridge, soon after its completion in 1929. Photo clo private collection of Jackf Klaff, 1929.

Fig. 1.5 Motorists Wait for immigration and customs clearance at the Beitbridge border's exit gate, koMalume, into Zimbabwe from South Africa, December 2014.

Fig. 4.1 A private Transporter takes a rest at Bulu rural service centre, Zimbabwe

Fig. 4.2 An old trailer rests besides a grain silo at Gatsheni's homestead

Fig. 4.3 The BSAC's rendering of clandestine migration routes to South Africa from and through the former Rhodesia around 1944. Map reproduced from David Johnson (1990).

Fig. 6.1 The two images above show ordinary immigration stamp imprints on a passport for entry and exit at the Beitbridge border. The image on the left includes a ghost stamp at the bottom centre.

Fig. 7.1 People wait inside koMalume as their goods get processed for customs clearance 



\section{$\boldsymbol{x}$ \\ INTRODUCTION: \\ Braving the Limpopo}

\section{A social situation of the borderland}

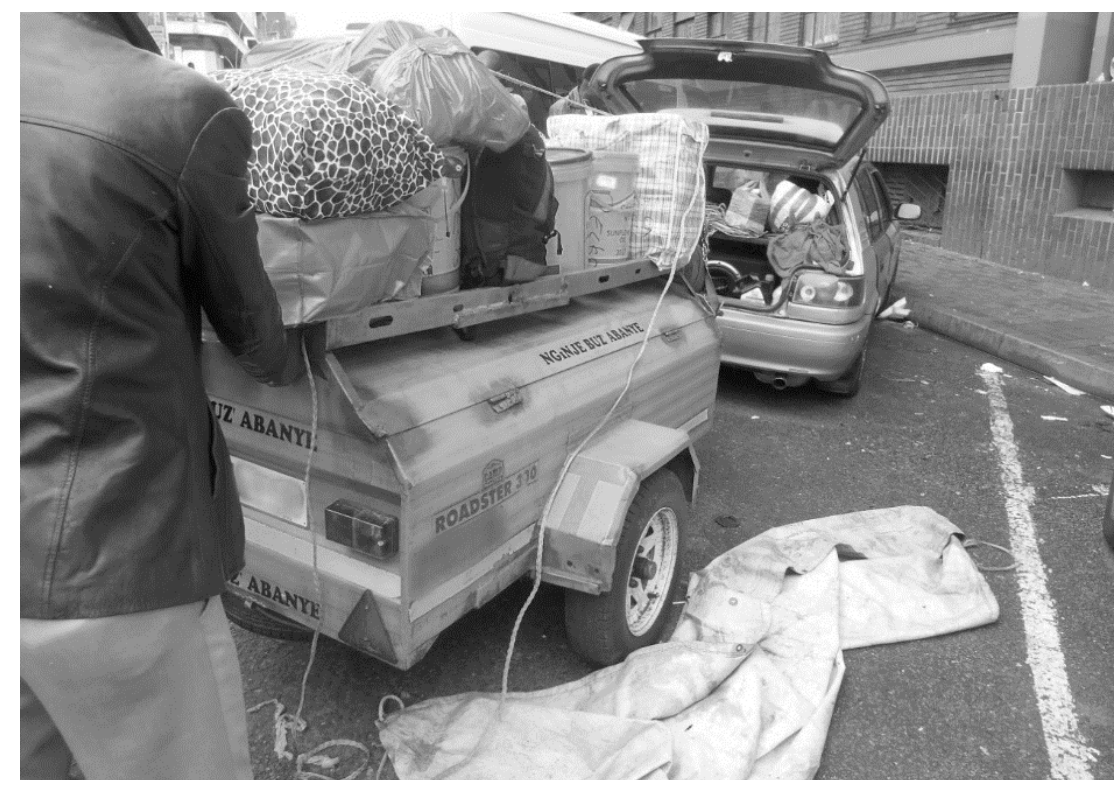

Fig. 1.1 Msholozi, getting ready to leave Hillbrow, South Africa, to Zimbabwe, March 2014

Msholozi, a private transporter, or umalayitsha, is one of many Zimbabweans who use their own cars, small trucks and minibus vans to transport people, goods, money and various kinds of contraband along the Johannesburg-Bulawayo motorway, 
and across the Limpopo Valley. In its entirety, the valley spans parts of Botswana, South Africa, Zimbabwe and Mozambique. It also defines the Limpopo River basin, a mineral-rich subtropical region that boasts a reasonable mixture of black African communal settlements, commercial agriculture and game reserves. The Johannesburg-Bulawayo motorway, a 900-kilometre road transportation corridor connecting South Africa to the Southern African interior through South-Western (SW) Zimbabwe, cuts the valley down the middle and meets the Limpopo River, the territorial boundary between South Africa and Zimbabwe, at the Beitbridge border post.

Between 2013 and 2017, I travelled this and other roads many times with Msholozi and a few other omalayitsha. ${ }^{1}$ This way, I could share the valuable experiences of crossing the border with transporters and their travellers. In this thesis, I reflect on several such instances of Msholozi, other omalayitsha and myself travelling between South Africa and Zimbabwe through the Beitbridge border. They appear below as insights into both their work of private transporting and this study.

One such instance was in Johannesburg, in March of 2014, where Msholozi appeared keen on having me travel with him to Zimbabwe and back. Apart from my intention to stay in Zimbabwe longer than he was hoping, I was equally keen to ride along with him. Msholozi drives a small sedan vehicle (Fig. 1. 1), barely big enough to fit three passengers apart from him. But like many other transporters, his car almost always has four passengers. Parcels in different shapes and sizes often take up much of the remaining space in the car that additionally has a light-duty trailer permanently attached to its back. Msholozi also owns a fifteen-seat minibus (upgraded in 2017 to a 22-seater); the likes of which have become a popular means of low-cost

1. Transporters (plural) - umalayitsha is singular. 
(and sometimes long-distance) public transportation in Southern Africa and elsewhere on the African continent. The minibus pulls an even bigger trailer, itself always (over)loaded with goods, particularly on its way to Zimbabwe.

As was often the case, Msholozi and I were leading a Toyota Quantum minivan on the March day in question. Upon reaching the Beitbridge border, and just before entering the fenced perimeter of the border post, Msholozi went through a carefully prepared series of papers, as if rehearsing to himself how the border crossing formalities might pan out. Later in the thesis, I discuss how this encounter with the techniques of border enforcement tends to reproduce border actors as particular political subjects at an embodied level. By asking me to perform a check on my documents as well, Msholozi appeared to invite me into a similar reflexive stance. In what appears as a mere affirmation of mundane border crossing rituals, Msholozi was in fact preparing both of us for a particular interaction with border enforcement; a space within which resides the social relations that make often-non-compliant border crossings possible.

Indeed, as I wrote down the notes on that crossing a day later, I recalled that although Msholozi needed the paperwork to get his car across the border, he had not used his passport during the entire crossing. I had at one point asked him about his passport, and how he had intended to cross the border without one. To that he had retorted: "passport - my face is the passport!" This, despite a series of permanent police checkpoints as one crosses the border, and where the compliance with formal crossing procedures is constantly enforced.

I rejoined Msholozi at one of these checkpoints when I came out of the South African departure hall after stamping my passport out of the country. He was in a rather animated and jovial conversation with members of the South African Police Service (SAPS). To an untrained eye, this conversation looked like 
regular banter. Msholozi, however, had called these men some hours before we arrived at the border, and they were expecting each other. In this case, their acquaintance worked to trump the strict requirements for passports and other travel documentation as a key part of the border enforcement procedure. Thus, what documents do to enable border crossings can sometimes also be done by talking, and through negotiations between state officials and undocumented travellers, especially with the help of third parties such as omalayitsha.

In this case, Msholozi's ability to talk his way through the official checkpoint represents an aspect of facilitation, a key element of Msholozi and others' transporting business. Acquaintance and relations of trust, such as the ones that were on show as I rejoined Msholozi, demonstrate some of the increasingly popular, although hidden, functions of travelling documents such as the passport. Whether present or absent, documents constitute an important site for an array of negotiations that shape everyday border crossings, particularly at Beitbridge and along the Johannesburg-Bulawayo route.

After leaving the South African departure perimeter, we drove across the Alfred Beit Bridge that straddles the Limpopo River into Zimbabwe. In Chapter Seven, I detail how our stop in the middle of the bridge is a rather permanent fixture of border crossings at Beitbridge. At the arrivals perimeter in Zimbabwe, vehicles are routinely diverted via two routes to their respective processing areas. Haulage trucks and other vehicles (light trucks and minibuses) towing goods in commercial quantities use the red route towards an improvised parking and processing area that has become known colloquially as koMalume (at uncle's place). Buses, small cars and travellers on foot take the green route that goes through the shaded area adjacent to the passport stamping halls. Both routes are subject to police and customs inspections, over and above the immigration procedure of presenting passports for routine stamping. 
In the middle of the open space that makes up the vehicle holding area koMalume, stands a basic steel frame, half-covered in a tattered green canvas. Ideally, the prominent steel structure should function as a gate through which light trucks and other vehicles drawing commercial goods pass as they get processed by border customs officials for entry into Zimbabwe. However, because of a combination of congestion, opaque bureaucratic procedures and especially the seemingly endless negotiations around both, the whole enclosure is almost always swamped with vehicles and people in various stages of waiting, but who nevertheless are often in a hurry to 'clear' the border. The steel gate appears to hold the inconsequential place of formal state regulations where everyday practices inside koMalume and across the border space have come to define a much more complex set of social relations.

Within the bustle that characterises koMalume, Msholozi went from office hall to makeshift counter to checkpoint all around the border perimeter, all the time half-talking his way through the bureaucratic maze with relative ease, half-presenting his papers and half-filling in some forms. The issue of not having his passport on him occupied a quiet presence throughout the crossing. Its significance lay in structuring a discourse that tended to equate the absence or presence of documents with either 'eating' or 'starvation' respectively. The presence of a complete set of travelling documents in a specific border crossing ironically pronounces hunger on the inspecting official, whose intention to discover eventual non-compliance would be rebuffed, and no grounds for 'negotiation' and back-handing of different kinds will be possible. Eating and going hungry describe the different outcomes the nature and presence of documents shape in specific everyday encounters between undocumented goods and people, state officials and third parties who are in the business of facilitating undocumented crossings. 
By not presenting his passport to officials manning the border, and by instead engaging in banter of seeming acquaintance, Msholozi appeared to thus be performing the symbolic task of warding off hunger among state officials. When they eventually came around to search his car for falsely declared goods and for undocumented travellers, they were merely going through the motions. By routinely engaging in these practices, Msholozi and other transporters have mastered the art of assisting border crossings, becoming accomplished exponents of the negotiations that shape the facilitation of undocumented movement across the Beitbridge border. The absence of these social resources represents a stark contrast in border crossings.

On days when I lacked the company of omalayitsha, it was obvious that border crossings are challenging for common travellers. The presence of documents, such as the passport, was itself often a source of frustration and delays. It can happen, as I observed more than once, that a combination of increased travellers and the presence of facilitators or brokers, such as bus drivers and omalayitsha, often creates opportunities for the buying and selling of entry into South Africa, as well as for not declaring goods coming into Zimbabwe and for border crossings in general. Without such intermediaries, documents alone sometimes do little to secure speedy and comfortable border crossings. It can, therefore, be said that, in their presence and absence, documents have a central function in how everyday undocumented border crossings are structured. When passports are present, cross border travel, rather than just a matter of presenting documents at the stamping counters, can sometimes still be wired through additional relations of knowhow, acquaintance and trust. Without these lucrative resources, the border appears as another space that uncovers the abjection of the disadvantaged. Negotiation, the border and the passport thus often interact in relations of both opportunity and disempowerment. 
Say'wel' iNgulukudela - An analysis

of the social politics of border crossings

These and many other experiences and practices that transporters routinely go through and engage in as they negotiate predominantly undocumented travel by labour migrants across the Beitbridge border between South Africa and Zimbabwe are the focus of this thesis. The reader who is acquainted with the history of South African social science and ethnographic enquiry will understand that this is not the first time a 'bridge' has been the focus of ethnographic enquiry into the reality of South and Southern Africa. In 'Analysis of a Social Situation in Modern Zululand', published in 1940, Max Gluckman broke radically with the predominantly functionalist cum colonial social anthropology of the time. By shifting the ethnographic focus from norm to actual practice, placing social process and history, negotiated social conflict, and a multi-sited socio-political perspective at the centre of enquiry, he demonstrated that the Zulus and the dominant whites were entangled in a single societal system that subjected them to one principal cleavage in eastern South Africa at the time (Gluckman, [1940] 1958: 64). Although much water has now flown under the bridges of Southern Africa, Gluckman's work continues to inspire contemporary critical ethnography (e.g. Oxlund, 2010) with 'situational analysis'. In its essence, this is an approach that stresses "the idea of the social, or society, as in a constant state of becoming, an open, a virtual ... a force in its making, going beyond what it might be said to represent" (Kapferer, 2015: 2).

South Africa has gone through two exceedingly dramatic shifts of political regime since 1940. Yet, albeit in transformed shapes, traces of the past's deep social and political economic fractures persist. This is epitomised, not least, in the predicaments of cross border mobility, which stands at the centre of enquiry in the present thesis. With tribute to Gluckman's historical achievement, the thesis builds around the analysis of a social situation that 
represents the negotiation of undocumented border crossings. The Alfred Beit bridge, which is at the centre of the analysis, is as much a concrete and material connection between the two countries as it is a corporeal construct. It is also a sign, symbol and omen, as well as a projection of various desires.

'Say'wel' iNgulukudela siyofuna imali' is the leitmotif of tragic but contestative Ndebele migrant blues stemming from colonial times. Its point is, 'we crossed the river Limpopo to look for money' - not through any welcoming 'door', but through a myriad of daily acts of hustle bridging troubled waters between 'the finite and the finite' (paraphrasing Simmel, 1994 [1909]). It is a hazardous migrant enterprise of the everyday, on which the sustainability of a multitude of precarious livelihoods in present day Southern Africa depends. Yet, it is also a source of much suffering and tragic early death of many migrant workers, today as in colonial times.

So, while Gluckman's analysis took off from observations of a day's pompous celebration signifying the opening of a new bridge on a part of the then British colony of South Africa, my own point of departure is that of millions of repetitive, yet largely improvised daily rituals and practices bridging the challenging borderlands between a depressive Zimbabwe and a not so welcoming post-apartheid 'Rainbow Nation'. It involves the daily cross-border movement of thousands of precarious migrants; whose livelihoods and destinies depend on the skills and ramifying connections of middlemen such as omalayitsha.

In the discussion that follows, I explore the significance of these movements as a specific mode of social politics with deeply rooted historical antecedents. This is to say that as everyday practices, border crossings are more than the mere enforcement of the border through official regulations and norms; they also represent the politics of informal people (Bayat, 1997) - contestations around the governance of movement at street level. Thus, they connect 
to struggles over access to labour markets and livelihoods in conditions of hostility and exploitation, and as such also access to spaces of belonging and participation, at both socioeconomic and political levels. Across the Beitbridge border space, such contestations derive from competing claims of border actors; claims that continuously shape borders as symbols of connections and discontinuities of a complexity of social, economic and political processes. Such contestations are important to analyse with respect to, on one hand, the way they reproduce border actors as political subjects. Beyond that, the ambition of this thesis is to utilise insights from everyday border practices to, on the other hand, make claims about processes of politics and economy that shape regional labour migration. I contend, thus, that negotiations structuring everyday border crossings are key to understanding the role of state borders in the connections and interplay between irregular migration, precarious labour and political subjectivity, as well as the general social transformation of the Limpopo Valley, of South and Southern Africa.

Throughout the thesis, I probe how border practices shape international movement and migrant labour within a general Southern African context of dispossession. ${ }^{2}$ I start from the premise that the enforcement of South Africa's borders, a country which hosts many migrants from Southern Africa and beyond, must grapple with notoriously denationalised labour patterns (Fine, 2014). ${ }^{3}$ At various overland ports of entry into the country,

2. The understanding of dispossession followed by this thesis is one proposed by Judith Butler and Athena Athanasiou (2013) which posits it in a double valence, or as a dialectic of deprivation and political responsiveness. This concept is unpacked in the conceptual discussion that follows.

3. Denationalisation here directly pertains the regional scope of the labour market system that sees a labour pool drawn from the rest of the Southern African regions converging in South Africa in search for livelihoods. Denationalisation also pertains, as Janice Fine (2014), quoting Segatti (2008) has proposed, the reduction in South Africa of the indigenous population into foreigners, which had the effect of blurring the distinction between black South African and foreign labour in colonial and apartheid South Africa. This denationalisation has important consequences for the 
the tension between cross-border movement and its enforcement is sometimes visible in border practices that accompany official attempts to manage officially unwanted but usable labour. Here, border enforcement practices aimed at restricting the entry into and exit from the country of low-, semi- and unskilled crossborder migrants are only partially effective.

In many cases, such controls partly work to sustain evolving practices where a lack of adequate grounds for admission does little to discourage such movement, but creates opportunities around its facilitation (Tati, 2008). As such, those entrusted with border enforcement, as well as local fixers and those engaged in undocumented cross-border movement itself, have come to interact in and benefit from these sometimes-ineffectual controls, particularly from their active circumvention.

These actors - the 'hyenas ${ }^{4}$ of the Limpopo - are only one visible manifestation of a broader system. As I presently discuss and show throughout the thesis, proletarian border practices, which involve the facilitation of undocumented movement across the Beitbridge border, dramatise a response to and engagement with broader structural processes of 'bordering' that drive a regional political economy which is partly built around and shapes cheap cross-border migrant labour. However, my argument is not that states, especially South Africa, and their actors - immigration, customs, police and officers working in the labour ministry and other relevant government departments - act in ways that deliberately seek to cultivate or sustain such a system. It is not the focus of this thesis to furnish such evidence.

reconstitution of the post-apartheid labour market and its associated politics of precarity, as well as the very notion of borders in the region.

4. The local actors who participate in the social economies of undocumented movement coalesce around private transport operators such as Msholozi (introduced above). While private transporters are locally known as omalayitsha, they call themselves and those they interact with izimpisi, or hyenas. More on this follows below. 
A broader perspective, however, suggests that cross border movement patterns have evolved within a context in which the stringent policing of movement conflicts with, or rather nurtures, the general proliferation and engagement of cheap migrant labour in the various sectors of the South African economy. It would appear that the tension between state territoriality and regional political economics shapes border practices that, in spite of, or more accurately, because of, official regulatory norms of border enforcement, are by their nature sometimes geared towards the illicit. What many would regard as smuggling and trafficking in this case can be demonstrated to represent the kind of leeway that reconnects to systems that continue to benefit from precarious labour, including those drawn from a broader Southern African region. In this thesis, I approach cross-border movement at Beitbridge as emblematic of how official border enforcement interacts with everyday social, as well as structural relations to shape such a context of border crossings. Thus, this thesis proceeds along this general understanding.

In some ways, the Johannesburg-Bulawayo motorway, and indeed the Beitbridge border that it bisects, both stand as enduring metaphors for how everyday practices of movement meet the laws that must govern them. If one considers that today, the millions of travellers passing through the Beitbridge border post annually (Mills, 2012) contrast sharply with about 200,000 annual crossings in 1990 (Crush \& Tevera, 2010: 5), one might imagine how much border practices there have been evolving over the last decade and beyond. But, the story of the intensification of movement across Beitbridge must be put in a broader historical and political economic context.

In the political economy of relations between South Africa and Zimbabwe that go back for over a century, the interaction between systems of domination and migrant labour finds a special place. This interaction is the subject of much debate in the region's scholarship on the history of colonialism, the political 
economy of migrant labour, the rise, fall, and effects of apartheid, economies of transition, post-independence neoliberalism and labour market fragmentation, Zimbabwe's authoritarianism and associated displacement economies, and so on. Within this vast field, this thesis aims to demonstrate the actual interaction between processes that bring about and sustain undocumented cross-border movement and precarious migrant labour, some of which connect from the ones flagged above, with everyday border practices shaping context-specific border crossings at Beitbridge. The hyenas of the Limpopo, who are the brokers of this interaction, are central to this discussion as they help me explore how social actors are implicated in the politics of movement, and more broadly in the very nature of Southern Africa's migrant labour systems.

This undertaking intervenes in several research contexts and is valuable in at least three ways. First, and in part due to its methodological approach, this thesis partly breaks new ground by carefully connecting a socioeconomic analysis of the labourmigration-border nexus to an analysis of the modes of subjective experience and social identity that characterise border struggles. In this sense, my study is also relevant far beyond the specific Southern African context in which my observations of the articulation of structural processes and mundane everyday experiences are anchored. Second, this thesis contributes more specifically to migration studies by offering a comparative perspective from a region that is undergoing rapid social changes, but that often escapes wider interest. By taking Beitbridge as a case study and an entry point, I show how systems of migrant irregularity and precarity interact with economic informality to drive contemporary forms of accumulation, dispossession and governance of society in a neoliberal, as well as politically and economically fragmented Southern African context. As I demonstrate, migration in this regional context enables a new view of what borders are and what they do. Third, my study helps us to think about the kind of human subject the migrant is, or 
becomes. The study enables a deeper understanding of migrant agency in situations marked by crisis and ambivalence. It offers a concrete analytical portrayal of the uncertainties and dislocations that accompany the meanings of being a cross-border precarious migrant. Through a concerted discussion of the tenacity and ingenuities of a set of unassuming political actors at the Beitbridge border, this study has implications for the continuing evolution of the nation-state and conceptions of subjectivity in post-colonial African countries. In this sense, it may perhaps serve as an opportunity to rethink not just the narrative of Africa's present and future, but also the narrative of migration itself.

\section{Thesis outline}

The thesis, as a whole, is structured into eight chapters. From their differing approaches, they converge on the place of third parties in broking undocumented border crossings at Beitbridge for over a century. They sustain the argument that facilitating undocumented border crossings is a mundane dramatisation of various contests around regional political economy, international movement, categories of belonging, spaces of political participation, social justice and social transformation, all of which are emblematic of Southern Africa's state-society relations in general.

The remainder of this introductory chapter sketches out the history of South Africa's relations with Zimbabwe. I explore the role of migration in colonial, apartheid and post-independence, neoliberal regional capitalism. I reiterate the nature of borders as sites of struggle before I describe the Beitbridge border specifically. At this point, I introduce border practices of facilitation under the concept of assisted border crossings. Assisted border crossings demonstrate how labour, migration and borders articulate with each other. Taking this as the frame within which I situate the problem that this thesis grapples with, I then ground articulation 
as helpful in fashioning my own analytical tool - the hyena concept - with which to discuss the empirics of the thesis.

Chapter Two is a brief outline of the methods and methodology that underpin this study. In Chapter Three, with insights from critical border studies and critical realism, I engage in a comprehensive discussion of the theoretical terrain and conceptual tools that situate and are mobilised by the thesis. Chapter Four relies on a combination of archival records, secondary empirical material and ethnography, to chronicle the historical role of middlemen in what was in colonial and apartheid Limpopo conceived as illicit migrant labour recruiting across the Beitbridge border. The chapter uses these figures as the backdrop of a substantive discussion on the tangle between irregular migration and precarious labour that has shaped the region's industrialisation processes from the precolonial times to the present.

In Chapter Five, I use observations and data gathered while riding along with omalayitsha and mapping the Beitbridge border to pursue a discussion that focuses more squarely on practices of assisted border crossings, as well as the identities that shape them, as they obtain in the present. The hyenas of the Limpopo, who are the exponents of such practices, are discussed in detail in view of what they and their practices mimic in a broader perspective. Chapter Six focuses on the role of travelling documents, especially the passport, in practices of assisted border crossings. In their presence or absence, passports, especially their perceived importance in cross-border movement, prove indispensable for the negotiation and facilitation of undocumented border crossings.

Chapter Seven continues the discussion of the previous two chapters, to explore the political subjectivities engendered by practices of assisted border crossings. Such a discussion makes direct linkages between contemporary everyday practices and experiences, and broader patterns that guide the social 
transformation of the Limpopo Valley and the Southern African region. In the concluding Chapter Eight, I return to Gluckman's situational analysis to provide a retrospective view on how assisted border crossings have been unravelled, layer by layer, throughout the thesis. I end the thesis by discussing the consequences for approaching undocumented cross-border movement between South Africa and the Zimbabwe the way I have done.

\section{The political economy of migrant labour: a regional overview}

The Southern African region in which the Limpopo Valley sits (see Figure 1.2) has been, for as long as contemporary historians can recall, a region of constant movement. ${ }^{5}$ Across such a time spectrum, in which mobility has been significantly associated with ongoing struggles over the regions' resources, this brief overview takes interest in mid-nineteenth century South Africa and Zimbabwe onwards. The overview aims to show that Southern Africa's path towards industrialisation ${ }^{6}$ represents a

5. Alois Mlambo (2010) provides a recent synthesis of a great many works of scholars on Southern African mobility from as early as the $1100 \mathrm{AD}$ epoch.

6. The general understanding is that the regional economy begins to exhibit robust forms of capitalistic accumulation from the early 1800s when the agricultural, trade and feudal economies of coastal South Africa gradually give way to mining and prospecting in the interior. In line with these changes, the British imperialists, who had wrested control of these coastal economies from the Boers and indigenous Africans, begin to show firmer interest in the interior as the mining boom took off in the 'Transvaal', culminating in the formation of the Union of South Africa in 1910 as a unitary, colonial state. It is thus from the 1850s that more or less distinct and corresponding patterns of the movement of black migrant labour start to appear, themselves soon circumscribed to drive the interest of colonial capital. British colonial hegemony in South Africa was succeeded by Apartheid in 1948, which ushered in a new, heightened phase of the coercion and exploitation of black labour. Apartheid ended in 1994 in South Africa. In Zimbabwe, British domination of Rhodesia ended in 1965 , but white settlers unilaterally declared independence and continued colonial rule until 1978. Zimbabwe attained its independence from settler colonial, or minority rule, in 1980, after a year or so of negotiations (see, for instance, Porter, 2014; Arrighi, 1966). 
radical shift in terms of both mobility and political economy for the most part because new forms of contestation, struggle and resistance came to bind up with overtly segregative systems of capital accumulation. From that point, these processes have been shaping the region's social transformation to the present along more or less distinct patterns.

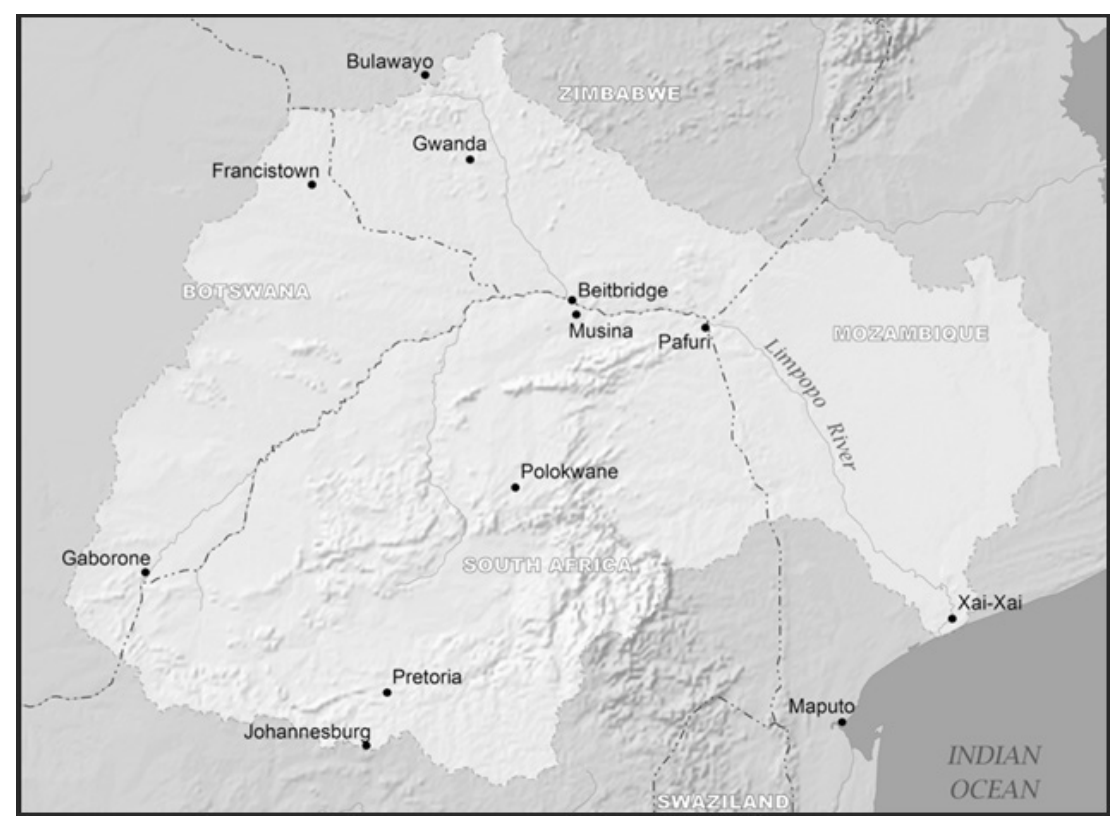

Fig. 1.2 The Limpopo Valley, shared among four Southern African Countries. Map courtesy of Francis Musoni (2012).

A more immediate aim of this characterisation is to follow the changing nature of African migrant labour from an initial period of largely free-roaming, if reluctant, waged employment, through colonial land dispossession and apartheid inspired racialised controls on both work and movement, to the post-apartheid era of general irregularity characterised by an ambivalent migration regime. Beginning with discretionary non-market compulsion, African migrant labour went through two successive phases of direct coercion. If colonialism focused more on land expropriation 
and the extraction of taxes from indigenous households, apartheid mechanisms build on these systems of dispossession to formally manage such labour circumscription, especially its movement and social reproduction. The post-apartheid era oversees a skills orientated regime of mobility where generally lax border controls nonetheless encourage rampant irregular movement and associated informality. Although these phases may appear discontinuous, this overview seeks to make general links between them along which some form of path dependence emerges to partly structure undocumented border crossings and their associated practices.

\section{Colonial encroachment and land dispossession}

In the first half of the 1800s, after the British had successfully annexed the Cape and Natal colonies in the south and east of present day South Africa, they set about advancing into the interior. In a period of political upheaval, ${ }^{7}$ and due to their inferior numbers, however, the British were initially content to share authority over the greater South African territory with Boer republics and African kingdoms. In a coexistence of general mistrust, they nevertheless progressively annexed more and more land through their constant wars with both the Africans and the Boers from the late 1700s. It is partly for this reason that the territory that makes present day South Africa had, by then, already been "teetering on the brink of some dramatic extension in imperial control", although the cost of such an effort had at first been deemed prohibitive (Porter, 2014: 85). So, although available land gradually fell into settler hands, and primarily British influence, the shortage of labour scuppered the expansion

7. The existing African kingdoms in this part of the world were undergoing their own political reorganisation under what became known as Mfecane (1750s to 1830s). The Matabele kingdom, which the British would later annex in what later became Zimbabwe, has its origins in these machinations in the Natal. 
of the early agrarian economy for both the British and the Boers under free market conditions (Feinstein, 2005). The lack of direct coercion of abundant but reluctant black labour had so far left early settler economies small and vulnerable to local, natural and global market forces.

A similar challenge appeared in the early twentieth century settler economy in Rhodesia (Zimbabwe), the territory immediately north of the Limpopo. Exposure to price movements in the world economy, coupled with a preference by indigenous Africans to produce and sell mainly agricultural resources rather than engage in waged work, had suppressed the expansion of the capitalist economy (Arrighi, 1972). This 'delay' in the participation of Africans in the regional labour market would soon drive European settlers towards more coercive methods in both territories.

A few decades earlier, the discovery of substantial diamond and gold deposits from the late 1860 up to the 1890s in the South African interior had seemed to confirm this trend. The incentive for "strong, centralised, overall responsibility for relations with the natives" was geared towards solving "the formidable character of the native question" (Porter, 2014: 86). The otherwise arduous Cetshwayo and his Zulu kingdom fell to British hands in 1879, followed immediately by two bitter wars between the British and the Boers in 1880 and 1889. Prior to this interregnum, a long series of 'Kaffir Wars' (1870s to 1880s) between the Boers and the Africans had largely succeeded in turning a broader swath of indigenous blacks, especially in the well-established white settlement areas south of the Limpopo and Orange rivers, into peasants and proletarians. At this point, "the 'native question' was no longer one of relations with external autonomous nations, but a question of domestic land allocation and labour recruitment" (Porter, 2014: 88). A combination of droughts that decimated the Africans' residual semi-subsistence, as well as the defeat of the Boers in 1902, completed the process of British 
expansion, resulting in the negotiated formation of the Union of South Africa in 1910 as a unitary state. Three years later, the Land Act of 1913 saw the setting aside of some 87 per cent of the country's surface area for whites, while the dispossessed blacks were resettled in so-called 'native reserves', where treaties were signed with them to 'protect their land rights' (Hasani, 2003). In any case, reserves were almost always too small and often on the most unproductive land.

It was during the careful territorial expansion [to encircle the mineral rich Transvaal] that gave birth to the Union that, in 1888, the imperialist Cecil Rhodes formed the British South Africa Company (BSAC) to occupy Matabeleland and Mashonaland in the north of the Limpopo, a manoeuvre that later led to the proclamation of Rhodesia as a British colony. By the late 1880s, the indigenous and politically powerful Matebele kingdom was inundated with settler requests for land grants, purportedly for mineral exploration. ${ }^{8}$ The belief was that Rhodesia could yield the same gold reserves as South Africa, if not more. Through a combination of negotiation and deceit, Cecil Rhodes had by 1889 gained British permission, unbeknown to the Matebele ruler, King Lobengula, to not only explore Rhodesia for minerals, but to administer it politically as a British Protectorate. By 1890, land claims were being sold off to settler buyers by the BSAC as concessions for mining. Finding little gold, the BSAC exploited a local conflict between amaShona and amaNdebele in 1893 to seize the territory on humanitarian grounds. Several rebellions by the indigenous Africans up to 1896 were snuffed out by superior BSAC gun power.

Up to 1918, BSAC rule via a Legislative Council seemed to be acceptable to white settlers who by now occupied prime Rhodesian land. However, Rhodes' Royal Charter contained strict stipulations

8. The British Empire, [N.d]. 
for the protection of black Africans. The British Crown had hoped to avoid the institutionalised theft of land from Rhodesian Africans as had befallen the same group in South Africa. Failing to either incorporate Rhodesia into South Africa or quell settler discontent over the Charter's protections, however, the BSAC handed over control of the Rhodesian territory to the settlers by 1923. Wasting little time in consolidating their newfound 'independence', settlers quickly rolled out a series of Land Acts to secure the redistribution of land under a dual tenure system (Riddell, 1980). The Land Apportionment Act of 1931, for instance, merely served to legislate a pattern that was some 20 years into existence. By 1902, Africans had already been expropriated from no less than 75 per cent of all land in the territory (Arrighi, 1972: 208). Nevertheless, the Acts served to justify the actual removal of the dispossessed into labour reserves, which, being administered through traditional chiefs as proxies, were to be officially designated Tribal Trust Lands (TTLs).

\section{Black labour in the capitalist economy}

The issue of black labour in the South and Southern African capitalist economy predates the official demarcation of the region's borders (Fine, 2014). In the absence of centralised administration, therefore, it should be borne in mind that well into the later parts of the nineteenth century, the matter of labour, particularly farm labour, was largely one of localised agreements between workers and employers. Janice Fine (2014: 331, quoting Crush, 2008) writes that it was upon this system that

... over time a parallel, more informal and unregulated system emerged as the regime signed localized agreements to allow commercial farmers to recruit temporary and cross-border migrants and in later periods sometimes offered illegal labour migrants the option of working on commercial farms rather than being deported. 
With theland question more or less settled by 1900, imperial capital, with the help of its erstwhile enemies in the Boer population, needed to do more to further induce proletarianisation. The imposition of various household and communal taxes on African communities in both the colonial territories of South Africa and Rhodesia appears to have significantly addressed the labour question (Wotela \& Letsiri, 2015). By applying financial pressure on otherwise semi-self-sustaining communal Africans, settler authorities had the aim of coercing enough waged labour, even among the most reluctant and independently minded, into a burgeoning system of racialised capitalist industrialisation.

One view is that the weak administrative capacity of the earlier settler authorities over African settlements away from industrial production enclaves rendered such coercion virtually useless. Another view, however, suggests that a continued semblance of independent 'tribal areas' later came to strongly subsidise the costs of labour reproduction for both colonial and apartheid capitalism (Wolpe, 1972). It may be argued that this pattern was already in place by the 1850s. Save for pockets of influence by African chiefdoms, which were often incorporated into the colonial systems of domination as allies and proxies to uphold the emerging regime of cheap labour, the European occupation of present-day South Africa was by then about complete, and African labour had become quite pliable.

Once the Boer Republics who had settled earlier and largely pursued farming enterprises across this region were brought under control, the British could more firmly press their political economic interests in the interior. By the 1890s, and with most former African settlements overrun and retained largely as native reserves, Tswana, Zulu and other migrants started appearing on the mines of the present-day Transvaal to seek waged work (Callinicos, 1980). Some of these workers were farm workers who were already accustomed to labour migration (Fine, 2014). Beyond land resettlement, the rapidly expanding mining 
industry necessitated the consolidation of industrialisation through direct strategies of coercing that labour. Strategies such as issuing migrant workers with short-term contracts in order to exclude them from the economic and social mainstream, the compound system where they were housed in single sex barracks and worked under oppressive conditions, and the requirement to return to their native reserves upon the expiry of their contracts (Crush \& Tshitekere, 2001) represent some of the bases on which apartheid later built its edifice.

In that new era of social organisation at the turn of the nineteenth century, the growth of the mining industry also oversaw the growth of cash markets, thus leading to the growth of commercial agriculture in the region. Charles van Onselen (1976) suggests that in response to the new markets in the interior, some settler landowners had initially used sharecropping by loaning African producers their land to work. But this meant that some such Africans could avoid wage labour through independent production. By soon deriving substantial profits from these arrangements and inheriting the systems the Africans had built, however, settlers soon rendered black tenants redundant, partly turning them into farm labour instead. From the perspective of both colonial capitalism and wage labour, the competition between gold and maize meant that mines attracted more labour, but prospecting for minerals and widespread speculation pushed up the value of land in general. The mining revolution is seen as having resolved the question of land by consolidating commercial agriculture, while black labour, including former sharecroppers, increasingly fell into exploitation and oppression. These general patterns are not without complexities, but they laid the ground for separate development that later gave birth to apartheid in South Africa. 


\section{Great apartheid}

In the context of this study, it is important to emphasise that the processes just described set in motion a political economy across the Limpopo Valley region premised on land alienation for indigenous black populations, labour migration, capitalistic centres of production, and predominantly European settler mining and agriculture. Thus, the emergence of segregative social engineering in both territories appeared in a racialised political economic regime characterised by a brutal extraeconomic coercion of black labour (Legassick, 1974).

To paraphrase Wentzel and Tlabela (2006: 50), the strategy of exploiting cheap labour on a large scale, as well as its control through the application of laws that governed movement and the compounds, lay the ground for "a system that dominated migrant labour in South Africa for more than a century". The full force of this system came into effect when the National Party (NP) won the 1948 general election in South Africa. In the wake of black labour militancy in the urban areas, the compromise that had held together British and Afrikaner (Boer) interests fell apart (Lodge, 1986). In its place, extreme right-wing politics sounded the death knell on British colonial influence. The Bantu Authorities Act of 1951, together with other Acts that further legislated the exclusion of blacks from regular society, oversaw the designation of native reserves as 'homelands', or Bantustans. These new enclaves of dispossessed indigenous people were meant to be spun off as independent countries for indigenous blacks. Largely overcrowded and economically poor, they succeeded mainly in creating a reserve army of 'surplus populations' (McIntyre, 2011). Black labourers could never hope for freedom to move and work as they wished in the now separate 'white' areas, and they were compelled to return to their 'homelands' after a lifetime of racialised work in the mines, farms and cities of apartheid South Africa. An aspect of this system of circular migrant labour was that in its racial bias, it conflated indigenous and foreign 
blacks into a single class by denationalising both (Segatti, 2008). However, in that same stroke, it reproduced migrants from outside South Africa as foreign in the second sense; a tradition that finds knew articulations in the contemporary post-apartheid nationalist discourse.

Apartheid was, in its essence, a way of systematically engineering a dual reproduction of labour in that it instituted forced circular migrant labour, kept cheap through administrative and political strategies. This came about by having the cost of labour reproduction partly offset by 'non-capitalist' sectors of the economy in the Bantustans. Dual reproduction also had regional ramifications in that, by tapping into labour reserves from beyond the territorial boundaries of South Africa, apartheid capitalism inherited and strengthened a broader regional migrant labour system. Although this scenario was also not without contestation, it largely defined the way colonial and later apartheid based administrative mechanisms attempted to directly and indirectly regulate people's lives, and especially their movement and labour, on a local and regional basis.

In Rhodesia, pressure on land in the reserves drove increasing numbers of Africans after the 1920s into labour redundancy. Giovanni Arrighi (1972: 222) writes that the gradual acceptance of waged labour within a dual or racialised system by Rhodesian Africans was less an original state brought about purely by colonial capital market forces as it was by non-market compulsion in the form of forced removals and their effect on peasant economies. If Rhodesia's fertile lands sustained its economic fortunes up to the 1960s, in no small part due to the economic impetus brought about by the two world wars (Johnson, 2000), such a boom failed to attract African labour. Thus, the demand for cheap labour in the commercial farms, mines and related industries often outstripped supply. Among black Africans, therefore, there was considerable reluctance to engage in wage labour, so that in Rhodesia, a "floating population of the 
unemployed" became a byword in official employment reports. ${ }^{9}$ A combination of low wages, the ever-present threat of forced labour and demand for African labour in South Africa's mines which were better paying, created a labour market differential that has spawned clandestine mobility patterns that endure to the present.

Through the colonial period, Rhodesia wished and often implored South Africa not to employ African labour arriving in its territory without authorising documents. However, primarily in the farms towards the northern border with Rhodesia, the potential benefits of engaging such labour meant that such requests to bar clandestine labour from entering went largely unheeded (Bolt, 2011). With British influence in the region on the wane, ${ }^{10}$ apartheid firmly in place in the mid-twentieth century South Africa and a significant part of African labour drawn from Zambia, Malawi and Mozambique, Rhodesia came into a political bind. International allies openly castigated South Africa's apartheid policies, and increasingly looked at Rhodesia with the same eyes. Unwilling to share power with African political elites, Rhodesian white settlers took the initiative to unilaterally declare independence from Britain in 1965, the aim being chiefly to maintain existing settler rights.

In the wake of what Britain considered a rebellion, rising militancy among black trade unionists, as well as the fragile and small settler population, Rhodesia's isolation necessitated the rapid but ultimately unsuccessful proletarianisation of the African populations (Arrighi, 1968). The declaration of independence culminated in the seizure of power by a core of right-wing settlers in a pattern similar to the emergence of

9. NAZ S2239. Labour Monthly: 1953 October to 1960 October. Southern Rhodesia Department of Labour Monthly Report: July 1960

10. South Africa was granted full independence by Britain in 1931. 
apartheid in South Africa. Such an interest coincided with the rise of the African nationalist movement which had the inevitable effect of heightening the minority regime's repressive machinery. The relative success of the settler government in curtailing the growth of the liberation movement had left the British government and other reformist groups with no alternative than to accept settler rule, which continued for the next fifteen years.

Africans from 'independent' Rhodesia and elsewhere who chose to seek work in South Africa at that time were met with a 'workplace racism' founded on an immigration policy that promoted a 'two gates system' (Fine, 2014: 332). Only whites, mainly from Western Europe, could enter South Africa legally, that is, through the front gate. Blacks were confined to the back gate, which barred those deemed undesirable while allowing low wage migrant workers on temporary contracts (Segatti, 2011). Caught up in this informal migrant labour system, such migrants were at times ignored, although sometimes marshalled into forced work in mines, on farms and in manufacturing, often later to be arrested and deported (Crush \& McDonald, 2001).

\section{Settler colonialism and apartheid as strategies of bordering}

What makes the more or less similar patterns of the development of colonial and apartheid capitalism in South Africa and Rhodesia interesting for this research is the development of a regional migrant labour system that connects them. In terms of historical context, therefore, I situate this thesis within scholarship on the political economy of settler colonial capitalism and the associated movement of black labour power between the two colonial territories. ${ }^{11}$ As indicated, there is consensus within this field that

11. Alan Jeeves $(1983,1985,1986)$, Sampie Terreblance (2003), Harold Wolpe $(1972,1988)$, Giovanni Arrighi (1968, 1970), Charles van Onselen (1976), Frederick Johnstone (1976) 
by the end of the nineteenth century, a pattern was established that saw especially black African males attempting to cross the Beitbridge border clandestinely to seek work in the farms and mines of South Africa (Johnson, 1990). van Onselen (1976) has suggested that to grasp this phenomenon, scholars need to view the region as part of a single economic system in which centres of production and labour reserves are connected.

My intervention in this debate would be to reiterate that in colonial economic outlook, and particularly in South Africa, borders were more about how race and class came together to bifurcate a new working class. Whites came to belong to a comparatively privileged group, and blacks to an oppressed, underpaid one. Although struggles always existed (the growth of trade unionism in tandem with anti-apartheid struggles as a case in point), the white working classes were perceived as allied to the administrative and capitalist structure, while the blacks subsisted in native reserves, Bantustan and township enclaves. The political and administrative motive to control territorial borders (and other boundaries) can be traced here. It has served as a grounding premise for how regional cross-border movement has become governed. Therefore, it has also shaped the border practices that interest this present study.

In sum, the movement of surplus migrant labour between Rhodesia and South Africa can be traced along distinct dimensions. First, the coercion of black Africans into wage labour through land appropriation and the imposition of taxes. Second, the simultaneous rise of competitive commercial agriculture and mining in both South Africa and Rhodesia, labour market differentials, and the formal and parallel/illicit recruitment regimes connected to such factors. Third, the

and Belinda Bozzoli (1987) are some of the preeminent scholars that have explored this field. 
exploitation and manipulation of African labour as a deliberate and well-organised strategy of creating and maintaining a highly racialised political economy, and the reorientation of borders and boundaries towards maintaining its edifice.

\section{'No black in the rainbow'}

In the post-independence era, which later discussions explore, the growing informalisation of the South African economy (Theron, 2010; Schierup, 2016), coupled with residual apartheid restrictions on movement (Fine, 2014) have continued to narrow official pathways for documented movement. Meanwhile, we are almost into the third decade of Zimbabwe's economic decline, which from around the year 2000 onwards, has been responsible for what Jonathan Crush and Dan Tevera (2010) have called 'Zimbabwe's exodus'. Millions of labour migrants and economic refugees from Zimbabwe have been feeding into a cross-border phenomenon that now sees the widespread clandestine crossborder movement of low-skilled Africans.

The 1980s marked a phase that saw a reconstitution of note to regional patterns of movement. As Alois Mlambo (2010: 53 - 67) has noted, up to this point, both Zimbabwe and South Africa had been net receivers of migrants. With Zimbabwe, especially the southwestern parts, experiencing political instability, and South Africa edging closer towards independence from Apartheid rule, the 1980s repositioned Zimbabwe as both a sender and conduit for increased southward human mobility. Nevertheless, it is the post-1990 phase that, for several reasons, saw such movement increase significantly in volumes, become mixed in nature (Crush, Chikanda, \& Tawodzera, 2015), and significantly tied up to broader informalisation processes (Schierup, 2016, 2017). 
Undocumented movement especially into South Africa has thus become a dominant feature of the post 1994 era. ${ }^{12}$ An initial stumbling block in the way of legalised movement was an immigration policy regime that has been significantly tied to the same exclusionary discourses of the past. Writing in 2001, Sally Perberdy suggested that such a migration framework is rooted in post-1994 South Africa's wish to be internally inclusive after decades of racialised segregation. Representing the interests of all South Africans meant shifting the exclusionary policies of apartheid to the external territorial border, so that, to clearly define those who truly belonged to the new rainbow nation, immigration policy had to clearly spell out those who did not. And those who did not are made up largely of the many African migrants now finding their way into a South Africa they perceive to offer better chances for their economic livelihoods. Upon arrival, however, they are confronted with an equally xenophobic climate built on a discourse that positions black foreigners in the same way that apartheid saw blacks, South African or not. 'No black in the rainbow' (Mapokgole, 2014) captures this racialising discourse, which connects the economic deprivation of blacks that proceeds from the past to its psychological effect on the African poor, a condition that breeds structural as well as experiential alienation, and in this case, turns poor blacks against each other.

In the era of economic liberalisation and increasing informality, an unresponsive immigration regime has meant that temporary migrants, many of them undocumented, have come to occupy vacancies in many sectors of the South African economy. Undocumented migrants are relatively important for such an economy because of their vulnerable position in the labour

12. Estimation of 'irregular migration' are notoriously unreliable, so that one should be extremely careful in (not) providing exact numbers. Perhaps one of the most balanced quantitative accounts of migration to SA appears in "Appendix B: How Many Are They? Migration Data Collection Issues", in Segatti and Landau (eds.) (2011) Contemporary Migration to South Africa: A Regional Development Issue. 
market as a distinctly precarious group that is easily exploitable (Schierup, 2016; 2017). The relation between irregularity and precarity is made worse by a politics of racialisation and deportation, ${ }^{13}$ which sees apartheid's exclusion of black South Africans from the mainstream shift to migrants from outside South Africa, who are targeted for their foreign status, and exploited as such.

In the context of lax controls of South Africa's territorial borders, however, both the exclusion and deportation, especially of Zimbabweans, constitutes a revolving door. Deported migrants often come back to South Africa immediately, a process that drives informality in work and irregularity/circularity in movement. Together with undocumented movement itself, deportations are politically important in that they project a picture of a South Africa that puts its citizens before migrants while keeping a major part of its workforce - foreign migrants in a state of exploitability. This makes my analysis of Beitbridge, a particularly intense entry point of such migrant labour, a unique case study that sheds light on a migration regime that, although it sits in a part of the world that generates less interest, is comparable to those found in different versions and in other parts of the world such as Southern Europe and the United States-Mexico border after 1994.

13. In recent years, South Africa has become a prolific in deporting undocumented migrants. Crush and Pendleton (2004) discuss at length South Africa's deportation regime. 


\section{The role of migration in regional capitalism}

\section{Precarious labour}

There is, therefore, a three-fold pattern that emerged with regard to regional, black African, migrant labour from colonial and apartheid Southern Africa. First, a regional differential created by abundant and 'better' employment opportunities that necessitated the movement of labour across international territories, Rhodesia/Zimbabwe-South Africa being a ready case. Second, and in spite of colonial and apartheid restrictions on movement and employment, sections of such movement started to proceed clandestinely. Third, on arrival in South Africa such labour was readily exploitable and exploited, together with many others who were exploited anyway through official racialised mechanisms. A floating population of the unemployed in Rhodesia moved clandestinely across the border and was easily turned into what in South Africa became known, in apartheid parlance, as 'employed prohibited natives' (Bolt, 2011).

There is very little in the corpus to suggest that migrants who sought to avoid what they felt was equivalent to their exploitation in Rhodesia found relatively better working conditions in South Africa. On the contrary, they became prohibited from working in South African territory that lay south of the latitude of $22^{\circ}$. The prohibition, however, left them available for employment in the region north of the Southpansberg Mountains in presentday South Africa, and in the flat arid veldt towards the Limpopo River (Bulpin, 1954). Nevertheless, the prohibition was never really enforced. Therefore, the prohibited natives came to refer to the indirect but legislated precarisation of this section of migrant labour in colonial and apartheid South Africa.

Precarity is a term that in political economy has come to denote unstable employment, the erosion of social protection and general vulnerability in living and working conditions as a general norm 
(Schierup, Munck, Brboric-Likic, \& Neergaard, 2015; Woolfson \& Likic, 2008). The term seems particularly appropriate to describe conditions in colonial Southern Africa, where labour and regional movement rights were already actively denied and labour protections blatantly absent.

The commercial farms that lie to the north of South Africa, where such migrants could be (and are) employed, came to represent how the colony sought to industrially govern undocumented movement from Rhodesia (Addison, 2013; Bolt, 2011; Rutherford, $2008,2010)$. While the fortunes of northern farms rose and waned over the years, they gained immense leverage over the farm labour market in general by acting as both a buffer for further movement south and by hosting fairly significant, if irregular, migrant labour from the north.

Today, the term mixed migration (van Hear 2011, in Crush, Chikanda, \& Tawodzera, 2015) has been proposed to capture mobility beyond just legal status. ${ }^{14}$ One vestige of this colonial/ apartheid edifice is that despite the mixed nature of irregular migrants arriving across the Limpopo today, northern farmers often still determine how, for how long, and when residence and work permits of 'their' migrant workers can be issued or terminated by the state.

14. Quite apart from the United Nations Human Rights Commission (UNHCR) definition which has to do with a mix of refugees, asylum seekers and economic migrants, Nicholas van Hear (2011) is interested in broader aspects of the mobility process. He asks scholars to consider the different stages of the migration process so that migration becomes mixed with regard to motivations, means of travel, conditions of travel en route and on arrival, as well as in terms of the communication infrastructure that enables mobility. 


\section{Dispossession and exploitation}

So far in this discussion, I have explored a broader Limpopo Valley context within which a regional migrant labour system with reference to colonial South Africa and Zimbabwe first appears. This is a political-economic context that projects relatively deep historical roots of dispossession and exploitation. As a qualification, one must note, as Thomas Nail (2015) has done, that to be a migrant always entails some form of dispossession, by which movement always represents forms of expulsion at various levels and scales. ${ }^{15}$ The kind of dispossession I have explored in the foregoing discussion, apart from Nail's characterisation immediately above, also rests on land dispossession, racial discrimination, the disruption by colonial capitalism of African traditional socio-economic modes of life, and the making and exploitation of an engineered vast relative surplus of black African labour. The discussion is, therefore, about dispossession of social status that feeds to historical and ongoing processes and systems of exploitation across Southern Africa.

This discussion has also shown how these processes emerge and have played out both in colonial and apartheid South Africa and in colonial Zimbabwe. It is perhaps necessary to add here that dispossession and exploitation did not stop with the coming of majority rule in both countries. In post-apartheid South Africa, the grounding principle of non-racialism and equal citizenship that emerged in 1993 from the settlement between the African National Congress (ANC) and the National Party (NP), ${ }^{16}$ have only

15. Some scholars, such as Bjanersen (2017, personal communication) have critiqued this idea as a classless reading of movement. However, Nail's argument is that the expulsion that covers all migrants, from the vagabond to the international banker, is the shared lack of individual control of processes of transit, although the selfdeception persists among the rich that the terms of their movement are mutually negotiated.

16. Which came about through a negotiated end to apartheid which is recorded as the Convention for a Democratic South Africa, CODESA. 
partially materialised. South Africa is today scourged by lacklustre economic growth, high unemployment and poverty/inequality as partly the result of neoliberal choices of economic management that emerged from that settlement (Buhlungu, 2010), as well as a somewhat kleptocratic ANC government. These preside over broad privatisation projects, fragmenting labour organisation, escalating inequality, informalisation of the economy and the proliferation of precarious work (Bond, 2014; Schierup, 2016).

In politically independent Zimbabwe, broad social programmes soon exposed the Mugabe government to debt, and international monetary institutions swiftly suggested solutions that entailed formulaic privatisation strategies. ${ }^{17}$ The dearth of political opposition encouraged authoritarianism, and the marriage between the two stifled prospects of economic growth and general prosperity (Alexander, 2001; McCandless, 2011). November 1997 is engrained in Zimbabwean memory as the point when the above problems finally pushed the national currency off a cliff, leading to a series of crises that have lasted to the present day, a part of which is visible in the numbers of people exiting the country, particularly through Beitbridge.

For the African migrant labourer, colonial and apartheid repression and post-independence neoliberalism and predation (including authoritarianism in Zimbabwe) represent a continuum of dispossession. Colonial accumulation by dispossession (Harvey, 2004), apartheid coercion and post-independence neoliberalism and misrule have been reconditioning especially black African labour as flexible through rampant informalisation processes (Theron, 2010; Schierup, 2016; Slavnic, 2010). Here is where processes of exploitation on one hand, and semi- and unskilled black migrant labour on the other, presently meet.

17. In Zimbabwe, these were known as Economic Structural Adjustment Programmes (or ESAPs). 
For migrants arriving in a South Africa that is primed for their flexploitation, ${ }^{18}$ travelling across the Beitbridge border without official authorisation reinforces their relative vulnerability, precarity and continued dispossession.

A discussion of border practices facilitating undocumented movement fits well within this broader regional political economy of dispossession and irregular migrant labour. Here is where border enforcement strategies that engage with it partly represent the site of struggle and contestation as social actors continuously navigate such structural constraints as highlighted above. This is the terrain to which the next section turns - the discussion on how borders and border practices articulate with processes of irregular movement and precarious labour.

\section{Struggles around borders}

Borders, borderlands and frontiers

The frequency, skill and tenacity with which Msholozi and other omalayitsha cross the Beitbridge border speak to thousands of hours accumulated while engaging with its social space. Although Msholozi does not reside in Beitbridge, the way his entrepreneurial activities constantly bring him to the border make him a typical 'borderlander'. The repetitive act of driving through and across the border, and bringing others with him, means that, materially and symbolically, he and many of his ilk constantly transgress not just the physical Beitbridge border, but also many other social, symbolic and ideological borders. This has the effect of reshaping, at least in part, who he is and what the border zone becomes.

18. Defined by Schierup (2016: 7) as systematically embedded deregulation, deunionisation and an ethno-racially rationalised disbanding of broader solidarities which brews a new cocktail of a casualised, socially insecure and disempowered multitude, bound into unfree labour. 
As critical border scholars have already proposed, in line with Balibar (2004), this study takes borders as more than mere demarcations that mark the limits of state territories. This is especially in the manner in which they do not just exist as political and social entities, but they themselves are made and remade on an ongoing basis. If the generally accepted idea of the border is that of perpetuating and reinforcing difference, the manner in which this goal meets with ideologies of racialisation in colonial and post-colonial Southern Africa takes on an extended meaning. In this case, Beitbridge, for instance, no longer demarcates difference between (colonial) Zimbabwe and South Africa, but also between the dominant whites and subjugated blacks, and presently the citizen South Africans versus African migrants from the rest of the continent.

In the colonial and apartheid eras, the border itself came to symbolise the further differentiation and discrimination of blacks from within the Southern African interior, over and above the already denationalised South African blacks (Fine, 2014). In this way, the term 'employed prohibited natives' (as it appears in the Department of Native Affairs archives ${ }^{19}$ ) in colonial and apartheid Limpopo, came to denote a further hyper-exploited class, not just black, but foreign in the second sense. Today's irregular migrants are constructed in a similar sense in South Africa, through racialising discourses and practices based on language and skin pigmentation differences, so that those who speak an unintelligible non-South African language and are of a darker skin hue become amaKwereKwere; the outsiders who stack lower down the pecking order in terms of access to a variety of rights.

If the above characterisation can be upheld, the borderlands of Beitbridge may be seen as part of a broader political and socio-

19. From colonial and apartheid South Africa. Chapter Four of this thesis addresses this in detail. 
economic network, where interests, cultures, people and powers intersect (Arozco-Mendoza, 2008: 27). Thus, if borderlands thinking stresses a positive and neutral interaction at borders, then it is the conflict, subordination and resistance on which post-colonial studies have put further emphasis (Chavez, 2013) that imbue figures such as Msholozi and other intermediaries with critical significance. Situating himself within the historical perspective of the Southern African border as a space of ongoing practices of discrimination and domination, Msholozi and other hyenas invite us to interrogate Beitbridge as a kind of 'third space', or a frontier in its own right (Bhabha, 1994: 19-39). ${ }^{20}$

The space of intersection and interaction alluded to above, is also, in Homi Bhabha's thinking, a "realm of inventions and conventions, initiated and maintained by day-to-day situations and encounters" (Naum, 2010: 106). The third space lies beyond binary antagonisms. Here, there is constant dialogue and remaking, where "even the same signs can be appropriated, translated, re-historicized, and read anew" (Bhabha, 1994: 37; cf. Naum, 2010: 106). Taken in this way, and by studying practices of facilitation and assisted border crossings, Beitbridge can be read as an in-between space, where through negotiation, identities are reshaped and personhoods reinvented. If the borderland signifies contestations that characterise domination and intermittent resistance, Beitbridge is at the same time a space where people live in between these two conditions, caught up in the interface between them.

This way of approaching the zone through which hundreds of thousands of undocumented labour migrants pass as they pursue livelihood sustenance helps to reconsider the place of

20. This is separate, but connected to the other view of the frontier as a labour periphery. I develop this view in the conceptual Chapter Three with insights from Mezzadra and Neilson (2013). 
facilitation in the cross-border movement. My argument is that, within a dominant context that continues to precarise regional migrant labour, ambiguous figures, practices and spaces recast the subject positions of social actors, while simultaneously providing a critique of dominant social processes within which such actors operate.

\section{The border as a site of struggle}

As has already been pointed out, the role of borders in configuring labour and cross-border movement emerges more clearly when they are viewed not as territorial demarcations at the edges of society, but as dynamic social institutions and practices of spatial and social differentiation (Newman, 2005; Paasi, 1999; van Houtum \& van Naerssen, 2002). As such, I engage theoretically and empirically with interventions which have been crucial in interrogating the place of borders at the centre of the political (and economic) sphere (Green, 2013). It is here that I seek to situate borders in the nexus between migration and labour. As I shall demonstrate, borders have played, and continue to play, a key role in configuring political economies of labour migration. I argue that they shape the nature in which movement articulates with processes of domination, dispossession and exploitation. Border practices, and particularly what I call assisted border crossings, make visible this nature of things.

Underlining the role of borders in the nexus between migration and labour seems urgent because they mark the social space in which both international migration and labour are actively configured. Thus, through this active configuration, what some scholars have called bordering (Brambilla, 2015), borders are reorientated so that they become more than social institutions. They become socially instituted themselves. It is largely through everyday practices that this social institution of borders is brought about. Bordering practice and performance have been suggested 
(Parker \& Vaughan-Williams, 2012) as ways of capturing how everyday practices and experiences both 'do' and 'imagine' borders. But, everyday practices and experiences are often imbued with negotiation, contestation, collusion and resistance. Everyday borders, if they could be called such, are therefore sites of struggle.

It should be clear from the brief historical overview above that this perspective finds immediate resonance in the Limpopo Valley. On this background, I explore throughout the thesis border practices with the view to uncover their utility in the continued movement of ostensibly different configurations of cheap labour across the Beitbridge border, as well as how the border itself is imagined by those who interact with it.

Sandro Mezzadra and Brett Neilson (2013) proffer the notion of 'border struggles' to capture how institutional norms and social relations are equally responsible for structuring everyday border crossings. This thesis borrows from their formulation to explore the relationship between border enforcement and the border's everyday social relations, exploring how, in this perspective, the Beitbridge border is shaped and reproduced. I scrutinise to which degree and how border crossings themselves are a site of contention, convergence and struggle. Of interest are the interconnections that define the Beitbridge border's practices and experiences. Questions that connect border practices to political economy may also be traced in how border practices, and their associated struggles, represent contestations around belonging, social justice and the ethics of movement.

\section{The Beitbridge border}

...the Beitbridge border post is a place situated in a spectacular landscape of rolling hills, gigantic baobab trees and layered with countless forms of legal and illegal, formal and informal activities (Trollip, 2013). 
In its entirety, the Beitbridge border stretches for 350-kilometres along a section of the Limpopo River that separates South Africa from Zimbabwe. The name Beitbridge ${ }^{21}$ refers to the official border post between South Africa and Zimbabwe. Beitbridge also refers to the town situated on the Zimbabwean bank of the Limpopo River, and even to the southern-most district of the Matabeleland South province of Zimbabwe. It is, generally speaking, the demarcation line between the two countries that is most commonly associated with the name Beitbridge.

To the south of the river lies the Limpopo Province, the northernmost province of South Africa. The border fence runs along the South African bank of the river (see Figure 1.3). This is perhaps indicative of the general politics of cross-border movement and of border enforcement between the two countries. On the Zimbabwean side, the feeling of crossing the border is one of general facilitation of the exiting human and vehicular traffic on the departure side of the gate. On the arrivals side, and especially koMalume, more attention is paid to the handling of goods coming in, the collection of duty tax, as well as the navigation of official procedures that often connect to extortion and bribery as people try to extricate themselves from the bureaucratic maze.

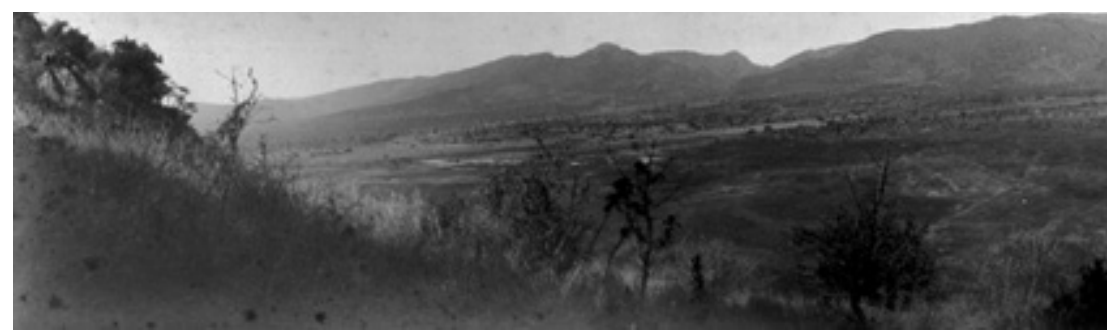

Fig. 1.3 A panoramic view looking towards Zimbabwe (Rhodesia) from South Africa. The Limpopo River can be seen in the middle ground. (Picture borrowed from Trollip, 2013).

21. Sometimes spelt as Beit Bridge. 
On the South African side, such feelings are inverted. There, enforcement pays more attention to the human traffic coming in, rather than the people and goods. All over the South African arrivals perimeter, constant body and bag searches, which double up as shakedowns and confiscations of holder-less passports in lieu of negotiated cash settlements - are the order of the day. Away from the gate, the border fence, which is intermittently patrolled by the South African military, has become ravaged by constant cuts and repairs. Clandestine migrants and the authorities take turns to leave their imprint on it. The spectacle appears geared more towards appeasing the formal border enforcement institution, while preserving a lucrative social economy built around the constant movement of so-called border jumpers determined to chance their luck in South Africa. What ties together this dynamic entity of elements into a whole are the intense negotiations around the rules and norms of crossing the border, a phenomenon that has bred a thriving hyena economy on both sides of the border gate.

The Alfreid Beit Bridge was constructed between 1924 and 1929 (Beit Trust n.d.). ${ }^{22}$ Due to increased movement between the two countries over the years, the bridge became too small and structurally weak to handle increased traffic. Today, the iconic bridge is used only for pedestrian crossings. Meanwhile, a private company was contracted by the Zimbabwean government to construct a second bridge that currently caters for vehicular traffic. This reinforced concrete bridge was commissioned into use under the build, operate and transfer model in 1995 (Trollip, 2013). In 2015, the Zimbabwean government eventually assumed ownership of the vehicular bridge and the revenue it generates.

22. As an aside, the border post, the town, as well as the bridge, were named after Alfred Beit, a British investor with an eye on infrastructural development in present-day Zimbabwe (Trust, n.d). Alfred Beit was a close friend of Cecil John Rhodes, the British arch imperialist. Together, they harboured an interest in connecting Rhodesia with other British colonies in an integrated rail system between Cape Town and Cairo. 
Today, increasing cross-border traffic harbours a corresponding increase in undocumented movement across both bridges. The two bridges are a site of constant facilitation of such movement, where immigration officials, the police, soldiers and other officebearers constantly negotiate with local fixers whose business it is to assist people and goods without authorising documents to cross in either direction.

\section{Assisted border crossings}

The completion of the Alfred Beit Bridge across the Limpopo River may have confirmed an enigma that continues to define popular practices across this border of South Africa and Zimbabwe (see Figure 1.4). Increasing economic interaction, partly evident in a 24-hour stream of circular cross-border traffic, has advanced abreast of the increased official enforcement of the border to varying degrees by both states. However, circular movement and state-led strategies of controlling it can be traced back to the onset of accelerated industrialisation in the 1850s. From that point, this conundrum immediately generated a steady growth of practices that have built around the assistance of people and goods lacking the requisite authorisation to cross the Beitbridge border (Murray, 1995). Evolving border practices that weave in and out of official border enforcement procedures thus took root and have evolved. Promising to expedite the border crossing process, these practices have encouraged lucrative social economies in which hyenas participate actively in assisting people and their goods to cross, and from which they derive a variety of benefits. 


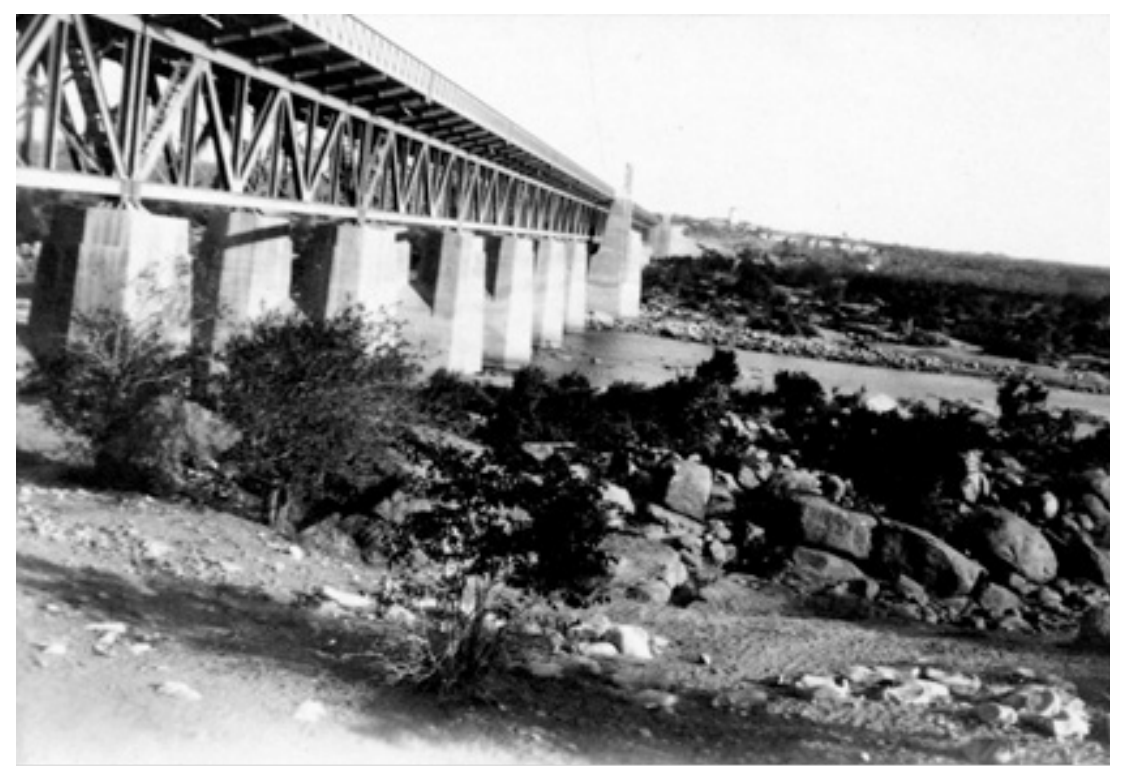

Fig. 1.4 The iconic Alfred Beit Bridge, soon after its completion in 1929. Photo clo private collection of Jackf Klaff, 1929.

In today's world of resurgent international borders (Andersson, 2014), practices of assisting people to cross them occupy very contentious terrain. This is a time when both the 'illegal immigrant' and 'the smuggler' are the immediate bogeymen on which panic and news headlines warning about the 'coming anarchy' are projected. Along this populism, the normative rhetoric regarding the collusion between state actors and third parties to facilitate the crossing of what are often deemed 'unwanted' 'illegal' 'aliens' and/or unrecorded goods, money and contraband elicits conflicted reactions in receiving countries such as South Africa. Such reactions often invoke panic, xenophobia and cynicism, especially among conservative political groups, the mainstream media and sections of the general public. Among scholars of migration and state formation in Africa, 'smuggling', 'trafficking' and border enforcement related 'corruption' are some of the terms that are problematised in the discourse. Some scholars have wondered, in the face of the 
increasing popularity of such practices that are themselves a symptom of informalisation, if the Southern African state has become subsumed in criminality (Vigneswaran, Araia, Hoag, \& Tshabalala, 2010). And, the same terms have compelled others to regard these phenomena as yet more proof the extent of disorder that defines the very workings of state-society relations in most of the African continent (Chabal \& Daloz, 1999).

In the present work, I take a different stance regarding the practices of facilitation that obtain across Beitbridge. I argue that in the Limpopo Valley, assisted border crossings are located at the intersection of border practices, irregular migration and precarious labour. Practices of hyenas, and the hyena concept itself, make it possible to demonstrate how a broader migrant labour system articulates with everyday political subjectivities. This in turn helps in thinking about the place of and interactions between everyday border crossings and a broader regional political economy of dispossession and irregular migrant labour, border enforcement, as well as agential strategies that navigate these structural constraints. Within this context, Mezzadra and Neilson's (2013) discussion of border struggles provides a key basis for understanding assisted border crossings as historical, structural, political and embodied processes.

Assisted border crossings approximate old and new forms of social exclusion in the Southern African region (the reproduction of cheap migrant labour on one hand, and neo-liberal reforms after 'deracialisation' ${ }^{23}$ on the other). Tied to the apparatus of exclusion that characterises border enforcement, the appearance of relatively disempowered migrants at the border fosters conditions in which third party actors increasingly feature to

23. Sub-Saharan Africa's political independence has been equated to mere deracialisation and not democratisation. The essence of this way of seeing Africa's independence is that the majority are still locked out of equitable political and economic participation in their communities through resource alienation (see Neocosmos, 2006). 
assist their attempts of moving across the border. With more Zimbabweans now seeking to travel into South Africa and sometimes back, the challenges referred to above mean that travellers and transporters are compelled to employ hyena strategies to broker border crossing, including resorting to their own ingenuity and social networks, as well as the assisted border crossings. When this happens, we are compelled to reflect on the larger role of assisted border crossings and the politics facilitation that enables them.

It is perhaps necessary at this point to flag the issue of 'corruption' as it may relate to a discussion of practices that I approach and conceptualise as assisted border crossings. I address this issue in Chapter Three (pages 110 - 115) with more theoretical reflection. It is enough in the meantime to point out that the issue of corruption at Beitbridge is well acknowledged, and arrests of 'corrupt' immigration and customs officials on one hand, and of facilitators such as omalayitsha on the other, are never far from the news headlines. ${ }^{24}$ Offering a breakdown of the kinds of corruption that take place at the Beitbridge border, Vickson Mundia (2014: 53 -58) has categorised the undervaluing of (imported) goods, assisted smuggling (where customs officials help travellers to smuggle goods into Zimbabwe) and 'push money' or the payment of bribes by haulage truck drivers to speed up the clearance of their customs documents as the norm.

By limiting his focus to the Zimbabwe customs authority, and by defining corruption as the use of public office for private gain, Mundia demonstrates how much corruption as a problem occupies the public psyche. Citing a study conducted in 2012 on public perceptions of smuggling at Beitbridge, he shows that 80 per cent of respondents felt at the time that smuggling was rampant. Mundia also shows how Zimbabwean fares

24. (Muleya, 2015; 2016; Evans, 2015; Brophy, 2016; eNCA, 2016). 
in international corruption rankings, with a score of 154 out of 182 ranked countries on the Corruption Perception Index (CPI). ${ }^{25}$ Scores from other indices such as that maintained by Transparency International (TI) corroborate Zimbabwe's poor record, which is shown to be only getting worse. At Beitbridge, corruption is seen as encouraged by a lack of computerised and automated service delivery systems, poor customer service and the use of family networks to perpetrate corrupt practices (Mundia, 2014: 59).

Although informative, Mundia's and similar studies (Trollip, 2013; Mills, 2012) fall on their singular reliance on the developmental state paradigm, as well as a statist view that denounces behaviour that conflicts with prevailing regulatory norms as immoral and counter progressive. This appeal to bureaucratic political discourses of corruption eschews the social and historical reality within which such practices operate. This is the same pitfall that moral panics on the 'rot' at Beitbridge fall into, which the mainstream media and conservative politicians do a decent job of fanning.

Nevertheless, the discourse on corruption has been effective in communicating the message that corrupt practices are criminal, and will be dealt with as such. Zimbabweans who participated in this study communicated a clear sense of worry about being caught and arrested for crossing the border without documents or for not declaring their goods and money. However, they also shared an understanding that this happens only when negotiation breaks down, when state officials and intermediaries have been deceptive, and so on. This says that, especially because of widespread collusion of state officials who are however inclined to deny their involvement, what is often termed corruption has utility in structuring the social relations of the border, especially

25. 182 being the most corrupt country. 
border crossings as such. This thesis adopts this stance, to argue that corruption represents a space of negotiation (Anjaria, 2011) where travellers, state officials and intermediaries navigate and secure claims in a border enforcement system that, by restricting low and semi-skilled movement, appears 'misaligned' with the kinds of movement and employment taking place across the region. Essentially, assisted border crossings emerge in the space that defines these contradictions and contestations.

\section{Hyenas, assisted border crossings and ukulayitsha}

Since the demise of Zimbabwe's economy two decades ago, a distinct type of transporting vehicle, driven by omalayitsha such as Msholozi, referred to in the initial section of this chapter, has come to dominate across the Beitbridge border space as increased numbers of people have been rushing for the country's exits (Crush \& Tevera, 2010). Private transporters, or omalayitsha, in the local language, are individuals who do not just transport, but also negotiate the crossing of mainly undocumented people and goods through the Beitbridge border on a regular basis. Over the recent past, they have become the face of assisted border crossings.

Using either a minivan or a bakkie, ${ }^{26}$ transporters are easily identifiable for drawing trailers packed high with consumables and second-hand goods on their way to Zimbabwe, or for transporting often undocumented travellers on their way to South Africa (see Figure 1.5). The acquaintance with the border that this frequent cross-border movement furnishes has placed omalayitsha at an advantage with regard to the intense negotiations that accompany the quest to accelerate procedures, as well

26. Bakkie means a light pick-up truck in Afrikaans, and is a popular name used in this business. 
as the press to exit the border gates or the need to circumvent documented travel. Negotiations such as these, and the social politics that define them, can hardly be viewed as representing a departure from the 'normal' functioning of the border. Indeed, more or less similar practices of the facilitation of people and goods appear in stories of border crossings dating back over a century. In that regard, practices of this kind significantly define rather than disrupt the nature of border crossings at Beitbridge.

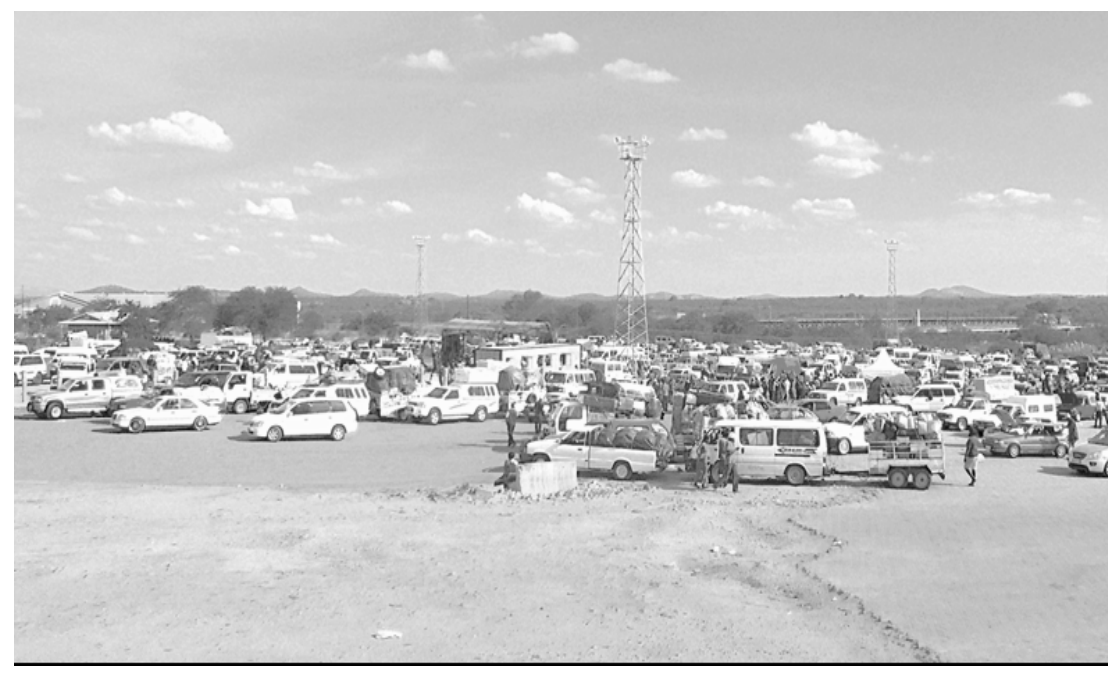

Fig. 1.5 Motorists Wait for immigration and customs clearance at the Beitbridge border's exit gate, koMalume, into Zimbabwe from South Africa, December 2014.

The rise of ukulayitsha

Omalayitsha first appear in the Zimbabwean discourse on movement around the year 2000, when the country started showing symptoms of 'crisis' and 'collapse' (Maphosa, 2010; Thebe, 2011). Umalayitsha is derived from an isiNdebele word ukulayitsha, meaning 'to transport'. Umalayitsha is the one who transports'. As an everyday register, ukulayitsha may mean a 
manner of taking money, people and goods across the border through various channels, or operating such an economic activity. Vusilizwe Thebe (2010: 654) has suggested that the term should be understood in the broader operational framework of this manner of moving as well as assisting people and things across the South Africa - Zimbabwe border - "overloading, human smuggling, and always with some form of cargo".

Omalayitsha are also referred to in the growing literature as informal remittance couriers, cross-border couriers and crossborder transporters (see, for instance, Maphosa, 2010; Muzvidziwa, 2012; Nyoni, 2011; Thebe, 2011). I conceptualise ukulayitsha as broader than just couriering or smuggling because as a practice it has a central role in the negotiation of movement as a process, and especially in border crossings. In that sense, I use ukulayitsha to include a range of practices that connect transporters, with whom many travellers cross the border for a fee, to a network of facilitators, state and non-state; practices that in their broader scope can be referred to as assisted border crossings.

It is important to note that omalayitsha call themselves izimpisi, or hyenas. A later chapter unpacks this concept more fully. It is enough to flag here that this endearment, for this is how they use the term, is an important concept regarding how formal border enforcement interacts with the social relations that structure border crossings. As I later discuss, the hyena concept is as much about the identity of border actors involved in negotiating and facilitating undocumented movement as it is about their embodied practices. The concept makes it possible to approach the social economies that are built around assisted border crossings as situated at the intersection of a rigid crossborder mobility regime and the widespread procurement of cheap labour in South Africa. It represents the synthesis of conflicting social processes, such as strict border enforcement and ubiquitous undocumented cross-border movement, the coexistence of legitimate cross-border survivalist livelihood 
activities and criminal acts, and the historical role of documents, such as passports and work permits, in the governance of life, labour and non-market compulsion. The hyena concept also helps to understand how border actors imagine themselves and their actions as political actors in a context of domination and dispossession.

As a general practice connected to transporting, it is not clear when ukulayitsha first appears. In this study, I connect it to a much older practice of 'illicit labour recruiting', which emerges in the Limpopo Valley as soon as people start moving across the region predominantly for economic reasons. Clandestine migrants are said to have been observed, as early as the late 1800s and the early 1900s, riding with African and Indian lorry drivers through the SW (colonial) Zimbabwean backroads in what were known as 'kaffir trucks'. ${ }^{27}$ More recent transitions in the development of this practice of moving people and goods can be noted as follows. Early migrants to South Africa often travelled back home, as they still do today, on holidays and breaks from work. A migrant with means of transport - usually a private car - would offer to accommodate friends/relatives and their cargo on the way home and back (Thebe, 2011). This was often a part-time and irregular service and not a business. Over time, such transport owners started extending help to distant friends and even strangers for a fee (Thebe, 2011). In this way, private transport operators have evolved their activities from the peripheries to the centre of the movement of people and goods in the region, mostly by embedding their activities in the lives of the people they transport.

27. NAZ, S138/40. Superintendent of Natives, Fort Victoria, to Herbert Taylor, CNC, Salisbury, 10 June 1927. In Murray, M. (1995). 'Blackbirding' at 'Crook's Corner', p 395. 'Kaffir' is a name that was reserved for black Africans in colonial and apartheid times, and carries a patently racist and pejorative connotation in the Southern African context. 
Ukulayitsha can thus be generally associated with movement that lacks some form of documentation or another, and omalayitsha have come to interact closely with people and goods that seek forms of transport that take into account their undocumented status (Maphosa, 2010; Thebe, 2011; Lovemore M. Zinyama, 1990). One can point out that the networks omalayitsha build and maintain with their clients are likely to be ridden with conflicts, contestation and constant renegotiation primarily because of the role of documentation in travel. With time, conflicts have particularly increased as omalayitsha have expanded their activities beyond solely working with kin and friends, which was previously thought to be the case (Thebe, 2011). ${ }^{28}$

Movement to and from South Africa has been increasing steadily in recent times before it jumped dramatically around the year 2000, in line with the political and economic challenges in Zimbabwe. The increasing demand for the services of omalayitsha, which has partly coincided with Zimbabwe's instabilities, is seen as having inevitably commercialised ukulayitsha. This partly explains the intense negotiations and wheeler-dealer practices that are themselves a source of income, but that have come to significantly define movement across the Beitbridge border.

\section{Cross-border informality, remittances and ukulayitsha}

Generally speaking, informality is often understood as a derivative of 'self-help' and resistance strategies that take root in the absence of economic opportunities from centrally planned 'formal' economies, often associated with the global south (Lourenco-Lindell, 2002; Slavnic, 2016). It finds its origins from

28. Thebe (2011) also notes that despite commercialisation, ukulayitsha has maintained a strong organic element, relying on kinship systems in migrant source communities in Southwestern Zimbabwe to maintain close connections between transporters, travellers and households. 
Keith Hart's $(1973,1985)$ work in West Africa, and was quickly embraced in the various International Labour Organisation (ILO) reports on third world economies that described phenomena which had characteristics that defied prescribed tools for measurement, regulation and stimulation. As a concept that has come to describe conditions that increasingly appear in all parts of the globe, however, informality has gone through sustained qualitative ambiguity. As Zoran Slavnic (2016) writes, problems range from naming, through classifying, to defining what it is. Added to these, there is, according to Slavnic (ibid.), a predilection to associate informality with certain actors rather than others. For different epistemological and analytical reasons, such as the marginality thesis, cultural distance, as well as the imposition of binaries between formal and informal, there has been a lack of clarity regarding the application of the concept to popular practices (ibid.). This thesis joins other voices (Likic-Brboric, Slavnic, \& Woolfson, 2013; Slavnic, 2011, 2016) that confront this reductionism.

Southern African studies on (urban) informality have already been engaging with the concept both empirically and theoretically. Empirically, it is the often statistically grouped segment of the working poor, seen as people operating outside of the 'recognised' formal market system (Raimundo \& Chikanda, 2016) that is often taken as proof of the existence of informality. This is often simplistically connected to the self-evident 'chaotic' nature of urban Africa that is equally seen as concrete proof of such informality. The closest we have come, in my view, to a definition of informality in urban Africa is captured in what AbdouMaliq Simone (2001: 252) has described as the effect of accelerated urbanisation which has had the consequence of producing:

... cities whose formal physical, political, and social infrastructures are largely unable to absorb, apprehend and utilise the needs, aspirations and resourcefulness of those who live and work in them. As a result, the efforts to secure 
livelihoods depend on largely informalized processes and a wide range of provisional and ephemeral institutions which cultivate specific orientations towards, knowledge of, and practices for, dealing with urban life.

Jan Theron (2010) has in this respect explored South Africa's experience of informalisation. ${ }^{29} \mathrm{He}$ traces it back to the challenges that have confronted South Africa's transition from apartheid to the post-1994 era. According to Theron, the place of politically influential trade unionism in elite politics came by way of conceding key protections for the worker at the altar of trade liberalisation and employment externalisation. In this context of a shrinking and fragmenting labour market and increasing informalisation from above', the spectre of a South Africa that was perceived by many would-be African migrants as finally ready for free movement was added (Vigneswaran, 2007). Practices that stemmed from the apartheid era policies of restricting movement, however, succeeded in blocking avenues for documented travel into the country, so that both irregular movement, and informal employment and livelihood strategies have become a distinct feature of the post1994 era (Segatti \& Landau, 2008; Fine, 2014; Crush, Skinner, \& Chikanda, 2015; Wotela \& Letsiki 2015; Schierup, 2015, 2016, 2017). The disintegration of Zimbabwe's own economy has especially added to these challenges so that many now find self-sustenance and livelihood support outside what is often measured and designated as the formal sector. Most of these livelihood strategies involve cross-border movement and entrepreneurship. Informality, or more precisely informalisation, are thus key aspects of this present work, and I visit this debate in view of linking it to crossborder entrepreneurship, border practices and especially their connection with assisted border crossings and ukulayitsha.

29. We may assume here that informalisation is the process by which informality comes into being. Theron (2010) and Slavnic (2010) discuss at length this process. As I will clarify in Chapter Three, and because of problems of 'naming' informality, this study is best served by talking about informalisation rather than informality per se. 
It has been acknowledged that mobility is essential to the urban informal economy in Southern African cities, and that among the most common manifestations of mobile informality in the region are the inter-urban linkages across international borders (Crush, Skinner, \& Chikanda, 2015). What interests me are the practices that establish and sustain such linkages at and across international borders. By focusing on border practices at Beitbridge, the relevance of my study rests in the idea that a significant part of what keeps the region's informal economy afloat is the continued ability of informal entrepreneurs to move across the region's border at minimal cost to their businesses. In fact, studies such as Chikanda and Tawodzera's (2017) suggest that such cross border informal businesses well established in Southern Africa are estimated to constitute 30 to 40 per cent of intra-regional trade.

A significant part of this USD 17.6 billion trade manifests in a burgeoning remittance economy (Bracking \& Sachikonye, 2010; Crush \& Pendleton, 2009; Crush, Skinner, \& Chikanda, 2015; Frayne \& Pendleton, 2009; Makina, 2013; Tevera, Crush, \& Chikanda, 2010). Estimates suggest that remittance flows from South Africa into its neighbouring countries in the region of the Southern African Development Community (SADC) had reached about USD 1 billion in 2012 alone. Remittances are mostly sent to immediate and extended family members for personal use. Remittances, more than anything else, are said to have held together a Zimbabwean economy that reached near total disarray by year 2008 (Nyoni, 2012). For this reason, remittances and what they may represent for border practices at Beitbridge warrant some attention.

This is especially the case, as Jonathan Crush, Caroline Skinner and Abel Chikanda (2015: 34) suggest, for small scale entrepreneurs' business opportunities in the remittance industry are more confined to the methods through which remittances in cash and goods are sent home by migrants. Across Beitbridge, 
for reasons related to the collapse of the Zimbabwe economy from the early 2000s, about half of all remittances sent to the country have been going via informal channels, with omalayitsha capturing most of this market (ibid). The centrality of omalayitsha in the remittance economy, over and above the general movement of people (dead, sick or living), goods and money is well acknowledged (Thebe, 2010). Their cross-border transporting practices have been credited, for instance by Thebe (2010), for having led to improvements in household food security and standards of living, especially in SW Zimbabwe.

The Cross-Border Road Transport Agency (CBRTA), a South African body responsible for the governance and integration of commercial road transport coming into and leaving South Africa, reports a clear increase in demand for omalayitsha (taxis) in the cross-border market as the number of travellers between South Africa and Zimbabwe increased. The agency estimates that in the 2014/2015 financial year, permits issued for taxi operations increased to 11,633, with those issued taxis plying the Zimbabwe route representing an increase of 22.17 per cent (CBRTA 2016: 49). Nevertheless, these numbers are likely to be an underestimation as some omalayitsha register their operations in Zimbabwe, while others may not be registered at all.

These figures are obviously significant, and tell the story of a significant cross-border phenomenon. What they do not tell, and what this thesis focuses on, is how informality transforms the ways we approach border practices such as assisted border crossings. As I show in Chapter Three, such a focus may, in particular, help problematise the links between informality and informalisation, everyday social relations, and what many consider as corruption and corrupt practices. 


\section{Framing the problem}

In light of the relations and practices outlined above, I argue in this thesis that assisted border crossings shape and are in turn shaped by the interaction between precarious labour, undocumented or irregular migration AND border practices. By seeing the three as in continuous articulation, the goal of this thesis is, on one hand, to trace the practices and experiences that show how borders merge with boundaries; that is, operating instruments of inclusion and exclusion in a broader social field. By focusing on border practices, the task is also, on the other hand, to explore how this articulation is understood and engaged with by social actors, not least through assisted border crossings by which such actors make meaning of their experiences and lives on an ongoing basis. Through this dual interest, and by way of empirical exploration, it demonstrates how broader processes and everyday experiences emerge, merge and find coarticulation.

\section{Labour}

There is, in general, consensus that while broader sections of the working classes are increasingly coming under the descriptor of precarity, it is migrants and people of migrant backgrounds who appear to fit more readily under the rubric of the 'precariat' (Standing, 2011). At the most general level, the condition of vulnerability that marks migrant precarity sees the curtailment of movement that produces a disposable labour force lacking in ordinary protections that would otherwise apply to counterparts with substantive citizenship endowments.

Carl Ulrik Schierup and others spell this out:

The rationale for designating a migrant precariat as a particular, compound category within a wider emerging global precariat, is posited in terms of the critical consequences of the articulation 
of precarious work and a precarious citizenship status ... which is instituted, formally and informally, across discriminatory and inherently racialised regimes of border control, welfare systems, labour market regulation, and political representation (Schierup, Munck, Brboric-Likic, \& Neergaard, 2015: 3).

Nevertheless, if precarity is a relatively new global norm in historical trajectory, I argue in this thesis that it has been foreshadowed in the longue duree of the political economy of Southern Africa's regional labour migration. As this introduction has already hinted, and as will be developed in the theoretical framework, Southern Africa's path to industrialisation has been predicated on a regional migrant labour system with the main ternate as the commodification,,$^{30}$ the racialised coercion and exploitation of a migrant labour force; a 'compound system' that offset the costs of the social reproduction of that labour and a

30. Labour commodification is treated not as a moment of worker alienation from the products of their labour in the transition to capitalism, but as a contested and evolving process that "has its own features, techniques, language and rhythm" (Maddison, 2008: 239). Such an approach helps to trace the movement of labour in the context of commodification from the initial conditions set at colonisation through political independence to later neoliberal reform and other neo-colonial political and economic crises in the region, with special reference to Zimbabwe as the principal originator of what I have termed surplus movement. In his conception of capitalist relations of production, Marx proposes that the historical condition of capitalism requires the availability of a free worker at "the market, as a seller of his own labour-power" to facilitate production of and exchange in commodities and money in such an economy (Marx, 1976: 272). However, the worker is "compelled to offer for sale as a commodity that very labour-power which exists in his living body" (Ibid). In this relation of exchange that also includes money as a measure of value, the conversion of factors of production into commodities (including labourpower) yields exchange value. It is this exchange value that tends to conceal what all products have in common, which is their use value. The difference between the exchange value of commodities and their use value represents a surplus, which, according to Marx, is primarily attributable to labour-power, extracted not in the sphere of exchange (as in pre-capitalist relations), but through the capitalist's control over the terms of production (Marx 1977, in Lebowitz, 2003: 5 -10). The point is that the commodification of labour per se is an integral part of relations of production in a capitalist, or free market economy. It is plausible to argue, from here, that the same hold that the capitalist has on commodification extends to shape how that labour moves (sometimes internationally) towards the centres of production. 
stringent migration regime. Political economic processes that are presently afoot partly emerge from and reflect this moment. In the Southern African case, precarity has been, as scholars (Theron, 2010) show, less a manifestation of a 'free' market as it was shaped partly by the enlightened self-interest of states and businesses, with emphasis on co-option of trade unions and on state collusion.

The coercion and exploitation of labour and its movement that marked the establishment of colonial capitalism in Southern Africa constituted the historical moment of the relative precarisation of black labour going forward. This coercion proceeds in the present day, not least through institutionalised xenophobia and the reinvention of racialised categories that exclude migrants of African origin in South Africa as amaKwerekwere (Kupe, Verryn, \& Worby, 2008). Thus, the basis for arguing that borders are a symbol of colonial governmentality in post-independence Southern Africa rests mainly with the continuing restrictions on the movement of labour, which, in regard to capitalistic production, finds incentive in available cheap labour in South Africa, coupled with Zimbabwe's crisis. What happens at Beitbridge today highlights more clearly a problematique that can be unravelled by looking at how structural processes of irregular migration are joined to precarious labour through practices that, although frowned upon, are accepted, sought after and widespread at Beitbridge. Such practices should be understood to make precarious labour connect with irregular mobility in a context of dispossession.

\section{Migration}

In international political economy, the term labour migration captures the ready association between movement and the possibility of selling one's labour in the international market. It is granted that the freedoms of doing both are increasingly under 
question, long captured in terms such as 'unfree labour' (Cohen, 1987; Miles, 1987). Nevertheless, the persistence and dynamism of searching for and doing work across international borders is without question, and the cannon reflects this.

The challenge is that, in the present nation-state paradigm, where territoriality is normatively reproduced as sacrosanct, movement largely represents an anomaly. Because social membership is often conceived as place-bound, movement is seen as a derivative of stasis (Nail, 2015). The appearance of the migrant in the world-historical schema is that of an aberration; something of an anomaly - of movement - in an imagined more or less sedentary state of social fixity. The place of the state in recent history also produces the migrant as ahistorical, a vagabond (Malkki, 1992). Here, again, the issue of membership settles the question of the migrant as one that belongs nowhere, territorially excluded from the place of their origin, and often socially excluded from their host countries on autochthonous and citizenship grounds (Comaroff \& Comaroff, 2012).

Approaching migration from the perspective of practice and experience helps to interrogate some of the social forces that drive it; "The social compulsion to move produces certain expulsions for all migrants" at territorial, political, judicial and economic levels (Nail, 2015: 2). These forces have also conspired to either not document the resulting forms of social organisation that emerge within 'migrant-hood' as a response to expulsion. Alternatively, they have produced a more or less skewed narrative of the migrant, in line with his/her perceived non-conformity and lack of membership status. This is especially visible in the discourse on irregular migration.

Socially constructed by the regulatory norms that govern both citizenship and international movement (Woolfson \& Likic, 2008), migrant irregularity is reflective of particular regimes of social organisation and movement that marginalise those who do not 
conform to this normative framework. As hinted above, in the Southern African case, the logic of colonial borders, although still applicable to state territoriality, orients waged labour towards the management of racial categories, first through the designation of labour reserves, labour compounds, 'group areas' and presently through cross-border movement, access to employment and the management of labour frontiers. Here, Didier Fassin's (2011) suggestion helps in that exploring borders is key to the understanding of how mobility is governed and experienced.

Exploring migrant irregularity in conjunction with border practices and labour represents a related undertaking. The aim is to necessarily uncover some of the silences and invisibilities that attend irregular border crossings. To observe the practices of irregular migrants is especially helpful in exploring how the social forces resulting in expulsion reposition the migrant, in her or his irregularity, as an important political figure who functions as a mobile social position and less as fixed identity (Nail, 2015). This understanding has important consequences for a discussion on the connection between undocumented migration, precarious labour and borders.

\section{Borders}

Borders and boundaries have always captured the critical eye in anthropology and sociology (Alvarez, 1995; Lamont \& Molnár, 2002). The renewed interest around them, especially in political anthropology, now sees reflection on how they have long been interacting more directly with social processes of domination, dispossession and exploitation (Mezzadra \& Neilson, 2013; Schierup, 2015). By interrogating borders from the perspective of everyday practices, I join these voices in underlining that borders are ubiquitous where labour moves internationally. I view border practices as directly affecting how that movement proceeds, and designating the kind of labour that results from that movement. 
This is why, in the colonial and post-colonial southern African context, borders have been seen as a symbol and instrument of coercion, and the general political economy of dispossession.

Nevertheless, within international political economy the articulation of borders with labour and migration constitute a severely understudied problem. ${ }^{31}$ Some of the reasons for this silence may relate to various globalisation paradigms which have in the past made a case for a 'borderless' world (Ohmae, 1999). They may also have to do with the statist and static twin idea that while borders are immutable, movement is an abnormality (Brambilla, 2015; Nail, 2015). By engaging in a conversation with and relying on critical border scholars such as Noel Parker, Nick Vaughan-Williams, Henk van Houtum, Carl Grundy-Warr, Prem Kumar Rajaram and Chiara Brambilla among others, the present thesis represents an attempt to, on one hand, recover the dynamism of borders, and on the other, to revisit their role in the labour-migration nexus across the colonial and postcolonial epochs in Southern Africa.

In the final section of this introduction, I explore this connection by showing how I will put to work the theoretical concept of articulation by adopting an analytics of the hyena concept, in order to connect these broader processes with local everyday processes in the Limpopo Valley.

31. The fields of critical border and borderlands studies are notable exceptions, but even those studies, as Mezzadra and Neilson (2013) have observed, tend to focus more on relations of power which are narrowly construed, more than on relations of domination that include exploitation; a perspective that allows for the interrogation of connections between borders and wider market processes. 


\section{Analytical concepts: articulation and the hyena}

The argument outlined above contains two related strands or paths of investigation that this thesis follows. The first relates to how labour, migration and borders are structurally connected within a system characterised by precarious, undocumented border crossings. The second relates to encounter, experience and interpretation of these structured processes during routine border enforcement, and the kinds of practices and relations these encounters and understandings give rise to with regard to undocumented movement and latently, to precarious work.

In order to conduct these parallel yet intimately related investigations, a conceptual tool is needed that enables us to identify and examine how the interaction between structural processes, time and everyday experience shapes assisted border crossings on an ongoing basis. Here, I rely in part to the concept of articulation as outlined by Mezzadra and Neilson (2013) who posit articulation as a methodological concept, fashioned to account for the ways in which borders divide as much as they connect. Put differently, articulation describes "a process of connecting and disconnecting, of constructing provisional and contingent unities that are always in negotiation and are context specific" (ibid.: 284).

As the debate has continued and its meaning evolved, articulation has come to address class relations within a wider context, where different practices, ideological elements, social forces and social groups are not only in constant 'aggregation', 'assemblage' and 'change' through connections of contingency, but are also historically embedded (Laclau, 1977; Hall, 1986; in Mezzadra and Neilson, 2013: 284 - 287). This understanding of articulation elucidates a discussion on the relationship between borders, capital, labour, temporality, space and social relations, and the ways they produce the kinds movement, accumulation and border practices that characterise contemporary flows and circulations. 
The connections of contingency alluded to above may be taken as positing related context specific interaction, co-constitution and interdependence between processes of movement, border enforcement and labour in the Limpopo Valley. By rubbing off each other, tapping into each other and limiting each other, such processes have had, I argue, a tendency to shape norms and practices that have over time defined the migrant labour system and its institutional as well as social forms on an ongoing basis. Thus, on one hand, articulation refers to broader structural processes of political economy, history and regional scales defining each other, and through that co-definition, on the other hand, shaping the specific forms of irregular movement, border practices and precarious labour obtained across the Beitbridge border space. But, articulation also implies the active institution of these processes through ideas, practices and experiences that designate (or actualise) the specific moments and instances of these and other co-relations. A focus on everyday border crossings is one way of locating and examining particular instances of such processes of articulation.

In the Limpopo Valley, such relationships of articulation can be followed in how precarious labour links to capital, and in how border practices are representative of competition, violence and resistance. Such relationships can be thought as having shaped a historically specific development of regional capitalism and the mechanics of Southern Africa's labour markets, which partly rely on the involvement of facilitators in the interaction between labour recruiters or employers, border enforcement officials and undocumented migrants, as well as in peculiar regulatory norms that shape the linkages between irregular migration, the labour market and border crossings. 


\section{Hyenas of the Limpopo and the materiality of articulation}

In order to make the conception of articulation more concrete and analytically operative, I propose that the idea and concept of the hyena exposes the underlying meaning of border practices as they pertain the actual facilitation of undocumented movement across the Beitbridge border. As developed in extended detail in Chapter Five, hyena identities and practices emerge within the economic, social and political processes that define a regional migrant labour system across the Limpopo. As an illustration of the struggles, negotiations and practices that shape those processes, such identities and practices represent the materiality of these complex interactions within the scope of everyday border crossings.

If border enforcement regulations and norms can be taken to stand for a part of bordering, or the processes of inclusion and exclusion that define contemporary capitalist modes of production (Mezzadra \& Neilson, 2013: 271 - 2), hyena practices and identities represent a kind of labour that works within and against such boundary-making and marking as a form struggle. As much as it is not a coherent entity, the hyena concept thus resists domination as much as it enables it. It can define convergence of meaning, language and action as much as it can spell disjuncture and conflict within and across groups. This internal incoherence is itself important for the practices that broker movement across various physical, social and symbolic borders, as well as for the shaping of related political subjectivities as mutable, uneven and in flux.

The analytical standpoint that I take in this thesis regarding assisted border crossings situates hyenas at the interconnection or articulation between different social processes. In connection to that, the border actors that are involved in assisted border crossings manifest the material practices that give meaning to those social forces that produce and reshape borders. As 
I shall argue in detail below, it could thus be said that the articulation between the different processes that shape border enforcement and border crossings themselves shape a context, a hyena economy, from which the social relations and political subjectivities that define the broader system of movement and labour emerge and evolve.

\section{Border practice}

The hyena concept as an instance of articulation helps to clarify this thesis' interest in border practice. It offers a way to approach border practices at Beitbridge from two angles. The first approach covers the socio-historical perspective which has to do with the production of dispossession in the Limpopo Valley, and the attendant political economy of cross-border migrant labour. As a perspective that is concerned with how borders shape various kinds of migration and labour within a general context of dispossession, it elicits the following questions:

a. How do practices that accompany border crossings help in the understanding of broader relations within a regional political economy of migrant labour?

b. How do border practices influence and are in turn shaped by the way irregular migration interacts with precarious labour?

The second approach follows an experiential and phenomenological perspective. This focuses of the production of lives, social relations and political subjectivities that are adapted to both the Limpopo Valley context, as well as the border space as imbued with hyena identities and practices. As this perspective is concerned with the everyday, it seeks to explore the following questions:

a. What role does the facilitation of border crossings by third parties play in the continued movement of undocumented migrants between Zimbabwe and South Africa? 
b. How do practices of assisting people and goods to cross the Beitbridge border shape the experiences and understandings of border crossings where requisite documents are missing or incomplete?

c. How does the negotiation of undocumented border crossings shape both political and economic participation of the different actors involved in such movement?

d. How have the social relations of the border been shaping the meaning of border crossings over time?

With the help of extended empirical discussions, the following chapters address and suggest possible answers to these questions. 


\section{$\mathbf{2}$ \\ METHODS AND METHODOLOGY: \\ Social history and mobile phenomenology}

\section{Entry points}

The fieldwork that furnished empirical material for this study was conducted in South Africa and Zimbabwe between March 2013 and April 2017, split into several visits that in total lasted about ten months. While the first visit in March of 2013 and the last visit in March of 2017 were shorter, the other two visits in 2014 and 2015 were relatively extensive and mainly focused on travelling between the two countries with omalayitsha. The visits also involved collecting life-story interviews and biographies of, as well as hangouts with undocumented travellers, omalayitsha, local fixers and guides who take people across the Limpopo River, South African immigration and customs officials, registered clearing agents who facilitate the entry into Zimbabwe of mainly second-hand vehicle imports coming through South Africa, officials at the CBRTA, as well as officials from the South African DHA and SAPS in Musina. This was complemented by many informal conversations with people in Beitbridge, Bulawayo and Johannesburg, many of whom travel through or work at the border, as well as with the many travellers who I inevitably spent countless hours with on routine border crossings. In total, I documented seventeen border crossings during this time. 
This fieldwork was complemented with archival research at both the South African National Archives (SANA) in Pretoria and the National Archives of Zimbabwe (NAZ) in Bulawayo and Harare. Desktop research also included reading and comparing archive material that other scholars (particularly Maxim Bolt, Martin Murray and David Johnson) who, together with Francis Musoni, are the few who have mined the archives for material relating to the history of undocumented cross-border movement across the Limpopo Valley. I have spoken to an eminent historian, Dr. Phathisa Nyathi, on SW Zimbabwean traditional oral and performance customs and rituals with the aim of deepening my understanding of the embodied meanings of the concept of izimpisi. I have also followed events related to the activities of cross-border movement and border practices in the press.

\section{Interviews and hangouts with undocumented migrants}

The process of finding and spending time with undocumented Zimbabwean travellers was a tentative one. It was important to remain unobtrusive to participants who often possess strong incentives to remain out of the purview of formal engagements that take interest in their undocumented status. The initial plan had been to simply travel with regular travellers between Zimbabwe and South Africa, and by approaching these travellers, introduce my research and ask them to refer me to people they know who - at some point or another - may have travelled to and worked in South Africa without documentation. However, this was difficult to sustain as the follow-ups and referrals took long times and more effort to arrange. It seemed that meeting people along a single journey and asking them for this kind of input did not, in many cases, prove persuasive or compelling enough for contacts to sustain an interest in my research. At the end, I spoke to friends, neighbours and acquaintances, and asked them to introduce me to their friends who fulfilled the criteria outlined above. 
It was during the initial informal conversations and hangouts with the participants I had been referred to that I would then introduce my research and solicit participation. In this way, I make no claims to representativeness regarding the sample of undocumented migrants I spoke to. In the end, I conducted 21 life-story interviews that are, on average, three hours long. Each interview was conducted over several meetings with each participant. Added to these, I had many unrecorded interviews and conversations with travellers, either during their journey or as they waited to travel into Bulawayo and Johannesburg or for their documentation to be processed at the border.

\section{Ride-alongs with omalayitsha}

It was the interviews with undocumented migrants that availed opportunities to meet with private transporters. Because they use their services often, I asked undocumented migrant participants to refer me to the transporters they knew, and to introduce me to them. Omalayitsha were initially eager to meet me, often because they saw me as one more potential customer. When I started to introduce my research, some began to lose some of their initial enthusiasm. In the end, I was left with two omalayitsha who allowed me into their company and agreed to share their experiences in interviews; Msholozi being the one who I travelled extensively with. Besides these two, I travelled with several other transporters, some of whom I disclosed my intentions to observe their work. I also travelled with other omalayitsha randomly, if only to make comparisons between omalayitsha that I had declared my research intensions to, and those to whom I had not. Msholozi still expected me to pay him the full travel fees, simply because I was taking space in his car. Other omalayitsha did allow me to accompany them, but these did not prove durable enough to sustain over longer periods. Although, Msholozi provided me with valuable access to his drivers and the people who they were transporting to other omalayitsha that he was in constant contact 
with, as well as to customs, immigration and police officers that he was particularly well acquainted with at the border. He also came to involve me rather closely in his practices and techniques of transporting, which tended to blur the lines between observer and participant. In such a fraught environment, my willingness to get drawn into such practices was informed by my wish to consolidate trust and gain better insight into the internal workings of ukulayitsha.

In February of 2014, while in Johannesburg, South Africa, I had asked $\mathrm{Fa}$, one of my research participants, if he knew someone in Zimbabwe who may have been a 'transporter' before the year 2000, by which time the phenomenon is perceived to have started gaining popularity (Thebe, 2011). Fa had promised me a phone number, to use well in advance of the day I planned my initial visit, because, as he had warned me, it takes 'preparation' to travel to Sanzukwi, SW Zimbabwe, where I would meet my potential participant. But he would look the number up first, and inform my promised host about my requested visit, and then get back to me. After waiting a while in Bulawayo for him to connect me to the former transporter, he finally sent me a number that I promptly called one Sunday morning, announcing my visit that very day.

It was in this way that I was introduced to Gatsheni, a retired umalayitsha whose story provides a backdrop to Chapter Four. Through his insights, I explore the historical dimension of the practices of assisted border crossings. Besides travelling, I spent considerable amounts of time hanging out at two spaces where omalayitsha gather to load their vehicles and pick up passengers. One of these spaces, in Hillbrow, Johannesburg, is called ezibayeni (loosely translated to mean animal enclosure). The other is Max Garage, a pickup point for Johannesburg-bound travellers in Bulawayo. 
The ride-along as a research strategy is inspired by Margarethe Kusenbach's (2003) contributions to street phenomenology. In conceptualising the go-along as an ethnographic tool that "brings to the foreground some of the transcendent and reflexive aspects of lived experience as grounded in place" (2003: 456), she aimed at interrogating how individuals understand and interact with their physical and social context in everyday life. My research shares this ambition of accessing insider understanding of what events mean as they unfold for their actors. However, what the ride-along seeks to emphasise is that being acquainted with research subjects does not mean that one naturally understands others' lived experiences.

\section{Mapping the border}

I met Skara, a registered clearing agent working for a Harare company, in April 2014. Skara's work mainly involved clearing imported second-hand vehicles for entry into Zimbabwe via the Beitbridge border with South Africa. Customs officials on both sides of the border will only accept documents that detail the nature and value of imported items, and with that, the customs duty due to the state through registered agents. In recent years, Zimbabweans have been importing second-hand cars mainly from Japan, and Skara - and many agents like him - have their hands full facilitating the entry of such vehicles at the border. This also means that registered clearing agents know many customs, immigration and police officials on both sides of the border. I anticipated that getting permission from border officials to observe the border would be challenging, and I had hoped that if Skara put in good word, I would be ushered in. Skara himself seemed to think that getting me access to the border would not be a problem. So, one morning, he took me to the border administration offices on both sides of the border. 
We ran into immediate difficulties as I introduced my study to senior immigration managers on both sides of the border regarding expressing the desire to interview them and observe their juniors. Despite prominently displayed A2sized organograms expressing transparency, diligence and customer friendliness, I was repeatedly and summarily shut out. Partly understanding this to be a deliberate attempt to conceal irregular state practices from research scrutiny, I abandoned that dimension of data collection. I would, nevertheless, inevitably find myself interacting with individual immigration, customs and police officers who I met while in the company of omalayitsha. On several other occasions, Skara and I spent time speaking and interacting with South African front desk officers in their line of duty, in social gatherings, and on one occasion when a close friend of Skara's, a South African Revenue Services official, visited him at his Beitbridge home.

Nevertheless, most of my mapping exercises were done as I waited with transporters or other travellers. It seemed that congestion and delays that characterise the border inadvertently work in favour of my research. Here, it was possible to speak with travellers, informal traders and transporters, and to observe their interactions with state officials and each other. Mapping the border also occurred outside the border perimeter when I spoke to mostly young men who at first appearance work as money changers, car cleaners and so on, but double up as facilitators working with omalayitsha to take undocumented travellers across the Limpopo River either through the border gates or via the bush. I gained many insights into the work of facilitation, especially their interactions with state security personnel who secure the border, but who often actively participate in guiding undocumented travellers themselves. 


\section{A social history and phenomenology of assisted border crossings}

\section{Social history}

My ethnographic fieldwork has been combined with research into the social history of assisted border crossings. In the archives and secondary literature, the practices that I study are indexed as 'illicit labour recruiting'. In this context, it is perhaps important to note that it is not a light task to mobilise information to build such a history of activities that, for all official purposes, are classified as illicit. It is thus necessary to caution, as Murray (1995: 376) comments, that "perhaps the detailed examination of what actually happened might be less important than in using what knowledge can be gleaned from available sources to provide a wider socio-historical context within which" practices of assisted border crossings can first be sketched.

The focus on the historical condition in which assisted border crossings first appear in the Limpopo Valley is helpful for the quest to understand the wider and evolving problems. Murray (1995) addresses some of these, and this thesis is indebted to his articulation of them. They include the relationship between long-distance irregular migration and the creation of a precarious migrant labour force, as well as the role of the law in differentiating legitimate entrepreneurial activities and criminal acts. They also have to do with the historical role of non-market compulsion, including force and physical violence. All of these, and quite separate from the uprooting of rural African labour and the compulsion to seek work in centres of production, define the space of movement directly, particularly the "conflict and accommodation, compulsion and compliance, obedience and resistance" (ibid.: 377), as representing the particular forces that combine in the formation of the labour market. 
And yet, Murray's incisive analysis tends to treat these forces as something of an anomaly, something peculiar, that is perhaps a distortion of an ideal historical labour condition in the Southern Africa region. This is also evident in his attempts to not just isolate these practices and forces to a small corner of the Beitbridge border, but also to a short time period (1900-1920). These forces did not just define the colonial capitalist labour market in general, they - and this is the intervention of this thesis - evolved, weaving into the very social structure of the regional migrant labour system, enduring in one guise or another to this day. Back then, "mine owners delivered themselves into the hands of private recruiters and labour contractors who demanded and received huge fees for their services" (Jeeves 1985, in Murray 1995: 377) in order to obtain labour with the collusion of the colonial state. And, this interlinkage between market forces and immigration policies appears today in the interaction between precarious work and irregular migration, which a stringent migration regime oversees in South Africa, and which border practices define at Beitbridge.

Through the contradictory and anarchistic nature of the capital accumulation processes, with their dependence on crude and extra-legal methods of procuring and shifts and changes through time, practices such as illicit labour recruiting prefigured the evolving and future practices that appear today as assisted border crossings. As I discuss in Chapter Four, a socio-historical analysis is important in addressing this genesis as much as it furnishes material scope for an understanding of assisted border crossings as an emergent practice (Bakewell, 2010). Such an approach synthesises the interaction between structure and agency to define present practices and possibly shape future ones as co-constitutive. It is here that I take up the contemporary experiences of border practices through a phenomenological approach, and later relate them to post-colonial subjectivities. 


\section{Mobile phenomenology}

Interpretive sociology, primarily exemplified by Alfred Schutz's (1962: xxx) phenomenology of the lived world, grapples with "the primary grounding of one's being in the world as not just situated in subjective space and time", but also as "rooted in an intersubjective reality". In the case of this research, acting in the world generally circumscribes the reality of subjective encounters in cross border movement. It also circumscribes the reality of transporting people and things across the border within a context of fraught regulation and the 'crisis' of the disconnect between practices of crossing the border and their significations and meanings (Mbembe \& Roitman, 1995). Subjective experiences of crisis present actors with a recurring unpredictability of negotiating irregular cross-border movement, which may shape their experiences inside and beyond particular 'imaginative possibilities' (Schutz, 1962). This statement hints at one of the goals of my research endeavour; to understand and demonstrate how omalayitsha and the people they interact with in their world make meaning of themselves and their practices within such a regime of subjectivity.

This research aim relates also to the subjectivities of the border's social space. It focuses on, among other things, what I will refer to as the magical (illegible) qualities of the state border (Das, 2004; Hoag, 2010), the 'personalization of the public' (Medard, 1982), and the exchange economies that these qualities of the border generate. At the intersubjective level, I also trace the possible reconfiguration of the border space beyond the potential for unpredictability and danger that attends public encounters with the state, or rerouting of public resources to personal ends. The subjectivities of the border's social space touch on how the translation of state regulatory norms through social relations may demonstrate instances of reification, appropriation and elision of these norms. They may be seen as akin to a point of simultaneous non-existence and presence of the state (Abrams, 
1988). These articulations represent conditions of possibility for both those engaged in the shaping of cross-border movement and those observing it to reimagine themselves within specific local geographies but also transcendental to them (Gikandi, 2011).

This follows from suggestions from phenomenological research that the human experience of its environment draws from the so-called 'coordinates of the living body' that work to re-insert the importance of place into the debate on space (Kusenbach, 2003). Connecting back to Merleau-Ponty and Edward Relph's 'perceptual space', I understand that such a sense of one's surroundings renders space as differentiated into physical, imagined and remembered places of personal significance (Relph, 1976). Indeed, Schultz recognizes the subjectivity of the body in the structures of the lived world, yet is not clear on the "primacy of place in our environmental experiences and practices" (Schutz \& Luckman, 1973, Kusenbach, 2003: 456). Taking lead, again, from Magarethe Kusenbach (2003), I thus partly pursue a phenomenological understanding of how actors involved in assisted border crossings engage and make meaning of the physical and social environment of cross border movement.

Such a perspective justifies my reliance on the 'method' of 'ridealong' across the Beitbridge border (Buscher \& Urry, 2009). The ridealong was complemented, among the strategies outlined above, by border mapping, which has elements of rapid ethnography (Millen, 2000); a kind of participant observation of the interactions that take place at the border, carried out largely when riding along with omalayitsha. This element of the research sought to address, in space and time, the "transcendent and reflexive aspects of lived experience as grounded in place" (Kusenbach 2003: 456).

While the seminal works on phenomenology have been inspirational, particularly in relation to the descriptions of the structures of the life-world, I mobilise Relph, Merleau-Ponty and Schutz's phenomenology to speak to the post-colonial African 
context, where various subjectivities are seen, in the nature of the post-colonial lived experience, to have been subjected to 'crisis', so that they not only produce subjectivities of 'crisis' but also represent the "crisis of the subject" themselves (Mbembe \& Roitman 1995: 323). These then produce particular "regimes of subjectivity" that fit within the context outlined above (ibid.: 324).

\section{Researcher positionality}

As a Zimbabwean who has lived in South Africa for about eight years from 2004, I have observed and participated in travel with private transporters long before this research commenced. As such, although I personally have never had to travel without documentation, my position towards assisted border crossings is partly informed by my close proximity to the experiences of people who find few legal alternatives in their quest for what they perceive as better life prospects in a different country. But, as this research experience has proved, and as this thesis shall demonstrate, what is legal and what takes place in practice at the border often ceases to occupy distinct or conflicting positions. Particularly, the view that often proceeds within certain media, governmental and non-governmental organisations, including some researchers, of what is commonly referred to as 'smuggling' and the broking of undocumented movement as morally bereft practices by ruthless individuals, is not played out in this research. Without romanticising practices that are sometimes clearly violent, it is enough to say, with Eric Wolf (1959), that people like omalayitsha and other actors in their networks play an important role in carrying out society's unacknowledged business.

My familiarity with these people and practices thus brought opportunities and constraints to this research process. I had less difficulty understanding the language and the sometimes-hidden scripts that actors used in their milieu as part of their general communication codes, or when they were wishing to veil details 
from certain ears and eyes. It was also easy to locate and obtain entry into people's lives and businesses. In many instances, the research process was aided along by my ability to more or less 'fit in'. In Zimbabwe, I lived in Bulawayo with my brother and his family. In South Africa, in both periods of stay, I lived in Yeoville, a predominately migrant inhabited part of Johannesburg. From here, I could stay close to study participants; both those who I interviewed and the transporters I travelled with. I also benefited from the School of Architecture and Planning and the African Centre for Migration and Society (ACMS) at the University of the Witwatersrand, Johannesburg, who hosted me while I carried out the research.

However, fitting in was not without its pitfalls. It meant that I may have sometimes been complacent in probing and reflecting on certain details that appeared 'familiar', only to realise later that such details constituted missed opportunities for being taken lightly. Also, travelling extensively with transporters was taxing, and the long distances involved meant that sometimes it was a few days before I could get an opportunity to reflect on the 'fieldwork', and write it up in the form of journals and diaries. While mobile research is gaining currency for its perceived insights into both theory and empiricism in studies of different kinds of movement (Buscher \& Urry, 2009; Sheller \& Urry, 2006), the fluidity and constantly changing nature of its conduct and process does not lend itself fully to immersion in the field and to furnishing 'thick' descriptions of its sites. This challenge is well taken, and in the case of this research, it meant that riding along with transporters was streamlined to a few transporters as describe above. 


\section{A brief note on ethics}

The study went through ethics vetting and approval at Linköping University. Ethics approval apples principally for the possibility to proceed with the study. However, as the context or field of research was outside of Sweden, and the study partly pertained the observation of interactions with South African and Zimbabwean state officials, the university approval did not carry the authority to afford access to the field site. I was aware of this limitation, as one must still ask for access from concerned authorities to gain entry to their spaces. For the South African officials who I directly interacted with through interviews, it was possible to ask for and gain permission to speak to and observe them. This was not the case with Zimbabwean authorities, who flatly and repeatedly refused to be interviewed or observed. In Zimbabwe, there is a requirement to request this kind of access from the responsible minister's office. The process can take a long time, and in this sense does not help research occurring under significant time constraints. I was left with no option but to not interview or observe them, although some observations were still possible in the company of omalayitsha.

All participants whose stories and views appear in this study have been anonymised. I asked Msholozi and Gatsheni, in particular, if I could use photographs of them and their property in this study, which they consented to. However, Msholozi and Gatsheni are not their real names, but rather the names they are known by in their circles. Again, they agreed that I could use these names. I pointed out to them that this means they may be identifiable in the study, which they also accepted. There are no real dangers to this as the views they share in this study do not reveal any specific information about any individuals. Although state officials may regard some of the views developed about them as painting them in negative light, no such views are not traceable to any specific individual. 
Concerning the ethics of carrying out research in spaces of mobility where it is not possible to gain full access to the field, there are questions that refuse to go away. One relates to how much researchers should laud informed consent as an integral principle of ethnographic research. I pose this question in light of some of my own ethical dilemmas that arose when conducting this research. I have already touched on the dilemmas I encountered while mapping the border. For instance, when state officials refused me access to a part of the research field, namely, observing immigration and customs officers as they went about their work, I gained it through omalayitsha. Therefore, I was eventually able to observe the same institution that had refused me, even if I could not have directly mentioned this to individual officers. I believe that this worked in favour of the research in that however well-intentioned state officials are, they were likely to have altered their behaviour in my presence. Or, at least taking my original planned approach would have limited the amount of perspectives I would have gained from the brokers of movement, as well as from the perspectives of the most vulnerable travellers.

Other dilemmas exposed the consent I got from transporters as tenuous, ebbing and flowing, as different social spaces passed under the research gaze. Omalayitsha ordinarily did not conceal the extra-legal aspects of their work. I explained my work beforehand to transporters, and those who eventually allowed me into their vehicles generally understood my role there. Thus, they often took me with them through the spaces they moved in, and they therefore consented to my presence in such spaces. Yet, even if I was able to, for instance, observe state functionaries against the wishes of their superiors, transport operators sometimes deliberately withheld certain details of their work from third parties if they deemed those details too sensitive. I generally understood this to have more to do with the nature of their often-clandestine business than with my presence. 
In light of the above, my access to their space widened and constricted without prior negotiation as we moved through different sites and interacted with different actors that we often met with little prior notice. It appeared that consent was something I sometimes simultaneously had and did not have, or something I could have more of and less of, all at the same time. My subjective understanding of consent would at times invite alarm, where I would question the acceptability and indeed the very ethics of my presence in particular spaces.

Generally, travelling with transporters also meant meeting many people who would find me already accompanying a given transporter. Having obtained consent from that transporter, I was thus often already a tenant of the travellers' own social space before they arrived and took their place in it. Consent, even if I eventually introduced myself to some travellers as a researcher, was always already partially given if its formulation in common ethics codes is upheld. Apart from that, this kaleidoscope of travellers, facilitators, state functionaries and other transporters that constantly came in and out of research view as I travelled back and forth with omalayitsha directly challenges the virtues of informed consent as something that is negotiated, disclosed and mutually agreed upon often prior to engaging research subjects or on an ongoing basis.

My experience therefore challenges the notion of "truly voluntary or informed" consent that the American Anthropological Association (AAA) code, for instance, values. During the course of my participant observation, it was not clear which parts of the actual observation of social situations constituted research, and which ones were representative of merely being there. Often, it was later in the day or early the following morning - or even much later in the writing process - that my reflection on recent events turned some experiences into research material, while discarding others. Whereas it could be argued that this distinction is of little value in relation to consent in research conduct, it still 
resonates with others (Dingwall \& Murphy, 2007) who have said that with ethnographic methods, a researcher tends not to be able to pinpoint moments in which their data collection properly commences, pauses or ends. This way, the privileging of consent and the consenting process at times become challenging, or even fuzzy from time to time, but also often counter-productive to the aims of ethnography.

It has also been argued that truly voluntary and informed consent are truly beyond what the research process accomplishes instrumentally, which is to "transform research subjects into objects" that are read and consumed by other people (Davidson, 2008: 57). If subjects fully understood this aim in research, so goes the question: How genuinely could they consent to being objectified? And without such an understanding, how fully informed and fully voluntary is their consent? On one hand, the 'relationality' informed consent insists on is always already a fractured one. The instrumental ends of fully informed consent militate against the principle itself. On the other hand, therefore, it is oxymoronic to talk of achieving full consent in research.

My view is that the idea of informed consent appears more as a "discursive attribution of selected qualities to scientists, scientific methods, and scientific claims for the purpose of drawing a rhetorical boundary between science and some less authoritative residual non-science" that betrays an institution-centred approach to the value of research (Gieryn, 1999: 4-5). It perhaps also highlights the role of institutions in shaping particular definitions of ethics (Larmont, 2000). For me, such approaches to consent are limiting to the conduct of ethnographic research.

Nonetheless, I agree that the principle has grown across research circles, signalling the role it plays in preserving currently shared understandings of the moral duties that attend research work. As a form of boundary work, however, ethnographers should perhaps continue to problematise the idea of informed consent, 
to lift it from its current position as a contested universalistic yardstick, and to position it within their distinctive research responsibilities, that is, to problematise and sharpen it so that it better speaks to their own specific research ethics. 


\section{3 \\ THEORETICAL FRAMEWORK: \\ Locating border practices in the political economy of migrant labour}

\section{Introduction}

\section{'Pay forward'}

Mkhize first travelled to South Africa from Zimbabwe in 1999, less than two years after he finished secondary school. He had left his village to explore his employment possibilities in Bulawayo, not that there were many; general unemployment levels were already high, even by 1999 levels (ILO, 2008; Jones, 2010). All this did not matter much in Mkhize's case, for he had not bothered to collect his secondary school national exam results. He was into his second year of 'not doing anything', as it is often said, and everybody in his family understood that things were not easy for him. He too understood this, but he insisted on going to the city because, as he said, he needed to see for himself what he might find.

Mkhize had decided, secretly, that the time had come for him to go to South Africa. He was eighteen years old. The time he spent in the city had been invested in finding out from friends how much it might cost to travel there, and what the travel routines were. The only problem was that he neither had the money nor a passport to do so. So, he had to be discreet, not revealing his plans to anyone in the family, otherwise he would be talked out of it. At the least, he would carry with him the opposite of what 
could be construed as travel blessings, something many wouldbe cross-border travellers take seriously as having the possibility of jinxing one's prospects in South Africa. Mkhize, therefore, kept low, waiting for an opportunity to present itself.

That chance came when his mother came to visit him and his brother's family for a week. She lives in the village, where Mkhize had been all the time, and she visits the city intermittently, where she runs regular errands. As she revealed plans for her stay, Mkhize soon understood that he had to find a time to go through her purse undetected. On a Saturday morning of that week, Mkhize's whereabouts became a matter of brief concern in the family home, and soon after, among the neighbours. When word arrived that he had been seen with a private transporter the previous night, his mother dashed for her purse and soon confirmed her suspicions. And so it was that Mkhize's initial journey to South Africa with a private transporter - umalayitsha - began. The stolen money would, however, only ever be enough to cover half the fare. His brother, who at the time lived in Alexandra, a boxed-in shantytown in the north of Johannesburg, was going to pay the outstanding fare upon receiving him. By arranging his travel this way, Mkhize became what many migrants and omalayitsha understand as a 'pay forward', in reference to his travelling debt to the transporter.

Such an arrangement is quite disempowering as it suggests that one who travels this way, for the duration of the journey, is seen merely in terms of outstanding money and less as a human with his or her own identity and initiative. In fact, such a person is kept in conditions not so different from someone who is kidnapped, up until the one responsible for receiving him/her settles the terms of the arrangement. 'Pay forward' is itself a concept borrowed from an old practice, in Zimbabwe and elsewhere, of posting letters through the regular mail service without stamps. In terms of the law, the addressee had an obligation to visit the post office to pay the postage fee as a condition of receiving the letter in question. 
Mkhize never forgot this experience. It was his very first time travelling to South Africa. Instead of taking in the smells and sounds of a new place, he had spent his first day under close surveillance by people who he had previously considered allies as they waited for his brother to swing by and collect him after work. Consequently, although he spent the next twelve years in South Africa without documents, he no longer asks omalayitsha to negotiate his crossings over the bridge or through the bush ${ }^{32}$ on his behalf. In the face of a phenomenon that mirrors the current happenings across the Mediterranean Sea or the Rio Grande in Mexico and the USA's case, Mkhize scoffs at the idea that Zimbabweans risk their lives in the bush and across the Limpopo River, or that they pay a lot of money to get transporters to help them at the border. He told me: "That experience taught me everything I need to know about self-reliance, and about social interaction ... When we were at the border, all it took the transporters was to speak to border officials. I asked myself; why couldn't I do the same?" He was a bit scared and awkward at first, but this is what he has been doing ever since he has been travelling between the two countries and across the Beitbridge border. "This is how I see it; if they think the money you are offering is little, then you have a choice to haggle more, or you give them what they ask. If you are good at negotiating, or if you are lucky, like me, you have no need to part with a lot to cross the border".

Although Mkhize positions himself against the work and utility of third parties in undocumented crossings at Beitbridge, his example offers a good starting point for a discussion on the theoretical context that informs assisted border crossings. 'Speaking to border officials' is an aspect of border practices

32. Crossing the Beitbridge border away from the border gates entails braving the Limpopo River; a dangerous enterprise. This practice is common among Zimbabwean migrants seeking to reach South Africa without documents. Chapter Four explores this practice in significant empirical depth. 
that this thesis expands on to discuss the place of everyday border crossings at the intersection of border enforcement and its social relations. This intersection represents a space within which to observe complex relations and practices of negotiation and facilitation, and their connection to broader processes of the politics and economy of the region's migrant labour processes.

\section{Speaking one's way through the border}

The idea that Mkhize, like regular transporters, routinely 'speaks' his way through the Beitbridge border sounds almost fantastic. It does, however, suggest that assisted border crossings, or the context of facilitation within which they emerge, cannot be downplayed in shaping border practices. Precisely because they might be viewed as representing informal politics (Bayat, 1977; Chatterjee, 2004), they warrant closer theoretical reflection. That is, assisted border crossings suggest foreclosures, openings and overlaps between different regimes of movement and socio-economic processes. Further, they affect the very nature of sociopolitical life in the Limpopo cross-border space. The dynamism and durability of speaking, signals more than just talking. Hinting at proximity (Anjaria, 2013) and negotiation, speaking should thus not be viewed as shaping what today looks like a permeable Beitbridge border. The possibility to 'speak your way' partly caters for millions of dollars' worth of undocumented traffic that passes through the Beitbridge border, including that which eventually gets 'intercepted'. And, it has been doing so for a long time. Speaking, and assisted border crossings, therefore, represent some of the actual parameters of undocumented crossborder movement across the Limpopo Valley.

Speaking to border officials also symbolises the connection between irregular movement and precarious labour in a broader scope. In fact, from Mkhize's experience itself, how irregular migration articulates with precarious labour is immediately 
discernible in his story. It is the border, especially the border practices, which appear inconspicuous, although constitute the powerful link between the two. Mkhize has spent over ten years without travel documents, a situation that has kept him in irregular cross-border travel. And, lacking such documentation has effectively confined him to precarious employment. His need to travel across the border without documents, between home and work, has many motivations. However, negotiating for it on an ongoing basis underlines a context that is common wherever low- and semi-skilled migrants seek work across the Beitbridge border without documents, and perhaps elsewhere.

Thus, the task of this chapter is to build a conceptual scope and tools for exploring how the border, and its associated practices, represent the materiality of the articulation between irregular cross-border travel and precarious work. However, rather than merely characterise these connections, this discussion centres border practices in a broader field as a way of uncovering their utility in the political economy of undocumented migrant labour.

\section{Passing for a documented traveller}

In spite (and in light) of Mkhize's life experience, documents are indispensable for cross-border travel. However, documents are bureaucratic artefacts that also find themselves at the centre of a complex network of relationships (Cabot 2012: 22) that at Beitbridge, partly rest on the manipulation of their perceived importance. We cease to see them as solely playing the role of categorising people as worthy or unworthy of international travel, work, stay and/or holidaying, however fragmentary that process itself often is. The focus of this thesis, and of this conceptual exercise, is not the documents per se, or what they say about such politics of governmentality. Although the centrality of documents in modern forms of movement is indisputable, in this thesis I am more interested in their role in the connection 
between regulatory norms, practice and utility in structuring broader processes, as well as their role in shaping political subjectivities that emerge from undocumented everyday border crossings.

The curious case of filtering and barring low-, semi- and unskilled migrants from entering and working in South Africa, matched closely by their active exploitation as precarized labour in the same labour market, is of basic importance to this discussion. In Southern Africa, and other parts of the continent, the historical moment for the dispossession of this labour pool, with its roots in dual citizenship regimes, gives Africans on both sides of border enforcement systems alienated positions regarding the role of documents in the governance of everyday life. But, it is the unpredictability, indeterminacy, vulnerability and manipulation that accompanies both the enforcement and everyday experiences of the border that further complicate the relationship between enforcement systems on one hand, and the people that handle, interact and are meant to be governed by such systems.

In terms of political economy, as I have discussed in the introduction, documents and bureaucratic systems, in which they are embedded, first appear in the lives of many Africans as tools for their exploitation and circumscription through racialised politics (Terreblanche, 2003). Many present-day state officials share this history of affliction, and now find that they wield bureaucratic power from a position of marginality. Some of the ways in which they get to convert this power for personal use have been discussed (Steinberg, 2008). But, it is the actual way exploitation and circumscription were achieved that continues to partly elicit ambivalent attitudes from many Africans to the past and in the present. By using bureaucratic administrative mechanisms to designate them as subjects, while others in their midst passed for citizens (Mamdani, 1996; Neocosmos, 2006), Africans have long understood that their disempowered 
status was (is) validated in and enforced through documents, which inevitably represent such systems of administration and governance. From the precedence of chiefs who governed them as colonial subjects, many Africans (the chiefs included) find their retribution in exploiting such systems for personal profit, for instance through their misappropriation of tax money and logistical resources, as well as through other everyday forms of resistance (Njoku, 2005; J. Scott, 1985).

The lingering notion that documents do not serve the best interest of dispossessed Southern Africans is therefore not new. Furthermore, it persists today mainly because disempowered Africans still find themselves administered through the same race-based systems of governance that are vestiges of the past. In former settler economies such as South Africa, Namibia and Zimbabwe, this role of documents in divisive politics cannot be stressed enough, as the introduction attempted to show. As early as the 1800s, slaves in the Cape colony of South Africa were forced to carry what were called 'passes' to control their movement. This pattern continued with the control of movement and labour from the colonial period to apartheid. And, as postapartheid immigration policy shows, it remains an issue in the present South Africa (Crush, 2008).

Resistance to documents is also not new, and names such as Charlotte Maxeke and Bertha Mkhize are immortalised in the women's struggles against the so-called 'pass laws' in South Africa. Such mobilisations set the scene from the 1940s onwards for a stronger defiance campaign, a significant part of which rested on the refusal to carry documents (Hellman, 1949). It should, therefore, be understood that there is a significant element of bureaucratic requirements for documents in the region that rests more on control of the movement of labour. In this regard, it should also be understood that the avoidance of documents as an implicit strategy of moving and finding work rests in resistance strategies to these mechanisms of control. 
This resonates with Barhane Araiah (2006) who writes that many African states, having inherited these colonial systems of governance, struggle to transform them into more or less democratic ones. As such, Michael Neocosmos (2006) appears vindicated in arguing that Africa is a case of deracialisation (which is itself in dispute, particularly in the current South African politics of 'othering' black migrants from the rest of the continent), and not democratisation.

There is therefore a certain general predilection in the psyche of the governed (Chatterjee, 2004) among low-skill migrants in the region to be suspicious of bureaucratic mechanisms, or at least to pay lip service to them. This form of engagement with both the power and magic of the state (Das, 2004), what others (Hoag, 2010) have termed the magic of the populace, takes on both this ambivalence to bureaucracies, and creative responses to state mechanisms of regulating people at the level of identity (often with a possibility for personal gain) (Mountz, Wright, Miyares, $\&$ Bailey, 2002). These positionalities regarding general attitudes towards border enforcement result in what I shortly discuss as illegibility. So, to restate, the possibility for undocumented crossings at Beitbridge is interesting enough. Therefore, I probe in this thesis this phenomenon and suggest that it is the play with the place of documents in enforcement systems that makes the likes of Mkhize illegible.

\section{The motions of border crossings}

It can therefore be argued that the manipulation of the importance placed on documentation continues to enable assisted border crossings. Pretending to fulfil the requirements of documented travel, and deriving benefit from the gravity of documents, is a practice many Africans feel little remorse for. In fact, it represents one of the ways in which they can make ends meet in circumstances that appear designed to 
exclude them from economic participation. Generally speaking, therefore, state projects of border enforcement and other public administration systems they serve appear already disconnected from the immediate concerns and preoccupations of many Africans, including cross border migrants. In the Southern African case, border enforcement has the added appearance of a coercive mechanism, whose presence can be said to represent an alienating and latently adversarial climate.

As we shall see, this mode of thinking is in tension with a dominant civil administration and border enforcement structure that largely relies on a state monopoly over legitimate means of movement (Torpey, 1998). In order to make sense of border practices of the kind described above, I propose the twin ideas of performance and ethics of illegibility as a legitimised, popular and bottom-up political responses to the illegibility of the state, and which scholars such as Veena Das (2004), Josiah Heyman (1995) and Jacques Derrida (1972) have debated. As performance, illegibility incorporates the rituals of border crossings as arbitrarily enforced through state infrastructures as well as practised, submissively or deceptively, by border actors. As ethics, illegibility draws from Janet Roitmans (2004) notion of illegal and yet legitimated practices that trump official regulatory norms.

My argument is that practices that characterise such performances and ethics are not synchronised, unlike the popular defiance struggles of the apartheid era. In my view, it cannot be said that resistance to and avoidance of enforcement mechanisms feed into 'a venerable culture of resistance', in the sense James Scott (1985) has used it, or in the sense that it has appeared within South Africa in the past. In the context of informalisation, which currently exists in the various arenas of public life in the region, performances and ethics that enable one to pass for a documented traveller could be seen instead as unpredictable and improvisational; predicated less on replicability as they are on 'off-the-cuff', spontaneous singularity that nevertheless retains 
enough repetitive patterns to be spread across a wider spectrum. Those who pass for documented travellers represent a 'multitude' that, according to Michael Hardt and Antonio Negri (2004), have noticeable singularities but maintain a collective force that, in this case, drives assisted border crossings.

\section{Border struggles}

In exploring practices of assisted border crossings I carry a dual aim as noted in the introductory chapter. On one hand, a bottom-up approach to border practices is about an everyday perspective on the research that focuses on experiences and social relations, as well as the production of various forms of subjectivity. On the other hand, and through a historicising effort, I tie this experiential approach to structural issues that shape dispossession in the region as a key part of the Beitbridge border's morphogenesis (Archer, 1982, 1995). The two forks need not suggest conflict in the ambition of this discussion. As I argue, and with insights from critical realism (Blackwell, 2010), tracing border practices across these two perspectives uncovers the possibility of connecting everyday phenomena to wider patterns. Although irregular migration as a mass phenomenon represents a relative (post-apartheid) novelty, rather than a historically continuous phenomenon, ${ }^{33}$ this attempt at tracing border practices in Southern African historiography partly

33. With insights from Jan Theron (2010), Carl-ulrik Schierup $(2015,2016)$ and others, I wish to reiterate that irregular migration emerged around the edges of regulated cross border migration (through agreements with neighbouring states). It followed the same process of circular migration back and forth between mines and agriculture in South Africa and distant labour reserves (similar to the role the Bantustans played in South Africa proper) as was guided by managed migration. Most of this irregular migration related especially to commercial farming in the north. In the post-apartheid era, due to a shifting political economic hegemony, this has changed fundamentally so that irregular migration has been matched by the institutional outsourcing of recruitment to a myriad of sub-contractors, a process that has greatly aggravated informalisation. 
clarifies how irregular migration (although it was a relatively small phenomenon compared to the present) and precarious labour have clear historical precedence and connections. Thus, they have played a part in shaping the interaction between institutional norms, social relations and the everyday experiences which the present accelerated patterns of undocumented crossborder movement and cross-border informality have built. From this narrow historical precedence, we can see how - although the particular quality of precarity has changed - with much more fragmentary patterns today than during apartheid (Schierup, 2015), the precedence for undocumented cross-border movement, a part of which rests in attitudes of resistance towards documents, emerges from such a fractured past.

Below, I first discuss assisted border crossings by placing them in their immediate context of the everyday experiences of mobility and the social relations in which they are embedded. As border practice, 'speaking', introduced by Mkhize above, locates the facilitation/negotiation of border crossings within what Mezzadra and Neilson (2013) have termed 'border struggles'. This is a way of signalling that the social relations which characterise border crossings are riddled with conflict, contestation, accommodation and negotiation, but also that they represent a space where (new) political possibilities and subjectivities emerge. In a subsequent subsection on facilitation and informality, I employ a critical realist perspective to propose an approach that addresses the agency of border actors and the ways in which their agency interacts with structural factors. It is here that the hyena concept as a descriptor of assisted border crossing practices finds promise. By tying everyday practices to structural patterns, this second section paves the way for the chapter's third part, which discusses the historical and ongoing political economic conditioning of border practices. In this discussion, I propose dispossession as a concept through which to understand the emergence of such practices in a broader context. Finally, the concluding part of the chapter outlines the broader social significance of reading border 
practices in this way. As I shall argue, this way of connecting minute border practices to wider forces has consequences for understanding evolving notions of being, as well as of social transformation in the Southern African regional context.

\section{Performances and ethics of illegibility}

The often unsynchronised, largely improvisational but commonly shared practices of assisted border crossings, or ukulayitsha, across the Beitbridge border may be characterised as performances and ethics of illegibility. This formulation concurs with other scholars (Rodriguez, 1996; Scott, 1985; Scott, 1990; Spener, 2009) that such practices do not represent a form of conscious resistance, much less an instance of class struggle, even though they do carry potential economic, cultural and political implications. The notion of performance helps me highlight several interrelated aspects of the practices of border crossing.

a. Performing the facilitation of undocumented border crossings

One of the basic ways to approach border crossings is to view them as a steeped in ritual. This follows from the predetermined functional processes of crossing the state border that involve the more or less set everyday practices by which a constant stream of people and goods arrive at the border and go through a repetitive procedure of filtering. The subjection of all these different people to the same process, which has been called 'border show business' (Coplan, 2012), has a tendency not just to dramatise but perform (Trollip, 2013) representations of the state in front of both its citizens and its own functionaries. It also represents a repetitive process of sifting and sorting people as desirables and undesirables. This is an act of articulating movement with labour on one hand, and regulatory norms with social relations on the other. The subjection of people to the banal practices of participating in this performance of categories, ritualistically reproduce border practice. 
However, the practices of crossing also represent a distinctly human experience regarding the constant encounters of different individuals with border enforcement. In the case of undocumented crossings, such border practices take on a creative form. Here, facilitation (often involving third parties such as omalayitsha, but otherwise taking the form of simple negotiation as in Mkhize's case) must come in where otherwise generally silent rituals of stamping and validating passports and other documents would suffice. As a creative act, facilitation proceeds within what Colin Hoag (2010) has termed the magic of the populace. Here, state officials may or may not attempt to stabilise a 'chaotic' environment in which they work, but they often find themselves having to respond to, and hence participate in negotiation with, intermediaries on behalf of undocumented people and goods. Thus, while upholding their 'station', they concurrently shape actual crossings through acts that collapse the ritualistic sorting of individual travellers. In the midst of everyday enforcement, facilitation necessarily assumes a play with the set border crossing procedures, mainly through acts of negotiation that govern the actual border crossings. Facilitation represents the synthesis of border enforcement and the border's social relations; a constantly shifting reality within a broader and dominant context of movement across international borders. Performances of facilitation therefore exist and represent the creative tension that defines the rituals of border crossings.

Performance, as one of the most embodied attributes of human action, also represents a kind of restored behaviour. This is the creative art of making a reality, or a 'structural elaboration' (Archer 1995, in Bakewell 2010: 1697), out of its representation. As an unintended but integral outcome of border struggles (seen for instance in conflict and negotiation between state actors, intermediaries and irregular travellers), performance assumes both concrete and shape-shifting qualities. This is where the everyday acts of negotiation are often grounded in make-belief as an ethics of illegibility. 
In order to capture this ambiguity, one should approach border practices as both real and magical (Das, 2004), and documents as both concrete artefacts (Riles, 2006) and as mere signifiers of both travel and belonging. Although all border actors are aware that the normative vision of border crossings is imposed, they accept that the very same vision creates a substratum of belief that people eventually embody and internalise. Legibility represents a "spectacle that sets the scene of ostensible exclusion, in which the purported naturalness and putative necessity of exclusion may be demonstrated and verified, validated and legitimated" (De Genova, 2012: 493). The negotiation that accompanies assisted border crossings therefore may be seen as the art of make-believe.

Facilitators, state functionaries and undocumented travellers all accept that missing documents present enough grounds for refusal of entry. This is the space of denial of entry. But, they also engage in border practices that negotiate passage in the face of denial. This is the denial of the possibility of denial as assumed by lack of documentation. The possibility of undocumented passage thus represents the space in-between the two forms of denial. This in-between space is one of creativity (Schechner, 2013), or more succinctly, creative misunderstandings, where realities are created anew (Naum, 2010). At the everyday level, facilitation is the manifestation of this creativity in the conduct of negotiating undocumented movement. Performances of facilitation exist in a space of social relations that makes it possible for dispossessed (undocumented) people to eventually be able to share in something that they ordinarily are excluded from.

\section{b. The ethics of illegibility}

The overlap between strict requirements for documented border crossings at Beitbridge and the ubiquity of undocumented crossing brings focus back to the subject of illegibility. As already stated, illegibility is not postulated here as related merely to 
the absence of documents in border crossings. As I will show, documents, including their feigned presence, play a significant role at crossings, and what happens in this role is of interest.

Following from Veena Das' (2004) formulation, illegibility is first understood in the sense of the inscrutability of the state, whereby its workings oscillate between a rational mode and a magical mode. Rational in the rules and regulations embodied in law and institutions, as well as in how the weight of their power is brought to the realm of the present through representations and performances. Magical in the realm of interpretation, application and manipulation of these rules in not always straightforward ways by those tasked with the duty of executing them. In invoking a lack of transparency, magic, according to Das (2004: 225-227), also hints at danger that proceeds from a combination of power and obscurity, as well as vulnerability for those who come into contact with these practices, including the ordinary masses.

Illegibility is thus about the potential for danger in public encounters with governmental institutions where the state can be thought of as at once authoritative and yet changeable from context to context (Derrida, 1982). I extend this understanding, and mobilise Colin Hoag's (2010) understanding of the populace as also capable of infusing such unpredictability to the workings of the state. I suggest that the interaction and possible synthesis between the two represent the kind of mutual illegibility that characterises border practices. This general unpredictability, danger and vulnerability, what Das call magic, spreads across the border space. It delineates the context within which border practices, in the context of undocumented travel, emerge during everyday border crossings. In this context of unpredictability, I denote danger, vulnerability and counter strategies as an ethics of illegibility. 
Accepting Heyman's (1995) idea of 'thought-work' allows me to arrive at an understanding which imagines officials translating their tasks to produce a contextually relevant and sometimes individually intentioned code of conduct. On the other hand, third parties and undocumented travellers read this context and, by combining it with their own needs and aims, engage with it in ways that have the effect of shaping distinct border crossings. In this case, such processes relate to enforcing cross-border movement in a context where border officials must negotiate with facilitators and undocumented migrants while wielding the power of border enforcement in a discretionary manner. In order for facilitation to work, and for the institution of border enforcement to hold, officials, intermediaries and undocumented travellers must necessarily feign compliance with requirements for documentation. If magic initially relates to the unpredictability in the workings of the state in everyday contexts, practices of collaboration with ordinary publics that are aimed at exploiting this unpredictability for instrumental ends give illegibility an extended meaning. It is these complexities that, as I argue, may be captured in the idea and concept of the hyena.

This meaning is further strengthened by the idea of an ethics of illegality. Following Janet Roitman (2004), one could suggest that border crossings take place within a widespread acceptance of behaviours, practices and beliefs that might be understood as illegal from the point of view of institutional border enforcement law, even though they are accepted, legitimated and serve important practical ends by those who engage with and participate in them. The ethics of illegality does pay attention to regulatory norms and their interpretation, but furnishes further leeway in how undocumented border crossings, or crossings where documents appear only in their aggregate importance and as not material enough to acknowledge that border crossings proceed along a polysemic terrain. That is, regulations apply, but only as far as they are allowed, subject to further and ongoing negotiation and reinterpretation. This morphogenesis (Archer, 
1995) has the capacity to produce a context-specific, 'organic' set of border practices that in turn signal a fluid interplay between governance and subject formation (Cabot, 2012; Das, 2004). The ethics of illegibility as a conceptual tool comes about by marrying Das (2004) and Hoag's (2010) notions of illegibility with Roitman's (2004) ideas on legitimated illegality to refer to practices that include state actors, third parties and travellers in the facilitation of undocumented border crossings. This is in view of both how border actors apply and manipulate border crossing procedures, and how they have come to accept this and other extra-legal practices as the way in which border crossings sometimes proceed.

\section{Assisted border crossings as practices of proximity}

Assisted border crossings are not to be seen as practices that simply skirt the law. When the law seems to not fully reach or discipline border crossings, it is mainly because of the process by which the application of the law is negotiated, and the way these negotiations maintain equilibrium in such border practices (Anjaria, 2011). In this sense, the interaction between border enforcement and the border's social relations does not represent a combative space. As facilitation suggests, this is a space of collaboration not of opposition, but of creativity, negotiation and transformation (Ortner, 1995 in Anjaria, 2011: 61).

It is crucial here to defer back to Maxim Bolt (2011), who, just as this study and others (Musoni, 2012) underline, does not seek to downplay different kinds of material and symbolic violence that pervades the Beitbridge border. Undocumented crossborder travellers often escape the threat of physical violence by paradoxically staying visible to state functionaries, especially the police and the military who are more likely to offer them protection, although are in other contexts the epitome of violence. When this view is brought close to assisted border crossings 
as practices of facilitation, the other paradox of a structurally violent immigration regime, evidenced by what at first appears like robust border enforcement mechanisms, is uncovered.

Although irregular movement is often criminalised, the regime simultaneously fosters even closer everyday interactions between state functionaries tasked with enforcement and the irregular travellers, often with the intervention of intermediaries such as omalayitsha. Thus, these encounters are characterised by their convivial and pragmatic air more often than not, securing border crossings even with the aid of various forms of exchange. In agreement with Anjaria (2011: 60), I see such relationships with the state as characterised by proximity rather than distance. The paradox of criminality and proximity makes such relations particularly lucrative, as those who can influence them are able to sell such influence for a price. This is just as applicable to the past practices of illicit labour recruiting as it is to current assisted border crossings. However, the historical continuity of facilitation and proximity do not suggest linearity and uniform applicability to all contexts. In the past, such proximity generally related to direct collusion of the colonial state with representatives from industry to secure cheap labour, which was enabled across the border through informal labour recruiters (Bulpin, 1954; Bolt, 2011). Presently, it relates largely to the uneven ways in which interactions between irregular migrants, omalayitsha and state functionaries perpetuate and transform both the practices and the structural context of contemporary border crossings that situates them.

\section{Delimiting border struggles at Beitbridge}

The interaction between institutional norms and social relations that structure everyday border practices defines the essence of assisted border crossings. Mezzadra and Neilson (2013: 7) build the notion of border struggles in a similar way, but they affix it to a wider 'grid' that brings law, power and citizenship to changes in 
labour processes, time and space in order to more comprehensively capture the contemporary configurations of borders. While borrowing from their formulation, I limit my analysis to the relationship between border enforcement and border crossings as representing a point of contention, overlap and struggle, as well as interconnection that defines border practices. By situating assisted border crossings here, border struggles become the prism through which institutional norms and regulations are received, understood, operationalised, negotiated and contested in the specific Beitbridge context of cross-border movement.

By mobilising insights from the critical border studies, border struggles hint at the contradictory ways in which borders materialise or disappear in social space. In line with Chiara Brambilla ( 2015), the understanding of border struggles that I mobilise here signals contestations around the aspirations of borders as markers of belonging; that is, as important sites of exclusion and inclusion. But, border struggles as a concept also seeks to capture "everyday practices by which cross-border travellers continually come to terms with the pervasive effects of the border" (Mezzadra \& Neilson 2013: 13) that constitutes them in various postures of subjectivity.

\section{Facilitation: the politics of informality and morphogenesis}

In a discussion of border practices such as this one, it may seem unnecessary to take a detour into the debate of migration infrastructure as proposed by Biao Xiang and Johan Lindquist (2014). Its significance, however, lies in their conception of the increasing involvement of third parties in processes of crossborder movement and employment. Thus, although the Asian context from which the idea of migration infrastructure is taken is vastly different from Beitbridge which I transpose, the authors' operationalisation of the concept of mediation is valuable. This is 
especially so when it is conjoined to other conceptualisations of mediation (Piper \& von Lieres, 2011, 2015) and refashioned in the mould of facilitation, as I do, to a non-class conscious informal politics of assisted border crossings (Neocosmos, 2011; Bayat, 1997; Chatterjee, 2004).

\section{Facilitation}

Migration infrastructure is about the dense interconnection between 'technologies', 'institutions', and 'actors' that enable and shape mobility (Xiang \& Lundquist 2014: 124). Characterised by commercial, regulatory, technological, humanitarian and social dimensions that denote its 'logics of operation', it signals the ways in which migration can no longer be about just migrants, but more about the arrangements comprising "migrants and non-migrants, human and non-human actors" (ibid.) who, taken together, mediate labour migration. The recognition that migration is increasingly mediated through processes of 'regulation', 'commodification' and 'intervention' keeps up with analyses of movement that consider broader political economic developments premised in market forces, state regulatory capacities and 'informal' social relations. This brings nuance to discussions on agency, suggesting that the subjectivities of undocumented travellers are conditioned by overlapping temporal, institutional and everyday relational dimensions of social space. This enables an exploration of the border practices of omalayitsha as belonging to a similar understanding of how complex arrangements and interconnections positioned at different scales articulate with each other. Facilitation offers a concrete empirical space to observe these linkages.

Facilitation can be mobilised to point towards three issues of importance for this thesis. The first is about the evolving social context of border practices in which assisted border crossings take shape as a politics of informality (Bayat, 1997; 
Chatterjee, 2004). The politics of assisted border crossings is informal because the complex social relations that govern its everyday form seldom coincide with the "lofty political imaginary of popular sovereignty" (Chatterjee 2004: 36), which in our case would manifest in more or less orderly regulatory frameworks and norms that are meant to structure cross border movement. Informality, in this case, is about ordinary practices of everyday life that, as strategies of makedo (Jones, 2010) by the disenfranchised, escape the purview of formal institutionalisation, but have the effect of being a significant counterforce shaping broader social relations. This understanding of facilitation bears some traces of how Lawrence Piper and Bettina von Lieres (2015) conceived mediation in the Brazilian civic activism sphere. The (political) view on facilitation that I take in this thesis does not directly resemble a form of resistance by the weak (Scott, 1985), or representation in public decision-making spaces, but rather engagement with disenfranchisement in creative, if atomised, responses within the sphere of the 'governed' (Chatterjee, 2004).

\section{Political and migrant subjectivities}

The second sense in which facilitation is mobilised has a performative element to it. It speaks to what border practices such as assisted crossings mimic and signify. In our case, irregularity in movement and precarity in labour does not suggest exclusion from the domain of politics. To push this point, Partha Chatterjee suggests that the entanglement of state functionaries, themselves operating in the domain of 'civil society' with 'nominal citizens' across the colonial epochs, leaves us with a kind of 'political society' (Chatterjee, 2013: 40). It is in this domain that border practices, which in this thesis are linked to colonial, transitional and neoliberal spaces, tend to transgress the lines of legality. 
This is the way in which the practices of undocumented travel appear to inadvertently acknowledge their transgressive behaviour at the border, but claim movement and access to a livelihood, and in a similar vein, as a matter of right and pragmatism (Chatterjee, 2013: 40). These claims are then negotiated on both political and socioeconomic terms. This dual awareness necessitates on the part of border actors, a reinterpretation of socially situated institutional practices, and a proclivity to approach assisted border crossings as practices of negotiating marginal resources thorough distributive as well as instrumental logics (Ferguson, 2015; Meagher, 2014).

The social relations that border practices script are thus the site of political agency and subjectivity for irregular migrants. To understand how they navigate border enforcement institutional mechanisms in the context of irregularity and precarity, this study partly borrows from the perspective of migration autonomy to seek to clarify agential strategies of travellers and migrants (Nyers, 2011, 2015; Nyers \& Rygiel, 2012; Papadopoulos \& Tsianos, 2012; Rygiel, 2011; Scheel, 2013). Migration autonomy is a way of privileging the perspective of the migrant analytically, suggesting that migrant practices have political significance (Nyers, 2015; Nyers \& Rygiel, 2012). At the very least, I approach autonomy as an agential strategy by which irregular movement is also seen as encapsulating individual and group ingenuities, by which actors navigate conditions of cross-border movement and migrant labour that are largely conditioned by structural dispossession.

\section{Banal corruption and the informalisation of border crossings}

The third sense in which to approach facilitation is to view informality in the context of what is often seen as corrupt practice. However, as I focus in this thesis on practices and experiences, it is perhaps prudent that I talk more about informalisation than informality per se.

a. On informalisation 
Addressing what might look like informalisation can be attempted through articulation and hyena concepts. As I stated in the Introduction above, articulation suggests the ways in which different institutional process, mechanisms and norms interact with each other in social space. On the other hand, hyena strategies represent the process by which the same processes are understood, consumed and adapted by actors materially and abstractly to their local Beitbridge context. Through these, powerful actors, including states and big business, as well as marginal ones such as migrant entrepreneurs and street vendors, are capable of engaging in informalisation practices (Likic-Brboric et al., 2013; Slavnic, 2007, 2010, 2011, 2016). State actors are particularly adept at this as they can contribute to and simultaneously oversee informal strategies, and do so through selective economic and political practices that have polarising effects on society; migrants generally tend to come off worse in such situations.

Zoran Slavnic (2010) draws from the example of north European economies to sketch a picture of two paths that informalisation generally follows; informalisation from above and informalisation from below. Regarding the latter, scholarship on informality in urban Africa, which this discussion has already flagged, provides ample space for conceptual convergence, although problems persist. In Africa's urban economies, as elsewhere, marginal groups are likely to be severely impacted by different informalisation processes. Such groups thus easily find themselves confronted by a variety of social problems, exploitation and stigma as a result. Regarding the informalisation from above, this discussion embeds itself in Slavnic's and Theron's (2010) propositions of strategies by which big business and state actors drive the process as discussed above.

Additionally, informalisation from above in the African context should be further understood in terms of the wellarticulated role of capital, sometimes in direct collusion 
with the state, orchestrating accumulation by dispossession often through acute strategies of abrogating responsibilities for labour. In the post-colonial neoliberal Southern African context, informalisation from above has also seen the collusion between international financial institutions and African states in 'structurally adjusting' African economies by instituting privatisation, Such strategies, by which the markets open up to international competition, have bound many post-colonial African states in heavy and recurrent debt, with debilitating effects on social protection mechanisms, as well as social coping, citizenship and political participation.

b. Everyday corruption

What I refer to as assisted border crossings, their negotiation and facilitation are often construed in dominant discourses on mobility and other social processes as corrupt practices. Pitting state functionaries and irregular migrants in interactions that appear to undermine border enforcement, these and similar practices may be seen as representing a failure of governance (Chandavarkar, 2007). The popularity of this view partly lies with its vast appeal in the developmental (African) state paradigm, where most of the work that seeks to lift marginalised communities out of poverty pathologises behaviour that conflicts with the prevailing regulatory norms. Such definitions of corruption tend to neglect the social and historical contexts that shape such practices.

In post-colonial political anthropology, corruption represents a well-explored topic (Anjaria, 2011; Blundo \& Olivier de Sardan, 2006; Das \& Poole, 2004; Gupta, 1995, 2005; Lindberg, 2003; Ochonu, 2014, 2016; Pierce, 2016; Roitman, 1990; Shah, 2009; Smith, 2007; Visvanathan, 2008). Giorgio Blundo and Jean-Pierre Olivier de Sardan (2006) in particular attempted to identify and describe a variety of 'tacit codes' and 'practical norms' that structure social relations in contradistinction to the public codes 
and official or legal norms that should guide these relations in the West African context. Blundo and Olivier de Sardan (2006: 4) identify an overlap between what they describe as the 'generalised informal functioning' of the state, and the corrupt practices that emerge from, but do not merge with, this 'real' functioning of the state. They suggest a 'complex of corruption' to recognise this overlap, and to unhinge their conceptualisation from strictly legal definitions. Their discussion, however, does not fully distinguish between different kinds of exchanges and socio-economic relations that take place at the public officialcitizen interface, leaving the discussion of what does and does not constitute corruption unresolved.

I do not offer to resolve this conundrum. While cognisant of the hold that corruption has in the public imaginary, I approach this phenomenon alongside Jonathan Anjaria (2011) as representing a space of negotiation that shapes practices of border crossings and the politics of irregular movement and precarious labour. In the Limpopo Valley context, as I will show in the following chapters, assisted border crossings represent the manner in which populations navigate and secure claims in a cross-border space that generally marginalises them. This is how Ochonu (2016) also conceives such relations, including the practices of assisted border crossings; that is, the creation of a relative sense of (economic) opportunity in an environment that otherwise offers limited formal livelihood opportunities for the poor.

The continued precarious work and irregular movement of Zimbabwean labour in(to) South Africa is partially dependent on the success of extra-legal negotiations with border enforcement officials at the official Beitbridge crossing point or further up and down the Limpopo River. In other words, irregular practices that see the assistance of Zimbabwean labour across the border may be considered illegal, and yet they are enabled by state practices as much as they are foreclosed by them. What often goes by the term corruption in this case, therefore, represents a kind of 
equilibrium between enforcement and social relations of the border with regard to the negotiation and facilitation of border crossings. An example may help this point along.

In June of 2016, owing to a perceived negative impact South African imports were having on the retail economy in Zimbabwe, the Zimbabwean government introduced an import ban on certain consumable goods (Maseko, 2016). The stricter enforcement of this ban soon resulted in a standoff at Beitbridge. The ensuing protests resulted in the torching of several Zimbabwean state warehouses that housed confiscated goods (News24, 2016), and the government later backtracked (Booi, 2016). This example can be applied to a general politics of negotiating border crossings. Here, the issue regarded more the narrowing of negotiation space that resulted in the violent protests, and less the application of law per se. The burning of state infrastructure communicated the utility of negotiations (or corruption) in shaping relations between travellers and the state. The message was that no one gains by using the law to squeeze the space of survival that negotiation occupies.

Practices such as the facilitation of undocumented movement are an integral part of the real functioning of border enforcement at Beitbridge. I contest the idea that they represent something 'far removed' from it, as Blundo and de Sardan (2006: 4) have suggested in their characterisation of corrupt practices. To help this argument further, for the marginalised, both irregular movement and border practices connected to it are part of a broader experience of regional dispossession that connects to precarious labour. Moreover, and as the burning of state warehouses shows, border practices that appear as negotiations of cross border movement are neither spectacular nor extraordinary. It is this banality of 'corruption' that allows claims on the space of movement and labour that appeal less to formal regulatory norms, but emerge when these same regulatory norms appear to exclude the marginalised from 
economic participation. Through everyday social relations and experiences that seek to breach these foreclosures, including those that take place at Beitbridge, actors are simultaneous reproduced as politically responsive.

\section{c. Informality and corruption reconsidered}

So far, I have highlighted the following broad themes that tie to the twin subject of corruption and informality. There is, in South Africa and Zimbabwe, convincing evidence that states treat what they perceive as informality with suspicion and disdain. In South Africa, regular clean up campaigns that are disguised as bylaw enforcement often end up targeting informal businesses in major city streets, most of them run by immigrants. I have tried to suggest that informalisation processes can be traced, at least in part, to practices such as illicit labour recruiting that are historically acknowledged to have persisted in colonial and apartheid Limpopo. These tied clandestine movement to both legitimate and unscrupulous recruiters and to colonial agricultural and mining interests in the north and further south. And yet, as the literature suggests, informalisation and its particular connection to irregular migration, are indeed fundamental markers of the post-apartheid/ post-colonial (neoliberal) age. With its present specific features, as Schierup $(2015,2016)$ has argued, informalisation is especially glaring if compared the apartheid (developmental) state, with its centralised state bureaucratic management and monitoring of both movement and labour.

In her work on displacement economies, Amanda Hammar (2014, 2010) has explored how authoritarianism in postindependence Zimbabwe has gradually come to validate violent state practices by which aversion to informality is invoked in pursuit of political coercion. The resulting displacement has combined with economic decline to add to the spectre of informality and informalisation. It is in this regard that one could say, with Carl Schierup (2017), that today's fractured 
rhizomatic neoliberal regime is indeed the playing field of both informalisation from above and the informal social politics that this present study is interested in.

The involvement of border farmers in informalisation processes illustrates the process just described. As Theron (2010) has eloquently demonstrated, by appropriating the duties of the state in regularising the employment of farm labour, border farmers, for example, have been benefitting from the conflict of interest that exists in defining the labour standards and maximising profits in the Limpopo agricultural sector. To some degree, those mining businesses that benefitted from illicit labour recruiting (Bolt, 2011) can be seen in similar light.

At the border itself, there is overwhelming evidence of the participation of state functionaries in the negotiation and facilitation of the undocumented movement of people and goods. The remittance economy also provides strong incentives for the derivation of gain from practices that shape assisted border crossings. At Beitbridge, these issues exist next to a seeming reluctance to streamline border crossing procedures, a situation that some (Mills, 2012; Trollip, 2013) have suggested is designed to encourage corruption.

There is also the notion of what Chatterjee (2004) has called heterogeneous time, whereby the neatly laid out regulatory norms, which are designed to govern movement according to a global capitalist paradigm, do no coincide with the experience of mobility for the ordinary traveller in contexts that do not shape the emergence of this governance paradigm. This resulting disjuncture, which Chatterjee suggests defines political society 'in the rest of the world', is elaborated upon in the Southern African context by the existence, among border actors and the general populace, of a general sense of alienation to bureaucratic systems that are sometimes seen as instruments of violence and coercion, rather than those of democratic governance. 
The issues that have been flagged above, I will argue, transform the understanding of corruption in the context of both informalisation and border practice. This formulation can be flipped around to say that practices which pass under the rubric of corruption, as observed across the Limpopo Valley space, and especially at the Beitbridge border, transform the understanding of what informalisation is, and how it is shaped and sustained in the everyday context. By utilising assisted border crossings to shed light on how borders articulate with undocumented migration and precarious labour, practices of both corruption and informalisation reappear as pragmatic strategies by which actors seek to get ahead by means other than those they believe to not work to their best interest.

While this formulation is not necessarily ground-breaking, it has many consequences for studies of the place of everyday practices in broader social relations. At one level, it lays bare, and begins to trouble virtually everything we have come to understand from the unexplained and taken for granted categorisations of crossborder mobility, border crossings and of migrant labour. In the context of this present work, it throws up questions related to the notions and meanings of 'decent' work, 'regular' movement, 'belonging', '(b)orders' and 'boundaries', and demands that one examines what one ordinarily accepts as the 'nature' of democracy, equality, justice and participation. This, I contend, is the spirit in which critical border studies intervene in current debates on migration, governance and society.

\section{Morphogenesis and subjectivities of transition}

The discussion above leads to a general problem that sits at the very foundations of sociological debates on how structure relates to agency in shaping social phenomena. Border practices, including 'corrupt' practices and informalisation strategies, lift the strength of social relations to a level which is more or less the weight of 
the normative border enforcement institution. Such practices also reify regulatory norms by submitting to, or proceeding within and along, or manipulating, their parameters. Thus, undocumented cross-border movement inevitably abides by regulatory demands of formal border enforcement, while at the same time it challenges and makes claims for rights and recognition (Nyers, 2015). The undocumented, therefore, succeed to both evade and manipulate as much as they establish and transform the same regimes and institutions. Those who remain sanguine about the strength of autonomy of movement over systems designed to control it, such as Vassilis Tsianos \& Serhat Karakayali (2010) and Thomas Nail (2015), have even proposed a political theory of the migrant. Such a stance sees both mobility and mobile figures as preconditions for the constitution and transformation of society.

Critical realists, however, are less enthusiastic about the conceptual and especially the analytical potential of migration autonomy. They have cast doubt over what Oliver Bakewell has termed the 'hyperactivity of agency' (Acher 1982, in Bakewell 2010: 1696). Building carefully from Anthony Giddens' (1984) structuration theory, critical realists are dissatisfied with approaches they feel offer little potential for the analysis of actual empirical research as a way of dealing with the impasse that often characterises discussions on the relationship between structure and agency. I benefit, in the present context, from Bakewell's critical realist approach to migration, which, by mobilising Margaret Archer's (1982, 1995) ideas on morphogenesis, suggests that there exists an analytical dualism between structure and agency that is temporally mediated.

To use the example of Beitbridge border practices, morphogenesis proposes that the consequences of previous 'illicit labour recruiting' practices across the Beitbridge border have contributed to a border enforcement environment that is riddled with informal practices that have today shaped, and continue to shape, assisted border crossings. The present context of the 
relationship between assisted border crossings and official border enforcement forms the basis for how border practices, and indeed border crossings, will evolve going forward. Whereas both border enforcement and assisted border crossings have been structurally conditioned this way, they are not structurally determined (Bakewell, 2010: 1697) as actors still exercise their agency in numerous ways. The social relations obtained in this context serve to further elaborate the border enforcement regime within which they take place, so that border enforcement (structural properties) continues to evolve in the context of the border struggles that shape border crossings.

It is at the intersection of structural processes and everyday practices that the tension and ambivalence between irregular movement and precarious labour are exposed and reshaped. The ambivalence of hyena strategies, as border practices and identities, represents and works with this tension. In carrying out society's unacknowledged business (Wolf, 1959), hyenas of the Limpopo resolve the contradiction between the restriction of movement, and active employment and precarisation. They also smoothen the inconsistences between the heightened border enforcement norms and the proliferation of criminal, informal and corrupt border practices. It is these ambivalent identities and practices that make it possible for boundaries around movement, work, belonging and justice to be erected at the same time that they are transgressed. These contradictions, I argue, are not marginal to society, but are at the heart of social transformation. This is the case not just in discredited systems of domination such as colonialism and apartheid, but also in contemporary neoliberal processes in most of the world.

The temporality of irregularity and informalisation, therefore, situates the specific transformation of the present, which, although history would have been key to setting the scene, admittedly take on a different form from colonialism and apartheid. Continuities that are carried over from the past often 
bear with them certain discontinuities. If I have come across as suggesting that present patterns of informality and irregular movement are path dependent, they should yet be seen to also be situated in qualitatively different migration and border enforcement regimes. There is perhaps a lingering question, however, on the extent to which the practices of hyenas are themselves path-dependent.

So far, the approach of this conceptual discussion on assisted border crossings has been from the perspective of everyday experiences and practices. This approach has from time to time been making overtures at the overarching structural processes that incubate these experiences and practices. Insights from critical realism, nevertheless, especially the idea of morphogenesis, offer a good point to continue the discussion by directly situating assisted border crossings within broader structural terrain.

Regarding path dependence, two important issues need to be flagged at this point. The first has been alluded to, immediately above, regarding transitions in the identities of facilitators in the long period framed by this research. I return to this problematic, what I call subjectivities of transition, in the following paragraphs. The other issue, which I briefly state here, but possibly warrants a future study of its own, relates to the continuities and breaks that structure border practices at the level of political economy. Labour recruitment in colonial Southern Africa and especially during apartheid was largely more centralised and formally regulated than today's fragmentary regime (Schierup \& Jogensen, 2017). Schierup (2017) suggests that such informal strategies of the present represent attempts to establish ideological distance from forced labour recruitment strategies of the colonial and apartheid era. The place of apartheid in sharpening and entrenching these practices warrants special attention. And yet, parallels are immediately evident in the current mobilisation of racism and covert management practices related to cross-border migration, with their appeal to othering and stigmatisation 
processes based on language (the amaKwerekwere phenomenon) and skin pigmentation, that are seen as tied to a broader project of exclusionary nationalism (Perberdy, 2001). These questions are not addressed in detail in the present study, but are flagged here to acknowledge their importance to current and future debates.

Another important question that has eluded this present task, but which could be of vital importance and necessitate further exploration, is the actual evolution, the genealogy, of the practices of facilitation themselves. Answering this important question may furnish important insights into the question of the transition not just of border practices, but also of the subjectivities that have been evolving with them. We could therefore have what could be termed subjectivities of transition first in the spirit of morphogenesis. This would acknowledge the place of border actors, throughout time, colluding, negotiating, resisting and transforming modes of (their) domination and/or governance through everyday border practices. Subjectivities of transition could also be thought of in terms of, in David Scott's (1985) conception, subject-constituting socio-political practices. This is the way that certain contextual subjectivities could be shaped by prevailing modes of domination and rule. This is important, especially when comparing practices of the colonial and apartheid past to the current ones, to more clearly map current transformation processes.

\section{Dispossession, frontiers of capital and surplus movement}

\section{Dispossession}

Dispossession, as I use it in this study, is a phenomenon that is tied to both the structural and the experiential dimensions of Southern African labour migration processes. Following Butler and Athanasiou (2013), such an understanding posits 
dispossession as a form of deprivation and separation from 'the sovereign self', and as political responsiveness. The first refers, for instance, to when people are stripped of their material possessions as a result of (neo)colonisation, war, neoliberal processes or other natural and human disasters. The second describes a way in which the individual exists in a "social situatedness and allocation, including [the] exposure to the possibility of being undone" (ibid.: 32). This second sense implies reliance on social relations - being bound to others as being both socially complete and vulnerable, ceasing to be a sovereign individual. Social relations also furnish the possibility to interact in processes of self-assertion, which has important political consequences.

Generally, dispossession speaks to the contemporary politics of economic precarity often characterised by temporary, low paying, insecure jobs, as well as poor or no welfare and social service provision, prominent features of current global neoliberal capitalism and characteristic of Southern Africa. The intense circular movement observable across the Beitbridge border illustrates, and is illustrated by, this understanding of dispossession. Here, humans are at an exposition - a defining point - where their search for substance as humans also presents them as commodities, where "they represent human as they do economic life" (Jonsson, 2013: 199). At the basic level, they represent the "violent appropriation of labour and the wearing out of labouring and non-labouring bodies" (Butler \& Athanasiou, 2013: 11).

With regulatory norms that secure 'cultural intelligibility', but simultaneously turn humans into 'speaking commodities' (Jonsson, 2013), I am interested in the conditions that both necessitate and shape movement, economically and socioculturally. These conditions represent a migration context that exemplifies, in line with Stefan Jonsson's characterisation, a world ruled 'by a capitalist logic piling humans and things 
onto one another as commodities'. It is a logic that breeds in the disaffected 'a new class ... whose life, work and thinking are objectively delimited by their position vis-à-vis the production, marketing, and consumption of commodities (Jonsson, 2013: 199).

The overlap between the individual and the commodity underscores the human element of movement within its political and economic dimensions. Dispossession as a concept exposes what it means, at the structural and experiential levels, to be materially and symbolically disempowered. As an instance or act of shedding the sovereign (unitary) self, practices that accompany this movement can perhaps also be seen to represent a step towards political and ethical responsiveness (Zaroulia, 2015). This is the way in which engaging with deprivation reconstitutes the dispossessed as political subjects. Undocumented movement, even if viewed in popular discourses as 'illegal', represents a part of this responsiveness. And, border practices locate such responsiveness at different political, economic and social boundaries. One entity that captures such boundaries, materially and symbolically, is the state border.

\section{State borders as frontiers of capital}

Considering the politics and economy of the irregular movement of precarious labour, the state border in general represents a tension and contradiction in the territorialist and capitalist relation. It is the wedge that lies between the expansionist logic of capital, which is driven by accumulation, and states' logic of fixity, underpinned by concrete territorial demarcations. In the Southern African regional scope, the market logic posits the territorial border as a filter and membrane through which labour can be socially reproduced outside the bounds of the capitalist production sphere at little cost to that sphere itself. 
The arrival of industrial capitalism in Southern Africa follows the same logic of its expansion that is evident elsewhere: the logic of power and productivity starts to derive from labour productivity rather than land productivity (Moore, 2013). It is this new matrix of accumulation that drives commodification. As elsewhere, capitalist orientated expansions, in the form of demographic and territorial expansion, yield commercial and manufacturing growth. However, increasing commodification eventually turns demographic and resource frontiers into commodity frontiers. And, it is these commodity frontiers that begin to force the movement of people back and forth in the colonial and apartheid setting, instead of the other way around (ibid.). This is the historical moment at which the territorial border comes to play an important role in modulating how people follow the frontiers of commodification. The concept of capital frontiers is therefore useful in positioning physical and other borders as a means of regulating cheap labour and irregular movement at the market level (often with the collusion of states).

In Southern Africa, the forced settlement of people in labour (or native) reserves, Bantustans and labour compounds represents some of the first appearances of the physical border. Through largely formal, centrally monitored and overtly racist practices, the enforcement of these borders necessarily alters the relations between the production sphere and that of labour's social reproduction, serving primarily the exploitation of labour power in the production and realisation of commodities. Thus, if the exploitation of labour power is vital for capital accumulation, such exploitation works to the degree that the cost of its reproduction can be suppressed (Moore, 2014). In many analyses of the political economy of labour, the connection between wage-work and its dependence on the contribution of unpaid work outside the commodity system is well established (Harvey, 2004; Moore, 2014). Scholars such as Wolpe (1972), Terreblanche (2003) and Schierup (2016), among others, have addressed the law of value in the context of the production 
of Southern African migrant labour power with cheap factor endowments. By situating myself within their work, I argue that the enforcement mechanism of state borders plays a crucial role in the suppressing the cost of labour reproduction which has the effect of keeping the production costs of that labour low, thus producing superfluous labour.

In this sense, the physical border also acts as a border between labour regimes, one within and one outside the commodity system; although both are orientated towards serving processes of accumulation. A more or less similar stringent, and yet informally managed, migration regulatory framework that is today accompanied by a discourse of democracy, exclusionary nationalism, struggles over citizenship and neoliberalism, all of which preside over significant policy lethargy in transforming and democratising the cross-border movement of low-skilled labour (Amit, 2015; Crush, 2008), sees many still crossing borders such as Beitbridge clandestinely. Without legal residence documents, they often turn to informal employment, where they remain vulnerable to exploitation. The border thus plays an important role in shaping irregular migrant statuses.

The concept of capital frontiers may thus expose how the Zimbabwean labour periphery has already been constituted as a frontier, in that it is here that the appropriation of unpaid work (Moore, 2014), the work that goes into the social reproduction of labour power, takes place outside the commodity system, but at the same time as a part of it. ${ }^{34}$ Speaking of how labour and consumption peripheries (such as Zimbabwe in this case) are incorporated into broader processes of capitalist accumulation across spatial as well as economic production boundaries,

34. As an aside, the remittance economy serves another illustration of how the Zimbabwean periphery serves the production core that lies within South Africa's territorial borders. 
Jason Moore writes that "appropriation, ... names those extraeconomic processes that identify, secure, and channel unpaid work outside the commodity system into the circuit of capital" (2014, webpage source).

Enforcement mechanisms and the social relations that define border crossings, whereby border practices shape its other function as a membrane that filters and selects people and different forms of circulation (Mezzadra \& Neilson, 2013: 5-7) speak to this work of appropriation. These practices can be understood as existing at the realm of work, and not of labour as such (Moore, 2014). They do not represent abstract social labour in the Marxist sense, but "the historically-grounded forms of geo- and bio-physical activity as they "bundle" with humanity's distinctive forms of sociality and embodied thought" (e.g. White, 1995, in Moore, 2014, above). This represents the way in which border practices themselves tend to escape characterisation as precarious labour, although they significantly shape it.

The understanding of the regional labour pool as constituting a frontier necessitates a corresponding understanding of the territorial border and border practices as the site where the reproduction of migrant labour as cheap is validated, affirmed, contested and resisted. A focus on these border struggles thus enables an understanding of the everyday experiences of undocumented border crossings as invariably connected to broader processes of capital accumulation that continue to shape a regional system of migrant labour that significantly characterises the Limpopo Valley. Thus, labour peripheries such as Zimbabwe necessarily redefine labour migrants as surplus populations in the Marxists sense, and spaces of their social reproduction as capital frontiers. 


\section{A case for surplus movement?}

Finally, from the perspective of capital frontiers, the redundancy of large swaths of Zimbabwe's skilled and unskilled labour force, as well as its associated 'exodus' from the country (Crush \& Tevera, 2010) as alluded to above, necessitate a visit to Marx's conception of surplus populations. The relative coincidence of the spectacular collapse of Zimbabwe's post-independence economy, and the continued perception of South Africa as both a sanctuary and 'greener pasture', which has seen unprecedented numbers of cross-border movement of Zimbabweans at Beitbridge, cannot be downplayed. This, however, should not detract from more fundamental structural dynamics that see what certainly looks like a 'disposable reserve army' (Marx, 1976) of migrant labour being drawn towards South Africa's centres of economic production. A significant volume of this labour includes many Zimbabweans. My primary interest here is not to argue for or against defining movement to and from South Africa as being that of a surplus population, although it is likely to be. My idea is rather to use this understanding (of surplus populations) to explore irregular movement across the border being subjected to de-skilling and de-qualification, in view of underemployment and exploitation in terms of both skill levels and wages; in terms of numbers, the movement is already in numbers - a mass (Jonsson, 2013) ) $^{35}$ and being precarised this 'mass' thus reproduces acts of its abjection and dispensability. Its source territory, Zimbabwe, represents a labour periphery, and in that sense, a capital frontier.

35. Stefan Jonsson analyses the public appearance of the 'masses' in interwar central Europe. I borrow the concept from how he sees it as partially understood at the time to express social anxiety associated with monumental change(s). In South Africa, the idea of 'illegal' migrants is often communicated in maritime images of floods, waves, deluge and so on to convey similar anxieties about South African society being overwhelmed. I leave out its other conception (at the time) as group-psychology and passion, although I am tempted to reconnect with its other constitution as a 'speaking commodity' (Jonsson, 2013: 196 - 201). 
In Marx's critique of political economy, especially his discussion on the organic composition of capital, the concept of the reserve labour army relates to the tendency of capitalist accumulation to encourage the increase "of its constant, at the expense of its variable constituent" (Marx, 1976: 623). By this it is meant the progressive creation of a segment of the unemployed and underemployed by capital's need to increase the mass and value of the means of production, such as machines, at the expense of the mass and value of the labour itself, in the form of wages and workers. ${ }^{36}$ The creation of a surplus working population under the capitalist mode of production represents a paradox in that while a surplus population is "a necessary product of accumulation," it is also the control mechanism of such accumulation as it constitutes "a disposable industrial reserve army, that belongs to capital quite as absolutely as if the latter had bred it at its own cost" (ibid.: 626).

In Southern Africa, this reserve army, or 'surplus population' finds another extension, in which it is connected first to colonial and apartheid era social engineering, and then to postindependence neoliberal reform and other associated crises of politics and economy. To recap, black Africans were forcibly removed, through colonial segregation, from those spaces that had been designated 'white', in South Africa (Maré, 2014) as in Zimbabwe (Stoneman \& Cliffe, 1989) and possibly elsewhere in the region. Subsequently they were resettled in native or labour reserves and Bantustans (Surplus People Project, 1983) that had

\footnotetext{
36. According to Marx, an expansion of social capital, in terms of its scale which is the collective of individual capitals, increase in production and the growth of efficiency or productivity for a growing number of workers as a result of capital accumulation, creates a scenario where the greater "attraction of laborers by capital is accompanied by their greater repulsion" (Marx, 1976: 625). Through these three connected processes, the working population gives rise, "along with the accumulation of capital produced by it, [to] the means by which it itself is made relatively superfluous, is turned into a relative surplus population; and it does this to an always increasing extent" (ibid.). According to Marx, this is a law of population found specifically in the capitalist mode of production, just as other modes of production have their own population laws.
} 
been allocated as their own native 'reserves' (colonialism) or 'homelands' (apartheid). In the interaction between these 'forced removals', and an evolving battle that ensured between African socio-economic and settler capitalist modes of production (Wolpe, 1972), the category of 'surplus people' takes on both the special colonial and apartheid segregative connotation, as well as the political economic one in the kind of labour that this colonial project first instituted.

This designation of surplus people thus set the preconditions, in South Africa, Zimbabwe and elsewhere in Southern Africa, for the forced circular migratory movement ('migrancy') between segregated labour reserves, mines, commercial farming and industrial centres. For the purposes of this thesis, it is from economically depressed Zimbabwe, the southwestern parts in particular, that up to today, evolving patterns of structural unemployment, struggles around 'deracialisation', neoliberal reform and cross-border movement continue to feed this 'surplus population', as well as its constant circular cross-border movement. Those with little or no resources to support their sustenance other than their labour power, such as the irregular migrants of the Limpopo Valley, have been further designated a 'surplus labouring population' (McIntyre, 2011), if only to also signal that they secure waged employment only precariously.

However, the integration of segments of surplus people into certain zones of production is never straightforward. The (lack of a) theoretical precision between the creation of native or labour reserves, and the absorption of their labour in formal employment in African settings have been previously explored (Amin, 1976; Araghi, 2009; Wolpe, 1972). Tania Murray Li (2009), for instance, argues caution towards an argument such as Farshad Araghi's (2009) which seeks to directly connect surplus populations with downward pressure of wages and job security by seeing displacement, surplus people and labour market processes as functionally integrated. It may, nevertheless, be 
argued that the existence of an unemployed/underemployed/ precarious mass in Zimbabwe is quite functional for the ways in which contemporary South African capitalism actually works.

The point, then, is to avoid a simplistic linkage between these processes, and to probe the distinct contingencies that drive them in different historical and political contexts. For example, Zimbabwe's economic problems of the last decade and a half, which have seen increasing numbers of people crossing Beitbridge, have had little to do with South African capital (Addison, 2006). Even if the two are said to represent coincidental trajectories of different histories, contingencies do exist, historically no less, in labour norms and practices in both countries, not least at the border, providing a privileged point for such links to be explored though a conceptual tool such as that of population surplus.

In today's South Africa, the status of economic migrants as a surplus is particularly reproduced in at least three ways that contrast to the formal coercion of such labour in the past: (a) by legal restrictions placed on both cross border movement and citizenship acquisition (Dube, 2014); (b) through discourses that exclude migrants from formal spaces of economic participation (Landau, 2010; Neocosmos, 2006, 2011); and (c) through "inconsistent border control and institutional practices across the political and administrative apparatus that give rise to permeable borders in spite of restrictions" (Schierup, 2016: 7; Tsianos \& Karakayali, 2010). This denunciation of precarious migrant labour that nonetheless is simultaneously sought and actively exploited in South Africa (Tobias, 2012), is what is conceptualised here as resulting in surplus movement. And, border practices play a significant role in reproducing this labour as surplus. 


\section{Conclusion}

This chapter has situated the thesis in ongoing debates on the social politics of cross-border movement. It places the question of the role of everyday border crossings in the social transformation of the Limpopo cross-border space. I have argued, here, that while the nexus between migration and labour is well established in the migration canon, the role of borders in shaping this relationship is often downplayed. The chapter has addressed this gap. In surveying these interconnected fields, and especially by mobilising critical border studies perspectives to address lingering questions on the nature of Africa's borders, it has explored their role in configuring movement and labour, as well as the political subjectivities of those involved in the practices that coalesce around assisted border crossings. By bringing together debates on the Southern African political economy of migrant labour and those on migrant agency through critical realism, the thesis offers a new take on the role of everyday border practices in the articulation between migrant labour systems and political subjectivities in the Southern African context.

The concepts mobilised in this discussion build on existing theory. Their import rests on how they are mobilised to speak to a historically important, and yet less studied Limpopo Valley context. Thus, one aspect of the conceptual discussion is a reflection on how the empirical material presented here sits with ongoing theoretical debates on borders, mobility and labour. The other ambition has been to formulate a conceptual tool that offers the possibility of connecting minute everyday border practices, experiences and ideas to broader processes that shape the regional migrant labour context that informs those practices. In other words, the aim has been to discern the place of assisted border crossings in macro structures and processes driving social and political economic change at a broader level. 
I have suggested that the social constitution of assisted border crossings could be regarded as illustrative of 'border struggles' (Mezzadra \& Neilson 2013). Quite apart from distance and conflict, I have posited border struggles as structured by relations of proximity (Anjaria 2011) and collaboration. As I will go on to discuss in the following chapters, border struggles are articulated in creative relations between state functionaries who speak on behalf of institutional structures, and intermediaries who bring both institutional actors and travellers into the particular social relations of the border that characterise irregular movement, precarious labour and what Homi Bhabha has called 'third spaces' (2004). Within this context of ambiguity, the acts of negotiating and facilitating irregular movement take on a form best exemplified by hyena strategies. One key area of such practices has to do with seizing the importance attached to documents only to rework it to both placate border enforcement and derive instrumental benefits, as well as to forge ahead with life within a context of dispossession.

The discussion above has also explored the concept of facilitation by placing it in three related fields of operation. The first was juxtaposed to emerging ideas on migration infrastructure, especially how it mediates labour migration. Here, facilitation was seen in a similar light as the space that, in the Beitbridge context, represents the everyday manifestation of the articulation between undocumented movement and precarious labour. The other field within which facilitation was operationalised was in the domain of informal politics, where facilitation and the negotiation of movement represent the disjuncture, as well as reconciliation, between a neat outline of regulatory norms and the complexity and chaos of social experience. The other field of operationalisation was that of informality and corruption. The chapter suggests that rather than imposing normative language on the practices that take place at Beitbridge, it may be more productive to speak about their utility in social space and social relations, as well as in the social politics of cross-border movement. 
Assisted border crossings, apart from being instances of everyday border practices and experiences, thus dramatise and mimic broader social and political economic processes of irregular movement and precarious labour. Through interventions from critical realism, I have made a case for situating border practices at the centre of contradictions that characterise everyday border crossings and the broader structural context that shapes them. I have argued that, over time, the interaction between structural processes and everyday practices gives assisted border crossings the context specific form they exhibit in relation to Southern African migrant labour processes.

It is this positioning of assisted border crossings that affords a reflection on the broader structural processes of dispossession. Practices of negotiating undocumented cross-border movement, particularly the everyday context within which they function, problematise a context of dispossession characterised by a tension between the proliferation of undocumented cross-border movement and its constraint by formal regulation. In such a context, practices of assisted border crossings uncover both the factors that bring about the movement and those that shape its forms as emblematic of the deprivation and responsiveness of the dispossessed (Butler \& Athanasiou, 2013). The continued possibility of such practices is as much a critique of the evolving processes of dispossession as it is a social politics that shapes the experiences of and responses to economic deprivation. This politics has implications for understanding, in the broader scope, how the Southern African state and society are transforming in everyday practice. Facilitation problematises the border as a site for the contradictions (conflict and accommodation) between conflicting norms and practices, as well as the ability of border enforcement to persist within such ambivalence, and indeed also of state-society relations where institutional norms appear and disappear unpredictably in complex everyday practices. 
Evidently, such structural conditions do not render either their own structures or the people interacting with them as immutable. With a critical realist eye, the discussion has attempted to signal that structure and agency influence each other, and that a historicising view of this interaction provides insights into how border enforcement and border crossings continuously shape and evolve with each other. Dispossession is one concept from which to begin troubling this interaction. It suggests that humans can be subjected to certain social and existential conditions, but that they respond to these subjections, and eventually, both their subjection and responses form an evolving social context (or entity) within which structure and actions become bound up in each other. It is within this synthesis that facilitation as a concept of understanding assisted border crossings derives its force. 


\section{4 \\ SURPLUS MOVEMENT AND ITS FACILITATION: \\ Border struggles in colonial Limpopo}

\section{Introduction}

This chapter traces some of the history of the involvement of 'third parties' in irregular cross-border movement between Zimbabwe and South Africa. The focus on third parties is primarily about contestations that characterise practices of assisted border crossings. But, the idea of third parties also hints at the 'third space' (Bhabha, 1994) of articulation between regional irregular migrant labour and South African capital that has been relying significantly on cheap migrant labour. The history of how the Southern African state and especially apartheid South Africa mediated the articulation between African labour and colonial capital is well documented (see, for instance, Arrighi, 1968; Wolpe, 1972). However, less attention has gone into understanding the spaces through which labour, especially regional irregular migrant labour, has been traversing between production enclaves and those of its social reproduction. A critical analysis of border practices is especially lacking. This is problematic because it is at the borders (writ large) that the contestations, which I discussed theoretically in the previous chapter, are most visible and intense. 
In what follows, I rely mainly on archival material, ethnography and secondary sources to explore some of the earliest appearances of a reserve army of labour in colonial South-Western (SW) Zimbabwe, and how it quickly appeared as illicit, but nevertheless essential, labour moving across the Limpopo Valley. The introductory chapter has already given a broad outline of this history and the aim of the present chapter is to register the main themes of relevance to the subject of surplus labour, its crossborder movement and the border practices that accompany it. An accompanying aim is to furnish a general understanding of the particular context within which the negotiation and meaning of borders emerge and interact with a history and political economy of migrant labour in the region.

In the colonial period, more than a hundred-year stretch up to the 1980s, undocumented cross-border movement into South Africa was framed as prohibited migrant labour. This was because the movement was initially composed mostly of young African males who were looking for easy employment in the growing, and better competing, South African economy (Mlambo, 2010). Colonial governments, especially in the former Rhodesia (Zimbabwe), but also in South Africa, were concerned about this phenomenon because of its effects on their labour markets. Practices that had to do with helping this labour force find employment in South Africa were known as illicit labour recruiting, ${ }^{37}$ making a direct connection to its irregular and ostensibly prohibited nature. With the passage of time, this movement has come to be understood as mixed, ${ }^{38}$ or multiplied. This is both in terms of the people who

37. This characterisation of illicit labour recruiting is taken from the colonial archives in South Africa and Zimbabwe. Other scholars, such as Martin Murray (1995), have also employed it.

38. This is partly in view of Mezzadra and Neilson's (2013) conception of the 'deep heterogeneity' that characterises time and space in contemporary global and postcolonial capitalism, and how this heterogeneity is connected by the ways in which labour power is produced as a commodity on a global scale. Multiplicity then, from their proposition, relates to how the composition of migrants ('living labour') is 
are compelled to travel with missing or incomplete documents, and in terms of the factors that force them to do so (Crush \& Tevera, 2010), which are too broad and complex to fit in the narrow concept of 'illicit' employment. For this reason, practices which in the past would have been called illicit labour recruiting, I call assisted border crossings.

I begin the chapter by introducing two important characters that help provide a context to this discussion. The first is Gatsheni, a retired private transporter - umalayitsha - who now lives in rural SW Zimbabwe. Gatsheni's story provides a first-hand phenomenological account of the conditions that compelled him to travel across the Limpopo Valley to seek work in South Africa without documents. As his story develops, Gatsheni turns towards assisting other people to travel in the same way, and manages to make himself economically secure in the process. For Gatsheni, this turn towards assisting people across the border is not a conscious political decision, rather it demonstrates how the border struggle becomes a force not just for performing the border, but also for an efficacious way of responding to structurally induced dispossession.

The other character is the subject of an urban legend, and of archival records on illicit labour recruiting across the Limpopo Valley. Going by the name of Bvekenya, itself quite telling of the vexatious figure otherwise known as Cecil Rutgert Barnard, this character chronicles the manner in which irregular movement was, on one hand, closely tied to the agricultural and mining sector in South Africa's colonial economy, with the collusion of the Native Labour and Native Affairs departments in colonial South Africa. ${ }^{39}$ On the other hand, it shows how the movement itself

bisected, divided and multiplied - in other words - shaped by practices of mobility and the operation of borders.

39. Their involvement in the employment of prohibited labour is discusses extensively in the following sections of this chapter. 
was always intensely contested, pitting initially unsuspecting irregular migrants against greedy 'recruiting' agents fronting big companies, some of who resorted to gratuitous violence in the fight for 'prohibited' labour.

These figures and their stories thus set the scene for a later discussion on the links between the Limpopo Valley's labour reserve as a frontier of capital (Mezzadra \& Neilson, 2013), and the practices of assisted border crossings as struggles around the legal, political and social borders that define both the material and symbolic tropes of dispossession. They place emphasis on a central tension that underpins the main arguments of this thesis; that is, while cross-border movement across the Limpopo Valley is an often-precarious undertaking, particularly for low-skilled Africans, prospects for employment, also largely precarious though relatively liberating, are always lurking around. My suggestion is that the practices of assisted border crossings that these two characters have engaged lie within this tension. A stricter border enforcement regime for low-skilled migration, combined with the relative ease of finding precarious employment, represents one way in which this form of labour is made and kept a surplus. When it appears across the Limpopo Valley, especially at the Beitbridge border, it does so as surplus movement in this sense. Third parties who broker this movement reconcile as much as they perpetuate this tension.

These stories can also be seen as showing how practices that mediate border crossings are themselves heterogeneous, reflecting the different identities and motivations of actors and processes that define border practices. These different identities, motivations and processes have come to reflect ongoing experiences of dispossession, even as deracialisation has reconfigured the power relations between those who move across borders and those who claim the task of governing that movement at the everyday enforcement level. More than representing the obstruction or 'corruption' of movement by 
other interests, such border struggles arguably define the flow of cross-border movement across the Limpopo Valley. As we shall see, the hyenas of the Limpopo have a central function in shaping this cross-border context.

\section{Encounters in the Limpopo Valley}

\section{Finding Gatsheni}

The circumstances of my encounter with Gatsheni, a retired umalayitsha, provide a useful backdrop to some of the structural and historical dimensions of dispossession and surplus labour, and its movement and mediation across the Limpopo Valley. A 64-year-old man, Gatsheni today owns a convenience store at the Sanzukwi rural service centre, towards the southern end of Mangwe district in SW Zimbabwe.

It was in February of 2014 that I travelled and met with Gatsheni in his rural home, over 200 kilometres from Bulawayo, Zimbabwe's second largest city, in the direction of Plumtree, on the border with Botswana. The ride to Plumtree from Bulawayo was straightforward. However, upon arrival in Plumtree, it was more than a two-hour wait before the next minivan could leave town for Sanzukwi. With clouds rapidly gathering over the north-western sky, we finally veered south along a narrow, tired road that runs next to the Botswana border towards the furthest recesses of Mangwe. It took us 70 kilometres of negotiating potholes and rain before the pavement ended at the Bulu rural service centre (see Figure 4.1). We would have to reach our destination, another 80 or so kilometres, on unpaved and muddy roads. 


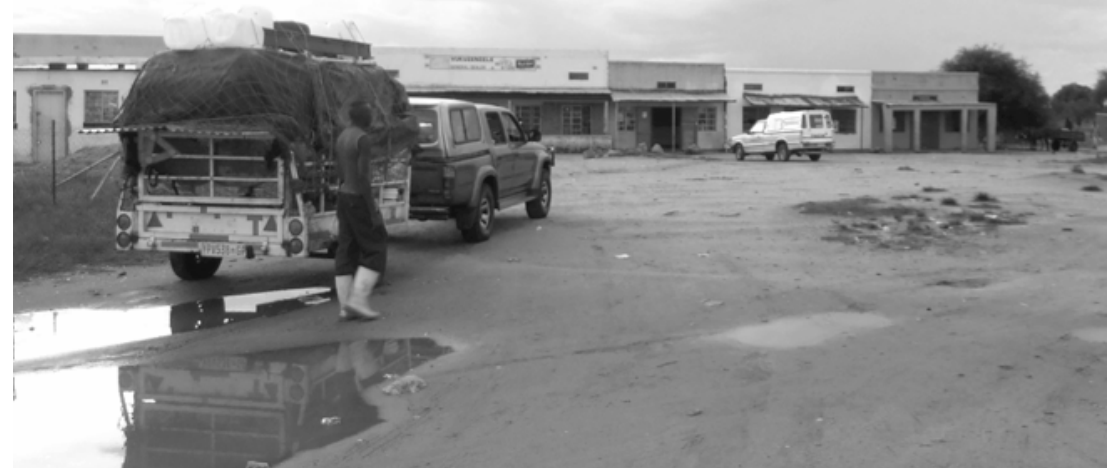

Fig. 4.1 A private Transporter takes a rest at Bulu rural service centre, Zimbabwe

From Bulu, progress became slow. At roughly ten kilometres before the Brunapeg Catholic Hospital and rural service centre, a flooded Mathongwane stream finally stalled us. The bridge was submerged below the overflowing stream. This bridge is about thirteen kilometres from Mphoengs' border post, a closer gateway between rural Plumtree and Botswana that transporters and residents have received with mixed feelings. ${ }^{40}$ We eventually got back on the road after a prolonged wait. When we reached Brunapeg after nine o'clock at night, a diesel-powered generator hummed behind a bottle store. The rest of the centre was in the grips of a power outage. Sanzukwi was another 10 kilometres

40. Mphoengs is about 140 kilometres south of the Plumtree border post and was commissioned after 2001 in response to increased volumes of cross-border movement by residents of rural Mangwe, who for a long time have been simply crossing the fence into Botswana and back for reasons of convenience. As a solution to clandestine crossings, it works for shorter visits into Botswana. Transporters I spoke to, however, complain that it is yet another border gate that is riddled with bureaucratic red tape and shady dealings mainly because its systems are not yet computerised. Economic migrants into Botswana and South Africa often ignore this gate as it represents a stumbling block in terms of requirements for documentation and legibility. 
or so away. Because of bad roads, we had to walk the last few kilometres and I finally reached Gatsheni's home late in the evening, and my host had started to suspect that the rains may have ruined my trip.

Walking around Gatsheni's homestead, one recognises immediate relics of the trajectory his life, particularly as a migrant labourer and as a private transporter, has taken. The homestead is well built, with some ten brick and metal sheet houses of varying sizes, all fenced in, neatly arranged and well maintained. This alone provides an indication that Gatsheni has been commanding the kind of income his neighbours have not had access to. His transporting business, and now his convenience store, has been paying him relatively well. As an aside, behind one of the grain silos of his homestead rests a big old trailer that Gatsheni would have used to transport goods from South Africa to greater Mangwe. Just like the bakkie, or the mini-truck he now uses to run the convenience store, the trailer still has the same South African number plates from Gauteng Province-

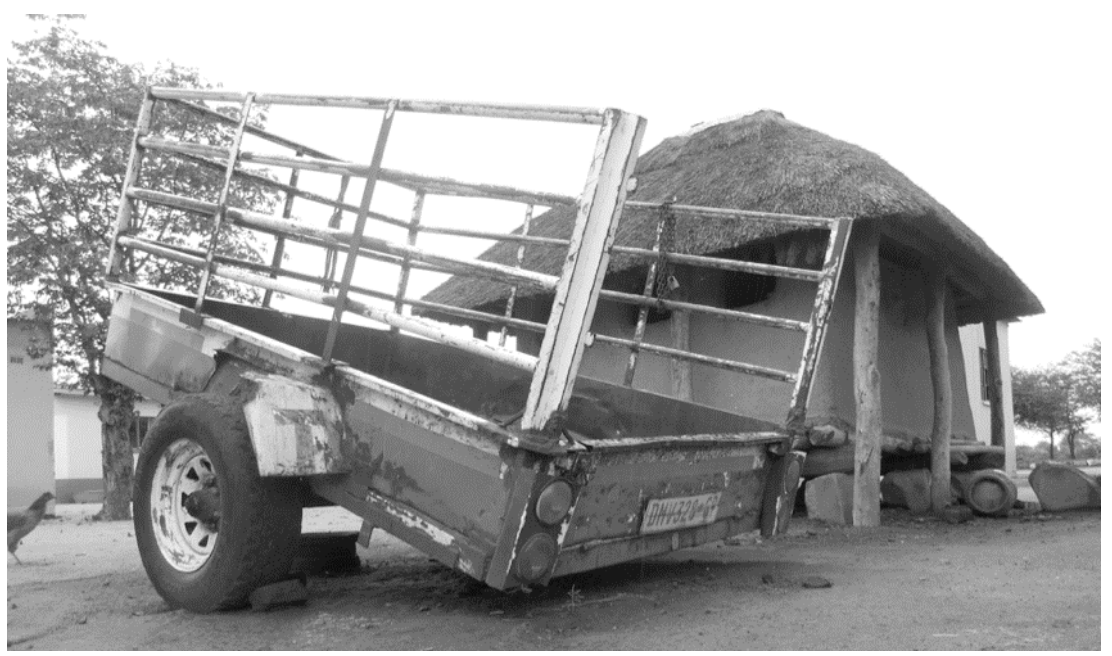

Fig. 4.2 An old trailer rests besides a grain silo at Gatsheni's homestead 
Born in 1952 in the former Rhodesia, Gatsheni attended rural primary and secondary schools in the south of the Bulilimamangwe Tribal Trust Lands. ${ }^{41}$ It was here that he achieved enough grades for his father to persuade him to supplement his education at the acclaimed catholic missionary boarding school of Empandeni, a measurable distance from his side of Plumtree town. At 19 years of age, however, Gatsheni was getting a little too distracted to focus on the esteems of further education. He regularly wondered how to emulate some of his colleagues who were crossing over to South Africa to find work.

Around the same time, events beyond Gatsheni's control would force his hand. His father, who had recently married another wife, decided to leave their home to start a new life elsewhere. For Gatsheni, this was a time of hard choices. His brother had joined Zimbabwe's third chimurenga - the nationalist war of liberation, also called the guerilla war. He, however, soon became a casualty. When Gatsheni learnt that his brother had succumbed to the war, it fell on him alone to look after his mother and their home. Looking around, the best option left was South Africa.

He left Sanzukwi in February of 1971. Because there was no direct public transport between Zimbabwe and South Africa then, he boarded a train from Plumtree town to Pilane just outside Gaborone in Botswana. At Pilane, he disembarked with about nine other migrants, and set for South Africa. Their aim meant crossing the border on foot near the present-day Madikwe game reserve, and then walking through rough country and private farmlands to Rustenburg town, some 280 kilometres further inland. For financial reasons, Gatsheni ended up staying a while in Rustenburg, only heading for Johannesburg after a few months of casual work. Once there, he initially struggled before he managed to establish a measure of control over his life and future.

41. I explain this later in the chapter 
In today's Sanzukwi, Gatsheni represents a special kind of patriarch. A married man of one wife and three children, he commands respect in the community for his audacity and personal accomplishments. Having held his family together, even though he spent most of his life away from them as a migrant labourer and transporter, neighbours revel in the kind of stature he projects in the village. ${ }^{42}$ A self-confessed workaholic, Gatsheni now spreads his time either looking after the convenience store or farming and livestock keeping in the village. MaNdiweni, his wife, speaks highly of Gatsheni and the family; although, it is clear that the two share a similar passion for work, for traditional family values and for business.

\section{The other side of the beckon}

Some 80 or so years before Gatsheni was born, the movement of people across the borders of South Africa and Zimbabwe was already an issue of fierce contestation (Murray, 1995). Nowhere was the practice of enticing migrants coming across the Limpopo River into South Africa more prevalent than at the intersection of the territories of present-day Zimbabwe, South Africa and Mozambique; the so-called Crooks' Corner. Although part of this labour may have veered towards either slavery or indenture (Delius \& Trapido, 1983), the enduring demand for it at the Kimberly and Witwatersrand mines, apart from other urban-centred manufacturing sites or surrounding commercial

42. Although migration itself and other social realities have been playing havoc with the traditional family, patriarchal values still invest the marriage institution (with children) as of particular importance. While MaNdiweni and myself were attending to the crops the morning after my arrival in Sanzukwi, a few people came inside the field. I suspect they were curious to see who I was. But they were also keen to praise Gatsheni's crop and to offer help to tend to it. This, they did, to earn a few meals and whatever other produce was ready for early harvest. But, it also seemed, according to both Gatsheni and MaNdiweni, that neighbours regard this family highly, and these interactions, particularly the tendency to avail nondescript help randomly, reproduce the particular respectability of the Gatshenis in the village. 
farms, engendered clandestine migration whose movement soon became the business of all kinds of labour recruiters across the Limpopo Valley. In his exposition, Martin Murray lists many unlicensed recruiters, including a Canadian named Buck Buchanan, a Welshman called Theodore Williams and Charlie Colesen [or Coulson], a Swede, among other "unreliable labour suppliers" (Murray 1995: 386).

None of them, perhaps, personify the practice of illicit labour recruiting across the Limpopo more than Bvekenya, or Cecil Rutgert Barnard, who came to perfect the practice at Crooks' Corner (Bulpin, 1954). Chronicled in the book, The Ivory Trail, Barnard started as a known ivory trader along the northern border of the Union of South Africa, venturing towards where the border met Rhodesia and the Portuguese East African colony, today's Mozambique. When he eventually dabbed into labour recruiting, which by the 1910s had become irresistibly lucrative, his acclaim became so spectacular as to vex the Rhodesian government in its desperate efforts to stem not just the recruiting of its 'natives' into South Africa, but also the seeming unchecked use of its southern border to stage such practices. A letter from The Chief Native Commissioner in Rhodesia to the Secretary for Native Affairs in South Africa registers this concern as follows.

The Rhodesian government is in full sympathy with your desire to check illicit practices in the recruiting of natives on the borders of this territory. You will remember that in the past we have invited the co-operation of the Portuguese authorities with a view to effecting the arrest of men, such as the Mr. Barnard mentioned in your letter under reply, who usually evade capture by crossing into Portuguese territory. A police patrol is now being dispatched to this part of the border. ${ }^{43}$

43. NAZ S428/469/1939 Draft letter from The Chief Native Commissioner to the South African Secretary for Native Affairs, 15 May 1918 
Bvekenya's story offers rare insights into the practice of labour recruiting in Southern Africa as told from the perspective of the recruiters themselves. A Scottish, Dutch-Irish descendant, Barnard, like many other recruiters, sought his recruits among Rhodesian and Portuguese East Africans and crossed the Limpopo River with them to hand over to mine recruiters, who dotted the northern Transvaal, for a fee. A lucrative business, illicit recruiting occupied a particular space that afforded the colonial South African state the possibility of benefiting from irregular labour while simultaneously pronouncing it prohibited. Formal labour recruiting was a norm in colonial South Africa, but Africans from outside South Africa were legislatively barred from entering and working in the country without permission. However, once they were in the country, they could be employed on the cheap owing to their desperation for work and lack of legal status. In order to reach that stage, they had to be recruited 'illicitly' by unlicensed recruiters, who then presented them to formal recruiting agencies working for different companies that sought irregular labour. It was in this context that Bvekenya was to become one of the many recruiters in the border region who combined his hunting activities with labour recruiting for the reef (Witwatersrand) mines. With greater demand for labour, the recruiters from the Witwatersrand rewarded him handsomely for his efforts, inviting bitter complaints from licensed recruiters from the Transvaal farmers and miners that lay closer to the border. ${ }^{44}$

Although Bvekenya worked as a recruiter for agents of big companies, he was no friend of the three colonial governments, nor of other illicit recruiters. Bulpin (1954: 181-194) and archival records on the policing of irregular movement in the region

44. SANA TAB GNLB 43984 'Suggestion that the District around Messina mine be closed for Recruiting'. Acting Secretary to local Board, Messina, to Director of Native Affairs, Johannesburg, 13 March 1912 
suggest that on several occasions, he was the target of coordinated efforts that sought his arrest or capture. The Rhodesian Police (also known as the British South Africa Police, BSAP) were eventually able to arrest Bvekenya for his recruiting activities, but no charges could be made to stick on him. Efforts to regulate the illicit recruiting business had left him exposed to Rhodesian law enforcement, which, as the archive reveals, was very concerned with both irregular migration to South Africa and the illicit recruiting practices that had proliferated around it. Nevertheless, Bvekenya had developed dense networks with local traditional chiefs, ordinary residents and business owners, as well as former state police officers. Nobody, in all three colonies, was willing to testify against him in court. On the contrary, according to Bulpin, many people volunteered to feed him, offered him shelter throughout his arrest and trial, and even paid the fines for spurious charges that were levelled against him.

From the Ivory Trail, it is said that when he was released, a local host, who had been sheltering him for free, lent him money with which he bought a new rifle from one of the local policemen. On his way back to Crook's Corner, he is said to have shot seven elephants and recruited several dozen Rhodesian black Africans along the way, "to compensate for his trouble" (197). The details about Bvekenya that emerge in the book may or may not be exaggerated, but the historical record backs up his legend.

As I develop this discussion later on in this and later chapters, I make the point that it is this knowledge of the local context and its worldview - its episteme - that affords social relations to develop that sometimes trump the ability of border enforcement to achieve its aims. But, it is also the relations that develop within this context that articulate the complex linkages between broader economic forces, exploitation of the vulnerable and the practices that emerge in the course of movement which connect them. Such connections define how the border is performed. It is these performances of the border - or border struggles - that situate its complex and changing 
meaning, as well as its constant state of becoming (Brambilla, 2015). Gatsheni and Bvekenya come into this picture from different ends. While they appear similar in that they are mere actors in processes that take shape structurally elsewhere, Gatsheni starts of as a target of both colonial capital and its intermediaries, or mediators, represented in this case by Bvekenya. Even though at the end they appear engaged in the same practice, Gatsheni share the same episteme as those he assists to cross, and at the end, partly with state actors, who all originate from a situation of shared general marginalisation. Bvekenya, on the other hand, represents a quintessentially self-reliant, relatively wealthy (we are told that he owned a farm in the Transvaal) opportunist who exploits gaps in the law to get rich fast. For these reasons, Gatsheni appears, through his life story, to carefully negotiate passage for himself and others across the border, while Bvekenya remains an outlaw who always just manages to elude state efforts to arrest and neutralise him. The overlap in their stories resides in how they both engage with the enduring structural dispossession that the border reproduces in the lives of those who attempt to cross it without documents. From this vantage point, one can only develop Pablo Vila's (2000, in Mezzadra \& Neilson, 2013: 3) view to suggest that the Beitbridge border is not just a geographical margin on territorial edges, but also a "complex social institution" that is marked by conflict and accommodation that accompanies the practices of assisted border crossings.

\section{Surplus labour in the Limpopo Valley}

\section{On surplus labour}

It is necessary to spend some time on the broader colonial relations that have played a part in the production of irregular migration in the Limpopo Valley, before returning to the practices of assisted border crossings that characterise it. If our discussion on assisted border crossings begins with Southern Africa's path 
to industrialisation, then the colonial occupation of present day Zimbabwe offers a good starting point. With occupation, or colonisation, human settlement was abruptly rearranged across the country along a dual land tenure system (Riddell, 1980). As I have shared in the introduction, the reserves were kept aside for Africans. The area that I travelled to in order to meet Gatsheni, which sits on the furthest end of the former Bulilimamangwe Tribal Trust Land (TTL), is one such reserve. It is known today as Mangwe communal lands, under the now symbolic trusteeship of Chief Sangulube.

In the southwest of Rhodesia, native reserves were created through the 1894 Matabeleland Order in Council to settle a haphazard land appropriation scheme in law (Stoneman \& Cliffe, 1989). These areas have largely remained underdeveloped in terms of infrastructure owing to their poor potential. As such, economically active people tend to leave them to seek work in the city as a surplus labouring population (McIntyre, 2011). ${ }^{45}$ At about 29 million acres in total at their creation, the native reserves of Rhodesia contrasted to the private ownership of 49 million acres of prime land by fifty thousand European settlers, achieved through a series of land Acts up until the 1960s. Acting as proxies for colonial administrators, traditional chiefs (such as Sangulube today) ruled a million or so Rhodesian Africans in the reserves (Morris-Jones, 1980). ${ }^{46}$ Another 17 million acres of land were designated as forest, unassigned or purchase land.

Planned post-independence land redistribution was initially slow, and only a few indigenous beneficiaries received title

45. In order to coerce the initially reluctant surplus people to sell their labour at the production centres, additional hut and livestock taxes were imposed on them, literally corresponding to the number of huts (or rondavels) and cattle each man had, so that they were compelled to find work, if not to supplement a subsistence livelihood, then to raise the imposed tax.

46. Mahmood Mamdani, in his (1996) discussion on citizenship in colonial and postcolonial Africa, refers to this as indirect despotism. 
deeds to the availed land. Thus, with some exceptions and contradictions, ${ }^{47}$ communal ownership of land perpetuated a cycle of underinvestment and low productivity (Moss, 2006). It is this imbalance in land ownership that the controversial fasttrack-land-reform-programme around the year 2000 sought to address, with disastrous political and economic consequences, especially for the poor (Hammar, 2008, 2010). ${ }^{48}$

The creation of reserves served a colonial development policy of tapping into a reserve army of labour, although it was also used to slow down black proletarisation by restricting title to both the city and rural land (Bush \& Cliffe, 1984). ${ }^{49}$ Meanwhile, the continuous lack of public infrastructural investment in the communal lands means that they still cannot support substantive social development. Many of them have, in any event, long been overpopulated (Palmer, 1977) and Gatsheni's decision to leave his Mangwe home in 1971 is not isolated among young black Zimbabweans, especially on the western parts of the country.

Within the broader context of movement between SW Zimbabwe and South Africa, Gatsheni's rise from the relative obscurity of the 'reserves', through his time as a migrant labourer in South Africa and as a private transporter to his current life as an

47. The post-independence Zimbabwe government embarked on state-led political and socio-economic reforms, initially targeting rural poverty by increasing social spending and actively encouraging rural development through the creation of rural growth points (Mapuva, 2015). However, together with neoliberal reforms that have scuttled the gains of welfarism of the 1980s (Sutcliffe, 2013), the state's privileged access to vast rural and urban spaces have bred authoritarianism, which has partly violently displaced significant numbers of the population in both urban and rural areas (Hammar, 2008), thus partly increasing poverty and rural underdevelopment.

48. The Association of Concerned African Scholars has, in bulletins 79, 80 and 82, offered a good appraisal of Zimbabwe's agrarian revolution and the associated political and economic crises of the last 2 decades. See Association for Concerned African Scholars (ACAS). (2008a, 2008b, 2009).

49. Giovanni Arrighi (1966) writes that access to property would have created the preconditions for a quicker mobilisation among the black populations along class lines, which would have put pressure on the colonial project of domination. 
entrepreneur, registers the central themes of surplus labour (its movement, perils and possibilities) and its mediation between Zimbabwe and South Africa. Essentially, how this surplus labour has evolved from the colonial times to its current forms, and the consequences it holds for the politics and transformation in the lives of those involved, constitute important questions for Southern African migration studies.

\section{Mobility and the internal mechanics of surplus labour}

Scholarship on the political economy of settler colonial capitalism and the associated employment in South Africa of black labour power from then Rhodesia and other northern colonies is well established. Alan Jeeves (1983, 1985, 1986), Sampie Terreblance (2003), Harold Wolpe (1972, 1988), Giovanni Arrighi (1968, 1970), Charles van Onselen (1976), Frederick Johnstone (1976) and Belinda Bozzoli (1987) are some of the preeminent scholars that have explored this field. While the present discussion on the history of Southern African labour migration is indebted to their work, it relies more specifically on an observation made by Martin Murray (1995) who emphasises that it is important to look at the internal logics of mobility if we are to problematise an often unexplained link between labour and capital that is assumed to sustain the cross-border movement of relatively poor black labour to the 'best' employers in the region. This relative lack of literature on the space of mobility also has an effect of producing the Beitbridge border as a partition that African migrants merely cross on their way to South Africa. For Murray, however, this space of movement must be understood "as a sui generis arena of conflict and accommodation" (376), where a variety of players, with a keen understanding of the 'rules of the game', 'drive' movement along particular patterns. Such a perspective offers an important view not just of the particular mechanics of the labour market, as Murray suggests, but also of border struggles that accompany everyday border crossings. 


\section{A floating population of the unemployed}

For a deeper understanding of this space of movement and its historical precedents in the regional economy including Zimbabwe and (the Union ${ }^{50}$ of) South Africa, it is essential, as I stated in the introduction, to account for the imperial infrastructure set in place by the British South Africa Company (BSAC) and its founder Cecil John Rhodes. In the 1930s, Henry Birchenough, president of the British South Africa Company (BSAC 1936: 4), praised the 'ideals' and 'eternal achievements' of arch-imperialist Rhodes:

What were the ideals of the man whose name lives for ever in the name of Rhodesia? The object which Cecil Rhodes had set before himself was threefold: To establish British ascendancy in South Central Africa, to develop the potential wealth of that part of the world, and to raise the lot of its native inhabitants. Subsequent history has shown the extent to which this purpose has been achieved. To-day the figures of population, Black and White, of mineral production, of road and railway mileage and of trade speak for themselves.

The Limpopo Valley, the area bisected by the Limpopo River which today marks the international border of the two countries, has always been a sight of various kinds of movement in both directions across it and today hosts a mix of people in terms of language and tradition (Bonner, 2003). But, it was partly the

50. The use of 'Union', the 'Union of South Africa' and 'South Africa' appears to change incongruently in the text. These changes are not careless, but reflect the actual names that refer to South Africa's chequered colonial past. Initially consisting of a motely and uneasy cohabitation between traditional African kingdoms and several republics of early Boer settlers, only in 1910, at the final defeat of the Boers by the British, does the region known today as South Africa adopt the prefix 'Union'. The name changes to just South Africa in 1948, when the apartheid system was officially implemented. I use 'Union' in an attempt to stay true to the specific period of British rule, or to the language of official documents at the time. Otherwise, I revert to South Africa as has been in use from 1948 to date. 
machinations of the BSAC that significantly reconstituted that movement, with lasting effects for the regional economic and labour market patterns (Wilson, 1972).

If one of the BSAC's aims was "to raise the lot of the native inhabitants of Rhodesia", then within 20 short years into the conquest, truckloads of black labour, pejoratively called 'kaffir trucks, ${ }^{51}$ were making their way south to the border area around Beitbridge (Johnson, 1990) in the hopes of reaching Johannesburg's reef mines. In order to understand this turn of events, one needs to, as van Onselen (1976: 228) has intimated, view the region as part of a single economic system in which centres of production and labour reserves are connected. Having had their livelihood patterns disrupted, and forced to pay regular, if imposed, hut and livestock taxes, the 'natives' had become compelled to seek work in the industrial towns - the gory colonial history behind 'Siyay' wel' iNgulukudela siyofuna imali, quoted in the introductory chapter: "We crossed the river Limpopo to look for money". But within the prevailing regional economic system, they actively avoided taking up work in places that promised low pay, and sought instead to move southwards, where jobs were deemed better rewarding. A record of a mining commissioner in Bulawayo, Rhodesia, from 1904 described the situation: "a flow of migrant labour created within a regional economic system became a central and enduring feature of Southern Africa" (in Phimister, 1988: 55). It was this flow that Gatsheni joined in his own right later in 1971.

As discussed above, however, most of the movement of labour down south in the beginning of the $20^{\text {th }}$ century initially had less to do with employment scarcity in the north. It appears that the natives of Matabeleland, like those from elsewhere in colonial Southern Africa, actively strived to evade waged labour as some

51. NAZ, S138/40. Superintendent of Natives, Fort Victoria, to Herbert Taylor, CNC, Salisbury, 10 June 1927. In Murray, M. (1995). 'Blackbirding' at 'Crook's Corner', 395 
scholars have suggested (Barchiesi, 2012). Up until the 1960s and beyond, Rhodesia's indigenous labour surplus generally coexisted with considerable job vacancies. Rhodesia itself was experiencing rapid economic expansion (Onselen, 1976). As a 1960 Labour Report would observe:

The reluctance of indigenous Africans to take up farm or mine work [in Rhodesia] is widespread and is reflected in comments from all the Employment Exchanges. There are approximately 500 farm vacancies outstanding in Mashonaland [northeastern Rhodesia] and there is no doubt that this figure could considerably be increased if success were to attend our placing efforts. Even in the small Exchange at Sinoia [Chinhoyi], which was specifically opened to deal with farm labour recruitment, none of the 38 placings during the month was in agriculture. ${ }^{52}$

Rather than simply seeking the next available job, it would appear that perceptions of labour value (however rudimentary) dictated the circulation of so-called 'natives' in a regional labour market. Indigenous Africans appeared to elect (voluntarily or under coercion) to sell their labour for better pay elsewhere, especially in South Africa. On the other hand, and especially in the agricultural sector, employers in Rhodesia responded to these forces by seeking workers from elsewhere (Bradford, 1993). Thus, Rhodesian migrant labour continued to trickle down to South Africa, while Malawian and Zambian job seekers went to Rhodesia, even though eventually they too often joined the southward trek.

An articulation of such movement as constituting a surplus partly rests in the fact that while institutional policies of the time desired for the labour to be controlled in particular ways,

52. NAZ S2239. Labour Monthly: 1953 October to 1960 October. Southern Rhodesia Department of Labour Monthly Report: July 1960 
labour market factors that the very same institutions initiated, benefited from and presided over, were partially working to push the movement of labour across a transnational (regional) capitalistic production system. On one hand, the creation of a racially segregated model of production more or less guided the movement of surplus labour through specific pass laws. On the other, the absence of a similar regulative framework for regional economic competition and coherent labour recruiting left gaps within which informal practices emerged. Similar gaps appear today in the tension and struggle between deracialisation forces that seek to emancipate black African labour, and neoliberal ones that generally pursue its (re)commodification. These tensions underline the proposition that throughout the period under review, labour market differentials, strict regulation of the movement of African labour and gaps in the enforcement of this regulation create a vulnerable labour force.

\section{'Employed prohibited natives'}

The trend of irregular migrant labour moving southwards had become a source of significant worry for the Rhodesian government of the mid-1940s. The labour commissioner at the time, A. J. Huxtable, implored his South African counterparts to cooperate with the state of Rhodesia in hammering out a solution to the 'labour' leakage in Rhodesia, warning that unless such an agreement was found with the Union of South Africa, the future of the Rhodesian colony was under threat. ${ }^{53}$ The problem had become so pressing that the Rhodesian Native Labour Supply Commission was bound to take Huxtable's concerns seriously. Reiterating the negative influence 'clandestine migration' to South Africa was having on the development of the state, Huxtable asked the Rhodesian government, through the commission, 
for a joint Central African Council (CAC) effort with the then governments of Zambia and Malawi to stem the flow of labour southwards. ${ }^{54}$ For the Rhodesian government, it became clear very early on that this trend was undesirable, and that in order to exert some control over it, it had to be designated prohibited.

As early as 1913, however, the Union of South Africa imposed a ban on the employment of all 'natives' coming from latitude $22^{\circ} \mathrm{S}$. This line demarcates the region north of the Southpansberg Mountains in present-day South Africa and in the flat arid veldt towards the Limpopo River and beyond (Bulpin, 1954). For the Union's own labour interests, agreeing to the ban was selfserving for at least two reasons. The first related to a fear that 'tropical natives' carried with them a sleeping sickness, which had to be prevented from spreading south and especially from drifting towards the Natal areas on the east coast of the Union of South Africa..$^{55}$ The ban was also meant to benefit commercial irrigation agriculture that was thriving in the northern regions of the Transvaal, next to the border with Rhodesia. It would effectively ensure that the region benefited from any labour that was coming from the north. In reality, however, the 'natives', as well as the settler agriculturalists of the north and the mining companies of rest of the Union did not observe the ban. Africans seeking work in the Union without documentation routinely found employment beyond the prohibition line, and would come to be known in the policy language of the time as 'employed prohibited migrants.'. ${ }^{56}$

54. NAZ S482/20B/46, RNLSC: Minutes of Second Meeting, 18 November 1948.

55. NAZ NB3/2/2 Rhodesia Native Labour, Stuart Erskine versus H. A. Key, 22 November 1918.

56. Ibid. 


\section{'Embarrassing numbers'}

For those Africans coming from or through Rhodesia who sought to reach the border with (the Union of) South Africa, several options became common (see Fig. 4.3 below). From Bulawayo in the South West of Rhodesia, they mostly either took a train to Gwanda or West Nicholson. From there, they utilised the railway lorry service to Beitbridge. Alternatively, private transporters would take them from Bulawayo through Matobo to Kezi, and from there they would head towards the Antelope or Legion Mines in the south-southwest. ${ }^{57}$ At this point, they were some 30 kilometres or so from the border with present day Botswana. Often the journey was continued from here on foot. ${ }^{58}$

The two mines (Antelope and Legion) each lie within fifty kilometres of Gatsheni's village in Sanzukwi, although the shortest way from them to the border with Botswana lies slightly towards the south. As a matter of interest, until the 1940s, Antelope and Legion mines were said to be operating at half capacity due to a lack of labour, and yet the approximately 100 workers arrived there each week from Bulawayo, transported by Indian and African private transporters, either refused to work in them or worked only for short periods before routinely asking to be released. ${ }^{59}$

As for Gatsheni, during his early years as a migrant, there were times when he became accustomed to travelling between his rural area and South Africa that he simple walked due southwest,

57. NAZ S1226, Lieutenant W. H. D. Walker, Assistant Superintendent of Police, Bulawayo South, to Chief Superintendent, BSA Police, Bulawayo, 24 July 1939

58. NAZ S1226, Chief Superintendent, CID, to staff officer, BSA Police, Salisbury, 15 June 1939

59. NAZ S1226, Chief Superintendent, CID, to staff officer, BSA Police, Salisbury, 15 June 1939 
crossing the Shashi/Tati River at the border with Botswana towards Selebi Pikwe, where he would hitchhike towards Pilane or Gaborone, and further on. This habit appears to have blended him into the rest of the southward trek.

Despite the best efforts of the Rhodesian government, labourers leaving the colony through Botswana were estimated to have been up to a hundred a day by $1942 .{ }^{60}$ The BSAP, a policing arm of the British South Africa Company (BSAC), conducted a survey of 'clandestine migration' in 1944 to ascertain the routes and the origins of southbound migration along the southern border with the Union. From the survey, the police estimated that 33, 500 unregistered migrants had travelled through Rhodesia to the Union, about 20 percent of whom came from the colony itself, with the rest coming from present-day Mozambique, Malawi and Zambia. ${ }^{61}$ In 1950, a total of 65,500 'clandestine migrants' from present-day Zambia (Northern Rhodesia), Malawi (Nyasaland) and Rhodesia were thought to have crossed into South Africa. ${ }^{62}$

It appears, therefore, that the colonial governments were fully aware of the problem of framing the undocumented movement of labour into South Africa as prohibited, particularly the fact that their efforts to control it were not achieving the desired results. This policy did not change from then up to, as I argue, the present. Despite a context that clearly makes the surveillance of this movement near impossible in the manner that Andersson (2014) describes for the northern hemisphere, this approach has stayed the same. Because they were acceding, especially on the South African side, to the interests of miners

60. NAZ S1226, Assistant Commissioner, CID Bulawayo, Minute, 20 June 1942

61. NAZ S482/509/39, "Clandestine Migration of Natives to the Union": General Assembly, Sub Insp Robotham, 5 January 1945

62. F137/Vol V1, Secretary for Native Affairs, South Africa, to Secretary for Native Affairs, Southern Rhodesia, 13 January, 1950 
and agriculturalists, both colonial governments indirectly ensured the reproduction of this labour as cheap. They acted, in other words, as a labour market force.

Some years back, in 1921, before the numbers of northern natives had reached fantastic proportions, the Union was hardpressed to clarify its position regarding the 'influx'. Writing to the Rhodesian secretary for native affairs, the acting director of native labour had expressed the Union's "embarrassment with the large numbers of the [tropical] natives coming through for employment". But those numbers, he had conceded, were of 'considerable value' to maize farmers of the Highveld. ${ }^{63}$ From an early stage, the two colonial governments had been engaging in discussions to try and resolve the 'native labour' issue. ${ }^{64}$ Nevertheless, it was clear that the Union government could not expend significant resources to turn back irregular migrants that practically landed on its doors at no cost, notwithstanding existing legal statutes such as the Immigration Act, the Pass Act or the Regulations Act.

63. SAB NTS 2025 26/80 2598/14/473. Acting Director of Native Labour to Secretary for Native Affairs, $18^{\text {th }}$ August 1921.

64. NAZ NB3/2/2 Rhodesia Native Labour, Stuart Erskine versus H. A. Key, 22

November 1918; NB3/2/2 2513/18 Chief Native Commissioner, to the Secretary of the Administrator, 6 December 1918 


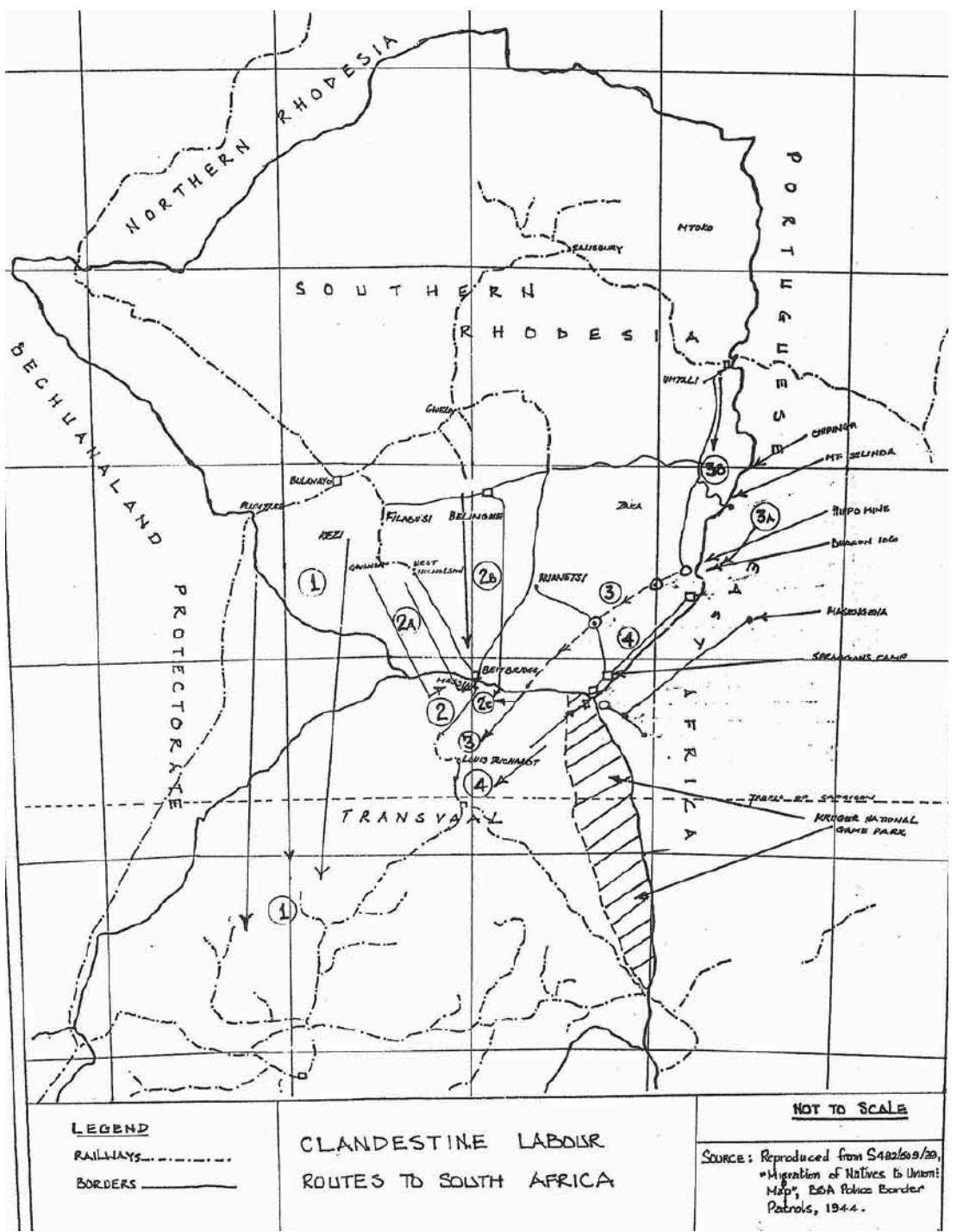

Fig. 4.3 The BSAC's rendering of clandestine migration routes to South Africa from and through the former Rhodesia around 1944. Map reproduced from David Johnson (1990). 
There existed several reasons for this reluctance on the part of the Union even to repatriate those natives who were known to be in the Union without documentation. This partly had to do with the "very long distance in most cases from the nearest centre at which the boys could be collected, the inhospitable country and the absence of machinery at the border to take them to their kraals [reserves]." ${ }^{65}$ For these reasons, and on the back of increasing inflows of northern natives, the Department of Native Affairs of the Union requested, in 1923, that it should no longer be asked to submit bi-annual reports on Rhodesian natives that were employed in the Union of South Africa. One reason was that the numbers were increasing too rapidly to be kept up with. Also, the 'natives', due to their mixed employment statuses, could not be "read by the department machinery" ${ }^{66}$ One reads in the above reasons not just awareness by the authorities in South Africa that the numbers of undocumented migrants were large, but that they were of use in the classic 'reserve army' dictum of cheap labour.

In fact, while the Rhodesians complained bitterly regarding the ambivalent attitude of their southern neighbours, the Union's 'native administrators' knew that a significant number of their farmers in the north had come to rely on African labourers from Rhodesia to complement their labour forces, and that they were therefore reluctant to see this source of labour summarily discontinued. ${ }^{67}$ With the Rhodesian government effectively prohibiting 'natives' from leaving for purposes of employment in the Union of South Africa, and with the Union quite happy to accept these voluntary irregular migrants, the stage was set

65. NAZ NB3/2/2 Rhodesian Native Labour, Letter from Acting Secretary of Native Affairs of the Union of South Africa, to the Rhodesian Native Affairs Department, 13 May 1923

66. NAZ NB3/2/2 93/280 Letter to the Chief Native Commissioner, Salisbury, from the Acting Secretary of Native Affairs, Union of South Africa, 26 July 1923

67. SAB NTS 2025 26/80 2598/14/473. Director of Native Labour to Native SubCommissioner, Louis Trichardt, 29 October 1924. 
for the growth of (the Union of) South Africa's settler economy, especially in the Transvaal, on the back of a significant population of 'employed prohibited migrants'.

\section{Building an economy with 'employed prohibited natives'}

\section{Phantoms, guns and farms}

In light of the context outlined above, it is clear that short of committed support from the successive South African authorities, the Rhodesian government was powerless to stop or even reduce the movement of largely young African males across its southern borders. Part of the challenge had to do with what the Labour Commission in Rhodesia saw as the misdirected effort of the colonial government in its preoccupation with seeking to procure labour from the northern territories to replace those who were leaving, rather than stopping the southward movement from the colony itself. The challenge with stopping the movement however, lay in the difficulty of applying the prohibition law. Rhodesian would-be 'clandestine migrants' to (the Union of) South Africa were free to move about in the colony, and could not be arrested unless they were caught actually attempting to cross the border. ${ }^{68}$ Also, the exact intentions of any would-be migrants from SW Rhodesia were difficult to detect before they crossed the border as they lived in the area and it could not be ascertained as to what and where their employment situation was. ${ }^{69}$ By 1943, migrants from SW Rhodesia, numbering upwards of 20, 000, were known to be "in regular employment in the Union of South Africa" (Johnson, 1990: 3). 
If leaving Rhodesia seemed relatively easy for black migrants, finding the rest of the way towards especially Johannesburg was a different matter. The lack of commitment on the South African side of the border to properly manage the movement of 'prohibited' migrants towards Johannesburg was principally for economic reasons (Bolt, 2011, 2012). The lack of direct state control over the incoming non-South Africans turned their movement down south into a risky affair. Without documentation, authorisation and therefore safety, many who braved this trek fell prey to exploitation along the way as a matter of routine. Migrants tell their stories of first entry into South Africa with a generally distinct sense of vulnerability.

Gatsheni, for example, remembers vividly what his very first journey was like. Recounting to me the terror that attended his journey, he started to tell his story in short bursts:

That path was too difficult. Way too difficult. It had ghosts. It had phantoms. It had all kinds of surprises. It had the police. It had white men with guns. And they could arrest or kidnap you. It was tough. Today, someone jumps into a car, and the next morning, they call you from Jo'burg. You couldn't dream it back in the day. It took us five days just to get from Pilane to Rustenburg [a distance of about $280 \mathrm{~km}$ ].

To be sure, some of the challenges encountered along the way related to banditry and especially labour recruiting. But fledging agrarian capitalism on the banks of the Limpopo River had a lot of influence on, and interest in, the exploitation of 'northern natives' who were coming in from over the Limpopo. Helen Bradford (1993) writes that employment and engagement of this kind of labour in and around the then Transvaal [northern South Africa] was generally of a coercive manner, which, like elsewhere in the world, was used to guaranteeing low wages. Whereas the employers, especially the farmers of the Southpansberg area in the northern Transvaal, saw this 
as a case of free labour, even insisting to state representatives that "prohibited migrants should be allowed to come in... and to work freely", colonial administrators, while also assenting to this view, did concede that the farmers could afford better working conditions, particularly wages, but "they wish to maintain a low wage at the expense of other farming communities". ${ }^{70}$ David Johnson (1990) shares a particularly harrowing story that appeared in a 1947 Sunday Times (a Johannesburg weekly) article, detailing oppressive employment conditions in the Bethel area of the Transvaal, where up to 90 percent of the workers were 'clandestine' migrants. The Sunday Times would record "well-substantiated reports of natives labouring under the crack of the sjambok [heavy whip]" and "of one African who was sjamboked to death on a farm" (ibid.: 4). This, I believe, relates to some of the phantoms that Gatsheni mentions without detailing. It seemed that, although he spoke freely of his experiences, some of them might have been too glaring to recount with comfort, especially in front of some members of his own family, including his wife.

As I continued to chat with Gatsheni, it was clear that his and others' movement towards Johannesburg was anything but smooth. To begin with, he found work right away when he got to Rustenburg. He needed to earn enough money to get back on the road. They used to wash river sand for pre-sell packaging. For six-day working weeks, they received a pittance in return. With a sense of injustice, Gatsheni and one other colleague left at the end of the first month. They were directed to a farm somewhere not too far from the town of Rustenburg itself. "Our job was to bathe pigs! For four days I washed pigs for a living". He says he left on the fourth day for Johannesburg, to join his brother whose address he had. "But when I got there, I was told that he had

70. SANA TAB HKN 1/1/52 17N3/20/2 Southpansberg Farmers Union to Native Commissioner, Louis Trichardt, 25 February 1948 
gone, possibly back to Zimbabwe [Rhodesia]..." Here, he trailed off momentarily, as if reliving the experience all over again. "Kwabamnyama [I blanked out]", he said eventually, wistfully.

Institutional influence on undocumented movement through Transvaal to Johannesburg was not altogether absent. The story of the emergence of (the Union of) South Africa's northern farms, which today employ a significant number of Zimbabweans, is a significant part of how South Africa has sought (and still seeks) to indirectly govern irregular movement from (former) Rhodesia into the country (Addison, 2013; Bolt, 2011; Rutherford, 2008, 2010). Such indirect governance continues, I suggest, to partially shield the market from a concerted discussion on its involvement in the continuing 'malady' of irregular movement. Just as it was for the colonial economy, such a position is still the subject of, in my view, misdirected debate in present day South Africa on the 'threat' of 'illegal aliens.'. ${ }^{71}$ But without more direct oversight, market players, such as the agrarian capitalists of the Limpopo, did (do) not only participate in exploiting this movement rather than engage it under legislated labour market standards, their influence in the matter becomes too big to bring under government control (Bolt, 2011). The following section on border farms discusses further the role of agrarian capitalism in structuring irregular movement into South Africa.

\footnotetext{
71. The term 'illegal aliens' became part of official discourse on undocumented migration from the establishment of the Aliens Control Act in 1913, which sought to clarify the colonial state's position on undocumented movement at the time. The use of the term has persisted up to the post-apartheid era. It owes some of its current usage to post-apartheid South Africa's first Home Affairs Minister, Prince Mangosuthu Buthelezi, who frequently attributed South Africa's dogged social ills such as crime, unemployment and disease to the presence of foreigners in the country. For a discussion on this, see Neocosmos (2006) and Tessier (1995).
} 


\section{Agrarian capitalism and colonial governmentality}

Border farms, border enforcement and precarious labour

The emergence of Limpopo agrarian capitalism has been studied extensively by scholars such as Helen Bradford (1993), Blair Rutherford (2008, 2010), Lincoln Addison (2013), Maxim Bolt (2011, 2015), Deborah Johnston (2007) and Jonathan Crush (2000a) among others. The present discussion finds its foundation in their work. My own interest in what have come to be known as border farms follows the intersection of (northern) South Africa's agrarian capitalism and its general proclivity towards cheap labour, irregular movement across the Beitbridge border and the relatively lethargic state interest in either directly intervening in the movement itself, or in maintaining effective oversight on how farms engage the labour that derives from this movement. My argument is that border farms, as quasi-peripheral production centres that are keenly interested in this constant supply of cheap labour from across the border, have had a significant role to play in reproducing such labour within the tropes of surplus movement.

This does not suggest that irregular migrants who cross the border into South Africa and Botswana all end up at the border farms. Further, it does not suggest that the responsibility for the control of cross-border movement has be abdicated by state authorities and shifted instead to the farmers. Moreover, I do not say that African migrants who have been attempting to move, and are in fact moving to South Africa and back with or without documents, merely find themselves at the mercy of greedy and exploitative farmers and other entrepreneurs without the migrants showing any agency, ingenuity and interest of their own. The idea of risk and vulnerability rather is meant to contextualise the limits to which the autonomy of those who move can be drawn. The point is rather that in the interaction of the above, a particular precedence in the approach, attitude and response of state authorities towards movement has emerged over time, and has had a bearing on 
the kinds of movement, as well as their mediation, that have been taking place across the border. My aim in this section is to demonstrate in broad strokes how official attitudes have shaped, and have been shaped by, understandings of especially precarious labour in colonial Limpopo.

As a point of reference on land settlement and especially commercial agriculture in South Africa, about only eight percent of land was allocated for indigenous blacks by settler colonialists, a travesty without parallel in sub-Saharan Africa (Beinart, 2001). But unlike in colonial Rhodesia, both mining and agriculture grew side by side, and a protracted struggle 'between gold and maize' for labour supply persisted throughout most of the twentieth century (Berstein, 1996). 'Northern natives' coming into South Africa naturally became a carcass over which the struggle was fought, which farmers sought to resolve by recruiting their labour from further and further into the peripheries, including from across the borders (ibid.). The idea of the greater Limpopo Valley as a frontier of capital does not find greater expression than in this contestation. The farmers of the Limpopo Valley were particularly favoured in this regard, seeing as they were strategically located closest to an eager workforce coming from across the river.

The story of how these farmers came to establish a thriving agroeconomy on an area so arid that it mainly survives on irrigation is a curious one. The settlers of the mid-nineteenth century were mainly ivory traders, although they may have also traded child slaves they captured from the local communities as bounty (Boeyens, 1994, in Bolt, 2011: 95). These hunters were driven out by armed locals in the intervening period up to the 1890s, by which time English and Afrikaner incursions into the north brought with them new mobility and conflicts around the creation of native reserves (Bolt, 2011: 96). Occupation of the newly conquered land remained mainly characterised by absentee ownership and speculation, and not without general 'piracy' and 'banditry' (ibid.). It was largely because of this restlessness, manifested 
largely in unchecked mobility, that the state was drawn in to assert its authority in the area. But controlling movement from the north also entailed focusing on the problem of 'banditry', in the form of illicit recruitment (I turn to this phenomenon in the next section) of those who were moving across the Limpopo for work mainly in the mines further south.

As already discussed, the authorities intervened here by imposing the so-called latitude $22^{\circ}$ line, which forbade employers from the rest of the Union of South African from hiring migrants from within the Tropic of Capricorn, the so-called 'tropical natives', so that they became available (in principle) for employment only in the northern Transvaal. When, through other state infrastructural interventions, agrarian capitalism suddenly expanded around the 1930 s, it found the latitude $22^{\circ}$ prohibition already in place.

The attitudes of the farmers to this intervention were welcoming. For them, such irregular movement constituted cheap labour, theirs to engage in their farming businesses, even going as far as making this understanding known by, and seeking its approval from, the state. ${ }^{72}$ The farmers got their wish, but the state sought to engage labour recruitment organisations that served the farmers in order to retain some oversight on the challenges related to the employment of 'prohibited migrants'. ${ }^{73}$ However, such a handsfree approach to managing movement was difficult to sustain given both agrarian labour needs and the abundant supply at the time. The main challenge was that such an approach could not do away with the irregular nature of this movement, and the forms of exploitation it perpetuated. So, even if the intentions of the state were to discourage movement down south by confining it in the northern Transvaal, thus asserting territorial control over the area,

72. SANA SAB NTS 2025 26/80 2598/14/473. Director of Native Labour to Secretary for Native Affairs, 13 December 1922

73. SANA SAB NTS 2025 26/80 2598/14/473. Director of Native Labour to Secretary for Native Affairs, 1 February 1923 
the agriculturalists soon came to rely on this very undocumented movement for their labour (Bolt, 2015). If the movement itself could not be stopped, neither could the intentions of African labour nor of the mines down south be changed. The prohibition, therefore, could do little to decrease the numbers of non-South African migrants who were clearly ingenious enough to continue coming through from over the river.

From the late 1940s until the late 1960s, the connection between northern labour supply and Transvaal agriculture came to momentarily weaken. Maxim Bolt (2011: 121) quoting Sampson (2005) writes that this was mainly as a result of internal movement controls within apartheid South Africa, ${ }^{74}$ as well as the various schemes that provided farmers with free prison labour, not least the coercion of black South African males into working within the compound system. This suggests that the decreased significance of the areas in and north of Limpopo as labour suppliers during this time had less to do with actual control of territory, but rather with intervention through local alternatives (ibid.). Farmers and miners themselves protested this turn of events, especially the suggestion that they needed to forgo their reliance on non-South African labour (Crush, 2000a).

From this, one could therefore see that the policy of not directly managing cross-border movement, but rather policing it, found continuities with the pass laws of the apartheid state. Policing movement, which appeared to be at odds with the economic needs of the Transvaal at the time, did not succeed in stopping undocumented movement across the border into South Africa. It is plausible to suggest instead that the movement could have been always evolving in the face of time, not least in response

74. Apartheid South Africa came into being in 1948 when the National Party came to power in South Africa. See (Clarkson \& Worher, 2013) for a general discussion on Apartheid in South African Historiography. 
to its policing. Nonetheless, a new player had entered the crossborder scene in the 1970s, whose presence both states were compelled to respond to.

\section{African nationalist movements, border security and migrant labour}

When Gatsheni left Rhodesia for South Africa, it was partly because his brother, the first born in his family, had died in the bush war - the war of liberation that led to Zimbabwe's political independence in 1980. At a broader level, the war had added a new dimension to cross-border mobility from the 1970 through to the mid-1980s, as collaborations between nationalist movements in Southern Africa with South Africa's African National Congress (ANC), through its armed wing, Umkhonto weSizwe, left the apartheid government worried that some of the people crossing the northern border belonged to the ANC, and therefore constituted a direct national security threat.

Thus, if the war gave fresh impetus for those not joining the struggle to leave for South Africa (sometimes through Botswana), it had a corresponding impact on the relations between the colonial governments of Rhodesia and South Africa, and on the attitudes of apartheid South Africa towards cross border movement. There is continuity in the manner in which the Rhodesian government dealt with 'guerrillas' - or liberation fighters - in the communal lands, and the manner in which the post-independence government dealt with the so-called dissidence problem in SW Zimbabwe. As an aside, marginalisation in the southwest of the country and the subsequent circular movement to South Africa follow the long belief in the region's suspected disloyalty to the Rhodesian/Zimbabwean state (Mate, 2005). ${ }^{75}$

75. I elaborate on this matter later when I turn to the post-independence Zimbabwean era 
On the opposite side of the border, a continuity lies in the manner in which the state again attracted more farmers (mainly through favourable financial schemes) to the border regions to act as a buffer and to enhance state capacity in the face of these ANC associated security threats (Bolt, 2011). Thus, the border farmers, again following a longer trend, came to rely on the cross-border movement for labour supply. Thus, as they complemented the state in 'policing' the border, they also in fact came to rely on the border's continued relative permeability for labour supply (Bolt, 2015). But perhaps the most significant continuities, and of relevance for this discussion, relate to the practices of labour recruiting, with a veneer of banditry (and later day incarnation as assisted border crossings) across the Beitbridge border.

From the discussion so far, it emerges that the Limpopo Valley, and indeed the Beitbridge cross-border space, has been one of contested movement, in great part because of its close connection to broader labour and colonial capital relations. And, the "transformations of sovereign colonial power" (Mezzadra \& Neilsonm, 2013: 4) can be observed in its articulations with market forces. It is these transformations, and relations between the colonial states and cross-border African labour, that uncover how the Limpopo Valley can be considered one site where colonial capital had negotiated the expansion of its frontiers through a combination of power, law and cross-border labour market differentials. Missing from this assemblage is the articulation between politics and violence that marks how African labour is turned into a commodity for colonial capital and its markets. Illicit labour recruiting is a good example to trace this nexus. 


\section{Illicit labour recruiting in colonial Limpopo}

\section{A territory swarming with recruiting agents}

If 1913 marked the time that latitude $22^{\circ}$ was imposed to restrict the movement and employment of 'northern natives' in the rest of the Union of South Africa, it is also plausible that the phenomenon of recruiting - a practice of helping, influencing and coercing irregular cross-border migrants into accepting employment in various places in the Union - had grown remarkably to attract concern and intervention by colonial authorities. The imposition can scarcely be accounted for without focus on the role that labour recruiters have been playing in the movement of people through the Limpopo (Murray, 1995).

According to a newspaper article recorded in van Onselen's (1990: 3) account, "on crossing the border into the Union, clandestine migrants found themselves in a territory swarming with recruiting agents [...], 'who spoke every language and dialect in Rhodesia and Nyasaland (present-day Malawi)"'. This became a common assumption among Rhodesian employers, who increasingly insinuated state incompetence in policing those parts of its territory that had become key staging points in the recruitment of potential labour southwards; a phenomenon they felt was likely supported and financed by employers in the Union. ${ }^{76}$ As I argue, labour recruiting across the Limpopo Valley, and its significance in shaping undocumented movement across the border, in many ways prefigures practices of assisted border crossings in contemporary Southern Africa.

76. NAZ S1226, “Native Labour”, circular letter to all CID stations, 28 February 1939. The letter, at one point, makes an explicit connection between the South African Chamber of Mines and recruiters of the Limpopo. 
To set the matter of labour recruitment in context, there always existed an institutionalised infrastructure for the formal recruitment and transportation of workers from the rest of Southern Africa to the reef mines in South Africa. Since its establishment around 1900, the Witwatersrand Labour Organisation (WNLA, popularly known as Wenela) was given wide migrant labour recruitment powers by treaty. By 1899, two thirds of all workers in the mines were from Mozambique alone (Harington et al., 2004). Although, the formal recruitment of foreign labour was stopped by Zambia and Malawi in 1967 and 1974 respectively, while Zimbabwe pulled out of the agreement in 1981. Recruitment from within South Africa was later pursued under the Native Recruiting Corporation (NRC). Wenela and NRC later combined to form The Employment Bureau of Africa (TEBA) which remains to this day. Recruiting outside the Wenela scheme was also rife, and was legal as long as the recruits were from outside the latitude $22^{\circ}$ prohibition, that is, if they were 'natives' of the homelands of South Africa.

Nevertheless, and parallel to this, illicit recruiting in the Limpopo Valley was possible in the first instance because the recruiting by the mines of the reef created an extra pull for potential labour among non-south Africans from neighbouring countries who retained an abiding wish to earn similar rewards to those that formal recruiting brought their fellow countrymen. But, recruiting came to especially be popular for several other reasons. First, the latitude $22^{\circ}$ prohibition combined with the determination of irregular migrants from the north to create economic opportunities around its active circumvention. Second, because of the widely reported poor working conditions in the Transvaal farms and mines, irregular migrants found themselves generally pushing further south, and found themselves open to the suggestions of recruiters. And above all, it was the fact that shopkeepers, traders, poachers and big game hunters of the north came to double up as informal labour recruiters. As such, this indirect disregard of the government directive, which tended to 
facilitate more cross-border movement by non-South Africans (Murray, 1995), may have partly been seen by irregular migrants as a viable way to get to the reef.

As a way of implementing the latitude $22^{\circ}$ prohibition, and in a response to illicit recruiting, the Union government, in collaboration with farmers, formed the Foreign Labour Recruiting Scheme in 1925 to regularise the recruitment and employment of farm labour in the Transvaal region (Bradford, 1993). Centred at Louis Trichardt, 125 kilometres south of the border, the labour scheme was to depend on a network of labour depots set up around the Limpopo as collection points for the main depot. But, the migrants were to be brought to these deports by 'native runners', after which point, they were to be brought to Louis Trichardt for assignment to their employers. ${ }^{77}$

If the initial irregular movement and employment of 'northern natives' in the border farms of the Union of South Africa left any ambivalence as to the status of Transvaal's commercial agricultural labour, the existence of recruiters complicated further the conceptual distinctions between free and unfree labour (Bolt, 2011), as well as between regulated and clandestine movement. First, it was not clear how the local recruiting was actually done. On one hand, the recruiters for the Foreign Labour Scheme did not have regular recruiting licences, while on the other, recruiters with licences were not allowed to recruit 'northern natives' as part of the prohibition. This policy gap created a space for the Transvaal farmers to illicitly recruit foreign farm labour through the use of 'local' assistants, or so-called 'native runners'. It also further handicapped the state in its attempts to manage irregular migration, and handed the initiative back to agriculturalists. It came as no wonder then that the labour recruitment scheme failed, and was eventually closed in 1949. 


\section{Highway robbery}

In the ineffectual management of cross border movement in twentieth century Limpopo by the state, the demand for labour that spawned the practice of recruiting for the farms and mines of the Transvaal, as well as for the rest of South Africa, soon became characterised by coercion and violence. If recruiting became a business in its own right, then it was largely a lawless one, in which making money - the capitation fee - from supplying recruits was the supreme goal. With the official native labour recruitment scheme having closed, illicit recruiting and especially its unscrupulous nature escalated. Gatsheni may not have explicitly mentioned any of these things in his account, but his story clearly implied and corroborated other accounts (Musoni, 2012) of the long existence of the practice of preying on undocumented migrants, whether for recruiting to the farms or for other reasons as they crossed the Limpopo Valley.

Even before the labour scheme was closed, the confusion around the licensing of recruiters and the mechanisms available to circumvent this scheme saw the farmers themselves relying on illicit recruiting to ensure their labour supplies (Bradford, 1993). But, in ensuring unregulated competition, "migrants were not merely being assaulted, or robbed, or being subjected to touts impersonating the police. Some were also being recruited at gunpoint, hunted like ostriches, or captured by dogs before being stuffed into lorries"' (Bradford, 1993: 115). A report submitted to the Native Commissioner in Pietersburg (Polokwane) reflects official awareness of this practice as early as the 1910s:

The manner in which recruiting is done across the borders amounts to little short of highway robbery. A licensed runner with a gang of boys is waylaid and the boys taken from him whether they are willing or not. Of course, the latter do not care 
who gets the capitation fee for as long as they can get down to work. The local term for the illegal agents as a class is the "bandits", and I do not regard it as too severe a one. ${ }^{78}$

It did not matter that knowledgeable irregular migrants still tried to avoid recruiters. Crossing without documentation, or on foot, was invariably a hazardous undertaking, as the following extract by a South African Labour Officer on an observed recruiting incident from 1947 details:

An European in charge of a lorry load of recruiters observed a native who obviously was trying to hide in the bush. The European instructed his Induna [assistant] to chase the native and 'bring him in'. The later was outpaced and felled on a knobkerrie. The two-inch scalp wound resulting from this attack was treated by a Messina doctor daily for a week before the native, then very ill, was admitted to the hospital as an inpatient. Two days later he died of tetanus. Subsequently the Induna, one Petrus Maraba, was arrested and brought to trial. Pleading guilty to, I believe, a charge of assault he was given a suspended sentence of two years. The accused thereafter left the Court a free man (in Johnson, 1990: 4).

\section{Policing illicit recruiting}

From the foregoing discussion, and perhaps as a generalisation, it is more difficult to effectively manage mobility where there exists little concerted effort to systematically maximise its benefit within a well-regulated labour market context and where there lacks the goodwill to govern it towards a nonexploitative regime. An enduring argument that follows from

78. SAB NTS 2025 26/80 2598/14/473. Report no. 56/13/405, submitted to the Native Commissioner, Pietersburg on 13 August 1913 
this proposition has dogged the debate on migration between South Africa and its neighbours (Crush, 2000a), and on perhaps economic migration in general (Andersson, 2014). For as long as labour market differentials between Zimbabwe and South Africa have existed, there has been a fear that providing opportunities for more people to migrate legally encourages even more migration (Crush, 2008). The flipside is that when these opportunities are closed, people generally migrate clandestinely anyway. This makes movement hazardous, engendering novel forms of migrant ingenuity in attempts to bypass enforcement mechanisms, especially at the border. It also increases the cost, in human and financial terms, of bringing movement under 'control'. ${ }^{79}$ The policing of surplus movement across the Limpopo has generally been grappling with this conundrum.

In this respect, policing has been, and continues to be, a game of cat and mouse. Here, I defer back to the emergence of a policing movement in the Southern African regional colonial context. In around 1910, Bvekenya received friendly advice on how to evade the police at Crooks' Corner should they come looking for him, which they did several times. Handed to him by an Irishman William Pye, the advice is at once the descriptor of how the place got its name: "Well, at the corner, where the rivers meet, there is a wonderfully handy beacon. [...] If you ever get into trouble, just remember the beacon." Explaining why recruiters like him came to live at the confluence of the three colonies, Mr. Pye continued: "Whoever comes for you, you can always be on the other side in someone else's territory; and if they all come at once, you can always sit on the beacon top and let them fight over who is to pinch you" (Bulpin, 1954: 28 - 31). Bvekenya went further than

79. For a concise discussion on this issue see for instance Ruben Andersson's (2016) magazine article on 'Who is cashing in on keeping migrants out?' New Internationalist, issue 489 . 
just make a semi-permanent camp next to the beacon, he prized it loose, so that if anybody came after him, "he simply moved the beacon, and placed himself in safety without the necessity of breaking camp" (ibid.: 31).

This advice offers a good analogy for a description of the prevailing attitude towards policing, not just by recruiters such as Bvekenya, but by the whole clandestine labour institution and its different players, including state functionaries, towards one another. To frame the same problem of policing differently, the intensity of policing efforts appears to have always remained a function of changing perceptions of labour shortage both in Rhodesia (Zimbabwe) and South Africa (Johnson, 1990). Other scholars have described the sporadic arrest and deportation of mine, agricultural and other undocumented labour migrants making up the numbers - as less a sign of state policing authority than a response to its limits (Bolt, 2015; Vigneswaran, 2007; Vigneswaran, Araia, Hoag, \& Tshabalala, 2010). Gatsheni detailed to me how he was arrested numerous times on the way to, from and in Johannesburg. But that never changed his basic attitude towards the threat of arrest. "Everybody goes through a rough patch once in a while", he said to me, describing how he was once arrested in Lobatse, Botswana, on his way to Rhodesia, but was taken first to Johannesburg, before he was taken to Beitbridge and left on the Rhodesian side of the border.

\section{Placating border enforcement}

Just like Gatsheni, irregular migrants have always exploited the porous border to evade border enforcement. When this has not been feasible or economical, migrants are said to sometimes have "enjoyed relatively smooth passage by obtaining passes to enter the Union from their friends and relatives already 
working there". ${ }^{80}$ Alternatively, would-be migrants sometimes even received detailed descriptions of what they needed to do or avoid if they were to make it to South Africa. ${ }^{81}$ Records demonstrate that the police in Rhodesia, the Union, as well as in Bechuanaland, present-day Botswana, have always been aware of these practices. ${ }^{82}$ One explanation for police ambivalence towards their policing duties in the face of such intelligence connects to perceptions of labour shortage and surplus. In the period around 1930, the effects of the Great Depression are said to have compelled the Rhodesian police to ignore clandestine migration and to relent in their abiding demands to have South Africa deport those Rhodesian migrants they were periodically arresting. ${ }^{83}$

However, as I have discussed above, if migrants found it easy to bypass the Rhodesian police, they found it more difficult to avoid farm labour in the Transvaal. A significant aspect of this difficulty lay in the entanglement of policing itself with mining and agricultural labour needs on one hand, and their methods of recruiting labour on the other. By the 1930s, soon after the Great Depression, expansion in the Union of South Africa's mining sector and its related industries created a greater demand for labour (Johnson, 1990). Rhodesian and other workers from the Southern African hinterland, responding to a shortage left in the farms of Transvaal, the Free State and

80. NAZ S1226, Minute by Assistant Commissioner, CID, Bulawayo, 20 June 1942. From my experience and research, this 'trick' was still in use as late as 2003, when I myself used it to get a visa to travel to South Africa on holiday.

81. NAZ S1226, NCO i/c, Kezi BSA Police to Assistant Commissioner, BSA Police, Bulawayo, 10 July 1942

82. NAZ S1226, Report to the Native Detective, Musimane, 27 October 1939; S482/509/39, "Clindestine Migration of Natives to the Union": general Summary, Sub Inspector Robotham, 5/1/45, 3 January 1945

83. NAZ S1226, Chief Native Commissioner to the Commissioner, BSA Police, 17 March 1934 
on the east coast, filled this demand. ${ }^{84}$ When the Farm Labour Recruitment Scheme was created, it was one way in which the Union of South Africa had hoped to assert territorial control of especially its northern borders by effectively rounding up "natives entering into the Union across the Rhodesian and Bechuanaland Borders". ${ }^{85}$ But, at this point, the purposes of policing and those of recruiting became entangled with state sponsored labour coercion.

Immediately any foreign Native is received into the main [Foreign Labour Recruitment] depot he must be served with a prohibition notice... Immediately after service of prohibition notices on a batch of Natives, they should be called upon to elect whether they desire to enter into contracts of employment in terms of the scheme or whether they desire to be repatriated. Any Native who has refused to accept employment should be transported to the border and ordered to return to his country of origin. ${ }^{86}$

Helen Bradford (1993) writes that such an infrastructure effectively became part of a wider effort to control the movement of non-South Africans, and those who were arrested and imprisoned under such a scheme became a significant source of agricultural labour provided by the state. The link between policing irregular migration and farm labour supply was thus further entrenched during apartheid times, and justified as "not the intention [of the state] to repatriate these Natives, but the Department [of Native Affairs] is anxious to gain effective control

84. S1226, Chief Superintendent, BSA Police, Bulawayo District to Staff Officer, BSA Police, 11 October 1937

85. TAB HKN 1/1/52 17N3/20/2 'Depots: Foreign Labour Recruiting Scheme'. Secretary of Native Affairs to Chief Native Officer, Pietersburg, 10 July 1947

86. TAB HKN 1/1/52 17N3/20/2 'Farm Labour Scheme: Special Instructions for the Native Commissioner, Louis Trichardt'. Secretary of Native Affairs to Chief Native Commissioner, Northern Areas, 3 March 1947 
over their movements and to offer them such employment in the rural areas as may be available". ${ }^{87}$

The image of the handy beacon reverberates even through the apartheid state's influx control and group areas policies as it also shines a light on the general policing of surplus movement. Different actors - irregular migrants, recruiters, state institutions and representatives of big industries - come together through the kinds of interaction that reproduce border enforcement as not merely an institution, but a set of social relations. It is within these social relations that the border struggles discussed so far connect broader processes that define a regional political economy that, by and large, fashioned, guaranteed and significantly relied on cheap African labour.

\section{'Assisted border crossings' in post-apartheid Limpopo}

\section{Contesting colonial borders}

The morning after my arrival in Sanzukwi, Gatsheni, MaNdiweni and myself continued our discussions at his convenience store at the service centre. This latter part of our discussion centred first on his later life in Johannesburg, as well as on the prospects for a good harvest and their retailing business. From the conversation, it was clear that Gatsheni felt he had managed, through hard work and a few lucky breaks, to achieve his lifelong ambition of being a self-reliant and respectable family man. The turn of the conversation struck a clear break from the difficulties of his earlier years as a migrant worker in South Africa. In that sense, it felt as if through his life course, Gatsheni had jettisoned the kinds

87. TAB HKN 1/1/51 17N3/20/2 'Foreign Labour recruitment Scheme - Louis Trichardt.' Secretary for Native Affairs to Commissioner, South African police, 18 April 1953 
of disadvantages that his earlier life circumstances had imposed on him. By engaging in particular bordering practices, he had displaced the effects that the spatial and socio-economic borders were meant to produce in his life. This demonstrates well how his life in turn has been performative of the shift in the identity markers that these borders had placed on him as an erstwhile disempowered African man. Like many migrants, Gatsheni had started at the bottom. A distant cousin took him in on the day he could not find his brother in Braamfontein. Initially, he found work as a gardener in and around the then 'Europeans only' residences of northern Johannesburg. It was nothing fixed; he worked different days in different residences. It depended on who needed his help. One day, in 1973, a white man from Karoi in Rhodesia hired him. He lived in Randburg, in the northwest of the city. It would appear that Gatsheni impressed this man, for he offered him a resident job as a general hand in the house. For the next 27 years, Gatsheni stayed at this man's cottage, next to the main residence.

And yet, financial independence was elusive, so that Gatsheni decided around 1976 that he would combine his job with other 'piece jobs' in order to complement his income. That seemed to work. In the intensifying guerrilla war that would lead to Zimbabwe's independence in 1980, Gatsheni started to visit home often, and to invest his savings there. First, he built a sizable head of cattle. In 1978, he got married. He would continue in this kind of situation until 1985, when his baas, or resident employer, got him a job at a firm, where he could hold down permanent employment for the next sixteen years.

Gatsheni's life is illustrative of the interaction between a regional political economy of migrant labour and the colonial/apartheid politics of citizenship as discussed by Michael Neocosmos (2006). Gatsheni's life as a labour migrant in Johannesburg connects with the narrative of South Africa not just as a so-called 'sub-regional economic power', but also with the apartheid urban economy 
that relied on the control of rural migrant labour, 'dormitoried' both in South African Bantustans and in the Tribal Trust Lands, or native reserves, further in the regional hinterland. And yet, as a black African who came to work and live, initially without permission for either, in an area reserved for European residence, he challenged and subverted the apartheid and indeed colonial borders of citizenship in the apartheid South African city.

The transformation of Gatsheni's identity through these processes illustrates how even within, and proceeding from, colonial and apartheid's heavily policed and bureaucratised interpellations, the identity of migrant labour as an instrument of regional political economy, and of Africans as non-citizens of the segregated city, were in practice always open to contestation, and indeed sometimes befuddled. ${ }^{88}$ But this subversion has another dimension.

Such Africans who have lived in the city, that is, as neither subjects of a 'decentralised despotism' nor 'rights-bearing citizens' (Mamdani, 1996), often continued to defy categorisation in the South African citizenship politics. In 1980, Gatsheni soon found himself having the option of returning and recreating a decent life for himself as a 'citizen' in a liberated Zimbabwe. However, the significance of political independence does not feature prominently in his life story. It was as if it never happened. The emancipatory potential of post-independence Zimbabwean politics and society (and not necessarily democratisation [Mamdani 1996: 26-7]), in terms of labour (for instance as a social force for decommodification) and of citizenship (with substantive rights in the new Zimbabwe as compared to what he would hypothetically wait another 14 years for at the end of apartheid in South Africa), seemed to not hold any promise for him. The political disturbances

88. This argument resonates with Francis Nyamnjoh's (2006) who problematises domesticity and mobility in the apartheid city. 
in post-independence SW Zimbabwe may also have contributed to the perceived inhospitality of the region. ${ }^{89}$ Gatsheni chose instead to acquire a South Africa identity document in early 1980, and continue as a circular migrant.

\section{The multiplication of labour}

Again, Gatsheni's experience and calculations were not illogical. Mahmood Mamdani (1996) writes that political liberation, under the rubric or discourse of deracialisation merely recast decentralised despotism (the racially bifurcated indirect rule of colonial subjects via traditional chiefs) as direct despotism with a new regimen of the tightened central administration of local authorities. In Zimbabwe, this policy took the form of a new kind of decentralisation, where government authorities at the local level were left to raise their own revenue for community development in the face of shrinking support at a time of neoliberal reform (Mate, 2005). This brought rural and urban communities in direct economic, and thus political, competition under a uniform system of administration. Further aggravating divisions between the town and country (Mamdani, 1996), this new form of decentralised despotism left rural inhabitants even more excluded from civil society.

In rural Matabeleland, this was exacerbated by a perceived political problem of dissidence between 1982 and 1987, in which further marginalisation was partly a result of a scorched earth policy to 'flush out' recalcitrant elements (Muzondidya \& Ndlovu-Gatsheni, 2007; Ndlovu-Gatsheni, 2008; Polzer, 2010). ${ }^{90}$ Gatsheni and many others from his side of the country

89. See footnote immediately below.

90. In what became known as Gukurahundi - the early rain that washes away the chaff before the rainy season - the post-independence Zimbabwean state deployed the army, the police Support Units, the Central Intelligence Organisation (CIO), as well 
initially felt threatened by the coming of independence to Zimbabwe, and sought to protect their relative economic and ambivalent political freedoms in apartheid South Africa. These reconfigurations of identity and belonging within SW Zimbabwe speak to how the shapes that characterise "the edges of the nation-state" (Brambilla, 2015: 19) are constantly shifting. Meanwhile, the possibility for South Africa to offer an alternative sanctuary also suggests that the border between the two territories is not just a territorial one, and does not necessarily coincide with the prevailing ideas of space, citizenship, identity and otherness in that part of the country. The state border therefore appears to interact with shifting social boundaries, so that the space where the physical border currently lies appears one of ambivalent continuities as well as contestations, albeit non-uniform ones.

But movement between South Africa and Zimbabwe was becoming both pronounced and difficult during the mid-1980s. The apartheid government escalated its enforcement of the northern borders through direct militarisation ${ }^{91}$, not least by encouraging farmers along the Limpopo to militarily defend themselves if the need arose (Werbner, 1991). This was a time when cross-border movement had become mixed with Black Nationalist (ANC) military incursions from SW Zimbabwe. The movement did not just increase; it also became more heterogeneous in scope. Incessant droughts (Thebe, 2011) also added to both the numbers and their character. It was also at this time that transport in consumables became added to the

as a North Korean trained special force, the $5^{\text {th }}$ Brigade, in 1982 in the south western regions to redress a fallout from the nationalist military struggle, and to construct a unitary national identity in the country. The resulting abductions, rape, murder, torture, death and cultural imperialism and indoctrination on citizens of the SW region are often seen to have had characteristics of a genocide, costing an estimated 20, 000 lives (Peace, 2008).

91. The Beitbridge border became electrified in 1986 to try and stop both suspected crossborder guerrilla movement and economic migration across the international frontier. 
movement of people, as migrants with relatives in Zimbabwe sought to support their kin by sending money and goods when they could not travel to Zimbabwe themselves.

The genesis of mixed migration (Crush, Chikanda, \& Tawodzera, 2015), beginning with displacement from the 1980s, found further impetus in the 1990s as economic structural adjustment programmes drove increasing numbers of economic migrants from diverse socio-economic backgrounds to South Africa in search for work (Lovemore M Zinyama, 2000). But, the end of apartheid in the early 1990s did not translate into the relaxation of immigration controls into South Africa. It, however, saw widespread trade liberalisation and externalisation of employment processes (informalisation from above) (Theron, 2010; Schierup, 2016) that accelerated the informalisation of the economy. As a result, Zimbabweans became part of a new Africawide trend of seeking better economic opportunities in South Africa (Adepoju, 2002), but predominantly found themselves in under- or self-employment.

With this mixing movement itself, and therefore the multiplication of labour (Mezzadra \& Neilson, 2013), the border proliferates into many things. Because of the different actors that engage with them, themselves bordered by different identities and circumstances, borders become polysemic, hypothetical and even fictive (Balibar, 2002), opening up possibility for the diversification of practices that nestle around them, and of the meanings that emerge from these practices.

The increase and diversification of cross-border movement presented Gatsheni with an opportunity to reimagine himself along these lines. A few years after he found permanent employment in South Africa, he had saved enough money to buy a car. By 1991, he had started helping friends and neighbours in Matabeleland South to take their goods home to Zimbabwe for a fee. He did this on weekends, and always made sure to return to work on 
Mondays, working night shifts for the duration of the sixteen years he held his job. The gradual encroachment of Gatsheni on border practices that broker cross-border mobility reflects the transition and entanglement of political life and broader processes of politics and the economy. The forces that shaped him as a labour migrant have, with time, brought him to a position where he is able to more actively engage with, and eventually also contest and reshape these very same forces. This is indicative of how labour can become socialised (Mezzadra \& Neilson, 2013: 91), and how practices that define these socialisations continuously shape and redefine society.

Irregular migrant labour, assisted border crossings and frontiers of capital

A combination of the volume of people now seeking to get to South Africa, migrants who sought to support their relatives in Zimbabwe by sending them consumer goods and money, as well as the initial unavailability of public transportation may have contributed to the demand for private transporting. "I should have started a long time ago!" Gatsheni had exclaimed when I asked him why he started transporting. Many participants in this study concur among each other that there were still very few public buses to South Africa by the late 1990s. The railway line connecting Bulawayo and Beitbridge was only commissioned in 1999. Nevertheless, formal 'passenger carriers' operated by both Zimbabwean and South African entrepreneurs could not fully cater for the needs of migrants to post or move unaccompanied remittances (Thebe, 2011: 654). ${ }^{92}$ As the number of people seeking to go to South Africa or send back goods and money increased, therefore the need for private transport also emerged and quickly increased.

92. One value of private transporting is that it responds to individual passenger needs, including door-to-door delivery. Other scholars (Maphosa, 2010; Nyoni, 2011; Thebe, 2011) have discussed this in detail. 
One particular designation of this new trend of cross border movement is that it is part of the increasing heterogeneity of labour that is directed and exploited by capital within a new, post-apartheid context of labour fragmentation, informalisation and accelerated migrant irregularity. But, the surges in such undocumented cross-border migrant numbers from the Zimbabwean labour periphery now crossing at Beitbridge serve to magnify and cast fresh light on the wider Limpopo Valley as a frontier of capital. While the pace of post-apartheid migration policy reform has been slow and attitudes towards a 'flood' of African migrants have hardened in South Africa (Crush, 2008), South Africa has simultaneously been employing increased numbers of undocumented migrants in more sectors of the economy than merely agriculture and mining. And although the South African Home Affairs ministry has been seeking to bar employment of undocumented migrants, employers have silently been reluctant stop the practice or give in to such pressure (Segatti \& Landau, 2008).

This contradiction was visible in 2002, when the new Immigration Act had to go through a prolonged vetting process before it passed through parliament. When it eventually did, some of its key elements, such as levies on businesses that hired foreigners, the establishment of immigration courts and a separate immigration branch, were fiercely opposed and eventually omitted (Crush, 2008). Some see these late amendments signal the pressure that the ruling ANC government came under from labour, businesses and other sectors with vested interests (ibid). These contestations are essentially about retaining a particular composition of labour. Border enforcement, and the migration policy regime that guides it, therefore acts as a filter and a membrane that, in Petti's (2007) terms, lets certain flows pass while blocking others. This also recasts the greater Southern Africa region as a frontier zone. Transporters and other mediators, including border enforcement agents, act to make both the physical border and the frontier region elastic, and in a constant state of formation. 
Coincidentally, from the 1980s, a 'special employment zone' has existed along the Beitbridge border which accords special status to farmers as border employers (Bolt, 2011; Rutherford, 2010). Representing an exception from the previous recruitment prohibitions, this arrangement has given farmers a way of directly recruiting migrant cross-border labour without recourse to normal migration policy dictates. At one point, the popularity of the special employment zone scheme led to the opening up of an 'informal' border post across the Limpopo River that led directly to the farms, the so-called Gate 17 (Lincoln \& Maririke, 2000). Zimbabwean migrants, economic or political refugees, benefitted from this exception in that they could immediately find both safety and employment if they were courageous enough to brave the Limpopo. This arrangement offers an even clearer illustration of the frontier process, the filtering of flows, as well as the role of capital in directing the process.

The above illustrates the recasting of the border as a set of social relations that articulate with broader processes of domination, exploitation and dispossession. Irregular migrants and intermediaries such as private transporters figure prominently in these social relations, not just as living labour, but also as protagonists in the border struggles that constantly shift the appearance and meaning of the Beitbridge border itself and the Beitbridge borderland. This necessitates further thinking on the relationship between labour power and the production of subjectivity, a subject that I will discuss in Chapter Seven. The strength of this view of cross-border processes is that it incorporates into cultural analyses the relations of exploitation, which are few in discussions of relations of power. To talk of exploitation relations does not suppose that the ability of the disempowered to engage with the border spaces from their position of marginality is nullified. Indeed, the idea of border struggles seeks to underscore the contestations that continuously remake the cross-border space and its meanings. 
Undocumented cross-border migrants play a significant role in these contestations, and more so as their irregular status goes against the very grain of regular movement, secure labour and border enforcement norms.

\section{The 'episodic' border}

This is well illustrated by what Gatsheni shared with me regarding his business of transporting. When I asked him how he used to help people cross the border without losing too much time to the border's bureaucratic red tape, he told me that he never transported so-called 'double-up', or people travelling without documents. He was careful to stay on the 'good side' of the law, he said. However, without a pause, he also shared with me how he had established rapport with border officials enough to know which officials he would usually meet at the border at given times. It was these individual immigration and customs officials who sometimes called him out of stagnant queues to let him pass without 'too much trouble'. The idea of conflict and accommodation that characterises border struggles emerges in this illustration, showing also how the border space is, in Rancière's (2001) terms, episodic; made up of interactions that are temporary and spatially contingent. The constantly changing experiences that Gatsheni had with the border suggest that the border space is understood as variable in its form and character, which approximates to ongoing encounters rather than precasts norms and patterns (Kumar Rajaram \& Grundy-Warr, 2007).

How Gatsheni routinely showed his gratitude for these favours was left hanging in my discussion with him, but it demonstrates well the silent encroachment of informal practices on border enforcement procedures that Asef Bayat (1977) characterises as the politics of informal people. In truth, this encroachment is the subject of the social relations that define, rather than distort, the meaning 
of the border and border practices. I asked another transporter the same questions I had asked Gatsheni, how he gained time at a congested, heavily bureaucratised border, and he told me that "now we speak with them directly, unlike before [in the colonial era] when, although these things existed, they were always done tentatively, in an indirect way, and with much anxiety"..$^{93}$ Here lies the promise of the facilitation practices of transporters as indicative of the co-constitution as well as contradiction of the border as a space of restriction and accommodation, of dry formality as well as conviviality, of foreclosures and openings. Border struggles have precisely to do with how this dialectic articulates on an uneven, contested and ongoing basis.

\section{Conclusion}

The above reflection offers an ideal exit point for the discussion of this chapter. Taking Zimbabwe's political independence and economic decline on one hand, and the contradiction, or internal logics between informalisation processes gripping the South African economy and a stringent migration regime on the other, this chapter has attempted to place practices of assisted border crossings at the centre of the changing, perhaps even contrasting the nature of border struggles across the Limpopo Valley. Such border struggles, the chapter has argued, illustrate how irregular migrant labour articulates with capital as much as it shapes the changing meaning of the spatial and social border as a synthesis between institutional norms and social relations between disparate border actors. Private transporters, and their interaction with both state actors and regular cross-border travellers, are at the centre of the contestations that define bordering practices.

93. I met Mthembo (not his real name) with the help of one of Zouma's clients on my way to Zimbabwe. Mthembo is a reputable transporter, although his drivers, as I gathered, have turned rogue. They have been found out to kidnap, rob and steal from their travelling clients. 
Assisted border crossings, therefore, represent the basic unit and form of these struggles and their changing nature, as well as have the ability to imbue the border space with its ambivalent, albeit changing meaning.

A major argument that runs through the chapter is that the nature of undocumented border crossings, as they currently exist and are facilitated across Beitbridge, have a long, although less debated, historical precedence. This historical scope need not be lost on scholars, policy-makers and various other stakeholders with an interest in not just the Southern African political economy of migrant labour, but on border studies in general. Although, the facilitation of undocumented border crossings and their insertion into the colonial and apartheid labour markets represent a relatively smaller context compared to the coercive space of influx control that characterise formal (colonial and apartheid) labour arrangements, it still uncovers how border practices are intimately tied to, and interact with, broader processes of labour and mobility that have endured and evolved over a long time. Such a broader view demands that we begin to take into account cross-border clandestinity in pre-1994 Limpopo. This will assist in how we approach ambivalent border practices such as illicit labour recruiters and assisted border crossings as partly sharing a historical continuity. It will help us to pronounce that border practices such as are characteristic of hyenas are not a new feature of the Limpopo borderland. And although they take on evolved forms that approximate to more recent patterns, they dramatise quite long-standing contradictions of processes that drive the region's political economy as well as its social transformation.

As Zimbabwe continues to struggle politically and economically, the volumes of people participating in cross-border movement into South Africa remain relatively high. This means that the practices which are the subject of this thesis have not only become mundane, but that they also continue to evolve. As for 
Gatsheni, although he stopped transporting in 2010, he still either travels or drives to South Africa to stock up on merchandise for his convenience store. Here, he recasts the Zimbabwean frontier zone not just as a source of labour but also as a consumer market. All these functions of the border illustrate how flexible and elastic it is as social form. Nevertheless, Gatsheni's changing encounters with the border, from being a migrant labourer to becoming a transporter to being a retail entrepreneur are indicative of the temporal and ongoing mutations of its relations.

A lot of the younger transporters have a grudging respect for Gatsheni, partly because he was able to seize the moment and make the most of transporting at a time when there were not so many of them on the road. They also admire him for retiring on his own terms. Here, Gatsheni once more beams with an evident self-satisfaction: "When they see me, they ask if I ever think of coming back to the transporting business. I tell them that although the name of my van is 'koze kube nini - when shall the time be - my time has already come, and for now, I am happy where I am". 


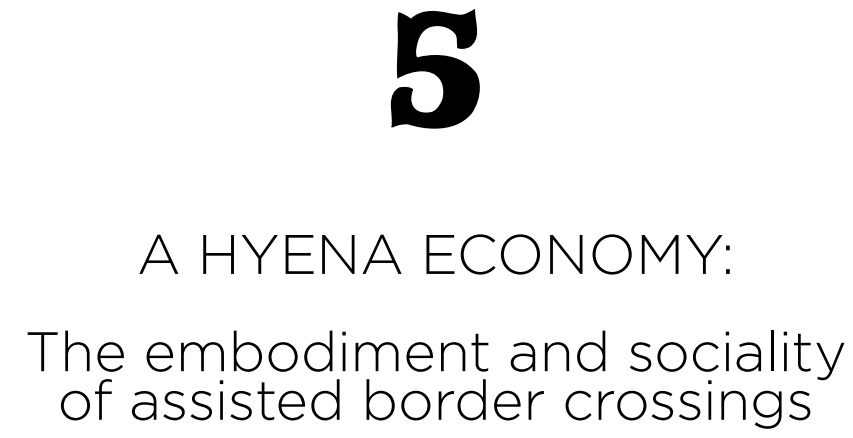

\section{Introduction}

Those in the know say izimpisi, 'hyenas', were once an admired, resourceful and rather eccentric crop of 'people smugglers'. The way they are said to have gone about helping undocumented migrants across the Limpopo River often sounds whimsical even poetic. Their craft seems to have naturally revolved around the river itself. Though an open secret, ukuchaphisa ('smuggling') was always done discreetly (unlike nowadays), away from the glare of curious onlookers. Hyenas seldom used the formal crossing point - the Afred Beit Bridge. For reasons of stealth, they braved the intermittent, crocodile infested waters of the Limpopo River by night. Several spots along the vast stream functioned as crossing points, while their camaraderie with both amagumaguma, bandits taking advantage of undocumented travellers, and state security (or border) officials helped partially secure their precarious enterprise. Today, the hyena takes on a slightly evolved character, yet retaining a central role in assisted border crossings - ukulayitsha.

As the story goes, having gathered a required number of undocumented travellers, goods or other contraband, a hyena would head for any one of their chosen points along the river to take them across. One fascinating story, revealed to me by 
somebody who participated in the arduous ritual, retells the adventures of a seasoned hyena - Msunduzi, who, after leading a group of 'border jumpers' a couple of metres into the water, would immediately turn around and face them, making sure to establish and maintain eye contact. The hyena's back would by now face the open waters. From here, the hyena would go through about a hundred-metres-long aquatic ritual by both walking backwards and humming a soft melody. As the hyena chants rhythmically, he would motion the group forward repeatedly with one hand. With the other, he likewise would rhythmically strike the water behind him to the one side and then the other - ahead of the entire procession - with a long umkhonto (spear), or stick.

It would appear that the whole performance was a half-dance and a precautionary measure, in case hungry reptiles lurked close by. Whenever the water proved too strong for some in the group, the hyena would reduce his repertoire to an almost motionless carol. At this point he would motion towards the beleaguered individual, for anyone in the group to offer a hand. The hyena knew his crossing routes quite well, so that his job appeared to amuse and captivate the audience more than to help with the crossing itself.

Those crossing this way invariably comprise men and women of different ages. In season, the water levels of the Limpopo regularly reach about chest height. Those eager to stay dry while crossing often take off most, if not all, of their clothes. One version of the story is that upon emerging on the other side of the river, members of the group are so closely together that it proves impossible not to steal gazes at each other's exposed bodies. Some women take license to pass comments about males they find particularly attractive. Some males, for their part, might invoke the idiom that 'ilihlo kalincitshwa' (the eye does not choose what not to see within its range) to fend off accusations of staring at half-dressed female bodies. Nevertheless, with the popularity of the practice at around the year 2000, some hyenas have come 
to be associated with the manipulation of their authority to elicit various favours from susceptible men and women. This is why those who still chose to cross the border this way are best advised to choose their impisi with particular care.

As I sat motionless in a minibus while taking in the details of this story, I recall that at first it sounded like a tale from a distant, unrecognisable past. I caught it midway, most likely towards the end. Perhaps because I was re-emerging from a short nap, the earlier parts of what I heard sounded like a strange dream. It also sounded like the subjects of the story represented a dying breed. The story and the circumstances within which I heard it could hardly be similar, although there were a few connections. It was about two hours before sunset. The storyteller was a woman a few years younger than myself. Let's call her Sihle. She sat next to the driver up front, while I sat immediately behind the driver, so that she was diagonally in my view from the other side of the minivan we were travelling in.

We were on our way to Johannesburg from the Beitbridge border. I caught the minibus at the edge of Musina town, at a popular but unauthorised hiking spot if you are heading 'down south'. Apart from the woman sitting in front, and two accompanying drivers who sat alongside me, I realised that none of the people in the minibus were acquainted with the drivers or each other. Many looked exhausted, as if they had been travelling for many days. It was a situation our transporters would later exploit rather ruthlessly. After I came on board, we ran quickly towards the edge of the nature reserve that engulfs Musina town, where the minibus refuelled and was almost ready to leave for Johannesburg. However, after a failed negotiation for potential passengers who waited there, we went back to Musina town. After another pass at the unauthorised hiking spot, we again stopped at the refuelling station for a while. Here, the driver collected his travelling fare while checking how many among us had their complete travelling documents on them. 
A direct interaction between the driver and myself ensued as he flipped through the pages of my passport. He was ascertaining if I had a permit to enter and reside in South Africa, as I had indicated to him. This would justify me paying 400 South African Rands $^{94}$ (about $€ 30$ at the time), a third of the amount he was charging those without complete documents. It was a half polite, half invasive conversation, one in which he started to announce to the group my travel history. The conversation revealed the regard omalayitsha sometimes have for their travellers. The dynamic suggested that at crucial moments, the generally polite interactions flip into aggressive, potentially violent instructions and demands.

The driver eventually came to the back page of the passport, which he needed to scrutinise in order to take down the kind of information long distance passenger transporters are legally encouraged to record. Here, he stumbled upon a detail that would perhaps alter how I experienced the rest of the journey. His wife was from the same district in Zimbabwe as myself. Hypothetically, and perhaps 'socio-culturally', this would make us fraternal relatives. We might meet again in the future, for instance. We might get to hear more about each other's families. We might even meet other people who know us both. In other words, we both discovered a relation, one that was an abstract, socio-cultural construction rather a concrete one, but one that nevertheless is still acknowledged and respected in cultural circles. It was this fact that compelled us to assume an automatic, if awkward, closeness to each other.

By the time we left the refuelling station, the tone of conversation had become more cordial. We shared snacks and cellular phone numbers. The banter had increased. Crucially, the chit-chat was helping me find leeway into the narrative the woman up front

94. This was a bit price in general comparison to the going rates those days. 
had been sharing when I woke up from my slumber. When my interaction with the woman and our driver had become more open and casual, we were steadily negotiating an uneven, unpaved back road that passes through the farms that lie west of the Southparnsberg mountain range. The omalayitsha we were travelling with had obviously calculated that the cost of 'bribes' to highway patrol police, fuel and tollgate fees combined would be too high for them to afford. Another explanation might have been that they were simply trying to minimise their expenses as much as they could while taking as much time as they could to get to Johannesburg, as it later became clear. I had been in a similar situation before, about five years back, when a cash-strapped umalayitsha took us along a slow back road on a knackered bakkie (pickup truck). So, although our present situation was unusual, it was not strange for me. Initially.

Things took a turn when we rejoined the main motorway around the Polokwane metropolitan area. This is where the first of the passengers asked to disembark, having reached their destination. It had been raining intermittently. The driver first complained that travellers were asking him to stop along a busy section of the road, something that constituted a dangerous and illegal manoeuvre. He would rather drive to a safe spot ahead, where there were authorised stopping points. At this time, darkness was starting to envelop us. The concerned passengers were getting agitated. As they voiced their surprise and frustration, one of the accompanying drivers exchanged seats with a traveller, and moved to sit against the passenger door, as if to guard it and block its access in case someone tried to exit by force. The atmosphere in the minibus became tense. My conversation with the driver trailed off. I felt uneasy and disorientated.

Along the N1, as the main motorway that cuts through South Africa from Musina to Cape Town is called, there are refuelling stations conveniently placed at regular intervals. One such 'garage', as they are called, is just off Polokwane city towards the 
south. It is here that we stopped. The driver suggested that we wait while he called a Zimbabwe-bound friend of his to pick up the now stranded travellers. He sounded sincere enough to keep our group calm.

While we waited, the driver pulled me aside and whispered to me that he was about to make some unpopular decisions. He would not stop until we reached Johannesburg. There certainly was no driver coming to return those that had missed their dropping-off points. "Whatever happens," he said before he rushed off, "don't feel that you have to say anything to defend anyone. Things may get difficult". "But don't worry", he squeezed my shoulder; "I got your back". With that he called everyone back into the minivan. My stomach went tight. As we got back on the road and the pattern of refused drop-offs repeated itself town after town into Johannesburg, I found that I was no longer able to converse with any of the drivers or even the woman sitting in front. My fear rested on what lay at the end of the journey. How many among us would actually reach their destination that night?

We reached Johannesburg with all passengers still in the minivan. Almost all of them had requested to disembark at some point or another. None of them had been granted their wish. However, none seemed to realise that they were now in the middle of what might be regarded as a kidnapping. The drivers had succeeded in allaying their anxieties. We were taken to Yeoville, a predominantly migrant inhabited part of inner city Johannesburg. As we arrived, a group of about ten men was waiting outside a dilapidated apartment building. The driver informed us that these men would be providing transport to each one of those who had missed their drop-off points. It was virtually all the people in the van. It was a well-orchestrated plan. With that he started assigning passengers to individual 'drivers' of private cars, and they would separately disappear into the apartment building. The private cars were in the basement 
level of the building, they were told. They needed to enter the building and proceed to the basement. All the passengers left the van, except for Sihle and myself.

The driver told me that he would personally drive Sihle and myself to wherever we lived. I sat in shocked silence. For a moment, perhaps three minutes, everyone left the van as drivers argued about who takes which passengers, while our driver hurried everyone to keep things moving. I asked Sihle what was going on. "These people have no idea", she whispered, "what has just befallen them". She seemed well acquainted with the situation. I asked, rather needlessly, what their fate might be. She looked at me helplessly, as if asking to be absolved of her knowledge of the designs of these hyenas, "they are about to get the biggest beating of their lives... and then they will be robbed blind!" At that point, our driver jumped back inside and looked straight through the back window as he reversed the minivan. Without so much as looking at either of us, he asked which one of us was dropping off first.

Hyena-name, practice, or both, or none?

An unrelated incident, but one that shines more light on the hyena concept and some of the social politics that animate it in Southern Africa, should help develop this discussion. Setting aside the gruesome nature of this incident, I wish to draw focus towards the link between the central figures of ritual practices, and the broader social understanding of the rituals themselves and of the social sphere they shape. I also wish to draw attention towards the ambivalent nature of these figures, but also the ambivalence of the rituals themselves. This, I believe, is of utmost importance in the understanding of the hyenas of the Limpopo and the kind of 'traditional' and contemporary life they prefigure, as my experience above and the second part of this discussion seeks to demonstrate. 
On 26 July 2016, a British Broadcasting Corporation (BBC) World Service news clip entitled; 'Malawian 'hyena man' arrested for having sex with children', caught my attention (BBC, 2016). In what the article described as 'horrific practices', an HIV positive man had been arrested on presidential orders for what the authorities described as defilement. The hyena man is known in his community for executing a 'cleansing practice', fisi, in which he is invited and rewarded by adults to sleep with new widows, barren women, women who just had an abortion or with young girls undergoing rites of passage to adulthood. The hyena sleeps with such women (and girls) as a way of driving away bad luck or potential calamity believed to hang over the community without such a ritual being done. I shall return to the arrest and the discourse that has framed it. Nevertheless, save for the man disclosing his HIV status, it is doubtful if he would have been arrested and the practice publicly denounced as it turned out.

The man in question had been the subject of a feature - 'Stealing Innocence in Malawi' - that was run on BBC's Assignment Magazine on 21 July 2016 (Butler, 2016). The feature focused on a traditional practice common in Southern Malawi, whereby girls are made to have sex with a 'hyena' once they reach puberty, as a form of ritual cleansing. Should the girls refuse, it is believed that a disease or some other calamity could visit the girl's family or even the whole village. Adolescent girls are routinely rounded up into a camp every year, where they are taught their pending duties as wives, not least how to please men sexually. 'Sexual cleansing' with the hyena represents the final stage of the ritual, which is arranged willingly by the parents. The custodians of this ritual believe that they are safeguarding the continued cohesion and preservation of Malawian traditional society from the malaise that comes with outside influences.

The ritual itself stems from an ancient belief that children are born 'cold', and in that sense, they are not dissimilar to a corpse. It is only at puberty that they achieve the 'heat' of adulthood. For 
girls, the transition to 'heat' must be induced by sex. Whereas in the past girls might have often reached puberty at a slightly older age, say 15 or 16 years, now they can be as young as 12 or 13 years of age. Then, the sexual initiation might have been the responsibility of a prospective husband. Nowadays, however, the job is given to a hyena, which in essence functions much like an appointed sex worker. As a practice that is sanctioned by the village, there is no shame or stigma attached to it.

There is, according to Father Clause Boucher, a Catholic priest and anthropologist in the village where the $\mathrm{BBC}$ documented the practice, a sense of secrecy around the practice that is nonetheless accompanied by a stubborn resistance at a broader level to end it. Those who are now advocating for its abolition complain that openly discussing sex is taboo in Malawian society, and yet rituals such as fisi simultaneously make reckless sexual practices a 'free for all'. Parents who were asked by the BBC if they would willingly send their daughters to a hyena expressed strong aversion, but conceded that the pressure from society proves too strong for them to oppose the ritual (Butler, 2016).

In Southwestern Zimbabwe society, hyenas have long been associated with defilement and cleansing rituals. According to Dr. Phathisa Nyathi, a preeminent historian of the customs and beliefs of the region, hyenas specialise in doing those tasks that are likely to defile ${ }^{95}$ the community were they to be done by ordinary people. A traditional practice that he picked as an illustration, in which the services of hyenas are needed and respected, concerns the burial of the dead. The belief is that whoever touches a copse risks defilement. Only known hyenas

95. Defilement is understood in the 'ritual' sense to mean that such 'victims' lose something of their self by venturing into taboo spaces. Defilement as was pronounced through the presidential order that got the hyena arrested represents the opposite of this, that is, ritual practitioners themselves are the source of stain on society. These two are dialectically linked as Mary Douglas (1966) seems to suggest. 
can execute the task of handing over a dead person from the living to their ancestors. This is done through the physical act of preparing a dead body for burial and the actual lowering a copse into its grave. Although a whole funeral procession washes their hands with umsuzwane, a special herbal mixture, after a burial ceremony as a miniature form of ritual cleansing, the special place of the hyenas as intermediaries between the living and the dead is acknowledged by offering them preferential treatment throughout the proceedings. After the ceremony, hyenas are offered a special traditional beer, utshwala bamakhuba, or amavulavula, to reify their importance to the burial rituals.

In Southern African contemporary street discourse, the idea of a hyena has taken on another meaning. Hyenas are sometimes associated with public figures that betray their station and the trust bestowed them by the community by converting things of communal value to personal use. Although this is a source of revulsion for many, such figures are simultaneously admired for their brazen and daring qualities. In that sense, as later discussion in this chapter shall demonstrate, identities and practices of hyenas appear to represent a kind of social politics that emerges in the liminal zone, at the boundaries of what is publicly accepted and what is frowned upon but tacitly acknowledged. Hyenas, thus, would appear to embody and articulate the contradictions of society. Hyenas seem to not only problematise and blur the line between the sacred and the profane, they also appear to question, as Mary Douglas (1966) discusses, why these distinctions are necessary and how they function in society.

\section{The hyena concept as identity and practice}

Throughout the rest of this chapter, I stay with some of the main protagonists in the contemporary economy and politics of assisted border crossings by using the hyena concept. I do 
so by opening up two main dimensions of ukulayitsha that are the subject of the above narratives. The first relates to the identity of transporters - a part of the izimpisi, or hyena collective I sketched in the opening chapter - and other key participants in the cross-border economy. I thus trace the selfconception of various mediatory actors involved in facilitating undocumented movement across the border of Zimbabwe and South Africa. The second dimension is about the performativity of hyenas and their practices. How can we relate these practices and experiences of facilitation to a broader social, politicaleconomic, ethical and normative context of movement across the Limpopo Valley?

To set these two dimensions into perspective, I argue that it is important to understand and explore the self-conception and identity of omalayitsha as hyenas, as this brings forward an aspect of the kind of work they do and how they understand it. I further argue that this self-identity should not be understood as simply limited to individual transporters and other actors working the Limpopo River. In order to fully capture the broader scope of what assisted border crossings are performative of, I propose that the idea of the hyena should be understood in the analytical sense pertaining to the entire context of ukulayitsha. The hyena concept can be thus understood as pertaining to those actors who actively participate in something akin to "conspiracies to avoid the law" (Heyman, 1998: 173), but also to those practices by which 'acceptable' forms of movement are negotiated, contested and reshaped. Ultimately, such identities and practices should be seen as constituting a whole within which the categories of political participation and belonging are decentred and rearticulated (Brambilla, 2015). The hyena metaphor is thus put forth as pertaining to a variety of actors and practices that constitute the economy of assisted border crossings, of which omalayitsha, as the focus and entry point of this research, are a significant part. 
This would concur with the understanding, as the empirical examples above show, of a hyena as both an individual person and/or extra-human surrogate, and as a ritual and/or broader practice, such as fisi. I will argue that it is through this the idea of the hyena as an equivalent to assisted border crossing, or ukulayitsha, holds better analytical promise. By establishing a connection between the self-conception of hyenas and their practices, it becomes possible to see not just the work of hyenas, but also their understanding of it as constituting $a$ ) responsiveness to domination and subjugation, and $b$ ) a rereading of political space from the point of contact between the governance of crossborder movement, and its actual arbitration and practice.

As the numbers of people seeking to cross the Limpopo at Beitbridge have increased and become mixed (Crush, Chikanda, \& Tawodzera, 2015) under a relatively heavily policed but informally managed migration regime, so too has the role of omalayitsha in assisting those without adequate official means. In the context of kukiya-kiya (make-do) and the associated political and economic decline that have increasingly swept into the very fabric of Zimbabwean urban life (Jones, 2010), scholars (Schierup, 2015, 2016, 2017; Crush, Skinner, \& Chikanda, 2015; Theron 2010; Segatti \& Landau, 2008) appear vindicated that the convergence between informalisation and migration irregularity is a postindependence phenomenon in Southern Africa. However, although it is true that the services of omalayitsha have increased over the past 15 years, it is equally true that izimpisi have been helping Zimbabwean and other migrants across the Limpopo since they first began travelling in large numbers to seek work in South Africa from the mid nineteenth century.

The role played by omalayitsha and those in their network in border crossing practices is perhaps therefore better understood as an evolved variant of the role that hyenas have played in this and other institutional arenas of SW Zimbabwean (as well as Southern African) cultural life, dating back beyond the colonial era. It is 
particularly striking that omalayitsha and other actors involved in assisted border crossings came to call themselves and each other izimpisi, especially in light of the attributes displayed by the hyena character in SW Zimbabwean and African mythology and folklore. This self-identity, including its parallels to folklore and myth, is an important starting point for a discussion of the social politics that accompany assisted border crossings in the contemporary period.

In embracing their ambiguous identities and roles, hyenas seem to intuitively communicate that their practices represent a key element of the reproduction of society itself, even if those practices may not be openly celebrated. Likewise, omalayitsha, as I have described above, refer to themselves and each other as impisi, or hyenas. They also refer to any other person they come into interaction with in relation to their work the same way. Within their fraternity, the identity is ubiquitous. They do this to acknowledge their identity and work, and where the interaction between work and identity places them in relation to other people, institutions, representations and ways of being. Such an embrace privileges their practices as performance of both their identity and the rituals of movement they are involved in as constituting key transformation elements of broader society.

Performance in this case becomes an important aspect, a paradigm, for rethinking the social politics and identities of the border (Parker \& Vaughan-Williams, 2012). The rest of this section explores the application of the hyena concept as it relates to the identity of omalayitsha and their practices. Later in the chapter, the discussion turns towards the economy of ukulayitsha, or the hyena economy, highlighting how its practices may be performative of socio-economic and political realities, and subject positions of the contemporary Limpopo Valley.

The above discussion has juxtaposed two cases that pertain to the hyena identity and its associated ritualistic practices in Southern Africa. It has provided general anecdotes of who hyenas are, and 
how they can be understood in context. In the following section, I use such understandings of the hyena to arrive at a discussion on the social politics of assisted border crossings. To do that, I first review some understandings of the hyena in African folklore which will help in the depiction of some of the practices and pivotal actors in the Beitbridge border-crossing scene. The implications of the hyena concept for identity, embodied practices and performativity are integral to the social politics I allude to. The aim is to demonstrate that hyenas are middlemen who, through their practices, significantly influence the "doing, undoing, and retracing of the border and other social boundaries in time and space" (Brambilla, 2015: 25). In this sense, omalayitsha, as quintessential hyenas, help uncover on one hand, the agency of a wider pool of actors participating in the economy of assisted border crossings. On the other, they illustrate how facilitation is indicative of the contestation around categories of belonging, their meaning and their naming. The hyena economy, of which border practices are a significant part, is thus itself performative of these contestations.

\section{Hyenas and the social politics of ukulayitsha}

Impisi is a scavenger otherwise known as a spotted hyena. Biologists refer to it as the crocuta crocuta. The hyena plays a rather strange role as a menace, trickster and fool in African folklore, including that of the Nguni people of Southern Africa. There are important elements of this characterisation that make the hyena work well as a human surrogate in contemporary Southern African traditions, particularly those found among SW Zimbabweans. Quite like the coyote of Mexican lore, the hyena figure has been a source of considerable wealth in Nguni folklore, cultural politics and embodied practices. Across folklore in general, the hyena is assumed to be a 'natural symbol', with a meaning that is deemed 'transcultural', and an anthropomorphic role seen as generally uniform (Sapir, 1981). My research finds that the hyena is of a 
multivalent nature, whose past in African folklore associates it with greed, foolishness and menace; in struggles over cultural norms and meaning, with duplicity and Machiavellianism; and in embodied practice, with daring adaptability and opportunism.

\section{Hyena in African mythology and folklore}

The impisi, also called the laughing hyena, for its giggling and howling sounds, is famed for its poor vision, good listening and smelling capabilities, a strong odour that is said to proceed from its anal glands, and for sleeping in natural caves and enlarged burrows usually dug by other animals (Frembgen, 1998). As the most common large carnivore that is also likely to hang out in relatively big packs, the spotted hyena is a rather social animal (Mills \& Hofer, 1998). It is not just openly competitive rather than cooperative, it is also a highly successful hunter and scavenger (Kingdon, 1988). Its reputation for success is said to be mostly built on flexibility and resourcefulness, thus the hyena tends to display greater plasticity (Kingdon, 1988) in that it can hunt, scavenge or forage alone, in small parties or in large packs. One of its more distinct features is its ability to move over long distances, sometimes at relatively high speeds (Mills \& Hofer, 1998).

As a human surrogate, it is generally depicted as greedy, gluttonous, ugly and foolish, as well as sly, powerful and dangerous - hardly a positive light. In 1935, Enerst Hemming way would write about "fisi, the hyena, hermaphroditic, self-eating devourer of the dead, trailer of calving cows, ham-stringer, potential biter-off of your face at night while you slept, sad yowler, camp-follower, stinking, foul, with jaws that crack the bones the lion leaves, belly dragging, loping away on the brown plain..." (1935: 34). We have, also, a figure that is "accustomed to live in the sepulchers of the dead and devour their bodies" (White, 1954: 30), and one that is also associated with sexual ambiguity (Magel, 1984: vii). 
The hyena's negative depiction is actually ubiquitous for much folklore. We are told that, in the transformative rituals of the secret societies of the Korè of the Bamana in Mali, people 'perform' the hyena by putting on zoomorphic masks and playing dramatic roles, both relating to the dirty habits, trickiness and nastiness of the animal, sometimes with a deliberate aim of inspiring fear among the participants. It would appear that the hyena's negative depiction reaches its height through its caricature by the Gèdèlè cult of the Yoruba, who, by putting on the korikò (the mask of the spotted hyena) at the end of the èfè (a ceremony) at dawn, seek to communicate a simple but effective message. The hyena is a scavenger that shows up after the hard work has been done and eats up everything (Lawal, 1996). It clears even the bits and bones left behind by big killers. Where the hyena can be seen, there can be nothing left afterwards. Nevertheless, in the mythology of the Tabwa of east central Africa, the spotted hyena is a solar animal that brings the sun to warm the earth (Frembgen, 1998), even as the Kujamaat of Southern Senegal and some in Tanzania associate it with witchcraft, seeing as they call it the wild animal 'of the night' (Mills \& Hofer, 1998; Sapir, 1981).

We have, therefore, a strong depiction of the hyena as a social outcast. This depiction should not surprise, because it carries important connotations not just about boundary marking in identity making, but also about the ambiguity of identity categories as well. This is important in the consideration of the doing of 'border practices' (Parker \& Alder-Nissen, 2012), by which the paradigm of performance is used to discuss how everyday processes constitute, sustain and modify borders, people's lives and social relations in the cross-border space. The duplicity, menace and scavenging qualities of hyenas are, therefore, significant in a discussion of the identity and practices of omalayitsha in the politics and economy of assisted border crossings. 


\section{Hyenas and ukulayitsha in the Limpopo Valley today}

In the present-day Limpopo Valley, the term impisi takes on a wider array of meanings that pertain to the human surrogacy of the spotted hyena. Three of these meanings are relevant in relation to the facilitation of undocumented movement across the Limpopo River in an environment of active and stringent policing of undocumented movement, and of general violence and criminality (Musoni, 2012). The first relates to a person hired as a guide by undocumented migrants to both cross the border and to negotiate the terrain, someone like Msunduzi. The second relates to a person hired to help his or her clients directly or indirectly negotiate, often through extra-legal but not necessarily illegitimate means, bureaucratic requirements imposed through official border enforcement. The third, connected to the second, relates to the mediatory role of the hyena in the formalisation of residence or legal status, which is also about the negotiation of present and future identities and subjectivities, what others have called the politics of becoming (Brambilla, 2015; Brambilla, Liaine, Scott, \& Bocchi, 2015). Each of these colloquial references to the hyena analogy are diffused all along cross border movement. Even if it is the first use of the metaphoric figure that is often narrowly understood to relate directly to assisted border crossings, all three uses are also applicable to the entire spectrum of cross border movement, including its facilitation historically and in the contemporary period.

a. Hyenas as guides and masters of the border crossing process

Like in the story that begins this chapter, a hyena is one who surreptitiously guides undocumented migrants across the Beitbridge border. In the earlier times, when undocumented African migrants first sought employment in South Africa, hyenas developed a reputation for being experts at guiding migrants across the Limpopo River away from the legal port of entry, where only those with requisite documents would be 
allowed to cross. They developed knowledge, networks and expertise regarding the terrain they traversed, including the dangers they might face and overcome. In the passage of time, the facilitation of undocumented entry into South Africa has evolved, so that the term impisi has been taking on a broadened meaning. Today, undocumented movement can proceed just as well over the bridge with the help of the same facilitators.

Omalayitsha, who have assumed the identity of impisi, have thus - through their work and networks - evolved the meaning of the metaphor to refer to a bigger array of actors involved in the phenomenon of undocumented cross-border movement. In this regard, and because of their knowledge of the perils and possibilities of the border and the road, they are the present-day masters of the cross-border terrain and the challenges they entail.

b. Hyenas and the negotiation of bureaucratic requirements

For those who lack the requisite documents from cross-border travel, or those that seek to bypass the arduous requirements for documentation that often result in delays and blockages to legal or documented pathways to cross-border movement, hyenas have become indispensable. Although both hyenas and the people they interact with while facilitating clandestine cross-border movement may feel and accept that their activities are seen as illegal, improper or contrary to the prescribed civic order, they may also feel that crossing the border in this way is neither immoral nor criminal. On the contrary, actors involved in these practices may in fact feel that they are making claim to a better life as a matter of pragmatism (Chatterjee, 2004). They may be very appreciative of the help of hyenas in accessing or breaching what they may feel is an apparatus of exclusion. Hyenas have the tacit knowledge and mastery of the rules of negotiating and accessing not just the state bureaucracy at the border, but also the structure of modernity upon which the immigration edifice is built; a structure made up of successive binaries of exclusion/inclusion. 
In the same vein, however, the devious and predatory attributes of hyenas underline the risk and violence that often accompanies border practices on one hand, and the contestation of the prevailing/dominant order on the other. While some of this violence remains as a legacy of past and present political and economic systems etched onto the social landscape, part of it has to do with the very acts of contestation and resistance that form part of the everyday encounters that take place at or around state borders. In this case, the duplicity and opportunism of hyenas may be seen to relate to the contestations and contradictions that frame their practices, whereby the social value of hyenas to those who seek and utilise their services is infused with the danger and hazard of the context in which these relations take place. This is in line with not just the ambiguity that surrounds the hyena figure, but also its appropriation and mobilisation for patently personal, narcissistic ends.

Regarding the ambiguity itself, almost all societies have traits, characteristics or practices that mirror the Janus-facedness of the hyena figure. Just as in the fisi rituals, such practices are given to ambivalent figures that society entrusts, often through sheer necessity rather than deliberately, with the dubious responsibility to execute. In Sons of the Shaking Earth, Eric Wolf (1959) proposes the concept of the 'army of the disinherited' to describe how characters similar to hyenas are representative of a social condition that is always shifting, and one that forces them to occupy the liminal passageways of society, remaining non-committal to any one position or spot. Society has done this by abdicating its "informal and unacknowledged business", so that hyenas take on the responsibility of brokering and carrying the "multiple transactions that cause the blood to flow through the veins of the social organism", weaving with their fingers the "network of social relations and communication through which alone men [can] bridge the gaps between formal institutions" (Wolf, 1959: 243). 
The hyenas of the Limpopo fit this description. State officials and broader societal actors who maintain close links with hyenas may benefit in various ways from these links, just as they police and sometimes vilify the same hyenas as a social malaise. This is the case with strategies of informalisation from above, whereby the difficult task of securing protection for migrant workers, say through work permits and social benefits, is abdicated to ambivalent middlemen, who, as much as they bridge the gaps between formal institutions, they also partly work to reproduce the same institutions and perpetuate their injustice. For the vulnerable, the appeal of hyenas is largely predicated on the immediate issue of basic survival.

The relation between state officers and hyenas, and by extension between formal institutions and social practices is, thus, ambiguous. It takes the ambivalence of hyenas to establish, as Wolf suggested, the vital link in the cross-border movement chain that acts as a bridge especially between the institutions of (im)migration and labour. To maintain a façade of a coherent structure or body, society (read modernity) maligns the hyena, relegating him and his practices to vice and immorality, even crime. Hyenas and the pragmatics of everyday life however debunk this social pretence. By confronting the contradictions in the structures of modernity, they appropriate its grammar in order to avail linkages across categories, across difference and through barricades.

\section{c. Hyenas and the politics of becoming}

The role and place of facilitators in the 'regularisation' of various migrant statuses, things and beings, such as in cross border travel, transporting, work and residence, are aspects of the practices of hyenas that may not be immediately discernible, but warrant closer attention. Itself a social process and a part of the negotiation of bureaucratic requirements, the regularisation of status is an aspect of movement in which the cultural capital 
of hyenas as middlemen is increasingly sought after. Hyenas 'regularise' beings, goods and mobilities by harnessing their own skills, experience and knowhow to access state bureaucracies on behalf of relevant 'clients'. Nevertheless, various acts, practices and attempts at regularisation reorient the border, cross-border movement, migration and the actors involved in its processes along broader dimensions.

Nowhere else is this role of hyenas more evident than in the convergence of holder-less passports, hyenas and immigration officials. In Chapter Six, I elaborate more on this phenomenon of 'ghost' passports. As will be clear from this analysis, the performance of border practices by omalayitsha and others, which is captured and illustrated by the figure of the hyena, contributes to a reconfiguration of the political and the social both at Beitbridge and across a wider political-economic context.

In this sense, an interpretation of the ambiguous incarnations of the izimpisi, or hyenas, show that omalayitsha are at the centre of the border's competing meanings. The practices they engage in are partly ambivalent, with the resulting identities rendered in constant flux. Nevertheless, these engagements do privilege the agency of both undocumented migrants and hyenas, often obscured by dominant discourses as silent or invisible 'others'. Such engagements re-centre them as protagonists of a counterhegemonic discourse and practice. By highlighting the contestation that accompanies both identity and meaningmaking in movement, they (the identity and practices of hyenas) also contest understandings of belonging and non-belonging. They help us re-visualise space and society, especially the issue of social categories. They also help in the understanding of the dynamism that attends these contestations, suggesting that struggles of meaning are also contingent on time and place. What the phenomenon of ghost passports and other characteristics of the hyena economy discussed below suggest is that the attempt to reimagine the border and associated identities 
is not an exhaustive one, but one that is solely based on ongoing encounters that leave the meaning of the border and the identities it spawns changing, open and unfixed.

\section{Identity, boundary-marking and categories of meaning}

The arrest of the Malawian hyena was followed by a debate ${ }^{96}$ on the exploitation of children at the hand of patriarchal Africa. The discourse predominantly juxtaposed their 'suffering' with the much-lauded idea that children are the 'future'. Levi Kabwato (2016), in his analysis of the discourse just mentioned, provides a parallel that helps the point I seek to make regarding the hyena identity. Reflecting on 57 undocumented children of Malawian origin who were intercepted in Rustenburg, South Africa, while being transported in a delivery truck to Johannesburg from Blantyre, Kabwato suggests that there is no difference between the children who were being 'trafficked' and the girls that undergo fisi initiation in Malawi. In both cases, he argues, society is either enabling these practices or silent about their existence, so that the hysteria about, and the condemnation of, the practices of fisi or ukulayitsha are disingenuous. To drive his point further, Kabwato continues, "...we have no moral authority to isolate one hyena from the cackle that is Malawi in its entirety ... we are all hyenas" (Kabwato, 2016, webpage).

In connecting the 'army of the disinherited' with the rest of society, Kabwato helps the depiction of the hyena identity that pertains the social politics of facilitating undocumented movement across the Beitbridge border. The array of actors

\footnotetext{
96. The debate proceeded mainly on social media, primarily on Twitter and Facebook. Levi Kabwato, who was significantly involved in the debate, shared some of his thoughts on his blog which appears here: https://thinkingmalawi.wordpress. com/2016/08/01/we-are-all-hyenas/\#more-212
} 
actively participating in the hyena economy demonstrates how society enables and benefits from and through undocumented movement. A big part of the migrant labour system can be said to be a hyena system, in which omalayitsha and other 'illicit recruiters' perform that system's unacknowledged business.

However, rather than a knowing silence around the existence of, and involvement in, undocumented movement and its crossborder facilitation, there is instead, among the hyenas of the Limpopo, open conspiracies to work 'with' and around the law. I argue that these conspiracies, as much as they are fraught with risks, violence and exploitation - Machiavellianism - they are also often seen as the most plausible means for cross-border movement for the marginalised. Further, they suggest a claim to the hyena identity by which the actors, not least omalayitsha, seek to reinsert themselves into the participatory politics at both embodied and social levels. It is also through this agency that the boundaries of belonging shift, and the meaning of categories such as documented and undocumented, outsider and insider, legality and illegality are negotiated, contested, transformed and translocated. In the final analysis, it should not be lost that this business of conveying undocumented migrants across the border, although it offers avenues for survival and for crossing social categories, also works to perpetuate ongoing systems of exploitation and domination.

\section{The disinherited}

When I asked Msholozi one afternoon why they call themselves and each other hyenas, he laughingly threw the question back at me. I speculated that their vehicles represent a spectacle that is not unlike what I imagined a hyena to be about, especially at night. The backs of their vehicles appear to sit low on the road on account of their heavy loads, so that their headlights always appear to dazzle, as if they were the eyes of some wild 
cat dashing across the African night. Besides, I went on with my speculation, momentarily carried away, they are always drawing a trailer, much like a hyena dragging a carcass. To this he laughed rather long and hard, perhaps more at my naivety than at the idea itself. When he had composed himself, he started to relate to me how omalayitsha are hard workers. "We can't help that there are people in need of our services", he told me. "Or that there are those who accept the money from you", I countered, in reference to regular backhands that grease the wheels of the hyena economy. All he cared about, he continued, is to make sure that he does not betray his customers' trust while making a living out of serving them.

It was a short exchange. However, its ramifications are wide. The people in need of the services of omalayitsha are presumable undocumented migrants and their households on both sides of the Limpopo. I will add to this list, border officials, border farmers of the Limpopo, various economic sectors that have come to depend on the informal labour of migrants, tardy bureaucrats and politicians who appear content to maintain a self-interested silence regarding the presence and exploitation of informal migrant workers in the South African economy, the neoliberal regime on which such contemporary capitalisms are modelled... the list goes on. That Msholozi zeroed in on the issues of pragmatism and reputation, however, also suggests that he also battles with the identity that his work bestows upon him. It takes us rather quickly to the common notion that omalayitsha have to live with the fact that, for the many people that seek and utilise their services, only a few like or trust them. In the end, they too need to make a living. They are, indeed, the army of the disinherited.

Although hyenas are hard-working, much like omalayitsha, their industry is often tied to theft and scavenging, giving them the kind of ambiguity that defies categorisation. Thus, hyenas, both omalayitsha and their extra-human anthropomorphs, thrive, metaphorically and symbolically, at and through the margins 
of society (Abrahams, 1985), "in the nooks and crannies, on the frontier between the human and the animal worlds", belonging nowhere, from which place they are able to act as if no place is out of bounds (Abrahams, 1998: 13). Mary Douglas (1966) concurs that the ability of figures like the hyena to defy categorisation imbues them with the power to transgress as well as appropriate these boundaries. Thus, the ambiguity of hyenas mirrors the ambivalence of that status and power that comes with figures like fisi, who are frowned upon and sought after in equal measure in human society (Gaudet, 1992). As the perennially deceptive and yet powerful dupe, the identity of the hyena prefigures an interesting analogy for boundary marking and meaning-making in cross-border movement in the Limpopo Valley.

Hyenas seem to accept that as much as they wield power over a significant part of cross-border movement, they are also disliked as much as they are needed. Both their ambiguity and significance uncovers the social contradiction regarding acceptable and unacceptable forms of movement, which the disarray of experience questions. They thus use that power to transform social boundaries, thereby reordering notions of social purity. This they do by not only embracing the hyena category, but by also using it to weave a web that connects different parts of society. Msholozi also shared with me that state officials who police them are called osompisi - those who hunt after hyenas an apt descriptor of how public officials are already a part of this ambivalent web that is the fabric of the hyena economy.

\section{Subverting the symbolic order}

Here I wish to connect to Mary Douglas' (1966) discussion on the identity boundaries that society creates to validate itself and its various practices. In a world of documented and undocumented movement, hyenas have come to be formidable players that challenge its symbolic order. Most of the ritual 
practices involving hyenas, including assisted border crossings, appear to rely on Douglas' particular distinction between the clean and the polluted, so that hyenas play the double role of both highlighting this distinction and transgressing it. If seen in this way, omalayitsha highlight the distinction between formal and informal cross-border movement only to transgress and transform the very distinction. This is one way in which they challenge categories and their limits, and contest the process of making meanings about movement and its processes.

If assisted border crossings function like rituals of initiation, then the mediation of movement is like the right of passage the dispossessed undergo in order to attain a state of restored identity; the border acting as the moment to scrutinise this process of becoming. Mary Douglas writes that "the man who comes back from these inaccessible regions brings back with him a power not available to those who have stayed in the control of themselves and of society" (Douglas, 1956: 96). At the border, all who traverse this space partake in the process of becoming. One might suggest that such power is seen in how the politics that accompany this process involves the changing meaning, limits and sociality of the border and of belonging.

Economically speaking, it might be interesting to also consider how assisted border crossings, as livelihood practices, intersect with social and microeconomic realities of those participating in cross-border movement itself. The demarcations through which territorial and social borders are enforced, especially the bureaucratic rituals by which acceptable forms of movement are continuously reinvented, invite the language of facilitation to dialogue with the forms of exclusion upheld by these demarcations. As a sight of social networking between various actors, practices of facilitation, such as assisted border crossings, create a unique mobile, cross-border and entrepreneurial experience. These interactions and networks play a role in societies built around migrant labour. I have suggested that 
they may structure specific dimensions in the negotiation and reformulation of identities. It may be said that through facilitation, omalayitsha continually constitute and recreate mobile sociality as part of a dual entrepreneurial and political process of becoming. Their ambiguous identities and resistance politics do not, however, allow for a precise or even vectored estimation of the extent of the new meanings they bring to the categories they contest. It is enough to say that they broaden or alternatively flatten them to offer new pathways for agency, for political participation, for justice and for belonging.

One way this happens is through the manner in which the hyenas of the Limpopo challenge the cultural invisibility of social outcasts (Rosaldo, 1993), including both omalayitsha and undocumented migrants. Hyenas illustrate how, even if society silences, obscures or ostracises them, their position as the in-betweens is both empowering and integral to the very functioning of that society. Their ability to challenge such attempts of silencing them suggests that their practices are performative of the particular socio-economic realties and subject positions that escape that order, or fail to fit into it.

\section{Risk, obligation and reciprocity in assisted border crossings}

A central question to ask is: What might be some of the aspects of facilitation that are illustrative of the hyena economy and its performativity? Among many, this section identifies and discusses exchange and reciprocity as a function of facilitation, 'eating' as a signifier of social proximity and access to resources (and lack thereof), and border crossings as movement through social categories. As some of the strongest material pillars of this economy, these have become imbued with symbolic and performative meaning. 
Engaging in such practices of exchange and reciprocity that characterise the hyena economy involves both risk and obligation. The tension between the two might be said to be emblematic of the convergence of the efficacies of border enforcement infrastructures and the kinds of sociality that that can be associated with ongoing processes of irregular movement and of informalisation (Roitman, 2004). Whereas civic authority systems insist on apparatuses of legibility, on bureaucratic procedures, as well as on documentation, social fragmentation is partly a critique of such systems of civic authority. This is because, in Africa, such systems are modelled, on one hand, on a racialised colonial apparatus designed for extraction, subjugation and domination (Blundo \& Olivier de Sardan, 2006), and on the other, on radical changes ensuing from political and economic decline more characteristic of neoliberal informalisation and authoritarianism, and Zimbabwe is one example of this.

When it comes to the facilitation of cross-border movement, hyenas and those they interact with must necessarily engage with this context and seek to navigate its challenges by employing the various practices that reside within and are informed by it (as discussed below). Such a context is, therefore, one of risk if the facilitation of undocumented movement seeks to challenge some of its parameters. However, if risk suggests the threat of violence and exclusion that the border socially, spatially and temporally represents for the disempowered, some of the practices characteristic of the hyena economy may be viewed as uncovering various kinds of openings, possibilities, entries and closures. These appear when the social politics of assisted border crossings meet the enforcement processes of the territorial border.

Facilitation, or the politics of negotiating this contact, confronts this risk within, among other things, the inherited attitude towards state authority in the post-colony (Blundo \& Olivier de Sardan, 2006). As a form of authority that is built from the 
top and imposed on citizens (or 'subjects') and thus carries little popular legitimacy, its function often carries with it a sense of despotism. Social fragmentation, including informalisation, has added to this challenge, so that the processing and governance of movement appear to involve practices that carry forms of brutality, accumulation of material wealth and prestige (Njoku, 2005).

In line with both this despotism and social fragmentation, the relationships that constitute contact with this regime of movement appear to flourish within an air of inevitable deference, malleability and resistance, as those involved engage in them while seeking to make a difference in their lives in such a context of deprivation (Butler \& Athanasiou, 2013). Such dispossession blankets virtually all border actors who are invariably economically disenfranchised. State actors are particularly vulnerable to economies of reciprocity by virtue of their contradictory position of access to authority and of economic lack, and the opportunities this ambivalence in their status avails. In the contemporary setting of Beitbridge, such practices highlight how the movement of people across the border is increasingly embedded in a similar flow of social relations.

\section{On obligation, reciprocity and ukutshokotsha}

The social relations that accompany the facilitation of undocumented border crossings are thus partly made visible by feelings and expectations of obligation, framed within a general climate of reciprocity. For the sake of analytical expediency, I seek to avoid a discussion of the exact taxonomies obligation and reciprocity might take. It is sufficient to say that obligation and associated forms of reciprocity are difficult to systematically connect to specific motivations that arise in the everyday footing of border crossings. The critique is that without an adequate window into the specific dimensions of social relationships involved in exchanges that accompany the negotiation and 
facilitation of assisted border crossings, it may be more fruitful to limit the focus to the kind of performance involved, than to explore the character of the social relationships implicated in the exchange (Appadurai, 1986; Smart, 1993). This helps avoid emphasising the distinctions between various kinds of obligation that accompany reciprocal behaviour and other exchanges, or alternatively to collapse distinctions that may exist by establishing a general connection between the performances of reciprocity to their specific motivations. There are, however, consequences for this formulation.

I earlier stated that the legitimacy of civil authority in postcolonial state institutions is significantly contested, and that the certain attitudes of citizens to this authority stem from a general position of alienation and adversity, so that the relationships engendered carry a sense of a combination of resistance, deviance, deference and plasticity. Regarding the forms of obligation and reciprocity that accompany the negotiation of undocumented movement, several observations can be made regarding exchange of material goods, also known as gifts. Firstly, following Smart (1993), it may be said that while those who exchange gifts during negotiation may not explicitly acknowledge the performance goals of the exchange, this does not mean that they are not aware of the instrumentality of such exchanges. Secondly, the exchanges that I shall discuss shortly should not be seen as equal, or as always reciprocated. The context in which they take place is integral to this imbalance. Also, obligation and the kinds of reciprocity it generates are not concrete qualities that can be measured. To restate Smart, they are a socially negotiated outcome. All these things mean that the task is less to discover the essential nature of obligation and exchange, but rather the form of the exchange, where the "explicit recognition of the goals is excluded from the performance" of the exchange (Ibid: 389). 
Essentially, the exchange of gifts and associated reciprocity act as a social guarantee where legal ones, in the form of documentation, may be absent. Reciprocity, and whatever other names it may be called by, can be considered an embedded practice that helps expedite procedures in border crossings. Its unique feature is that it happens in the context of genial, convivial relationships that use the trust they generate to trump both official border enforcement and to insulate against betrayal and other forms of deception.

The strength of these relations is uncovered when hyenas must negotiate with strangers. In the absence of trust, and the sense of geniality that accompanies reciprocity, hyenas use the cultural capital they have accrued working the border to pursue their facilitatory tasks through a practice called ukutshokotsha. Unlike kukiya-kiya, by which actors do whatever they can to put a deal together (Jones, 2010), or haggling, a negotiation for a price at the open market, ukutshokotsha is the specialised art of attaining short term goals (opening the way) where relations of acquaintance may be missing between omalayitsha and those they are negotiating with, but where absence can be made up for through the performance of trustworthiness.

As a socio-cultural practice, $u k u t s h o k o t s h a$ is generally associated with playing card games, particularly poker. Ukutshokotsha literally means 'to shuffle cards', which is the art of bringing them into a random, if strategic, order. Ukutshokotsha, however, should not be understood as the art by which omalayitsha, local fixers, and state functionaries - izimpisi - attempt to confuse or trick each other in their negotiation of cross-border movement. As a way of rearranging an initial order, ukutshokotsha should be understood as a contingent performance by which izimpisi seek to bring about a favourable outcome from their everyday and ongoing encounters with the border space in order to facilitate border crossings. Ukutshokotsha especially applies where respective parties try to influence a negotiation process in their own best interest in the context of tenuous relations of 
acquaintance and trust. This view further develops Sandro Mezzadra and Brett Neilson's (2013) concept of 'border struggles' which captures a related social reality and border actors rely more on contingent everyday social relations than on institutional border enforcement to gain outcomes across international state and other socio-economic borders.

While it may sometimes involve bribes, gift-giving and other forms of exchange, ukutshokotsha is often mobilised and functions as a performance to 'prove' the competence of a hyena where relations of acquaintance are deemed weak or missing. Ukutshokotsha, therefore, still relies on a certain level of manifest trustworthiness in that it is often initiated and engaged in by omalayitsha through whose cultural capital as 'known' transporters make it work as a stopgap measure where otherwise longer and durable relations that facilitate genial reciprocity would suffice. Ukutshokotsha plays a social function that mimics more durable relations, even though it takes place within palpable time constraints and heightened unpredictability. The function of these relationships, in so far as they aid the negotiation of undocumented movement, relocate the enforcement of the border towards other social forms, functions and practices. It is this malleability of the border that sometimes reproduces it as efficacious and permeable.

\section{Conviviality and deference in exchange}

At the beginning of this thesis I chronicled my experiences as I shadowed Msholozi. I referred to an instance where Msholozi used his 'face' in place of his passport in order to cross the border from South Africa to Zimbabwe. Where he was required to show identity and travel documents so as to be cleared for crossing, I suggested that he 'talked' with state officials manning the exit gates. What I did not mention explicitly is that on that day, he did not have to offer anything other than warm greetings and 
chitchat in exchange for his passage. I did mention, however, that as a matter of routine, Msholozi and other transporters often call state officials working at the border way in advance, in order to verify if those officials will be working at the particular time that they plan to cross the border. This they do because they want to make sure that when they cross the border, they will meet and interact with those officials that they are acquainted with.

Acquaintance, however, does not mean that omalayitsha gain free passage at the border. Transporters such as Msholozi, who through the many years they have been crossing the border, have built relationships with state officials and other people who help them move people and goods across. As part of this network building, they exchange gifts, in the form of money and other things, with each other. Msholozi, for instance, can leave something - money, fast food or other meals, or some other gift - without an immediate expectation of reward. Conversely, those that Msholozi might pass on the road and especially at the border, might ask him to leave something, even if it is not in immediate exchange for anything that Msholozi might need at that time. In return, both parties might call in a favour at some other time. Indeed, they - in this way - deepen their relations by employing the tactic of deferring reciprocity and blunting it of its instrumental edge.

These tactics of deferring reciprocity work to downplay both the instrumentality of the exchange (which is to open the way for undocumented passage) and the unequal relations (between state officials and middlemen). This often succeeds in infusing the relations within which they function with conviviality. Transporters frequently use these kinds of relationships to evade the kind of scrutiny that often accompanies accusations of bribery, or to cater for those times when they might genuinely have nothing to give in exchange for a needed favour. In that case, the sense of obligation and genial reciprocity that these relationships are built on is held intact through trust built 
over a long time. The privileging of social relations over dry bureaucratic formalities of border crossings, again, reinvents the border as a malleable social form, and as enabling the agency of the marginalised which reinserts them into participatory politics, albeit through socio-cultural avenues.

\section{Ukutshokotsha as gift exchange}

At this point, this discussion has veered closely to a classic anthropological subject, namely the nature of the gift and its relation to other forms of exchange. The gift, as initially argued by Marcel Mauss (1954) and later by Pierre Bourdieu (1977), is presented spontaneously, disinterestedly and voluntarily, although it simultaneously creates an obligation for reciprocation if the parties involved must retain a position of equality. According to Bourdieu, the obligatory part of gift exchange must remain unacknowledged if it is to truly define the nature of the gift. This self-deception, what Bourdieu calls misrecognition, ensures that the system of gift-giving holds. Following Alan Smart (1993), I wish to suggest that while the assumption that the gift and other forms of exchange will be reciprocated appears to hold in the Limpopo Valley, such obligation to reciprocate takes an indirect, relatively deferred nature. Deferred reciprocity as I have outlined above brings into focus the idea of both misrecognition in exchange and obligation in reciprocity. If obligation in exchange is present but temporally dispersed by the deferred nature of reciprocity, it follows that the explicit recognition of instrumental goals in exchange is peripheral to the performance of gift exchange itself (Smart, 1993: 397).

This bracketing out of the outcomes of the presentation and of motivations as open questions in the exchange can be contrasted with the moment when omalayitsha must negotiate passage with officials they do not know. With their knowledge of the 'system' at the border and their experience, omalayitsha sometimes find that 
they have to convince either public officials or the people they are helping that they can negotiate a successful crossing, even without prior relations. Here, they have recourse to ukutshokotsha, an expedited way of building enough trust to allay the perceived risks of negotiating with 'strangers'. Whereas both Mauss and Bourdieu have argued that 'the truth of exchanges', that is, the intention to oblige, as well as the expectation of immediate reciprocation, devalues the gift and represents it instead as an attempt at ingratiation, I suggest that this essentialism needs to be questioned. At Beitbridge, ukutshokotsha provides another layer in the apparent absence of trust relations and genial reciprocity by which exchanges in the facilitation of movement still proceed within tight time constraints. Even if these may include a visible and direct exchange of gifts, they do involve ukutshokotsha as a performance that proves the competence of the mediator as a hyena, and as an avenue by which omalayitsha can manifest trustworthiness where they have no previous relations to bank on, and not enough time to build them.

Ukutshokotsha does not always work. I have observed how omalayitsha can sometimes end up waiting long periods of time while officials and their co-workers withhold interaction with them, or where their goods get confiscated, or their passengers get arrested for various immigration infringements. Here, other factors, such as sudden changes in procedures, miscommunication and the failure to execute ukutshokotsha well may be the reason that the expedited practice of obligatory exchange and reciprocity within the hyena economy fail. Ukutshokotsha demonstrates how, as Smart (1993: 405) has suggested, these exchanges may be seen as contingent performances, rather than as repetitions of socially prescribed mediation behaviour within the society of the mobile that I have focused on.

As contingent performances, and notwithstanding the fact that they sometimes fail to produce the desired outcome, relations of deferred reciprocity and ukutshokotsha thus present cross-border 
movement as a domain of negotiated possibilities. It is these performances that illustrate the politics of becoming, where dynamic social relations that offer new openings, possibilities and closures usurp the more or less consistent patterns of set border enforcement rituals.

\section{'Eating': commensality, social proximity and access to resources}

Gift exchange is also common in the arena of food and its consumption in social settings. Other than what food means for the sustenance of life, I wish instead to focus on eating as well as the associated sharing of cooked food, which in social terms may be seen as a performance. As Vannini (2008) has suggested, eating is a ritual that involves actors and an audience. It is in this fundamentally interactional context - which may involve eating the same type of food, sharing from the same portion or setting, or exercising certain bodily functions - that simultaneously hints at intimacy. Commensality among those that travel with omalayitsha is a distinct indicator of familiarity, empathy and exchange. At the beginning of this chapter, I related how in the minivan I travelled with on the day of the 'kidnapping', the food I shared practically as well as symbolically weaved me, albeit temporarily, into the circle of omalayitsha and Sihle.

It is striking that while sharing food, as a performance or the creation and sustenance of relational bonds, is a widespread practice among omalayitsha and those they spend time with, it is not necessarily a spontaneous ritual that is universally practised. There is a way in which practices of eating can mirror the structuring of power relations in a social setting. My interest lies with the way the selective sharing of food can be helpful in symbolising similar relations of power and of access to resources. David Cheal (1988) has discussed in The Gift Economy how gift exchanges are reflective of personal ties, and how they suggest 
shared social positions or spaces for the parties involved. I have observed how food sharing between omalayitsha, travellers and public officials acts as a way of cementing social bonds within the hyena economy.

If food sharing is a signifier for close relations, selective food sharing is performative of the weaknesses and lack of durability of the relations that take root in the undocumented economy. Even before the situation had turned sour in the minivan we were travelling in, those who had shared in the eating, including myself, appeared to, through the sharing, build a kind of shell around themselves within which they could avoid falling victim to the spectacle that followed. The ritual of selective food sharing had simultaneously recast us as part of the scheming; the Machiavellianism and the ruthlessness of omalayitsha who we had travelled with. One lesson from selective food sharing may be that cross-border movement as a space of ongoing encounters is not only emancipatory, but can be a contradictory arena of perils and possibilities, of openings that are also themselves closures.

\section{To eat}

It is interesting to observe the sharing of food between omalayitsha and public officials. If omalayitsha represent the private sphere and public officials the public, the act of sharing food is particularly telling in relation to the assumed social distance between ordinary travellers and public officials, especially when they are on state duty. Mlalazi, a customs officer with the South African Revenue Services (SARS), came into the purview of my research when Skara, a registered clearing agent I introduce in Chapter two on Methods and Methodology, formally introduced us over braai (a barbeque/grill). Although Mlalazi was not on duty at that time, he was in full uniform, with his name and what I assumed to be his force number displayed prominently above his left breast area. The conversation over food suggested that Skara and Mlalazi 
had known each other for some time. They knew each other from work. When clearing goods (Skara's specialty is cars and other bulk automated machinery) across the border, Skara must initiate the process on the South African side of the border. A laborious job, the work of a registered clearing agent goes faster when $\mathrm{s} /$ he knows customs officials who can expedite the process.

The social distance that immigration and customs officials, and indeed state agents exude from behind their counters, is cast in a different light once they mingle with the general public with or without their uniforms. The flattening of distinctions between the private and public in relation to the functions of state officials, I will suggest, is partly possible if it is geared towards fulfilling obligatory exchange through genial reciprocity. In a manner not too dissimilar to business acquaintances closing a deal over a game of golf, Mlalazi's shared braai with Skara hints at several of the issues I touch upon here. In particular, it suggests that Skara seldom has to engage in ukutshokotsha as long as he times his clearing duties to coincide with Mlalazi's on-duty shift. But, it also relocates border practices towards an openly social realm. The border literally turns into a resource that can be used not just to structure social relations, but to monetise those relations as well (Coplan, 2006).

Both Skara and Mlalazi have obviously done well economically under this and similar relationships they sustain across the public-private divide. Just like omalayitsha, their continued sustenance of and reliance on the relationships they cultivate as and with intermediaries have seen them grow in stature both socially and economically, and perhaps also politically. Skara has managed, from his work as a registered clearing agent, to accumulate assets far beyond his regular income. Mlalazi seems to be doing well himself. His body size was a subject of a poignant comment after I introduced him to Msholozi. "Udla kusale - you have the enviable pleasure of throwing away excess food after eating your hearts content", was Msholozi's way of greeting him. 
Such sociability between state officials and certain individuals such as omalayitsha opens doors for access to resources that would otherwise remain inaccessible. If undocumented cross-border movement is about attempts as stringing together livelihoods for the disempowered, the work of facilitating such movement is itself also a source of great power, socially and economically, as the discussion has suggested. It is apt that such power and access, as powerfully alluded to by Msholozi, represent and are represented by the act of eating.

\section{When compliance pronounces hunger}

Equally important is the allusion to starvation with regard to how state officials benefit from their encounters with omalayitsha and undocumented travellers. Here, the adherence to border crossing regulations by travellers is equated to a lack of benefit to state officials responsible for enforcing documented travel. This is generally viewed as starvation (the inability to eat) by inspectors on duty. This idea of starvation surfaced when we were crossing the border with Msholozi in March 2017 from Zimbabwe into South Africa, and when the inspections of our minivan began in earnest as we first entered the border gate. Because almost everyone had a passport (even though the majority of those passports did not belong to their bears that day), and we were drawing no trailer (often an indicator of money made from transporting goods), Msholozi kept telling the state officials that their search constituted 'indlala zodwa' (pure starvation), in reference to the fact that the officials would struggle to find any infringements on our collective part. Were we to be found in breach of the law, as was often the case with undocumented travel, Msholozi would leave something for the officials to get past the security inspection. This would constitute some gain for the inspectors, who would thus 'eat'. But since there was none today, he half-apologetically informed the officers that they will find nothing, and therefore would starve. 
At the subsequent inspections on leaving the Zimbabwe side of the border gate, just before one drives across the bridge, Msholozi repeated the same statement that his minivan brought with it starvation, and the inspectors seemed to understand that they would indeed starve, although they continued to carry the inspections anyway. A part of this was a deceptive act on Msholozi's part, to dissuade the inspector from reaching the back of the car, where there indeed sat undocumented travellers.

Border socialities that equate the performance of official duties with private gain - or eating - are partly illustrative of the forms of brutality and the accumulation of material wealth and prestige alluded to above (Njoku, 2005). They structure a border environment where state officials, in spite of their bureaucratic authority and power, are still economically disempowered, and like everyone else, are part of the same search for livelihoods as omalayitsha and undocumented migrants engage in. They are all symbolically constituted as such by a broader structure of dispossession that institutes labour migration and the informalisation strategies they are now bound up in. If the border itself has become a business (Coplan, 2006), then its reconstitution as such reshapes the identities of its actors, as much as it rearticulates its function as an instrument of exclusion and deprivation.

\section{Bureaucratic socialities}

Some authors have suggested that when this blurring between the private and public happens, especially with regard to the delivery of services by border officials, we may begin to talk of the personalisation of the public (Blundo \& Olivier de Sardan, 2006; Medard, 1982). This characterisation is often connected to a moralising discourse on 'corrupt practices', especially in situations such as the ones I have described throughout this thesis, where the quest to expedite procedures at the border is 
often met with a deliberate pursuit of delays in order to create the conditions for facilitation, and for personal income accumulation. What I have gathered from my research is that in the scenarios described above, the sociality at the interstices of the publicprivate divide, take the 'generalisation' and 'banalisation' of what people may consider corruption further, which nevertheless, as Olivier de Sardan (1999) has observed, tends to remain in the realm of rumour and gossip. This tends to intermingle the political and the social, so that the two become semantically determined, and corruption loses its force as an issue of morality and turns into something of a commonly acceptable practice.

My own intervention leans more towards Confucianism where, with a layer of either personal ties or trustworthiness performances built into gift exchanges or other forms of perceived ingratiation, most of what emerges for analysis includes relations of obligation, connectivity and reciprocity. Indeed, right in the middle of a hard-line stance towards perceived corrupt practices at the border and a relatively rigid border enforcement structure, there is a sphere of sociability in which quite personal and cordial relations, regarding the purposes and processes of obligation, emerge which appear to trump the "cold of bureaucratic rationality" (Torsello \& Venard, 2016: 39) to aid the otherwise difficult border crossing of people and goods. It is within this sociality that the micro-narratives of movement are re-scripted.

Crossing the border as a motif

for passing through social categories

One sub-narrative about movement, (cross-border) mobility and various kinds of associated temporality is travel itself - the act of being 'on the move'. And unlike the delays and social interactions cultivated at and around the border and other ports of entry, the act of travelling appears to have a more fleeting character. After all, travel is associated with conveyance, momentum and flow. 
But, this fleeting character of travel is deceptive. In line with various kinds of mobility, travel has its own kinds of sociality that are built on interactions that make conveyance possible. Granted, travel, and being on the move as such, represent an ambivalent space (Klaeger, 2013). For instance, travelling by road is seen as fraught with fear and desire, terror and fascination, risk and possibility (Masquelier, 2002). Road travel appears wellsuited for a discussion of relations of risk and obligation as they pertain to movement across and through social categories.

From the empirical material I have gathered while travelling between Musina and Johannesburg, either along the N1 highway or other roads, I can submit that such travel becomes both an experience and a site of struggle, contradiction, expectation, solidarity and harm. Travel in this setting seems to be imbued with the notion of 'suffer to gain' (Hart, 2011; Melly, 2013), by which those seeking to cross the border with the help of facilitators appear willing to endure the wounds and sufferings inflicted by the road as a price to be paid for the expected and perceived allure of the destination, which symbolically also represents the future. The obstacle course that is cross-border travel, with the border as the biggest stumbling block, is no longer a mere rite of passage. It starts to assume a series of barricades, the surmounting of which promises better life prospects, chief among them is upward social mobility.

Often the obstacles along this 'road' do prove overwhelming. Things do no always go to plan; highway banditry is on the increase and incidents of passengers who have been robbed at gunpoint regularly grab headlines both in South Africa and Zimbabwe (NewZimbabweVision, 2015; Muleya, 2016; Huni, 2015). For example, Msholozi narrated to me an incident where armed bandits tried to force him off the road, with his passengers, in an attempt to rob him. Road travel thus simultaneously represents danger and opportunity for the different actors plying it. For any one of them, the road represents a space of transient 
ambiguity where dreams can gradually materialise according to expectations, or can quickly turn into nightmares. The road, just like the border itself, is thus not a mere strip of black tarmac; it is a space of various kinds of agency and resistance, and to quote Rajaram and Grundy-Warr (2007: ix), a zone of 'rogue embodiment'.

Thandazani, a resident of SW Zimbabwe and a former undocumented migrant in South Africa, narrated to me what appeared to illustrate this notion of rogue embodiment. In what appears as a conflation of travel rituals as the performance of hope, the obligation to support each other in a zone of risk and danger, and the role of hyenas as the middlemen who connect the two, Thandazani gave a picture of how this embodiment plays out in the actual border crossing:

There is hardship when you cross on foot. One, there are these people called amagumaguma who lie in wait for those attempting to cross via the bush, to ambush and mug them. We came across them, my first bush crossing. We came across them. But our leaders and us, we were many, those amagumaguma were three. Our facilitators spotted them in the bushes, waiting to ambush us. We surrounded and overpowered them. They beat them bad. It was shocking. We carried on without further troubles. The only problem is; there used to be a very high wall (fence) erected to discourage crossings. We were supposed to go through this wall. The others would lift part of the topmost part of the wire while you climb through. You were meant to fall on the other side of the wall. And then there was a second fence that was also that high, almost 7 meters I would say. You were supposed to scale that fence and when you have climbed, you did not have any support to let you down gentle. You simply fell to the ground. No one cared if the fall fractured your limbs or not, you were expected to walk on. And once you cross, the walk turns nasty; izimpisi start to harass and hurry you along. Everything changes suddenly in the treatment you get... 
That risk and obligation simultaneously play out is evident in the way the physical strain of crossing, including the associated dangers, is at the same time tied to not just the feelings and expectations of obligation to get help and for those crossing to help each other, but also to the expectation that izimpisi can be trusted with undocumented strangers' lives, by both border jumpers and omalayitsha themselves. This performance of hope, as illustrated above, is complimented by another narration from Sipatsha, on his own experience of crossing the border through the bush:

As soon as you arrive at Beitbridge, the driver (umalayitsha) hands you over to an expert guide (impisi, or hyena) to cross via the bush.... But you must run after the impisi from Beitbridge to the other side, otherwise it's unimaginable what might happen to you if you lose the one running ahead of you... It's a tough tough thing.

These narratives, which have echoes of the 'native runners' of the colonial period, demonstrate how the ties and relations that sustain this push across the barricades erected for purposes of exclusion are sometimes tenuous, with the absence of deeper social relations adding to the instability. They can, nevertheless, be contrasted with a different exposition of risk and obligation on the road. The reference I made earlier in relation to my previous trip with Sgebengu, an umalayitsha (page 199) who owned a dilapidated bakkie, needs further clarification. When he picked me up at Musina, Sgebengu already had a group of women and children who looked like they had spent a day or two on the road. My first impression of him was of a gentle but quite firm elderly transporter. As I later travelled with him a few more times, including once when he was transporting a dying migrant back to Zimbabwe, I learnt that he had a fearsome reputation for employing violence to secure favourable outcomes, but also for protecting his clients from the dangers lurking around. 


\section{Performing hope}

The first time I met him, Sgebengu had spent too much time on the road and had lost all the money he had made on that trip. He had bought food, van repairs, and had made way too many phone calls. When he took me into his bakkie, at first, he asked me for my travel fee. But when he was forced to spend that, he borrowed more money from me in order to feed the people in the car, but also to negotiate for more money to be wired to him through mobile money transfer. He ended up taking all the cash I had, with the promise that he would give it back to me when we arrived in Johannesburg. As we made slow headway on a hot day, Sgebengu shared numerous stories on the virtues of responsibility among transporters, and continuously used his own example as a testament of honesty, business integrity and empathy. There was a sense that he had a closer relation with the women and children he was transporting, and this translated in the way he took personal responsibility over them, and how this came through via his sense of obligation towards their safety and general welfare on the road.

While preforming his obligation towards his clients by taking care of them and narrating his own virtues, Sgebengu was simultaneously performing hope despite the ever-present dangers and risks that attend travel. The above examples suggest that for those expecting travel to embody a process of becoming, where they can reasonably expect to realise the plans that induce their desire to travel in the first instance, various experiences with omalayitsha can affirm that possibility. Other experiences show the road to sometimes be a trap and a zone of confinement and the story at the beginning of this chapter offers a good illustration of this. The contradiction is that these two opposites, possibility and peril, dream and reality, can frame a simultaneous experience, an 'unruly present' (Melly, 2013) of ambivalence, which is itself as much a crisis of the postcolonial subject as discussed by Achille Mbembe and Janet Roitman (1995), but also 
a transcendental (Gikandi, 2011), if contingent, one, where certain forms of social collaboration defy geographical locality and lay claims on ways of becoming, on self-knowledge and on agentive social transformation.

\section{Conclusion}

In this chapter, I have focused mainly on the performance and rituals of assisted border crossings. By using the hyena figure as both identity and practice, I have discussed how hyenas function as the vital, although unacknowledged, link between social processes - such as rampant undocumented movement and stringent formal border enforcement - that sit in dialogue with each other. At once extra-legal and highly sought after and therefore of high utility, hyenas represent the very essence of how society resolves these contradictions. I have argued that hyenas as social actors and as practices rebuff the social pretence around the immorality of irregular movement and 'unconventional' border practices. By subverting the dominant symbolic order, hyenas help us to think critically about the received wisdom on the limits of belonging and justice.

The idea of facilitation is principally about how these contradictions are negotiated. Although hyena identities and practices appear informal in the context of prevailing regulatory norms, they mirror the general informality in movement and work; characteristics that have now become defining features of contemporary Southern African political economy. Such identities and practices also play a significant role in shaping the social relations of border crossings from which broader patterns of cross-border movement are partly shaped. This is also the same sphere from which the political subjectivities of border actors partly issue. 
This issue of subjectivities is important because it casts such border practices in a broader light, with wider social significance. Especially when seen in respect to what formal border enforcement, through the symbolism of documents, does to categorise people, facilitation finds legitimacy and popular appeal among the excluded. Because formal enforcement and documents, as extensions of civil governance, appear in the lives of the marginalised as instruments of domination and coercion, facilitation presents itself as a way around such coercive strategies. Imbued with genial conviviality, it contrasts sharply with a dryly formal bureaucratic mechanism. This is the same sense by which people relate to practices which may otherwise be seen as corrupt.

As informalities, hyena networks and practices signify how broader processes, norms and mechanisms of cross-border movement and work interact with each other in the material sense. Facilitation represents how these processes, norms and mechanisms are understood, as well as engaged with, consumed by and adapted to actors in the local context. If figures, networks and practices of hyenas appear as corrupt, I have argued above that when seen in their local context, and through the prism of facilitation, they can be understood as representing a social space of negotiation in an environment of dispossession and marginalisation, which in the present is defined by general informality. The creativeness of those that must respond to this context often means that they have to invent strategies that subvert or clash with dominant discourses and orders.

Hyenas emerge and thrive in such a context. Not only do they know how to transport undocumented migrants and goods between, for example, Johannesburg and Bulawayo, they also develop unique social relationships with state officials, touts, local fixers and others to help the undocumented migrants through. Through their cultural capital, they demonstrate and challenge us to think of border crossings in the context of 
dispossession and responsiveness as a domain of negotiated possibilities; a space where the micro-narratives of movement and life are rendered visible.

The work of hyenas also uncovers the contradiction between what dominant societal narratives de/legitimise and the everyday practices that shape social change on an ongoing basis. Here, one may bring into view the mastery of the crossing process as the reimagining of the border that, on one hand, avails the kind of performance rituals that make the border bureaucracy accessible for the ordinary traveller, and on the other, reconstitutes what it means to be mobile, excluded, resisted and to become.

The essence of this discussion has been that for relatively poor people dreaming of a better life, cross border travel is not as open as the post-independence climate and informality have promised it to be. This lack of openness is built into systems of neo-colonial domination and rule, neoliberalism and ubiquitous informalisation, often as elite state projects, which are at their most intense in the global south. For those who dare to dream of a better life under these conditions of dispossession, and who seek to do so through cross-border movement, their most plausible avenue to do so is through the help of middlemen. Hyenas represent the connection that exists between the different classifications that the contemporary global order is made of. They provide the atlas that helps to navigate the knowledge system. They provide a way of mastering the structure of officialdom in order to appropriate its syntax, so that they can find a way around the barriers that structure the governance of movement, and the exclusion of those condemned to the margins of modern society. Above all, hyenas provide access to both the game of cross-border movement itself and the strategies that enable one not to be caught out by its rules (or ruses). 
It is in this respect that it has been possible to focus on the hyena economy, or the society of the mobile. More than just the actors involved in undocumented movement and its mediation, such an economy or society is also about the processes involved which result from the distinctions, demarcations and categorisations that characterise cross-border movement. The hyena economy contests these distinctions, challenging their authority as a "curtailed conception of justice" that is also an incomplete or misrepresentation of human need (Rajaram \& Grundy-Warr, 2007: ix). Its social politics reimagines justice and its limits, while simultaneously confronting the broader processes of contemporary neo-colonialism, neoliberalism and informalisation. The hyenas of the Limpopo do not represent a total or even coherent system. Neither do they suggest a more systematic neo-liberal, neo-colonial or commodification world than there really exists. Nor are they meant to be read as capable of dismantling the system of domination they are navigating. They do, nevertheless, suggest a need to re-examine the present order that ineffectually lords over social dispossession. They also suggest that efforts at such re-examination should recognise the chaos, contradiction and dynamism of social process. To echo Rajaram and Grundy-Warr, they suggest that many hidden but not necessarily passive geographies and political forms that confront current ideas around justice and belonging exist. 


\section{6}

\section{'GHOST PASSPORTS': \\ Disembodiment, illegibility and the negotiation of undocumented border crossings}

\section{Introduction}

A close friend of mine, Tarisai, a young Zimbabwean scholar in Johannesburg, once approached me with a request. His young sister, who works in the hospitality industry without a work permit, needed the visitors' visa on her Zimbabwean passport extended by a few more months. This was in 2015, during my 'ride-alongs' between South Africa and Zimbabwe with Msholozi. The request rode on two basic factors. Because Tarisai knew me, and I knew Msholozi particularly well, Tarisai was confident that the passport would be stamped and returned safely without his sister having to travel to the border to do this herself. Acquaintance also presented a possibility to negotiate easier and cheaper payment terms for this errand.

As it turned out, Msholozi accepted to get the passport stamped. But he also took a longer time - about four weeks - to do this, so that Tarisai eventually became anxious. He started to put pressure on me, and I was forced to transfer that pressure on Msholozi. Msholozi was not amused, but the passport eventually returned to the owner, with the requisite extension, and the matter was settled. Sometimes, passports sent to the border in this way get lost. In other cases, however, they may 
not be processed at all, although unscrupulous omalayitsha and immigration officers at the border may connive to issue them with fake stamps.

This example illustrates a phenomenon that occupies the central focus of this chapter. 'Ghost passports' are passports whose holders enlist the services of third parties, such as omalayitsha and regular bus drivers, who then take the passports to the border post to get them 'stamped' on their behalf. Low- and semi-skilled Zimbabwean migrants seeking work and other opportunities in South Africa must contend with a migration regime that robustly restricts their movement into the country. Nevertheless, they can find opportunities for precarious, often undocumented, work within the country's mining, agriculture, hospitality, domestic and informal sectors, among others. For those without longterm work permits, a nagging feature of their continued stay and work in South Africa is to regularly travel to the country's ports of entry, such as the Beitbridge border post, to negotiate more residence days on their passports. Without adequate financial resources or time to do this, many Zimbabweans who seek such extensions turn to the services of omalayitsha and other facilitators, who cajole immigration officers for extension stamps on 'ghost' (or holder-less) passports for a fee.

The phenomenon of ghost passports inverts the lens often associated with undocumented travel. In this case, documents get to travel without their holders. How this comes about, and what it reflects for the social politics of movement, and especially everyday border practices, occupy the focus of rest of this discussion. The movement of ghost passports privileges the role of social relations that structure everyday border crossings for those with short-term residence prospects in South Africa. Practices involving ghost passports revolve around gamesmanship that relies on decoupling documents from their owners. Such practices of sly civility (Bhabha, 1994), visible invisibility and disembodiment, accompanying the phenomenon 
of ghost passports speak to various strategies by which border actors interact within, engaging with a border enforcement structure they can both abide by and pay lip service to in equal measure.

Specifically, disembodiment - the separation of travelling migrants from their documents - represents a strategy of makebelief that is neither mere evidence of the magic of the state (Das, 2004), nor of the populace (Hoag, 2010). Rather, it emerges as part of a broader facilitation process by which the different actors involved in the handling of ghost passports combine what Janet Roitman (2004) calls the ethics of illegality - covered in Chapter Three - with the 'magicality' that characterises the encounter between the state and regular members of society.

For many Zimbabweans, the passport has sometimes played another role beyond proving the identity and intentions of the traveller who moves across international borders. It has also functioned, on one hand, to placate the respective border enforcement systems through which it passes. Moreover, it has played a significant role, both in its presence and absence, of the different practices of negotiation and facilitation that characterise cross-border movement. Both the lip service and gameplay it oversees in the facilitation of undocumented border crossings rest on the central importance of the passport in official border enforcement, particularly at Beitbridge.

In line with this proposition, the rest of this chapter is as follows. The next section briefly revisits the theoretical premise on which the chapter builds. The section approaches the phenomenon of ghost passports as representing an ethics of illegibility. By this, the chapter seeks to view the social relations that make it possible for border enforcement mechanisms to ensure documents get read in the absence of their owners as emblematic of an ethic whose manifestation is seen in the merging of norms around illegality (Roitman, 2004) with the illegibility (Das, 2004) 
of the state. This synthesis, what Magareth Archer (1995) calls morphogenesis, represents the manner in which regulatory norms synthesise with everyday social relations and practices to produce, over time, a reality that is constantly evolving.

The following section describes the conditions that bring about the phenomenon of ghost passports, connecting both ghost passports and make-belief to 'border struggles' (Mezzadra \& Neilson, 2013). This brings into view the broader structural constraints that present a challenge for ordinary travellers to fully participate in documented movement. Thus, as much as these practices and strategies represent agency, ingenuity, political responsiveness or even trickery, they occur within a dominant structure of dispossession and various creative responses to it that condition movement and its everyday practice.

The third section uses this proposition to argue that practices by which people decouple themselves from documents should not be seen as overriding the forces that compel travellers to submit to prevailing regimes of cross-border movement. It argues that the more people appear to evade the mechanisms of control at Beitbridge, the more they reify them. Such practices that drive the phenomenon of ghost passports may signify attempts to negate the dominant structure of dispossession in the service of which border enforcement prevails. However, through the sheer force by which such manoeuvres seek to both evade or placate enforcement, it can be seen that they mainly succeed in submitting to the general spirit of official border enforcement. Nevertheless, border enforcement must contend with such practices, and the two tend to evolve together. This way, they arguably define each other.

The fourth section demonstrates the above argument well. Here, we observe that the gamesmanship around ghost passports may sometimes fail so that actors turn on each other and, in a riposte illustrative of the symbolic violence of official mechanisms, let the illegibility and unpredictability of the state trump their 
own efforts at negotiating official procedures. Actors involved in border practices here demonstrate their willingness to give in to what they may consider unsympathetic rules, but only as far as those rules hold. In many ways, this illegibility of the state is acknowledged by most border actors who view their own actions as not insurrectionary, but as ways of exploiting spaces of border enforcement that appear malleable. As soon as the rules cease to extend their reach, there remains some level of play. In other words, where the law does not reach, one can play with that law and the gamesmanship that facilitates undocumented crossborder movement on the sly.

The final section discusses what people do to evade control as illustrative of the idea that it is movement that necessitates its control by institutional measures. In that sense, institutions and their responses are always tracking behind what people do not just to escape such institutions but to make meaning of their own lives. The chapter concludes by underlining what I see as its central contribution to critical border studies, namely that border practices such as the handling of ghost passports, present a privileged site from which to critically analyse evolving relations of domination, dispossession and exploitation in everyday cross-border movement and living labour, as well as the contestations that characterise these relations. Strategies such as disembodiment and make-belief, some of which appear in the parallel lives of the passport, offer examples of agential responses that challenge these relations at the interface of border enforcement and everyday border crossings.

\section{The ethics of illegibility}

As Tarisai's and many other examples demonstrate, recent history presents a chequered past for the Zimbabwean passport. The number of people seeking to travel outside Zimbabwe started to significantly increase from late 1990s and early 2000s. 
This initially related to the conditions tied to acquiring a South African or British travel visa; two of the most popular destinations of the time, which drew the spotlight on the passport as a site for various kinds of make-belief. For those travellers who could not furnish the requisite supporting information regarding their intentions to travel to and reside in prospective host countries, a common solution often had to do with manufacturing proof in the form of borrowed cash or forged bank statements, and improvised host addresses, next-of-kin or even accommodation. The passport, especially, came to play, in some instances where a travel visa was eventually granted, the extended role of validating these half-truths.

The emphasis on the passport, or its perceived importance, for documented or undocumented border crossings offers a basis for what I conceive as an ethics of illegibility. To recap an argument that has already been made in Chapter Three, this ethic ties a collective understanding of the centrality of the passport to a normative border enforcement infrastructure regarding what can be done with this understanding to make both the passport and people passing through - often 'separate' - enforcement mechanisms. Because the passport legitimises cross-border movement from a regulatory standpoint, manipulating this very function in turn enables those not able to comply with official requirements to both placate the enforcement mechanism and cross the border undetected by it. Put differently, such undocumented crossings are intricately tied to the apparatus that facilitates the documented ones. Thus, if the state is said to exude magic in the way in enforces documented crossings, those who cross without documents can respond with magic of their own.

As we will see, the 'magic' which is at issue here is in fact a product of the interpretation of and engagement with regulatory norms by both state officials and 'subjects'. Thus, illegibility stems from the synthesis of norms, their interpretation, application, negotiation, manipulation and even resistance as part of the 
context of everyday practices that shape border crossings. Such border practices include behaviours, practices and beliefs that carry an air of illegality if presented from the view of immigration procedures, even though they are legitimated and sought after by those who mobilise them. The legitimation of practices that are otherwise seen as criminal suggests, at face value, that regulatory norms are out of sync with the reality of those who seek to make ends meet in a context that alienates them. My argument is that, as much as one might concur with this view, one might need to look beyond this explanation, and to consider with Roitman (2004) why such practices are necessary. The point is that official enforcement mechanisms would persuade us to reject this behaviour as non-conformist, if only to ward off inquiries about how the same behaviour benefits structures of exploitation and capital accumulation. Informality in Southern Africa works in a similar way, in that it appears as a blight on society and attracts attention towards its eradication. Meanwhile, it redirects focus from those who benefit from it, such as the farmers of the Limpopo as well as other industrialists who make up the bulk of the South African economy.

In the frenzy of everyday experiences, the manipulation and game-play around the passport, as I have discussed in the earlier parts of the thesis, rest on the perception that it is an important travel document. This perception, rather than the document itself, becomes a prime good, so that those with access to passports, or the systems that process them, sell this influence to placate border enforcement mechanisms that deriving instrumental benefits of their own. This is why, both when passports are present or absent, or when they appear in the possession of third parties, they still rely on additional networking and insider relations of trust and acquaintance in order to make border crossings possible, comfortable, or speedy. The issue is that as much as game-play affords border crossings, it feeds into an overall structure that benefits from undocumented border crossings. 


\section{Ghost passports and make-belief}

As I stated above, significantly more travellers to South Africa started to cross the border at Beitbridge from the late-1990s. This was partly due to the increasingly difficult political and economic conditions in Zimbabwe. Towards the mid-2000s, collaborative efforts between the two countries saw travel conditions into South Africa becoming progressively relaxed. This was partly in response to an increasing proportion of travellers who were finding them too stringent and cumbersome to comply with, and were therefore travelling clandestinely. Proof of financial selfsufficiency as a requisite for acquiring a travel visa, for instance, was scrapped in 2005 (Mail \& Guardian, 2005). This partial easing of the requirements of cross-border travel encouraged more people to seek the passport, applying even greater pressure on the issuing offices.

By the second half of 2006, the Zimbabwean immigration department's passport issuing offices could no longer cope with the number of lodged applications, whether for new passports or renewals. The paper used to make passports itself ran out, and the authorities were not able to replenish it in sufficient quantities (News24, 2006). Some travellers greeted such a development with cynicism. At around nineteen months, the waiting period for a regular passport (if the application had been accepted) was a lengthy inconvenience. Many thus simply travelled without it, routinely choosing to use omalayitsha to get them across the border. Upon arriving in South Africa, undocumented travellers sometimes chose to avoid arrest by applying for political asylum (Amit, 2015) while others went underground (Vigneswaran, 2007). Yet, some illegitimately got hold of authentic South African identity documents. As a way of further simplifying the condition for documented cross-border travel, the South Africa Department of Home Affairs eventually introduced by the end of year 2009, a free 90-day travel visa for Zimbabwean travellers, usable within a twelve-month window. 
It would appear, therefore, that the relationship between the passport and movement during the last twenty years has been loosely structured around, on one hand, enforcing a strict regime of cross-border travel for Zimbabweans seeking to travel to South Africa and elsewhere. On the other hand, when this failed or was under severe stress and movement continued despite strictures, the control regime had to make concessions in order to close the rift that emerged between movement itself and its governance. This separation suggests that in the Zimbabwean context, the passport, as an artefact (Riles, 2006) of bureaucratic practices surrounding documented travel, is sometimes less tied to individual bodies, identities and reasons for travel, and more to mere bureaucratic procedures, practices and rituals. In other words, the passport continues to fulfil the requirement for crossborder travel by submitting to stipulated rules mainly through its assumed importance. In reality, passport holders routinely submit to these requirements in a piecemeal way. As a matter of fact, such passport holders distort this mechanism as they and their documents live different lives. The various attempts, especially by the South African immigration department, to ease the conditions for entry by Zimbabweans is indicative of attempts to close this rift.

The decoupling between what the document does and what its owner does, however, has not rendered the passport irrelevant in cross-border travel. Quite the opposite: the passport, in so far as it validates the game-play around both documented and undocumented travel, and as a document that many actors in cross-border movement have something invested in (Cabot 2012), adopts a parallel life of its own. Its dogged importance, even if this can be manipulated, makes it central for both documented and undocumented travel. The life of the passport is closely bound up in border enforcement systems that produce and govern it, but is also related to how the social politics of negotiating undocumented movement is enacted. 
When the South African Department of Home Affairs eventually granted Zimbabweans a free 90-day visitors' visa in 2009 (NGOpulse, 2009), as well as the possibility of getting work permits if they could prove employment status, a new importance was again attached to the passport. At this time, other policy shifts regarding the governance of movement in and out of South Africa came into effect. For instance, a previous moratorium on the arrest of undocumented Zimbabweans living and working in South Africa was lifted in 2011 (IRIN, 2011). This was after several Zimbabwean consulates in South Africa had started to issue passports for their nationals in 2010 . And, in general, the pressure on the application and waiting times for Zimbabwean passports eased while previously robust arrests of undocumented migrants resumed (Vigneswaran, Hoag, Araia, \& Tshabalala, 2010). However, while this signalled a desire by state authorities to recouple legal process with travelling bodies - thus tying the lives of documents to those of their holders - not all Zimbabweans living in South Africa applied or alternatively received work permits, that is, became fully 'regular'.

By granting permits to Zimbabweans working in South Africa, the so-called Zimbabweans' Special Dispensation Project brought some 250, 000 people over into the realm of the documented (Chiumia \& van Wyk, 2014). This represents one of the most comprehensive attempts in recent times to create an avenue for Zimbabweans travelling to, as well as living and working in South Africa, to be legible to state bureaucracies (Scott, 1998) and be amenable to their control (Cabot, 2012; Cohn, 1987; Comaroff \& Comaroff, 1991; Dirks, 2001; Mamdani, 1996; Thomas, 1991). Nevertheless, some of those who participated in this project, as well as the others who did not, have failed to fulfil all or some of the conditions set for documented travel; thus continuing to find creative strategies to evade or by-pass the demands for and challenges of ensuring enforcement. 
For those without long-term permits, constant circular travel through the border is required to extend their stay in South Africa. Further, the increased volume of people seeking to get stamps at the borders and the delays that accompany this mean that many people once again resort to the services of facilitators to either do or expedite this work for them. The stringent border enforcement system means that passports and other travel documents remain indispensable for border crossings. However, with some unable to either travel to the border to seek permission to stay in South Africa, or to show any documents at all for similar reasons, Omalayitsha now find themselves in the lucrative business of conveying holderless travelling documents - ghost passports - across the border, primarily for the purpose of fulfilling bureaucratic requirements. The passport is thus disconnected from the movement and intentions of its holder, and it appears that state authorities can do little to eradicate the life of appeasement and game-play that the Zimbabwean passport sometimes fulfils.

Scholars (Brenneis, 2006; Cabot, 2012) have previously demonstrated how, by following the lives of documents and paying attention to the bureaucratic practices and processes they travel through, it is possible to catch a glimpse of some of the complex and changing meanings that documents take on. By contrast, my aim here is to follow the Zimbabwean passport as it moves across the Beitbridge border, not just through the bureaucratic processes of the immigration departments, but also how it disparately moves, sometimes in the absence of its owners, in the custody of private transporters - omalayitsha - in the socio-cultural spaces of negotiation that define cross-border movement across the Limpopo Valley. My aim is less to delve into the workings of state bureaucracies at the Beitbridge border, but rather to trace how the practices that separate passports from their owners as they cross the border represent disembodiment, and - as a response to the deprivation of regular movement how actors engage in creative strategies to eke livelihoods that simultaneously appear as informal politics of the dispossessed. 
Disembodiment is here understood partly from the perspective of creative responses to exploitation and circumscription (Wolpe, 1972; Terreblanche, 2003; Mamdani, 1996; Neocosmos, 2006). While migration autonomy scholars (Rodriguez, 1996; Papadopoulos \& Tsianos, 2013; Nyers, 2015; Rygiel, 2011) may suggest that movement is capable of constructing its own pathways beyond those imposed from above by states, the phenomenon of the ghost passport contests this view. Such pathways for autonomy cannot be said to undermine border enforcement. As I have already discussed, disembodiment in the case of Beitbridge may be best understood as not so much an escape from enforcement processes in a way in which both the passport and its role in crossborder movement may appear to negate border enforcement. The very fact that the passport establishes grounds for cross-border movements suggests that clandestine movement submits to the general regime of movement on which such enforcement is based. In a broader analysis, undocumented migrants exemplify the dual sense in which Butler and Anasinathou (2013) have discussed dispossession.

Maxim Bolt (2012) observes that travellers seek to avoid the violence and surveillance that attends the Beitbridge cross border space by staying visible to the 'authorities'. In the case of ghost passports, the migrant adopts a strategy of disembodiment in the same way. Nevertheless, by resorting to pretence (of which ghost passports are an illustration) to stay visible to the bureaucratic apparatus and enforcement mechanisms, migrants appear to acknowledge the broader structure of circumscription and domination that drives such enforcement. Disembodiment in this view is a strategy of subversion, survival and agency that represents a 'social reality' (Nyers 2015: 27) that characterises the relations that emerge in conditions created by the imposition of strict regime of cross-border movement that discourages the mobility of labour with low skill endowments. 
Focusing on how omalayitsha and other actors handle and get ghost passports stamped at the border uncovers crucial but largely invisible ways in which travellers use 'sly civility' as a strategy of false compliance (Bhabha, 1994, in Nyers, 2015: 29). In this way, ghost passport holders use "vernacular forms of legal knowledge in which the passport is embedded" (Cabot, 2012: 20) as an ethics of illegibility to re-inscribe themselves into the border enforcement matrix while creatively asserting their agency in movement. The phenomenon of ghost passports emerges as a site where undocumented migrants seek formal status and negotiate the often-unstable continuum between make-belief and legibility. Through the practices and negotiations that surround ghost passports, the decoupling of legal processes of immigration from bodies becomes visible. The separation between the two acts as a way in which legibility, as imposed on people through the passport, is appropriated, reworked, manipulated and ultimately affirmed in the facilitation of border crossings. This has the effect of distorting the boundaries of inclusion and exclusion that legibility, in the name of the passport, makes assumptions about and seeks to uphold.

\section{'Documents help, but we're not waiting'}

When I started doing fieldwork by travelling with omalayitsha in 2013, it was obvious that the modalities of their transporting business, and with that the main source of their incomes, was shifting, or had shifted, significantly. About two years before then, omalayitsha had still relied on transporting consumer and other second-hand goods from South Africa to Zimbabwe, or undocumented migrants in the opposite direction (Thebe, 2011) as their main source of income. Transporting consumer goods is still popular, but it is no more lucrative, as it is easier for migrants to wire money back to Zimbabwe for a reasonable fee. Also, many undocumented first-time cross-border travellers can use the passport to gain short-term residence in South 
Africa, or appear to have learnt how to negotiate their way into South Africa without having to rely solely on pricey omalayitsha. Ghost passports have come to compensate for the diminishing importance of these other sources of income. And although Zimbabweans living and working in South Africa routinely ask omalayitsha to stamp their passport for them at the border while they continue to fulfil their employment responsibilities, among other reasons, it was only one afternoon that I discovered how extensive and contested this practice had become.

It was on a day that the road from the Beitbridge border to Musina town in South Africa, a fifteen-kilometre stretch, had come under heavy security surveillance following a reported armed robbery at Musina. ${ }^{97}$ Having already had his undocumented travellers sent back while they attempted to cross the border through the bush, Msholozi was keen to avoid any further difficult encounters with state officials and the law. His anxiety stemmed from the fact that he was carrying something in the region of twenty or more passports, some of which he had already stamped at the border on behalf of their holders. His worry was if his car were to be searched by state security officials, the passports would be discovered, putting him - and the rest of us - at risk of arrest and even detention. To reduce the risk of being caught, Msholozi had pulled open the dashboard of his small car and strapped the passports to the steering bar, fastening the dashboard back in place. He had then asked me to keep an eye on them, making sure they were neither visible nor could fall out from underneath. It was Msholozi's remaining source of income for that trip, and he was both nervous and keen to protect it.

Many transporters, including bus and long-distance haulage truck drivers, have incorporated this practice into their regular transporting routines. Because of their familiarity with the

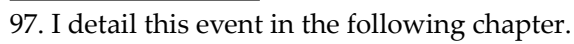


immigration and customs procedures, as well as the state officials that work at the Beitbridge border, they occupy a unique position which can assist those Zimbabweans living in South Africa who either lack time or the access networks to get their documents processed across the border. And, there is no shortage of passports in need of stamping.

Depending on whether a passport has overstayed its allotted days, getting ghost passports stamped can vary in price. Passports without overstays would usually be stamped for around sixty to seventy-five per cent of the money it would cost their respective holders to travel to the border and back. This fee varies depending on negotiation abilities. The fee is also lower if one is acquainted with a relevant transporter. However, if passports have overstayed, and have thus been flagged as such in the official immigration system, the cost depends on a rough calculation of the fine ${ }^{98}$ a given 'overstay' may attract, with the understanding that omalayitsha and other transporters would charge less than such a fine, but would almost certainly negotiate with bureaucrats to get the 'overstay' expunged from the system. Many customs, immigration and police officials on both sides of the border are well versed in these practices, and negotiations around the stamping of ghost passports via facilitators such as omalayitsha can often be characterised through the different performances (familiarity, trustworthiness, ukutshokotsha, etc.) I have discussed in the previous chapter.

As I have hinted above, practices such as the stamping of ghost passports represent the enactment of a particular game-play of decoupling bureaucratic processes that reproduce and are built around the passport on one hand, and travelling bodies, their identities, actual experiences and intentions on the other.

98. The Immigration Services Branch has recently, in an attempt to reduce the handling of cash, imposed only time bans on overstayers, as opposed to cash payments. 
In order to understand this, I wish to refer to the stamping of ghost passports as a particular embodied practice that appears in its own negation; that is, as a strategy of disembodiment or invisibility.

As an element of embodied practice or agency, the disembodiment that takes its form in the logic of ghost passports may very well be seen by some as characterised as a form of criminal deviance. But, this holds only insofar as we embed practices of facilitation in bureaucratic political logics alone, such as those represented by official immigration procedures of the border. Here, we may notice that when, from time to time, various actors are arrested on accusations that - in one way or another - relate to the practice of stamping ghost passports (eNCA, 2016), this logic is affirmed. But, as Janet Roitman (2006: 247) succinctly comments, when these 'sacrificial lambs' get rounded up, it simply means that the innocent are only those who have not yet been caught. From such a perspective, arrests simply mean that if the stamping of ghost passports is a transgression, then it is also a normalised one. And, if it is a norm, other logics necessarily inform it and make it both acceptable and functional for an array of actors involved in the practice.

Therefore, disembodiment can be seen in the light of what I explain as the ethics of illegibility. Such a view seeks to ground cross-border movement not in its enforcement by states, but in ways by which it takes place in the social relations that are shaped in the footing of the everyday. This view incorporates not only the understanding actors have of their participation in irregular movement, but also acknowledges and contests the application and enforcement of official border-crossing procedures themselves. The point of critique for practices that are said to characterise disembodiment is that some of the actors that shape its strategies are themselves state actors. Therefore, the sites of such disembodiment production, where only passports are rendered legible to border enforcement 
systems and not the people to whom they belong or who man the bureaucratic systems, are characterised by the kinds of tension and contradiction that are often engaged with and surmounted through different kinds of persuasion, pretence and make-belief.

For reasons that autonomy in movement may suggest a privileging of agency, homogeneity, avoidance, evasion and abstraction, noted and subsequently criticised by some scholars (Scheel, 2013; Sharma, 2009), I likewise minimise its significance to this discussion. Autonomy scholars are likely to lift the kinds of ingenuity and creativity that characterise ghost passports as indicative of the movement's own pathways. However, if such a phenomenon proceeds under a broader dominant structure of surveillance, policing, repression and violence that lords over movement across the Beitbridge border, such creative strategies merely approximate to political responsiveness as a valence of dispossession. The example of Msholozi's anxiety at the prospect of arrest is a clear testimony to this. Ghost passports are therefore not, as I have developed in the conceptual sections of Chapter Two, about escaping control, but more about creatively engaging with it (principally through pretence and make-belief) to simultaneously evolve and reshape it. The phenomenon of stamping ghost passports fits very well within this mould. The means by which ghost passports are stamped appear to undermine the enforcement system, but the outcome - in this case stamped passports (and compliance) - reinforces the same system, even if that system is one that produces "differentiation and stratification of legal statuses and subjectivities" (Andrijasevic, 2009: 398).

This appeal to the 'law' testifies to the dogged efficacy of state infrastructures, and of the resilience of contemporary dominions. Those border actors whose practices appear to trump enforcement mechanisms are equally wary of the consequences of undermining the law, and what that means for their livelihoods should its full force reach them. Jahman, 
a Zimbabwean national who has travelled repeatedly to South Africa by means of omalayitsha, sometimes without documents, explains how he understands the acceptability of the phenomenon of ghost passports. After explaining how he often sent his passport to be stamped out of South Africa whenever his visa 'expired' while living there, he went on to detail his life situation without a residence permit and crossing the border without a passport:

The danger is ever-present, my friend, it's always there. But, only in the law... But then, one must learn to evade the law. They most likely will arrest you when they catch you, but until such a time arrives, it means you can thrive. Even when I cross the border, if I manage to avoid questions about my passport, then there is no story. If they should find a way to put me in a corner regarding the status or whereabouts of my passport, then that means I have been caught....

The ethics of illegibility do not preclude the reach and force of the law. In this case, they simply represent an improvised reality of movement that is created in the gaps and spaces that the law fails to occupy, or that the official border enforcement apparatus is unable to read.

Jahman justifies the logic of illegibility in the following way;

Of course people break the law. We must break the law! But the law puts us in a position where we are left little choice but to break it. Is that wrong? If you don't give a person a passport, don't expect that person to sit around and do nothing until you feel like it (honouring the requirements for documented travel). People will always find a way to travel (even if it means evading legal requirements). But omalayitsha are better placed to deal with the law on our behalf. They understand the border. And, why shouldn't they? The treatment we get at the border is not right. The situation, with all the charges, fines and extortions that 
go on there in the name of papers, demands that the law be broken. Omalayitsha make things move. If you follow the law, if you pursue papers to the end, those papers will rob you of your bread.

Jahman's statement does not merely describe the particular position of an individual and his passport regarding 'the law', it weaves together the constraints that hamper movement, as well as the strategies around such constraints, the role of bureaucrats in exploiting stringent immigration regimes, inefficiency, the role of mediators in 'making things move', and all of this within an overarching condition of legitimated illegibility. His interpretation of the border is informed by a complex of issues, requirements, obstacles and challenges he feels need to be overcome in order to continue following the same motivations that brought him and others to the border in the first instance. What is clear is that such a need to moralise strategies that trump bureaucratic procedures appears deeply embedded in structures of dispossession, domination, exploitation and novel forms of ingenuity. There are clear economic and political forces that do not just compel people to move, but also restrict that movement. The play with passports represents one way in which they imaginatively respond not just to border enforcement mechanisms, but also to their general condition of dispossession.

To Jahman, conditions that bring about the need for strategies of make-belief and disembodiment are clearly affixed to conditions of disempowered that are nevertheless partly made visible by those who wield bureaucratic power at the border. Steven Pierce (2016) has discussed attitudes of citizens towards a somewhat extortionist environment fostered by street-level bureaucrats in their interactions with ordinary people in parts of Nigeria. He transmits the feeling of 'oppression' as a way in which ordinary people often describe how they experience constant demands for various tokens of appreciation from public servants for official services rendered. For them, oppression refers to acts that are 
deemed disempowering, but are nevertheless seen as a general quality of people in 'government' (2016: 6). There is a similar sense in which state functionaries at Beitbridge, who appear to have a vested interest in maintaining a difficult regime of crossborder movement, partly in line with immigration policy, seem to represent a broader dominant structure of oppression and exploitation. State actors and the conditions they cultivate at the border are seen by migrants such as Jahman as forcing them to purchase their movement through negotiations and other forms of exchange across the border, including participating in the phenomenon of ghost passports. Such perceptions demonstrate the perceived links between border enforcement and general conditions of exploitation and disempowerment that shape people's lives at and away from the border.

In the opening discussions of this thesis, I gave an exposition of how people get held up at the Beitbridge border. I suggested that travellers often expedite their crossing if they have third parties to facilitate their movement in exchange for money. Their resorting to mediators says little about whether they feel 'oppressed' by public officials for the services rendered. Nevertheless, their feelings towards such wilful or forced arrangements with facilitators could be a vindication of their sense of disempowerment at the hand of a stringent migration and border enforcement regime. In this way, although they could still ordinarily submit themselves to border enforcement systems, sometimes through proxies, it is often because they view the controls that govern cross-border movement as an obstacle that needs to be surmounted more than as a legitimate system they willingly 'present' themselves to.

Meanwhile, this is the same worldview that street-level immigration, customs and police officials may share. As the discussion in the last chapter suggested, they may seek to be treated (at their regular work, at a random checkpoint or at a routine inspection by their superiors) as scrupulously duty- 
bound to their station. On the other hand, they share the same conditions of dispossession as the travellers whose crossborder movement they enforce. Because these officials share the same episteme, they are adept at reading, interacting with and interpreting those logics, worldviews and scripts that shape undocumented movement. Rather than seeing them as conflicted individuals, it may be more fruitful locating their ability to read these sometimes-contradictory scripts within prevailing struggles by which borders articulate movement in general (Mezzadra \& Neilson, 2013.)

In terms of illegibility, the involvement and participation of state officials in both regular border enforcement and the facilitation of ghost passports suggest that the regime of movement that incubates these practices is conflicted. Such conflict largely resides, as I argue, in how African bureaucrats navigate regulatory structures and their own relative dispossession. When they come to interact with everyday situations of cross-border movement, through their official employment, they must necessarily imbue the general governance of mobility with their own worldview, which might fracture the ways institutional ideals of border enforcement are meant to work. As they wield power from a position of marginality, they seem to mingle 'work' with their own reading of border enforcement. This is to say that, whether they are aware or not, there are broader processes of alienation and dispossession that border enforcement mechanisms institute, or do, and that they themselves are in service of. This is precisely why this thesis argues that enforcement practices demonstrate, at the everyday level, how irregular migration articulates with precarious labour in a general context of dispossession.

Disembodiment suggests that travellers bring their own codes, practices and logics into migration and border enforcement processes so as to participate in cross-border movement while aiming to maintain the imperceptibility of their practices to such processes. The phenomenon of ghost passports in the 
first instance demonstrates how it is possible to analyse crossborder movement not simply as a site of control but also as one of negotiation and border struggle. Here, travellers and migrants get to be politically responsive in not necessarily vociferous platforms, but more through mundane, everyday acts that -in this case - include false compliance (Scott, 1986). Notwithstanding, disembodiment also affirms the strength of the control structures themselves. Thus, as an aspect of illegibility it demonstrates less a form of outright insurrection as it merely reveals avenues of agency, political action and creativity within these structures, complicating further reductionist binaries between victimhood and voice, security and agency, or control and autonomy.

\section{A slap in the face}

To illustrate the extent of the kind of controls that restrict travellers' ingenuity in those attempts where they have to falsely comply with travel requirements, one only has to observe the frequency with which ghost passports attract ghost stamps. These are stamps issued by genuine immigration officials. However, the stamps are nevertheless neither register in the digitalised system, nor can be traced to the very officers who issue them. When ghost passports arrive at the border, part of the fee omalayitsha collect is given to these immigration officials, who then stamp the passports and return them to the private transporters. As I have discussed in the previous chapter, this works fine when omalayitsha and state officials know each other well. In such cases, officials rely of their networks of trust, both with facilitators and their colleagues in uniform to negate the risk that comes with the use of valid stamps on ghost passports.

However, it is not uncommon, especially when these networks of acquaintance are missing, and therefore where trust is lacking, that officials accept money that is often exchanged for these stamps, even when they are unwilling to issue the stamps or 
remove the overstays on the system. In such cases, they often cover the part of the stamp that will give them away should there be a suspicion of this kind of practice. If suspicion were to be aroused, an investigation can, for instance, match the stamp to the official who used it for official duties within a given time. Officials who issue ghost (or fake) stamps will usually take care of this by covering a number that reflects the stamp prints on a passport (see Figure 6.1 below). When a passport receives a ghost stamp, omalayitsha would say that the owner of that passport has been given 'a slap in the face', or bamtshaye ngempama. Now, a slap in the face worsens the problems that already attend a ghost passport. The next time such a passport passes through the border enforcement system, the stamp indicates that the owner of the passport attempted to get it across the border in their absence, which is a big problem. Also, the overstay will persist in the official record, the penalties will increase and the money paid to fix the passport would have been for nothing.
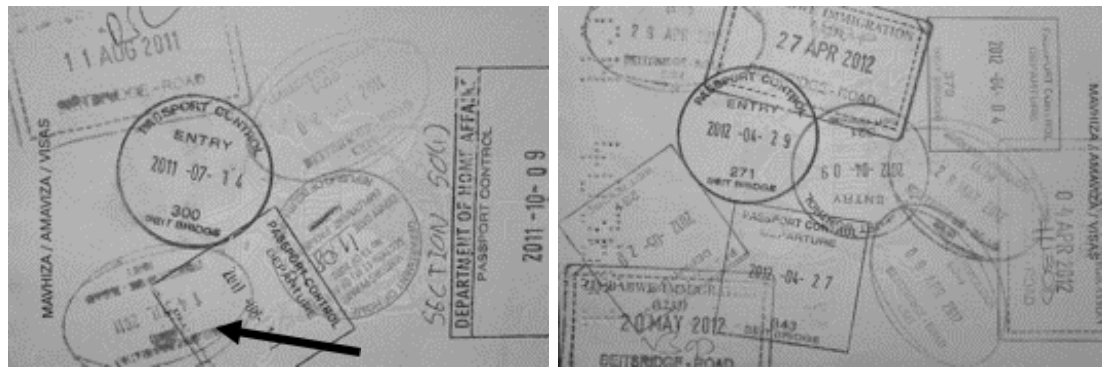

Fig. 6.1 The two images above show ordinary immigration stamp imprints on a passport for entry and exit at the Beitbridge border. The image on the left includes a ghost stamp at the bottom centre.

A slap in the face offers a good opportunity to problematise interactions and relations between 'street-level' or front desk state actors, omalayitsha and other private transporters, as well as holders of ghost passports. Msholozi was keen to point out that omalayitsha who allow fake stamps on the passports of their clients are unscrupulous and smear hard-working transporters like him. He felt that genuine omalayitsha 'fight' for 
their customers, and they treat them with respect and care, and should never take people's money and ruin their documents for nothing. In that regard, he often keeps ghost passports with him until he can find the right immigration official to stamp them for him. Although, this comes with the risk of: misplacing the passports; increasing the potential of getting caught with holderless (ghost) passports should his car be stripped; or, straining his relationships with anxious passport owners. Therefore, he prefers to manage these risks over jeopardising his business by being deceptive, including accepting fake stamps.

The issue of ghost stamps, the so-called slap in the face, underlines the ways in which there are not just contested border enforcement practices, but contested identities and allegiances within and between the different actors in the alternative crossborder movement space. On one side, there are those who believe that they are already engaging in behaviour that runs contrary to immigration and bureaucratic laws, and therefore cannot be bound by any civic codes. They thus adopt a tit-for-tat mentality, where the only rules they follow are about flouting state laws, accruing as many resources as they can and swindling as many people as they can, for as long as possible. Meanwhile, there are those who, although they are partly driven by financial gain, distinguish border enforcement and immigrations laws from other state laws, and are thus willing to challenge them while abiding by, generally speaking, all other laws. This presents a key point in internal contestations and boundary- and identitymarking among cross-border movement actors themselves; the layering of unpredictable alliances that characterise border practices. But, these internal contestations are said to characterise the broking of tensions between border enforcement and undocumented border crossings, the governance of mobility and the precarisation of labour, as well as the different identities and motivations of the various border actors. 
A slap in the face introduces another dimension to both the passport and its holder. If ghost passports represent a splintering of the lives of passports and their holders, a slap in the face illustrates the violence that defines both this splintering and various practices covering it - by state and other actors. This violence is also symbolic of not just border struggles, but their ramification in the realm of dispossession in general, particularly how the forces of capital (on behalf of which state mechanisms and officials invariably operate) work to reproduce flexible labour (Rygiel, 2011: 3). The slap dramatizes a dire life, whereby the passport fails in transition (or crossing the border) but stands as an alibi for stalled life, broken relationships and entrenched disempowerment.

The space that ghost passports inhabits reflects how both documents and their holders are, on one hand, already navigating a rigid and restrictive migration and economic livelihood context, in which they simply try to appease the border enforcement mechanism through their own devices. On the other, together with state officials, facilitators and others, they construct and facilitate an alternative interpretation of state norms that avail an alternative process of interaction and border acumen. That order uses the bureaucratic system to sustain its own non-state processes. Stated differently, facilitatory networks use the Beitbridge bureaucratic immigration system as an alibi against, and a conduit for, their own non-conformist practices of movement.

Fundamentally, the kind of thought process by which some omlayitsha distance themselves from their 'rogue' counterparts, and by extension make a similar distinction among state officials, is itself a testament of a fraught border landscape within which people negotiate border crossings. Thus, there are many border actors who, as much as they respect civic authority and seek to abide by it, are compelled by their conditions of dispossession to utilise available socio-economic opportunities that the border 
opens. All these cases illustrate a way of redrawing the border by rearticulating the ethics of movement, for instance along particular understandings of illegality, which speak to the same issues of dispossession, as well as to exploitation and domination in the context of what may be sometimes seen as a rigid migration governance regime.

\section{Illegibility, precarious living labour and dire life}

The analyses and observations presented above should help in moving away from the idea of 'corruption' as a major defining feature of the practices discussed in this chapter, and of the temptation to label the actors involved in these practices as corrupt. As I argued in the introductory chapters, it is hardly productive to see the border itself as a pervasively corrupt space. In other words, I position myself against the temptation to delve into a discussion on, or offer a typology of, 'corruption'. As Pierce (2016) and others (Anjaria, 2011; Ochonu, 2014, 2016) have suggested, rather than focusing on legal categories to define social practices, one is better off locating the subject of corruption, which many states, development organisations and scholars are no doubt concerned with, in a broader and more complex discursive and relational field. Such a field pertains material practices as it does moral discourses. With that, as I have suggested above, the aim is less to explore the bureaucratic political logics through which movement across the Beitbridge border may be viewed, and more the practices, relations and understandings of this movement by its actors across the publicprivate domains. The task is therefore to follow how people speak about, relate to and position themselves vis-à-vis their experiences of crossing the border in general, and of practice of stamping ghost passports in particular. 
To return to Janet Roitman (2004, 2005, 2006), the practices that characterise this space see the simultaneous reification of states' capacity to impose controls on movement on one hand, and the entrenchment of practices that contest, negate or bypass such efficacies on the other. Roitman has discussed this splintering of regulative logics as often interlinking and overlapping, partly proceeding from dynamic redistributive networks. An anecdote provides insights into how these logics may overlap and interlink at a mundane level at Beitbridge.

\section{Dire life}

When one arrives at the first gate of the Beitbridge border perimeter from the Zimbabwean side, one notices disorderly private cars parked on a slightly elevated section of ground to the right. The cars work as pirate taxis. They ferry cross-border travellers coming through the border gate from South Africa to their preferred next stop, often a pick-up point for onward journeys. Among them is a mixed group of informal traders, including moneychangers, hawkers of prepaid cellular airtime recharge cards, iced water and other good sellers, as well as touts who, for a small fee, persuade travellers emerging from the border perimeter to use these parked cars. The touts also operate makeshift carwash stalls at the back of the parking area, cleaning the same cars as a way of complementing their incomes. Many of them look dirty and unkempt, as if they are too busy to find time for personal care. They are called matsotsi in local parlance. Loosely translated, this means that they are hoodlums or thugs. As a descriptor of their ways of earning an income, matsotsi is a label assigned to them by the police and other state officials. It particularly relates to their other work as local hyenas (or izimpisi), people who private transporters call upon to guide their undocumented travellers across the border, either through the bridge and its many checkpoints, or through the bush and across the Limpopo River itself. Fekete, a twenty-something year old man, is one such tsotsi (in the singular). 
Over hanging out together and discussions during the year-end holidays between 2014 and 2015, Fekete spoke about his work touting, car washing and as a hyena. A lucrative line of work at times, being a hyena especially came across as something of a serious hazard. Threats emanate from the ever-present possibility of being arrested by state officials for 'human smuggling'. But, they also have to do with conflicts among matsotsi themselves for income opportunities, as well as the violence that pervades the bush, where bandits, or amagumaguma, may attack them. Fekete largely spoke in monotone whenever he narrated the many violent incidents he has either witnessed or experienced where undocumented travellers, and sometimes himself, have fallen victim to amagumaguma. Often recalling gruesome incidents of robbery, physical and sexual abuse in extended detail, the resignation in his speech spelt shockhorror. By contrast, he was jovial and upbeat as he narrated stories of his many encounters with state officials, including his countless arrests by members of the Zimbabwe Republic Police and the South African Police Service:

The only problem is how much time and connections you have at hand to successfully negotiate your release. The police are very reasonable people. They often release you if you can reach an agreement with them in reasonable time. Of course you must give them 'something'. The worst is to be arrested at the end of the week, like on a Friday night, when regular officers go away for the weekend. In that case, you may have to be processed (fingerprinted, statement taken and docket prepared) by someone you may not know, and over the weekend, for a court appearance on Monday morning. By then, your chances of negotiating a release have dwindled vastly. But, because of my many arrests, while I am at the police station, I have come to expect that my friends in the force will let me go as long as my colleagues outside can guarantee that they are working something out. 
This excerpt sounds almost generic for many relations between state officials and private actors who may fall foul of the law across the Zimbabwe-South Africa border context. Just like Jahman above, there is no attempt by Fekete to diminish the profound legal force of the law as an agent of either condemnation or liberation. This comes through when they both explain their and the state officials' role in the law's active circumvention.

What is of further interest, however, is his contrasting attitude towards the lawlessness that pervades the bush and the ambivalence that appears to sometimes define law enforcement. Here, the context within which police officials, in parallel with their counterparts in border enforcement, interact with non-actors who facilitate undocumented movement, is one of proximity and conviviality. Fekete has more to fear from other 'law breakers' than those responsible for enforcing it, even if his line of work would suggest an opposite set of alliances. This can be taken to illustrate the context within which the phenomenon of ghost passport proceeds.

\section{The ambivalence of enforcement}

From the other end, the attitude of custodians of that law with regard to both their official duties and their social relations warrants some attention. At the level of bureaucratic politics, their attitude suggests the (ab)use of public office to secure private outcomes. But this is not the whole story. It is important to consider how state officials refer to the same 'culprits' who they use their official influence to extract private rents. By calling them matsotsi, they discursively construct them as a social menace that needs to be eradicated. But, from Fekete's own embrace of the term, and from the descriptions of his different lackadaisical arrest experiences, there appears to be no real corrective force or even inclination behind either law enforcement or the designation of local hyenas as matsotsi - a problem to be eliminated, by the 
police. This absence of will has little to do with a lack of capacity. It appears that by positing matsotsi as a problem they are only minimally interested in fixing, state officials inadvertently demonstrate some of the ways in which they use their work to leverage other social relations, their corresponding logics and worldviews. By combining the two, they are able retain their jobs as civil servants while accruing status and other resources in a broader field.

In line with their official station, state officers are eager to draw the line between lawful conduct and the lawlessness manifested by matsotsi. By so doing, they justify why they should continue arresting them, or at the least seen as disapproving of them in the face of the law. But as both undocumented movement and the role of matsotsi in it are ubiquitous across the border, state officials and matsotsi, as well as private transporters and other actors who participate in the economy of undocumented movement, have developed rapport and networks of reciprocity and redistribution to address mutual needs and benefits. This way, both the construction of matsotsi as a problem and the comradely interdependence that exists between them, state officials, private transporters and undocumented travellers, sometimes enforced with the threat of the law, suggests the kind of overlaps and interlinkages alluded to above.

There is little doubt that the mechanism for arrest, detention and prosecution of offenders such as matsotsi exists and can be effectively mobilised when the circumstances demand. However, through a partly exploitative and partly redistributive logic, this mechanism is sometimes manipulated, negated, by-passed and ultimately reaffirmed by the same actors - enforcers, 'offenders' and third parties - to whom it applies, rendering it both efficacious and ineffective. It becomes a site for the exploitation and affirmation of state power, as well as for the cultivation of relations of an instrumental, redistributive and perhaps even predatory nature. 
This mutual regard between matsotsi and state officials may serve further to illustrate a point about the phenomenon of ghost passports. When the law is rendered ineffective to detain and convict Fekete and others, it is not because its objective instruments are missing. It likely means that those it governs, on both ends, have chosen to only pay it lip service. Apart from its regular standing, its other use as a threat to enforce alternative arrangements simply means that it is reified at the same time it is undermined.

The same can be observed with ghost passports. When passports can pass through and register in the absence of their owners, there is nothing in the process to suggest that the enforcement mechanism which handles cross-border travel documents is broken or incapacitated. What is clear, however, is that the people subject to this mechanism have chosen to use it for other purposes, while at the same time paying it lip service. They are as keen for the mechanism to remain functional as they can do little to weaken it. And, when they are caught exploiting it, they are indeed punished accordingly. However, their interest in maintaining this infrastructure of domination is useful if it is used for other personal or instrumental interests. The enforcement structure and the strategies of its manipulations are thus co-constitutive. We marvel not, therefore, as Roitman (2005) has observed, that the strengthening of state infrastructures can proceed in tandem with what she refers to as growing informality.

The lives of passports (and thus of people they mirror) are not just parallel, but are in constant interaction, as well as under constant stress from both official and non-state forces; at once subject to further splintering, as well as being re-forged in a singular, emergent (Archer, 1992) mode of cross-border movement. As such, the slap in the face signals their fragmentary and malleable nature. Contestation, resistance and negotiation renders these lives, of which the passport is a disembodied 
signifier, as modelled in everyday border practices, but as also caught up in violence, unpredictability and flux that structure their precarity at experiential and structural levels.

\section{Flight}

A general reflection on the social relationships between people and documents is perhaps warranted. When people sometimes conduct themselves differently from how their travelling/ identity documents 'say' they do in the border crossing process, a situation ensues that represents a distortion of the order that imposes the passport as the central relic of that order's rituals and practices. In other words, a struggle arises, indeed one that this chapter has sought to follow, which relates to how the systems governing movement are meant to classify people in relation to their access to, belonging and participating in, certain cross-border spaces. As human mobility is older than states and their mechanisms of border enforcement (Nail, 2015), there is no reason not to expect that mechanisms which are meant to control people crossing the border will often be challenged in different ways. However, the more pervasive practices that underline the separation of people from documents, such as the phenomenon of ghost passports, underscore a need to reflect more on the shifts that occur regarding not just how state and non-state actors relate to travel and documents, but indeed to categories of inclusion and exclusion, as well as to practices of control and coercion, especially those who challenge or seek to escape this control. Also, relating to this issue is how to imagine (postcolonial) space and contested subjectivity in the everyday practice of movement, but I leave this matter for the following chapter.

One may notice that for as long as movement across the Beitbridge border has been an issue of vested state interest, attempts to bring it under a semblance of civic control have met different kinds of contestation (Musoni, 2012). This is not unique to Beitbridge as 
other studies have demonstrated different kinds of 'resistance' elsewhere (Spenner, 2009; van Schendel \& Abraham, 2005; Nail, 2016; Rygiel, 2011). The idea behind the ethics of illegibility is that, rather than celebrating these kinds contestation as indicative of insurrection, as some of the literature on autonomous movement has suggested (as cited in Nyers, 2015), it may - in this case be prudent to consider them as creative engagement with mechanisms of control, reifying and evolving them. There are, of course, political consequences for this formulation with regard to the different actors that participate in movement across the Beitbridge border. Thus, a more immediate question regarding the significance of contestations around documented crossborder travel lingers.

To turn to some of the insights coming out of the literature on autonomous migration, the question of people versus documents, and what they represent, is partly one of movement pathways versus control. The point of contention is that as movement challenges spatial as well as social demarcations of the insider and outsider that the border represents (Mezzadra \& Neilson, 2003, in Rygiel, 2011: 4). Therefore, it becomes the focus of regulation. Rygiel's (2011) intervention, which the issue of ghost passports is perhaps illustrative of but also contests, is that controls on movement come after and appear as a response to the movement itself. It may appear that if movement precedes its regulation, then such regulation has come to not just overbear on it, but to also predominate it. This has the tendency to recast strategies of escaping this control and of flight as devious and dangerous, which, according to prevailing discourses, they are. However, as I have demonstrated in earlier chapters, strategies and practices designed to resist this control appear across the Beitbridge border space in one form or another for a period spanning over a century. They also appear to bear ties to broader processes of politics and economy that benefit directly from such processes of precarisation. If this formulation is the starting point, illustrated in the initial chapter discussion that controls respond to and 
accommodate patterns of movement, then the practices that nestle around the phenomenon of ghost passports merely serve as creative ways in which movement attempts to escape control (Papadopoulos, Stephenson, \& Tsianos, 2008; Rygiel, 2011: 4) The case of ghost passports is itself but one of many ways in which the agency of cross-border travellers manages to pierce through and challenge a more dominant border enforcement structure and its politics of control. What this chapter also demonstrates, is how this resistance to control is fraught with violence, unpredictability, coercion and compromise. Disembodiment is still subject to modes of its control, as much as control is itself continuously modified by strategies such as disembodiment. The result is that in the ensuring struggles between escape and control, which revolve around the lives and travel documents of relatively vulnerable Zimbabwean migrants, the abjection, resistance and evolving disempowerment of actors who find themselves navigating alien systems and exploitative structures is uncovered

Therefore, if the purpose of the passport in movement is to reign in people's escape from control, seen more clearly in how their movement appears tied to their further precarisation as wage labour, then its effectiveness across the Limpopo Valley is clear, although not without contestation. The willingness to 'play' with the law and yet to not out-rightly dismiss it, suggest that the negotiation, manipulation and resistance which often characterise everyday border crossings, subsumed in the tension between control and resistance, engender the kind of practices that are exposed to the violence and friction of this contestation. The border enforcement apparatus appears coercive, fragmentary and malleable, so that the social relations that ensue within this context shape the border crossings that sometimes pass under the phenomenon of ghost passports. These practices are important in their ability to furnish relevant examples of how the border as a social space is engaged with, imagined and rearticulated through everyday practices of movement. 


\section{Conclusion: Make-belief as appeasement}

The passport remains a key relic for cross-border travel between Zimbabwe and South Africa. This is the case in terms of border enforcement requirements and in relation to negotiating undocumented travel. Regarding the latter, the passport in the least functions in various instances as the anchor or foundation from which to establish, understand and calibrate the modalities of crossing the border with incomplete or missing documentation. This chapter has attempted to examine how the passport, in travelling without people - the opposite of how movement without documents is often approached and framed - seeks to placate and mimic dominant representations of cross-border movement. This alternative pathway of movement, premised on sly civility and an ethics of illegibility, centres on gameplay that characterises the phenomenon of ghost passports.

Ghost passports appear without their owners. Through strategies that include disembodiment, and by deceptively engaging the same bureaucratic systems, people decouple themselves from documents, thus reorienting the very meaning of such systems. By only paying lip service to the systems erected to 'read' their 'identities' while on the move, strategies of disembodiment are seen less as insurrectionary, and more as ethics of illegibility They are about how economically active bodies are produced by, and in turn shape, the parameters of dispossession and categories of exclusion/inclusion. If, on one hand, this means that disembodiment is a metaphor of disempowerment, on the other, it speaks to how the disempowered can still be politically responsive, if not in ways that subvert structures of domination, then in the ways that redefine their modes of operation.

Disembodiment, or strategies of (in)visibility, also make overtures at an ongoing debate on migration regimes as control strategies that appear after reining in 'supposedly' unruly phenomena. There is a growing body of migration literature, especially on 
informality and on borderscaping (see, for example, Roitman, 2004, 2005; Andersson, 2014; Parker \& Vaughan-Williams, 2009; Brambilla, 2015) which suggests that despite these control mechanisms, phenomena such as that of ghost passports ask us to broaden the scope by which we read and examine relationships that characterise movement. That is, such relations contribute in the shaping of a complex social landscape.

The recent history of the Zimbabwean passport has been evolving fast, but it speaks to issues of mobility that have been unfolding for a long time. That Zimbabwean passports find space in the politics of undocumented cross-border movement between South Africa and Zimbabwe suggests that there is more to undocumented movement than just paperlessness. A stringent migration regime engenders strategies of movement that do not necessarily dismiss, but engage with the need for, documentation. In this case, this engagement encourages make-belief, facilitation strategies by which actors appear to abide by official border enforcement requirements, even though they manage to do so partially. What ensues are everyday strategies that must contend with an unpredictable context, where strategies to escape border enforcement mechanisms engender social relations that themselves seldom escape surveillance from migration control.

The synthesis between border enforcement, its social relations and the contestations within suggests that border crossings, particularly the phenomenon of ghost passports, occupy a fraught terrain. The splintering of identities that appeal to various modes of crossings, but remain under a dominant force that seeks to domesticate them, presides over practices that constantly test the enforcement mechanism, often finding ways and room to continuously reshape its rigid structure. The flux between control and resistance, itself testimony to various kinds of bordering, opportunism, suppression and manoeuvre, speak to a broader spectrum of 'play'. Omalayitsha, through hyena strategies, use this play to constantly shift the boundaries of 
accepted forms of movement. This has the effect of redrawing the boundaries of belonging, inclusion and border regulation, even if this reshaping of the social landscape of cross-border movement represents ongoing struggles. 


\section{$\boldsymbol{Z}$ \\ CONTESTING MIGRANT SUBJECTIVITIES: \\ Crisis, ambivalence and political identities of transition}

\section{When fear visits}

Several times between the years 2015 and 2016, I had the opportunity to share thoughts with colleagues on the kind of people Beitbridge border crossings 'make'. I recall that one of the conversations had quickly settled on the different forms of self-reprehension and distress that often go with presenting oneself before border officials, with or without documents. These were highly skilled Zimbabwean nationals working at a university in South Africa, who were sharing stories of the anxieties they sometimes went through in checking 'themselves', and in double-checking the state of their documentation, much like Msholozi did in the beginning paragraphs of this thesis, as they approached immigration counters and other border control points. The consensus was that every traveller coming into South Africa, perhaps in comparison to entering other countries, goes through this condition as a mental response to what they consider the ordeal of interacting with border officials. They confirmed what I have observed many times at Beitbridge.

The sense of vulnerability, unpredictability and potential danger that these colleagues attested to is likely to be more acute among new, undocumented and other travellers with generally low 
skills. This is so because their degree of uncertainty regarding the possibility of entry, or the general border procedures as one goes through the enforcement mechanisms, may be higher. In general, however, many Zimbabweans who cross at Beitbridge are familiar with what they consider a persistent attitude of distain directed at them particularly by South African immigration officials. Such an attitude often finds outlet in unpleasant language, the issuing of shorter than otherwise available residence days on passports and vigorous body searches. Such an attitude also finds echoes in a general climate of xenophobia towards African immigrants in the country.

However, this form of the (re)constitution of the subject (Mamdani, 1996; Mbembe \& Roitman, 1995), is neither new nor limited to the South African side of the border, as well as to Beitbridge. The border space, particularly its techniques and efficacies of control, what some have called border governmentality (Fassin, 2011: 214), tends to render travellers significantly circumscribed. The stringent immigration policy regime that South Africa has maintained over time, despite changing conditions of movement and work as have been explored above, is significantly responsible for this circumscription. It is at the border gate that the question of the very categorisation of different people is at its most visible, and where some humans tend to be clearly uncovered as precarious living labour in the classic sense. ${ }^{99}$ At the embodied level, this may appear in part as a crisis of the person. ${ }^{100}$ On the other hand, and certainly in the case of the Beitbridge border, this is also where responses to the techniques that render the person an object of control are activated and can be discerned.

99. This is borrowed from Karl Marx's critique of Capital, but it is used here as developed by Mezzadra and Neilson (2013). The thesis and this chapter develops this concept more.

100. Mbembe and Roitman (1995) have called this the figure of the subject in times of crisis. 
In this chapter, I wish to bring together two discussions about the possible political consequences of social interaction in similar situations and spaces in the post-colonial context. The first, developed by Achille Mbembe and Janet Roitman (1995), pertains to what they have called 'the figures of the subject in times of crisis'. It explores the production of a simultaneously disorientated and cynical subject as a consequence of the 'excesses' of post-colonial African state power. The second, developed by Victor Turner (1969, 1982), and with resonance in Mary Douglas (1966), has to do with how the magicality of treading dangerous 'liminal' spaces can be a source of 'shamanic' power for those who dare to do so. The place of go-betweens, the shamans, is not forgotten in a study that involves the role of hyenas in these acts of subtle spatial and social transcendence. By situating these two approaches as mutually constitutive, and layering them with related notions of subjectification, the chapter seeks to explore the production of 'subjectivities of transition'.

\section{Subjectivities of transition}

\section{'On the subject of crisis' and 'the crisis of the subject'}

In analysing strategies by which people negotiate undocumented cross-border movement, particularly ones that both undermine and reify the state mechanism of control, the last chapter brought the discussion closer to the issues that Achille Mbembe (1992a, 2002), Mbembe and Janet Roitman (1995) and Judith Butler (1992) take up in their various works on 'subject(ificat)ion', or the processes by which subjects are (re)produced in postcolonial contexts of crisis. ${ }^{101}$ Zimbabwe's exodus can be taken as an

101. The conceptual understanding of crisis should be the same as that which Mbembe and Roitman (1995: 324) employ, which, owing to different kinds of emergencies, 
example of such crisis. Indeed, this extension of the previous discussion partly nestles on the figure of the undocumented subject that must traverse a context of general unpredictability, improvisation and indeterminacy that defines crisis (Mbembe \& Roitman, 1995).

For Mbembe, such a context partly characterises postcolonial power relations as a world of meanings by which state power is dramatised for and imbibed by subjects through a simulation and mimicking of spectacle and ceremony that leaves both dominant and dominated in a state of what he has called 'impotent zombification' (1992a: 4). This loss of vitality, as he calls it, is produced when subjects, owing to them sharing the same body of ideas or episteme, have to constantly negotiate multiple identities. The possibility of mediating these shifting identities is brought on by the actors' (dominant and dominated) ability not just to read but also communicate in the same 'signs and knowledge' that enable them to navigate "social life, political relations, and individual conduct" in a "precarious equilibrium" (Mbembe, 1992b: 132). It is this condition, by which identities enable subjects to change personas, that partly frames crisis.

Mbembe and Roitman have discussed the two forms this crisis takes. The first, the 'subject of crisis' manifests as "a constitutive site of particular forms of subjectivity" that arises from a lack of coincidence between practices (facticity) and their meanings (ideality) (Mbembe \& Roitman, 1995: 323). The flipside of this condition entails the challenge to give meaning to such moments. For my purposes in this study, such a 'crisis of the subject' is fostered within a general atmosphere that combines the various

has to do with physical and mental violence that issue from the everyday experience of life at all levels of society, separating that experience from the available language and meanings that explain and interpret it. Such conditions of crisis have a tendency to cripple people's responses to the situations they face. Zimbabwe's exodus offers a good example for such an understanding of crisis. 
subject-constituting social practices that characterise border enforcement and border crossings in conditions of informality, simulation or make-belief, and other forms of 'creative misunderstandings' (Naum, 2010).

I suggest that such subjectification comes about both as a product of history and as a variable of space. Through processes that partly evolve over time and are somewhat shaped by contestations and struggle that bear the imprint of local social forces, this kind of subjectification speaks of unstable identities built on both strategies of coercion and the quest for parochial legitimacy (Mbembe, 1992b). Such shifting identities are themselves neither coincidental to the evolution nor to the governance of movement, and are particularly central to the production of the Beitbridge 'borderscape' and its subjectivities.

\section{Ambivalence, ritual and subjectivities of liminality}

Mbembe and Roitman's 'regime of subjectivity' (1995), as sketched briefly above, can be counterpoised to notable discussions on ritual analysis. The work of cultural anthropologist Victor Turner (1969) has influenced thinking around what has variously been referred to as the 'borderlands', 'third spaces' or 'liminal positions' in so-called 'traditional' and 'post-industrial' societies. He is known for his methodological and processual analysis which builds on van Gennep's (1960 [1908]) work on the rites of passage; an allegory depicting a person's movement through social corridors and across thresholds of social status. The importance of van Gennep's (1960) typology was to demonstrate that as individuals crossed thresholds, they momentarily find themselves in in-between statuses, with no claim to any. Turner's interpretation (1969) of this liminal space, however, has inspired a rich body of critique. 
The significance of approaching the border by using Turner's notion of the threshold is that it positions the border as a rich social space, as opposed to, for instance, a demarcation line at the external limit of a society or territory. The interaction and relationships that develop in what he calls a temporary liminal zone, tend to exhibit, according to him, intense awareness of shared experience, or communitas. Because of the severed attachment to various social statuses, Turner imagined this space as a kind of social equaliser where everyone is more or less the same. The liminal position, or liminality, was for him also a position of dynamism and of a kind of disorder (Turner, 1969) as there are no social hierarchies or allegiances to enforce a semblance of discipline. Communitas and liminality, while demonstrating a struggle between anti-structure and normative or hierarchical social positions, also present a moment of symbolic power.

Liminars, as Turner designated the actors that occupy this position, possibly including the hyenas of the Limpopo, possess the potential for a cultural critique or even a deconstruction (Weber, 1995) of structural constraints by traversing their spaces. However, even if they (and Turner) offer a critique and reinterpretation of Douglas' (1966) ritual uncleanliness, their temporality and furtiveness can be seen as dialectically affirming the prevailing social order. Indeed, Turner's (1969) processual analysis envisioned a potential reintegration into a prevailing social order. Further, Weber (1995: 530), referencing Rosaldo (1993), writes that Turner's privileging of both a 'homogeneous' communitas and a social order of 'proved values' to which liminars return, make for a problematic subject position, one that does not account for temporal and political factors, and one that is constrained by a palpable and rigid model of ritual analysis.

Arguably, Turner's (1969) conception of the social drama that characterises what he terms liminality, particularly the interaction and relationships of communitas, can be used to characterise 
'marginal' spaces (or more precisely zones of transition, or third spaces) if extended to allow for the positional ambiguity and the socio-political contestation inherent in both cultural forms and their analysis. Mary Douglas' (1966) take on liminality positions social actors such as the hyenas of the Limpopo within this space of ambiguity and contestation, which for them becomes a source of power. As discussed in Chapters Five and Six, liminars become powerful because they dare to reach the zone of transcendence, in which they can both be their 'ordinary' selves and still reach for horizons not accessible to others. In other words, they can mobilise and deploy ambivalent identities to their advantage. If applied to experiences that animate everyday social life, such as those that take place at the Beitbridge border zone, this removes the social levelling assumed to prevail in liminality, in the process shifting the spatial and social border in different ways. This also has a tendency to reproduce a potent, if furtive, political subject, and is in line with the thinking that ritual transcendence of necessity tends to periodically escape, elide or partially trump hegemonic mechanisms of control.

\section{Subjectivities of transition}

The subjectivities that embody the various experiences of the border zone, which connect to both crisis and ambivalence, can also be connected to the notion of transition as used by both David Scott (1985) and Mezzadra and Neilson (2013). Such a notion engages simultaneously with the spatiality of the border as a point of division and connection, as well as its sociality as a space of socio-political practices. Thus, transition relates to the international division of labour (Mezzadra \& Neilson, 2013: 23), and to the governance of living labour through various border enforcement techniques (Scott, 1985). Subjectivities of transition in the Beitbridge border zone can be thought of in terms of the role of border in sorting skilled from unskilled labour, or precarising migrant labour, and thus producing distinct kinds of 
subjects. At the same time, this role of the border can be traced in the production of subjectivities that are shaped by prevailing modes of domination and rule.

As the case of Zimbabwe demonstrates, subjectivities of transition can be uncovered in settings of significant socio-political upheaval that are often accompanied by rapid economic decline, creating significant levels of documented and undocumented migration across international borders. They can be glimpsed through the kinds of interaction that proliferate at international borders, where elements of state, market and patronage meet as different actors participate in the 'hyena economies' that emerge in conditions of disempowerment. Changing economic and social relations often mean that strategies of opportunism, accessible to a few, are used to manipulate prevailing structures to facilitate or broker access to desperately sought-after sources of livelihood. But, such relations also produce unstable identities as people shape and are themselves shaped by the ambivalent border spaces they move through.

While calling such 'opportunism' brokerage, ${ }^{102}$ Deborah James (2011:318) notes that facilitation in these circumstances, more than a mere use of state assets by some to provide means for those less able, is also the context in which social actors are produced by

102. As a concept, brokerage has been used, especially within political anthropology, to analyse relationships of dependency and clientelism (Eisenstadt \& Roniger, 1980; Gluckman, 1955; Long, 1968; Randeraad, 1998). Brokerage has been viewed as inadequate in accounting for the strength of what others have called the 'informal politics' of bargaining and negotiation (Bayat, 1977; Chatterjee, 2004). This is especially the case among those who celebrated the triumph of the political power of states and other institutional domains in effecting structural controls, such as in the entrenchment of property rights, which were seen to reduce the role of local relations (Mitchell, 1990). Other scholars have explored the connections between brokerage and the contexts within which it emerges (Boissevain, 1996), and the linkages that persist between corruption, patronage and continued poverty in parts of Africa (Mwenda \& Tangri, 2005). This paper situates itself within a revival of interest that has driven a desire to explore the inner logics of brokerage so as to understand its nature and continued role and importance in social relations. 
the social situations they help shape. In other words, facilitation becomes a tool that helps shape the identities and subjectivities of the actors that produce the mechanism (facilitation) itself. By focusing on the Beitbridge border between Zimbabwe and South Africa, where the states' infrastructure of controlling crossborder movement is increasingly contested, we get an idea of the variety of facilitation practices as a way of exploring how social action shapes space and different subject positions.

\section{Temporal multiple subjectivities of the border}

Here, it is first instructive to take another brief look at the past. As I have already pointed out several times, successive states on both sides of the Beitbridge border have tried in different ways to control undocumented border crossings over the years. The colonial government in Rhodesia began, although in a rudimentary way, to control the cross-border movement of clandestine labour as early as the1900s (Murray, 1995), escalating surveillance of the border zone by 1929 after the construction of the Alfred Beit bridge across the Limpopo River (Trollip, 2013). In South Africa, the Union government imposed, in 1913, a prohibition on the recruitment of labour from north of the 22 degrees latitude line for work both in the mines of the Witwatersrand ${ }^{103}$ and elsewhere in the South (Murray, 1995), due to concerns about the movement of unchecked migrant labour.

Later, the surveillance of the border zone formed part of counterinsurgency measures utilised during struggles for political liberation in both countries. The construction and electrification of the border fence in 1986 (Bolt, 2015; Musoni, 2012) were indicative of both a continued concern around unregulated

103. The Witwatersrand is the area in South Africa within which a large portion of South Africa's gold mines are located. 
border crossings and the increased need for state intervention to stop the movement of African National Congress (ANC) cadres during the anti-apartheid struggle. Today, the number of crossings, documented or otherwise, continues to surge, despite attempts to tighten immigration controls in post-1994 South Africa (Crush, 2008). In effect, there is an entrenched history and sociality of undocumented crossings that appear to not merely predate, but also significantly (though only partially) trump state-based border control mechanisms. Through the enduring political economy of the local Venda and the Shangaan people, ${ }^{104}$ narratives of erstwhile indigenous nations crisscrossing the Limpopo River in flight and in conquest, and the eventual emergence of state-led mechanisms to bring the Limpopo River under colonial dominion as a state boundary between Rhodesia (Zimbabwe) and South Africa, the control of movement across the border has had a fairly dismal record, as this thesis has already suggested.

The efforts to control movement are but one part of each states' involvement in regulating border crossings. From an institutional point of view, the bulk of movement across the Limpopo has partly been seen as driven by the 'formal' and 'informal' labour needs of the two countries (Onselen, 1976), as well as apartheid South Africa's 'foreign policy' (Bayart, Ellis, \& Hibou, 1999). However, in line with common global mobility trends in times of economic difficulties, the increased surveillance of movement across the Limpopo River has also succeeded in promoting undocumented crossings and international 'smuggling and trafficking networks', which the mining and manufacturing economy of the Witwatersrand has sustained and benefited from for a considerable period of time. ${ }^{105}$ A parallel economy

104. The Venda and Shangaan are two ethnic groups whose members can be found in both Zimbabwe and South Africa

105. This paradox of movement is not unique to the region, as it appears to be an almost ubiquitous technique of neoliberal migration control, characterising, for instance, the 
has grown and endured that thrives on clandestinely enabling, facilitating and recruiting people to seek better opportunities by crossing the border into South Africa and beyond. And, the actors who participate in this economy span various institutional realms.

It is also important to mention the states' other role in movement and border crossing: the active participation of state actors in underground (in the legal sense) international economic networks as part of state business or for private gain. Partly, this has to do with apartheid South Africa's incursions into the subregion in pursuit of political outcomes through military means. But it also refers to: the state's active encouragement of an array of criminal gangs; the participation by security officers in crossborder criminal enterprises; the doubling up of border farmers as a security buffer between Rhodesia and South Africa, with active encouragement by the apartheid state; and other 'smuggling' operations by state agents/officials in order to enhance state resources in the fight against the revolutionary forces of the ANC and the South African Communist Party (SACP) in response to the state's international economic isolation (Ellis, 1999). While cross-border 'smuggling' networks became a resource for the political economies of the region in the late colonial era (Ellis, 1999), they were built on, and then themselves nurtured, a culture of blurred boundaries between official duty and private enterprise on the one hand, and 'smuggling' as state or private business as well as a crime, on the other. Ellis (1999) demonstrates the ways in which state officials tended to 'wink' at such a culture in the past, even if it occurred outside their ambit. In a similar vein, Bolt (2011) describes how a post-independence Zimbabwean farmer simply drove his vast array of mechanised agricultural equipment across the Limpopo River when, for political reasons,

Aegean Sea as one of the most porous and heavily policed theatres of border crossing in Europe. For a detailed discussion of this, see (Tsianos \& Karakayali, 2010) 
he decided that he was better off farming in South Africa. My own research, and that of Ellis (1994) and others (Bolt, 2011) ${ }_{1}^{106}$ suggests that cross-border movement of undeclared bulk goods and equipment continues in both directions across the Limpopo Valley, involving individual go-betweens with links to both states, state security officials, international underground economic enterprises, traditional leaders, criminals and other actors on both sides of the river.

The different actors who are implicated in everyday crossings are people who interact at different levels and according to different, but interactive, logics. In this way, we can consider their interaction as a platform for the analysis of the mobility governance regime that is more than just state-centred. Border practice suggests that illicitness, if indeed it should be called that, is in fact part of any state (Abraham \& van Schendel, 2005). From this perspective, a re-examination of mobility and its governance simply joins similar voices that call for a focus on micro-processes of movement in order to understand their role in shaping and critiquing broader trends (Burawoy, 1998).

From this historical sketch, it is possible to discern the dissonance between the presumed orderliness of border enforcement and the actual border practices that have been shaping the Beitbridge border space. The coincidence of the different subjectivities is itself indicative of the kinds of transition that have been shaped by colonial governmentality and regional political economic forces, as well as by how these and other forces have been reifying

\footnotetext{
106. Maxim Bolt (2011) records the case of a farmer who, when he felt that he could no longer farm in Zimbabwe in the late 1990s, simply drove his mechanised agricultural equipment across the Limpopo River to settle in South Africa. In my case, a research participant who works as a manager at a local hotel at Beitbridge, who is also a local resident and a former Zimbabwean army officer, drove with me about 80 kilometres due east of Beitbridge, to a spot where army personnel, amagumaguma (bandits) and other wheelers and dealers broker and facilitate the transfer of various kinds of contraband and other bulk goods across the Limpopo River.
} 
as much as they have been shifting, if not often erasing the border. Practices that straddle official-unofficial, legal-criminal, formal-informal and state-civil society lines seem to flourish at Beitbridge by appearing to render the spatial border as a third space, a zone of ambivalence. Nevertheless, by approaching the practices alluded to above as subject-constituting ones, I hope to (re)present the border as a zone of transition, where subjectivities define the very core of social and political life locally at Beitbridge, as well as regionally and at a broader level.

\section{Waiting on the move}

In the December of 2014, I spent time in the towns of Beitbridge and Musina to observe people as they crossed the border between Zimbabwe and South Africa. In Southern Africa, and especially at Beitbridge, the longest holiday break in December sees many Zimbabweans and their goods crossing the country's borders to be with their families. The exit gate as one comes into Zimbabwe is thus a place of long queues and delays, and my observation confirmed how this can be a harrowing experience for travellers (Trollip, 2013). Directly under the overhead sun, this section of the border enclosure was the scene of intense activity. The limited cover that extended from the immigration clearance counters was shared between buses, private cars and the many bags being stripped bare for routine inspection. The surge in activity at the border was not surprising. The end-of-year holiday break in Southern Africa is a time generally characterised by congested travel. ${ }^{107}$ At this time, internal and international migrants embark on the annual 'trek' (journey) to their 'traditional' homes, one of

107. The time immediately before Christmas witnesses perennial spikes in travellers passing through the border. Recent records place the highest number in a single day at 42, 435 travellers on 23 December 2012. This number is much higher if undocumented travellers passing through the gates are taken into account (see Trollip, 2013). 
the few annual opportunities they have to be with 'faraway ones' (friends and family). ${ }^{108}$ On this particular afternoon, it seemed that the need to cross a border, and the delays involved, would be felt nowhere more than at the Beitbridge border post.

At the border gate, different individuals milled either purposely or aimlessly around the arrivals enclosure. Others pushed and shoved in bloated queues that snaked away into the sun. Sporadic scuffles broke out amongst impatient travellers, and private security guards constantly battled a disorganised and frantic press for passport stamping, which often seemed to overwhelm them. On one occasion, when a senior immigration officer appeared from inside the building to intervene in a scuffle between a security guard and an irate traveller, he found himself having to deal with a particularly 'foul mouthed', angry traveller.

A few steps back from the site of this commotion at the immigration counters, the ground rises suddenly into an oftenvacant, sparsely built, ridge that falls away into an expanse of ground to make up the rest of the 'Arrivals' enclosure, koMalume (see Figure 7.1). On this day, the ridge too was a hive of activity. One queue led to an offset, standalone police counter, where returning travellers were paying fines for failing to produce valid travel documents. A mixture of travellers and hawkers in varying postures dotted the rest of the embankment.

The other side of the ridge housed an expanse of waiting vehicles in yet another massive and disorderly queue. It was

\footnotetext{
108. Holiday travel across Southern Africa is yet another visible manifestation of the enduring group areas project that was designed to confine black Africans in economically unproductive labour reserves, from where they repeatedly travelled back and forth to work in the region's industrial cores. Although more recent political and economic upheavals have meant that inequalities take on a more regional scope, necessitating systematic cross-border travel (quite separate from but related to intensive cross-border entrepreneurial activity), their origins are rooted in the colonial era (see Gluckman, 1940).
} 
unclear whether most of these vehicles were simply waiting, or if they were 'holding' (forming) a queue. In the middle of this mass stood a makeshift structure, covered in a skew, worn green canvas sheeting. Some vehicle owners seemed eager to get their automobiles through this standalone gate, and thus swarmed several individuals in lime and orange bibs, who also held stamping devices in their hands. The men in bibs were customs officers. It was principally through them, the police and immigration officials that the official exit declaration and clearance could be gained in order for all travellers to proceed beyond the border into Zimbabwe.

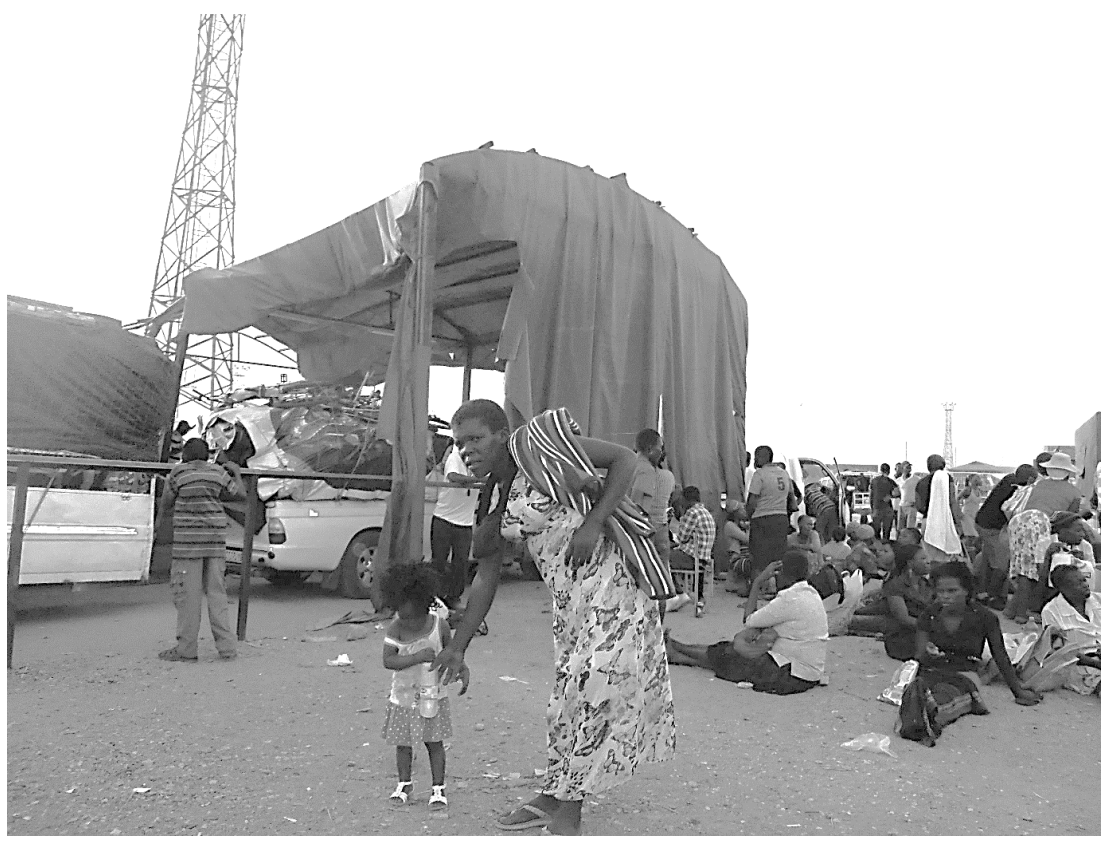

Fig. 7.1 People wait inside koMalume as their goods get processed for customs clearance

Commotion was only one characteristic of the exit perimeter. The other was a foreboding repose. In between those rushing back and forth lingered others who seemed in different stages of a prolonged wait. Despite all the urgency and the surge in numbers 
that suggested a rush to cross the border in time for Christmas, many people appeared to be 'held back' by the border. In an area designed to manage and facilitate movement, this general lethargy was very obvious and the seriousness of this blockage was large enough to constitute a crisis, yet the fact that it held steady, suggested that there was a hidden outlet to it.

Hawkers who formed part of the waiting crowd sold iced water (the heat was oppressive), pre-paid cell phone airtime and money exchange between South African Rand and United States dollars, among other things. They came and went. Most of them did not carry any identification documents, thereby ignoring a strict compliance order from the Zimbabwean Immigration Department. They have been working as hawkers at the border long enough to use their camaraderie with state officials to gain entry and exit, with or without documents. When passage through the front gate is difficult, for instance when 'friends in uniform' are not on duty, they sneak into the enclosure through several holes in the perimeter fence, a few hundred meters from the Limpopo riverbank. They simply pay those who patrol the perimeter fence iskofu (token money) for entry and exit, ${ }^{109}$ as well as help 'tout' an alternative exit for those unwilling or unable to pay the fines imposed for their 'undocumented' status. ${ }^{110}$

In his nuanced study of what he calls Zimbabwe's new economy, Jones (2010) has explored people's survival strategies under the accelerated social and economic difficulties of the past decade. As the 'traditional' formal economy gradually declines, new

109. I was first alerted to this option of exiting the perimeter by a small boy, about ten years of age, who sells cell phone recharge vouchers, iced water and presumably, sneaks people in and out of the perimeter himself.

110. Zimbabweans returning from South Africa without passports, or with expired residence or work permits are required to pay a fine, which at the time of research was about 200 South African Rands. For a debate on the fines and other kinds of negotiation that facilitate passage through the Beitbridge border, see for instance (Evans, 2015). 
instinctive forms of 'make do' survival strategies and economic action have become prominent, coalescing around a generalised culture of evasion, kukiya-kiya (Jones, 2010: 286-7). Social institutions and the law, as well as cultural norms and hierarchies, have not escaped the assault of a new logic of 'cleverness' and the exploitation of available resources with an instrumental eye on survival. From its former position at the margins of Zimbabwe's urban consciousness, Jones (2010) argues that this new 'culture' has come to dominate everyday existence, resulting in a seismic shift in how people relate to the urban economy. This influences how they both constitute themselves and are in turn constituted as subjects.

There are similarities between the small-scale economic-activitycum-opportunity-seeking that characterises the broader and increasingly cross-border economy and the complex interactions found at the Beitbridge border. Strategies by travellers, facilitators and state officials, such as the exchange of money and negotiation of passage, mirror a similar make-do logic. Jones' (2010) analysis adds nuance to previous studies of mine labour (Onselen, 1976) and border crossings (Johnson, 1990) that have sought to trace practices that have redefined institutional mechanisms and border praxis over the years. However, in articulating socioeconomic disempowerment, van Onselen (1976), Johnson (1990) and others pre-suppose a subject position that is politically emaciated and socio-culturally empty, whose narrative is subsumed within linear institutional and social contexts, and whose struggle merely constitutes strategies of deviance from, and disobedience to, associated institutional mechanisms.

As we have seen in the previous chapters, however, the social relations of everyday border crossings at Beitbridge reveal a far more complex positional and political picture. Not only do individual actors engage in practices that at one and the same time rely on and undermine state mechanisms, they do so within the particular evolving context of the Beitbridge border 
that shapes their social action. Their actions are influenced by and proceed within the tensions that characterise the margins of the political, cultural and economic. It is at this point that a consideration of the broader multiple political economies of Beitbridge help to locate the border's contested subjectivities.

On this particular December afternoon, the processing of travel documents appeared to go at a steady pace. Travellers who were found to have minor documentation or immigration infractions were steadily directed to join a queue meant to help them sort out their problems. One is, of course, not taking into account the many others who found alternative solutions elsewhere. Nonetheless, those who waited around had something or other amiss in relation to their travelling statuses such as no passport, an overstayed permit, undeclared goods or goods in commercial quantities. The apparent efficiency that attended the document clearance process took place alongside a tariff evasion and gratitude negotiation game between travellers and state officials. This played out through a mixture of stupendous bureaucratic red tape and different forms of 'greasing the wheel'. ${ }^{111}$ Both travellers and state officials often seemed to be biding their time. They ordinarily do, eventually, find a third way to facilitate between themselves by exploiting gaps in the fence and in the law. Thus, the wait was more than just milling or sitting around. It was a kind of 'moving while waiting'. It involved a process of indirectly engaging, by way of available proxies, with the blockage that delayed the exit every traveller so dearly sought. This was both hidden and obvious.

One only had to ask how to bypass or, as is often the case, pass through official travel requirements. ${ }^{112}$ That many travellers

111. Others who have recorded experiences of exiting the border into Zimbabwe have come to the same conclusion. See for instance Trollip (2013) and Mills (2012).

112. This is what I did, and my participants gave open responses, partly because they imagined that I was also trying to exit the perimeter in a similar way. 
pass through the border in the prescribed way is both the object and result of the state's regulation of movement. But, enforcement at Beitbridge also aids non-state regulated passage. There is, on the one hand, a significant number of people without travel documents, work or residence permits, who are willing to pay for their safe passage at the border. On the other hand, few actors find participating in the economy of undocumented crossings resistible given the level of remuneration for state officials who man border crossings, the potential for extra earnings that facilitating this passage represents, as well as the precedence that exists for such practices. As effective participation in this economy requires a veneer of adherence to regulatory rules, it engenders both a reluctance to loosen the red tape (especially when it results in protracted delays and higher monetary yields) as well as its robust enforcement. This gives a perception of strict regulation while also ensuring that undocumented crossings yield good returns for the facilitators. In this way, both documented and undocumented crossings co-exist and are bound together through particular internal logics.

As this thesis suggests, the subjectivities of transition have nothing to do with dichotomies between the formal and informal, legal and criminal, and official and unofficial that the structures of border enforcement seek to represent. The social spaces these subjectivities produce is characterised by vacillation, uncertainty and various kinds of potential that are the result of unstable representations that arise from contemporary cross-border movement. These, in turn, mirror a disconnect between the actual everyday practices of crossing the Beitbridge border and their significance and meaning (Mbembe \& Roitman, 1995). Such uncertainties and disconnections tend to shape people's experiences both within and beyond what they imagine possible about their lives (Schutz, 1962) so as to demand an analysis of movement that pays attention to the dissonance alluded to above. 
Although the experiences described exemplify challenges that accompany otherwise routine (but not determinate) border crossings, as zones where meaning resides in constantly changing configurations of experience (Turner, 1982); the gaps that often lie between the experiences of border crossings and their meanings tend to render border spaces as spaces of ongoing reflexive transgressions and transcendence of social structures (Mckenzie, 2001). In this way, it is possible to imagine the acts of crossing the Beitbridge border as cultural acts, infused with both uncertainty and creative possibility which lie at the interstices of representations of space (Lefebvre, 1991) and their limits. This helps enrich the reading of the border crossings as not just taking place within a particular 'regime of subjectivity', but also as representing struggles for the re-appropriation of actors' ability to live by their wits (La Hausee, 1993 in James, 2011: 321) as they hold together their lives in contexts of rapid social change.

\section{Contesting everyday border subjectivities}

On another day, in February 2015, I travelled from Bulawayo to Johannesburg with Msholozi, who I had (at that time) been shadowing for more than a year. He collected me at around 2:00 am. His choice of departure time reflected his desire to avoid the plethora of police roadblocks on the 360-kilometre stretch of road between Bulawayo and the Beitbridge border during daytime. ${ }^{113}$ Also, he wanted to arrive at the border by sunrise, when the numbers of travellers crossing into South Africa is likely to be at its lowest ebb. Ordinarily, Msholozi drove back and forth between the two cities every week, covering approximately 2000 kilometres in the process. His weekly mileage increased

113. Avoiding roadblocks is another way of saving money; the police, who Zouma called osceluncedo ('beggars'), have effectively turned these into bribe collecting/informal tolling spots. 
substantially during holiday times, when more people were seeking his services. This meant that he was often tired, and always ready to take power naps along the road, despite the constant threat of robberies and/or attacks on the highway. ${ }^{114}$

Before we left Bulawayo, we picked up four more travellers including a mother and child. Only one of them had a complete set of travelling documents. The child had no travelling documents whatsoever. Although the child surprised Msholozi, he nevertheless did not mind his/her paperless presence. Taking a passport-less child across the border is a serious crime that is vigorously policed at the border in order to prevent human trafficking (see Bunke, 2016; Nshimbi \& Moyo, 2016). ${ }^{115}$ It was therefore a serious risk for Msholozi, but the mother and child would yield him up to six times more money in charges when compared to a passport carrying individual traveller.

Our drive to the border was uneventful.

At Beitbridge town, Msholozi stopped briefly at a filling station. It was not for refuelling. He drove straight to the back of the petrol station and turned off the engine. After waiting for about ten minutes, he instructed the two women at the back of his car, one carrying the toddler, to disembark. A man had appeared from among the crowd and presently stood next to the driver's door, talking on his cell phone. He soon shoved it into his pocket and informed Msholozi that he would only have to wait two hours for him and the two women on the South African side of the border. With that, Msholozi drove with those of us remaining in the car to the border gate, leaving the two women and the child with the man at the petrol station. After fulfilling the crossing

114. Zouma has related to me several of his own near misses with criminals of this sort.

115. These authors discuss the prioritisation and strengthening of anti-trafficking legislation across the Southern African region. 
formalities - laced with much banter with state officials on both sides of the bridge - he drove to a petrol station outside the South African exit gate. Once there, he turned off the engine once more and began his wait. This time, however, the wait was longer.

The man who had collected the two women and the child on the Zimbabwean side was one of the local hyenas, one of the matsotsi or 'fixers' with whom Msholozi works, and whose activities we briefly dwelt on in Chapter Six. The fixer had spoken to Msholozi well in advance, and the two had agreed to meet each other at a petrol station in Beitbridge. In this context, that hyena's job is to help take undocumented travellers between Zimbabwe and South Africa. For a fee, he either passes over the bridge, paying off immigration and customs officers, as well as soldiers and policemen who man numerous checkpoints across the border gates. Or, he avoids them altogether; braving the Limpopo River and its crocodiles, and choosing instead to negotiate with the border patrol, as well as amagumaguma, who make a living by ambushing 'border jumpers' coming through undesignated crossing points in the bush. Although this is a dangerous option, it can be a cheaper one.

Around 1:00 pm and five hours into the wait at the petrol station, Msholozi's voice started to rise sharply over the phone. He had given the hyena enough money to avoid the bush, he shouted. And yet the women had just been chased back into Beitbridge town by soldiers in a foul mood. The hyena's scheming had cost Msholozi valuable time, the border crossing by his travellers had been botched and his own standing as a reputable transporter was being smeared. Dropping the call abruptly, he kicked at the air. He turned sharply and flung an empty fizzy drink can into the fence. With that he dropped rather heavily into his seat in the car and hurriedly drove off onto the highway, not only fuming with rage, but also laden with failure. He got his hyena on the phone and scolded him again for wasting his time. He demanded that he hand the iskofu back to the women so they could travel back to Bulawayo. He would take them across the border himself the following week. 
I have given two illustrations of the complexity that characterises subject-constituting social practices and interaction at the Beitbridge border. The delays in the conveyance of travellers across the border suggests a level of sociality between travellers and state functionaries that goes beyond a mere glitch in the technology of statecraft that is meant to manage the movement of people. Within this space, different kinds of interaction and negotiation appear to unwittingly test and undermine the mechanisms designed to manage border crossings. In this way, but especially with the collusion of state functionaries in the negotiations for crossing, the border produces a kind of sociality beyond mere subject(ifica)tion (Jansen, 2010) to and through state mechanisms.

If one were to consider the two scenes at Beitbridge, one might focus, for instance, on the two large queues (one for stamping passports and declaring goods, the other for the undocumented to pay their fines) which may be compared to the confrontation between soldiers and 'border jumpers', and the passage, through various kinds of negotiation and other kinds of appreciation, of undocumented travellers over the bridge and through the holes in the border's perimeter fence. One senses from these instances that, with or without documents, it can be a challenge to cross the border. Nevertheless, on balance, it is easier to cross those undocumented through the gate than at undesignated points along the border. This seems to overturn the logic of documented travel, with passports supposedly meant to "certify us as persons worthy or unworthy of certain cross-border movement" (Jansen, 2010: 4). Here, the meaning of documented travel seems to constantly shift and change.

However, and as we have seen in Chapter 6, this does not mean that the purpose of the passport is lost. For instance, when negotiations with soldiers for safe passage through the river break down, the threat of arrest and imprisonment that is implicit in the logic of carrying valid documents is activated. 
In this way, the passport does not offer a cover to negotiate undocumented border crossings; it is the foundation for it. For instance, the price one pays for undocumented crossings may be directly proportionate to both the lack of documentation and the inability to negotiate for that lack. At a broader level, as this and the previous Chapter Six discuss, these daily social interactions between state agents and those they 'rule', proceed within an unstable balance. They may serve certain core interests of states, for instance to encourage a vigorous policing of the border, but with or without the intended outcomes. More serious breaches that are perceived as a threat to the integrity of the border regime may, for instance, be punished, while those that warrant smaller penalties may be 'winked' at for a reasonable personal fee. Such representations of the border offer a terrain for renegotiation, through different subject constituting practices, of the meanings of the border space and attendant subjectivities. The space and the people it hosts appear to mutate, taking on different meaning with passing moments.

The contradictions that make up border practices that sometimes appear to undermine the mechanisms of border control constantly redefine the subject positions of border actors. On the one hand, it is safer to cross where one is protected by state security, even without documents. Border officials appear to simultaneously enforce border control mechanisms, protect transgressors and derive personal benefit from their official stations. But, the manner in which this happens is never clearcut, and involves a lot of risk and danger. Again, the altercation between facilitators and soldiers on the banks of the Limpopo serves as an illustration. In this way, the border functions as always, but its purposes appear to have been routinised as a register of improvisations. What it represents and what it affords actors can be the same or can differ. Further, they can mutate from time to time, depending on specific demands and circumstances. The subject of this zone of transition is one that can best be placed within Mbembe's frame of constantly changing identities. 
As our freshly reconfigured journey to South Africa proceeded, Msholozi could barely manage his anger. He should have done it himself, he raged on. He had only given the responsibility to the hyena because he himself was already carrying many people's passports for stamping at the border. Handing over the other responsibility to the hyena was Msholozi's way of managing the risk of unexpected arrest - by spreading it. None of this self-exoneration was enough for him to save face. Rumour had it that a huge roadblock had been mounted at the weighbridge a kilometre from the petrol station on the South African side of the border. The police, the army, the Immigration Unit, and the highway traffic police would be everywhere. Something was wrong. As it turned out, fifteen kilometres further along the highway, at Musina town, a large section of the highway had been cordoned off. Armed robbers had broken into a local bank branch earlier in the morning. They shot dead one security guard and kidnapped the other. ${ }^{116}$ As a result, security along the whole border zone had been heightened. Few people were taking any chances, not least state officials. As he settled into the long drive to Johannesburg, Msholozi wondered whether this could explain why the soldiers had swooped on his hyena and the women, and had almost arrested them.

What the Beitbridge border represents is therefore in constant flux. This has a direct impact on how travellers approach the border enforcement mechanisms, and indeed how they are constituted by their encounters with its constantly changing form. Even if states have no means to impose total control over movement, it is of interest to ask why enforcement can be entangled in the kind of regime of subjectivity this chapter discusses. Clearly, some of the struggles between the regulatory norms of enforcement and

116. The exact details of this incident vary. The kidnapping was Msholozi's version, gathered from the grapevine that morning. The incident itself made the news - even in Zimbabwe (Muleya, 2015). 
the practice of border crossing are seen through the strategies of negotiation and confrontation, subjection and consent, and coercion and resistance. These constitute struggles over the production of the very meaning of movement in general, and border subjectivities in particular.

\section{Crisis, social practices and subjectivities of transition}

The history of everyday border crossings between Zimbabwe and South Africa, and the plural subjectivities around which they are structured and shaped, suggest that the forms of interaction highlighted in this chapter are not new, but predate the advent of international frontiers in the region (Manheru, 2015). This history also questions the idea that colonial settler economies in the region may have generally presided over a Torpey-esque states' monopoly over legitimate means of movement (Bolt, 2012), which would suggest a more or less predictable enforcement mechanism. While states have deployed their infrastructural and despotic powers (Ron, 2003) to control border crossings for over a century, with a questionable degree of success, there is very little to suggest that they lacked the material resources to wrest effective monopoly, or significantly minimise undocumented border crossings (Crush, 2000b; Klaaren \& Ramji, 2001; Minaar \& Hough, 1996; Musoni, 2012; Oucho, 2006). The challenge has largely been both economic and socio-political, and points to pending questions in the realm of citizenship and modes of belonging in colonial and post-colonial projects.

Many African states have struggled to transform the political, legal and geographical infrastructures of the extractive economies of the $19^{\text {th }}$ century (Araia, 2006) into sociallyinclusive ones. At the heart of this (lack of) transformation lies the bifurcation of citizenship and modes of belonging as geographic and legal norms, split between constitutional and 
customary law, civil and traditional society, rights and customs, town and country, and citizen and subject (Mamdani, 1996). Border crossings, therefore, and the interactions at the presentday Beitbridge border, have emerged out of this fragmented and incomplete political project. Market pressures, not least the informalisation of the region's economies, have exacerbated the unresolved crises of the political and cultural, seen in the fragmentation of these institutions in post-colonial Africa. The migrant workers who travel in a circular fashion with or without papers do so less out of a socio-political attachment to states that the idea of citizenship, for instance, should imply. They follow a path of least institutional and political resistance, and their economic calculus brings into view this prevailing fragmented process of subject formation, one that uncovers their subject positions as citizens and as subjects in the (post) colonial sense.

In times of economic crises, this detachment throws economic pursuits such as the ones described by Jones (2010) and those observed at the Beitbridge border towards multiple, improvisational positions and reconstituted institutional spheres. Here, subject formation depends on forms of authority governed by other frameworks in addition to state and customary ones. What appears now as one consequence of postindependence 'deracialisation', rather than democratisation (Neocosmos, 2006), is the manner in which issues of 'legal' cross-border movement have become matters of conflict and accommodation that involve differing forms of authority as well as subjectification, or the making and remaking of different subjectivities.

Hegemonic representations (Lefebvre, 1991) of the Beitbridge border space, predictably, do not assume this plurality. States struggle to project a unified vision of border zone governance; one that may or may not be shared by state functionaries, travellers and other actors. By collapsing this plurality, dominant ideologies 
of the border space disorient both their own representation and people's sense of themselves within it. This is the particular moment that alienates practice from representation, and action from its significance. Slipping in and out of legality is, for travellers, less a matter of subjecting themselves to the rituals of cross-border movement generated and governed by state apparatuses, than one concerned with searching for livelihood and the meaning attached to this. It is these subjectivities that constantly mutate, and from which other possibilities to reshape the border space and its actors emerge.

To return to Mbembe and Roitman's conception of crisis, what border procedures are expected to represent concerning the governance of crossings, and how both state officials and nonstate actors use the border to drive their everyday interaction, are characteristic of these identity shifts. Further, negotiating crossings is itself never a clear-cut exercise. Thus, there is the added aspect of unpredictability in border crossings. As such, both state functionaries and other actors who 'personalise the public' (Medard, 1982) are never certain that they will not be caught, or that their acts will achieve their desired outcomes. Everyone is, to some degree, looking over his or her shoulder, and the anxieties that this chapter opens with take another form in the process of renegotiating crossings and subject positions.

Cross border movement is a manifestation of the hope and desire through which people seek to rise above their challenges to achieve and sustain life's long-term goals. However, the particular forms of subjectivity and their representational crisis demonstrate that the uncertainties and unpredictability of the present barely lend themselves to any such long-term goals. Whatever people do, thus, necessarily depends on narrow subsistence horizons. These uncertainties, which signify the moment of crisis, make up the kinds of interaction currently observable at the Beitbridge border. 
Yet, crisis also involves the challenge to give meaning to such moments. Representations of the border space and the practices that take place within such spaces are in constant tension, often resulting in a partial mistrust of one's actions, intentions and plans. This 'crisis of the subject' is fostered within a general atmosphere that combines the economic and political uncertainty which characterise migrant life. Uncertainty seeps across the border space. The waiting, wheeling and dealing within the border passages, or the break-down of negotiations for undocumented passage, are both underlined by the ever present and unpredictable threat that attends such public encounters with states (Das, 2004); it reorients the social life of border crossings towards not just the crisis of border enforcement that characterises border crossings, but also the uncertainties around the kind of subject produced by this crisis. As Mbembe and Roitman (1995: 324) explain in a different - yet related - context, this results in a regime of subjectivity; "a shared ensemble of imaginary configurations of everyday life" characterised by:

The entanglement of a plurality of real and not wholly distinct formations; the combining and packaging of experiences lived by people at all levels of society; the physical and mental violence that issues from the lack of coincidence between the everyday practice of life and the corpus of significations or meanings available to explain and interpret what happens, to act efficaciously and, in so doing, attempt to overcome the spectre of nothingness.

\section{Conclusion}

As Msholozi joined the motorway to Johannesburg after his disappointments at the border, the rumoured roadblock ahead did little to calm his fears about the stash of 'ghost passports' hiding somewhere under the dashboard of his small car. The source of his dread, despite having carried people's passports 
countless times, was less the fact that he would be unable to explain himself to unknown officers, or the possibility that it could cost him large sums of money if he were actually caught. The real problem was that the passports had, in fact, been officially stamped at the border, and being caught with them would have meant exposing a long chain of people to possible arrest and blacklisting, and in the process put his business and other people's livelihoods at risk.

In dealing with border practices as attempts to re-appropriate actors' abilities to produce the border space, Bolt (2012) writes that in the face of the borderscape's perennial uncertainty, characterised by mottled forms of surveillance, danger and fortune-seeking by both state and non-state actors, many seek to legitimise their presence by staying visible at the border, irrespective of their station, motives or documentation status. The phenomenon of posting their passports for stamping in absentia at the border (discussed in the Chapter Six) is one way in which those crossing the border manage the uncertainty and precarity of their livelihood, seeking strategies by staying visible to the apparatus of border enforcement. They, however, do so from a position of ambivalence. Their visibility manifests through a manipulation in the visibility of the crossing process as demanded by state institutions. The careful way in which this invisible visibility is negotiated relies on exploiting those sites that the law is blind to, undermining institutional control mechanisms. Such strategies reposition border subjects as themselves furtive, and it is this ambivalence that is a source of power, uncertainty, fear and danger. It is this multiplicity and the constantly changing identities that partly characterise the transition. In one way, this is the manner of being a subject that is unhinged from predictable conceptions of social space and its relations and subject positions.

The need for, and success in, staying visible is nevertheless a reaffirmation of the same subject positions that they undermine and befuddle, but which retain quasi-emblematic significance. 
As the economic decline of the Southern African Development Community (SADC) countries has accelerated and cross-border movement has increased, the securitisation of the border becomes more evident. However, securitisation in this case does not translate into the effectiveness of security imperatives and actions, as suggested by Coplan's (2012) observation that bureaucratic red tape is only matched by its active circumvention. It appears that the institutions of the state which guide the interaction between state functionaries and travellers (documented and undocumented) retain limited significance, in inverse proportion to the general sense of security and authority of the state (Coplan, 2012). The subject-constituting social practices of enforcement appear themselves implicated in producing ambivalent subjects.

An analysis that allows for these dynamics is likely to also open border spaces as zones of political struggle over "who gets to re(tell) the story, and from which position" (Weber, 1995: 532). As a matter of course, these struggles spill over into the terrain of narrative and tend to contest the narrative mode itself. In this sense, the narrative acknowledges multiple identities of both subjects of analysis and analysing subjects, thus allowing room for self-reflexivity, and therefore the ability to utilise a perspective that resists narrative incorporation, something that Turner's symbology struggles with (Rosaldo, 1993; Weber, 1995). The lessons learned from such a perspective can add significantly to our studies of migration, politics, economy and society in the Southern African region. 


\section{8 \\ CONCLUSION}

\section{Introduction}

I begin this concluding discussion by expanding on the observation I share in Chapter Five, where I relate how compliance with border enforcement requirements by Msholozi pronounced hunger for inspecting officials (see p. 233). I do this not because I wish to merely return to the subject of eating, important as it is. The aim is to, once more, bring border practices to the centre of a general summative discussion of the main points that this thesis is making. From that vantage point, the discussion more succinctly emphasises some of the major contributions of the thesis in general. I reflect on these contributions by way of connecting them to another concrete everyday situation. By so doing, I reiterate how border practices afford a view of broader processes that link migrant irregularity, precarious work, informality and social change as a contingency of history and as an ongoing process.

The social situation I will share shortly is taken from more recent field notes, observed and recorded in March of 2017. In the context of the study, the situation is of iterative relevance in that it partly presented me with an opportunity to assess some of the analysis of the preceding chapters against concrete situations as they continue to unfold 'on the ground'. With the benefit of analytical reflection, this final situation helps to paint a fuller picture of the main contributions of the thesis in general. 


\section{When a good day's work means starvation}

On the $29^{\text {th }}$ of March in 2017, in the course of a regular day's chores, I called Msholozi at around mid-morning to find out if he was leaving for Johannesburg from Bulawayo on the following Thursday as per his usual schedule. ${ }^{117}$ By recalling the pattern of our meetings and trips spread across the last four years, I had good reason to suspect he was around town. When I reached him on the phone, he told me that he was in fact leaving that evening. Although this was short notice, I myself had strong motivations to leave that night, but I wanted to chew the matter over.

Later that day, when I called to tell him I would be travelling along, he informed me that he was, in fact, leaving in less than 30 minutes, and bade me to hurry up. I scrambled a few of my things into a bag, and had my brother drive me in haste to Max Garage. ${ }^{118}$ There, Msholozi and I exchanged greetings, and he quickly pointed me to a 22-seater Mercedes Benz Sprinter minivan, a new replacement for his Toyota Quantum. He also informed me that he would not be driving his small car that day. After throwing my bag in the trailer, and stuffing some other things under the seats in front of me, we were ready to leave at around 20:00 hours. On this Msholozi surprised me, because omalayitsha often pretend to be leaving imminently, only for them to drive around the rest of the city for hours. They often only leave after gathering a full complement of passengers to get them maximum travel fees for their trip.

117. Msholozi travels between South Africa and Zimbabwe every-week. He leaves Johannesburg every Sunday by midday, usually arriving in Bulawayo, Zimbabwe early morning on Monday. He then leaves Bulawayo for Johannesburg on Thursday night, arriving there by midday on Friday. This schedule changes in response to demand, especially in relation to major holidays when more people seek to travel or send goods. However, Msholozi can return to Johannesburg early when he finishes all his errands in Zimbabwe earlier than expected. This was one such day.

118. The distance between Old Magwegwe and the city centre cannot be more than 10 kilometres. 
After driving about a kilometre along the Beitbridge border main road, Msholozi ordered the minivan to stop. He then asked all of us to disembark from the bus and gather outside. Only then I learnt that most of the travellers in the minivan were omalayitsha, their drivers and fixers. He took his time to get everyone to pay. Although many of the transporters turned out to have one issue or another with the documents they were carrying, Msholozi negotiated with them in a friendly way about how much they could pay. ${ }^{119}$ The negotiations were less about whether each passenger had his own passport (as omalayitsha can use other people's passports to negotiate crossings), but more about whether the passengers were carrying any passports at all (as they possessed the skills to use whatever passports they had to pass for regular border crossers).

As it was dark, I was not able to closely observe how many izimpisi carried their own or other people's passports, what I have termed 'ghost' or 'holderless' passports. From the nature of the negotiations, however, it appeared that most, except one man, a regular undocumented traveller, had a passport of one kind or another. As people who are particularly adept at using other people's passports, as well as soliciting for official stamps on them, it was no surprise that many of them were confident in assuming the identity of strangers. However, having documents at all is what determined how Msholozi was going to charge them the travel fee. ${ }^{120}$

119. This negotiation is not the same as that which takes place between omalayitsha and regular undocumented travellers or state officials which take place within significantly unequal power relations. In this respect, what I witnessed on this occasion was more like haggling, rather than the kinds of negotiations I conceptualise in the rest of the thesis as structuring relations of facilitation of movement.

120. March is not a time of the year when many undocumented travellers use omalayitsha. Thus, Msholozi was not going to make a lot of money for the trip. The upside for him seemed to be that he did not have to worry about spending a lot of money paying state inspectors who would intercept him to check for undocumented travellers, as these izimpisi would negotiate for themselves. 
The passenger without a passport was a 'pay-forward', and he was asked to sit at the back, on account of him not having his passport, so that with about 22 passengers carrying real or ghost passports, state officials inspecting the vehicle would either tire or lose hope of finding undocumented travellers before they reached him.

When we arrived in Beitbridge, the trailer we were pulling was hooked behind a different minibus, and the drivers were given a mandate to 'bring it across' the border to South Africa where Msholozi was going to take it back at a fuelling station just outside the border gate. The reason for this was that with many people in the car carrying other people's passports or no passports at all, it would be better that the minivan crossed without a trailer. That way, it would attract less scrutiny from inspecting state officials on either side of the border by passing for an ordinary private minivan.

As I already stated, inspections of vehicles that omalayitsha operate are closely related to the notion of eating, or its opposite; starvation. The discourse on eating significantly structures interactions between omalayitsha and state officials. On this night, it started when we were crossing the border, when the inspections of the minivan began in earnest as we first entered the border gate. This is where Msholozi kept telling the state officials that their search constituted starvation, in reference to the fact that the officials would struggle to find any infringements on immigration rules in the van. ${ }^{121}$ I should repeat here that the logic behind pronouncing hunger to the officials stemmed from the fact that if he were to be found in breach of the law, he would leave something for the officials to get past the

121. The reference to eating, I have argued, should be understood in the context of state officials wielding bureaucratic power from a position of marginality which often forces them to convert that power to personal use. 
security inspection. This way he would ward off hunger among them, as they would thus 'eat'. Saying that they would starve was a way of saying he was in compliance of border enforcement requirements. A part of this was a deceptive act on Msholozi's part, as he was of course well aware of the ghost passports as well as the passport-less man.

On the South African side, right in the middle of the bridge, we met a contingent of South African Police Service (SAPS) inspectors of cross-border travel, among whom a white male who held a senior position was also present. As a senior officer, he had a reputation for refusing bribes, or so Msholozi and his drivers suggested, cursing their bad luck. When we were asked to disembark, Msholozi and his drivers debated whether to ask the passport-less man to stay in the van, and to call a junior officer to inspect it. They counted on giving that officer something if he 'discovered' this man. But they were not sure what would happen if the senior male chose instead to inspect the vehicle. So, they asked the passport-less man to disembark also, but to 'never approach the white man'. When a black junior officer ended up inspecting the van, they argued about why they had let the passport-less man out of the van, as they now would have to negotiate for his passage in the open, just a few meters from the 'white man'. They succeeded in shielding the 'pay forward' from the gaze of the senior official, ${ }^{122}$ and thus were able to leave 'something' for the junior officer on the sly.

The arrivals hall on the South African side was almost empty, with two immigration officers alternating stamping passports with looking in their cellular phone devices. Zimbabweans without work permits have a possibility to get up to 90 days on

122. This they did by taking the initiative to speak to the junior official and announce to him the travel status of the man without documents which allowed them to gain leverage in driving the negotiation process through what I have discussed before as ukutshokotsha. 
their passports, but this has become a point of negotiation and enterprise for immigration officers. ${ }^{123}$ While I waited for my passport to be stamped, one impisi approached the officer in front of me and asked for more days on behalf of one of the women we were travelling with, and for 100 Rands, she got an extra two weeks.

Outside the hall, we waited a while for the other travellers to finish getting or negotiating stamps on their passports. However, before everyone was back, Msholozi turned the engine on and headed for the exit gate. The others would find us waiting for the trailer outside the gate. At the exit, we had to go through one last inspection.

It was quite a spectacle. ${ }^{124}$

We were asked to disembark from the minivan and to bring all our carry-on luggage with us. However, some of that luggage remained in the minivan as its owners were not present. But the SAPS officers who manned the checkpoint proceeded to search the bags that remained in the van. Some izimpisi later lamented that the police officers were stealing money from the unattended bags. I did not see this, so I could not verify the accusations. But, from the conversations that proceeded afterwards, it seemed that this was a regular practice. While I watched, about three passports that were discovered in the carry-on luggage bags were confiscated, with the threat of burning them, unless their holders 'showed up'. ${ }^{125}$

123. Regular travellers are used to this practice, and with the help of omalayitsha, approach stamping officers with the request for more days upfront which is usually facilitated by sliding a paper bill in-between the pages of their passports.

124. This is the last inspection before one finishing the border crossing process, and therefore, it tends to be tough. But it has also become the site of intense negotiation, coercion, harassment, extortion and bribery between state officials and non-compliant travellers.

125. This was coded language to suggest that in order to regain possession of the passports, their 'owners' would have to pay some money in the form of bribes. 
Others later reflected on a kind of vehicle and body search such as they had seldom seen before. When a bag belonging to an absent female was turned inside-out, one impisi remarked that the officer should go easy, lest he discovered wet underwear inside. "At my age," the officer looked up, "how much underwear do you think I have discovered?" That seemed to elicit a general round of laughter. That officer retained the three holder-less passports that night.

As we waited for the trailer to arrive at the garage outside the border gate, the man whose passports had been confiscated appeared, confessing to not having enough money to rescue his passports. He eventually asked other omalayitsha to give him more money, with which he negotiated his passports back. He clearly seemed to exude enough confidence and initiative to eventually secure the passports.

After we had hooked the trailer to the back of the minivan, we travelled to Johannesburg without incident, apart from Msholozi apologizing to virtually all inspectors that stopped us by pronouncing starvation on them, in relation to his obvious pride in 'complying' with immigration regulations.

\section{The social situation of undocumented movement}

What I have detailed above is a typical social situation of a largely undocumented border crossing. Writing in the 1940s, Max Gluckman points out that particular social situations represent some of the key sites wherein from the interrelationships, a researcher can make inferences on "the social structure, relationships, institutions, etc., of that society" (1940:2). By taking the behaviour of members of a community on a given occasion and comparing it to their behaviour on other occasions, an analysis may reveal "the underlying system of relationships between the social structure of the community, the parts of the social structure, 
the physical environment, and the physiological life of the community's members" (Ibid: 10). It seems opportune that I return to a particular occasion - a social situation - of border practice, an actual border crossing with omalayitsha, to begin a summative discussion of the main points of the thesis. The discussion, therefore, relies on events that emerge from a single occasion to infer on general points that the thesis is making.

In a way, the incident above tells the general story of this whole thesis in its entirety. Here, I isolate a few issues from the above field notes to reiterate the main points of the preceding chapters. I start with the 'pay forward', before discussing the 'white man' among SAPS officers. I then speak briefly about the contingent of transporters in the minivan, before touching on the woman that 'jumped me' in the stamping queue. Later I relate, again, to the subject of eating via the 'routine inspections' and the significance of 'unhooking' the trailer. This then leads to a concluding discussion about the broader significance of this thesis.

\section{Irregularity as informal politics}

The man without a passport, the so-called 'pay-forward', stands for a significant cross-border phenomenon of both irregularity in movement and precarity in labour. While the phenomenon itself is old, it has taken on new forms in relation to general informalisation in movement and work as a quintessentially postcolonial and post-apartheid phenomenon. In this new, evolved context, however, I have suggested that the path-dependence of these border-crossing practices without documents and engaging in informal work, even outside the coercive strategies of the colonial and apartheid eras, should not be downplayed. Gatsheni's story in Chapter Four, for instance, backs up this claim. It suggests that there were always ways to escape the controls of movement that were set in place by the apartheid government, and that, just as he was able to live and work in areas not meant 
for him, although within noticeable precarious arrangements, his example is not isolated. Francis Nyamnjoh (2006), for instance, has demonstrated how domestic work in apartheid South Africa offers a vantage point from which to interrogate both informal work and the efficacies of influx control in the apartheid city.

The 'pay forward' also stands for a certain kind of social politics. The main argument of this thesis is that as informal politics, undocumented crossings represent a contestation around the governance of cross-border movement at the everyday level. Such contestations mimic broader struggles in relation to access to decent work and livelihoods for the dispossessed. This is not to say people without documents prosper through these strategies. The point is more that they find avenues, however small, to manoeuvre within a dominant structure that is coercive and exploitative, sustaining largely precarious livelihoods within it. Undocumented movement and its possibility represent struggles over access to spaces of belonging and rudimentary participation in localised political and social modes, albeit these struggles may be neither purposive nor conscious.

Undocumented movement comes about and is possible because of what I have identified as the dialectic between historically produced, segregative, migration management regimes and processes of capitalistic accumulation within a coercive and increasingly informalising environment. People like the 'pay forward' appear to escape control, but in a broader view of things, they are affirming an order that produces and thrives on their precarisation. Theirs are strategies of survival in such a context.

Vestiges of the past and continuities of the present

'What is this white man doing here?' This was Msholozi's immediate reaction as he prepared to stop for the police inspection roadblock in the middle of the Alfred Beit bridge. 
One answer to Msholozi would be that the man symbolised the past, and that that past continues in the present, even if with many discontinuities. Msholozi's instinct was to wish the man was not there. I am convinced that if we had not been caught within the narrow confines of the bridge, he would have avoided him. Latently, the man's reputation for refusing bribes seems to support this view; narrow control and very few other considerations.

Many irregular migrants would prefer to avoid him too, in the past and in the present. In the past, he would have stood for the archetypical master who racially segregated them and sought their compliance to his whims through force. This mode of thinking persists among many blacks, not so much in terms of the master-slave dynamic, but in the sense that a white man still stands for privilege, power and resources. It was for the same reasons, as I have argued, that blacks avoided documented travel: systems of colonial and apartheid control, which the white man wielded so effectively in the past, were geared towards their coercion and exploitation. As soon as the white and the black man were in direct interaction, they were in an unequal relation, and documents appeared to formally sustain this inequality.

In terms of broader contemporary social relations in Southern Africa, this is what the white man still stands for; indirect coercion through systems of precarisation and neoliberalisation. The discourse of 'white monopoly capital' that currently grips South African public debates, just like the Marikana debacle, is partly connected to these dynamics. The man's senior position in the group also supports this view. His presence represented a foreclosure to the regular negotiations that are usually possible across the bridge. He simultaneously stood for a stringent migration regime and its associated border enforcement techniques, both of which happen in the present but issue from the past. Just like most things that are ambivalent at the border, his presence communicated these contradictions. 


\section{A bus-full of hyenas}

In some ways, I considered myself lucky to have met so many transporters travelling in one bus. There was simply too much experience in the facilitation of undocumented crossings, and in private transporting - ukulayitsha, sitting in one place. They may not have had many special stories to randomly tell, nor did I probe them for their experiences. However, their mode of communication, their demeanour, as well as the spirits they exuded in the minivan, were telling in relation to what they think of, and do about, the negotiation of border crossings. They came across as both heavily invested and engrained in assisted border crossings.

Such an atmosphere stood for the skills and abilities that make for the success, or at least continuation, of the performance and rituals of negotiated undocumented movement, what I have been calling assisted border crossings. In my analysis, I have suggested that they stand for a myriad of actors that connect together in hyena networks to make up what one might call a social economy of the mobile. They are not just the basic actants of such economies, which nestle around assisted border crossings, but they also stand for, in practice and in identities, a space that exposes, critiques and engages with society's contradictions. They make it possible for undocumented travellers to cross the border. One might say that, in so doing, they participate in perpetuating a broader system that shapes and sustains precarity in movement and in work. At once seen by many as interested in making money and lacking in people and business skills, they are nevertheless sought after for performing, in the eyes of those that need their services, the noble task of helping the disempowered sustain livelihoods and forge ahead with their lives in narrow spaces. Also, even if they befriend border officials and cultivate relations of conviviality and trust, they use that friendship to bring about border outcomes that subvert, elide or bypass enforcement mechanisms, which in the view of some may amount to bringing official border enforcement into disrepute. 
I have made several observations regarding this ambivalence of hyenas. I have argued that as informality, hyena networks, practices and identities signify how broader processes of irregular cross-border movement, precarious work and contradictions between them are shown to interact in a microcosm of everyday life. In this regard, their identities and practices are representative of a space of negotiation in an environment of dispossession, coercion and marginalisation. They challenge Southern African border thinkers to approach assisted border crossings with this realisation in mind. If hyenas could be accused of subverting the symbolic order of contemporary cross-border movement, then the task is to probe what that symbolic order stands for, and to challenge received wisdom regarding access to spaces of belonging and justice, including a consideration of the limits of those spaces.

However, as my field notes illustrate, their work is seldom coherent. At best, it consists of an ongoing series of improvisations. Before one can celebrate them, this consideration helps to situate their work in a context where their orientation against prevailing structures imbues them with unpredictability, violence and a certain level of arbitrary instrumentality; that is, with their own kind of magic as Colin Hoag (2010), echoing Mary Douglas (1966), has suggested. This incoherence is illustrative of the complexity of social process, but also of the messiness of popular, if non-class-conscious, struggles of the everyday.

Paying one's way in

To return to the above notes, the way immigration officers inside the South African passport stamping halls alternated their work with indiscreetly looking in their phone is unremarkable in the Beitbridge border scene. I have briefly reflected on this attitude earlier in this thesis, to say that it ties to a general disregard in which they hold Zimbabwean travellers who present there in 
attempts to gain entry into South Africa. But, with the help of the above example, this attitude ties to how the woman comes rushing in with a fixer to attempt to get more residence days on her passport. The incident was almost silent, open, and seemed to take precedence over a regular passport stamping in which I was already participating.

As I have discussed in Chapter Six, passports alone sometimes do not do enough to gain travellers access into South Africa. Although they remain indispensable for cross-border travel, they have come to work in unexpected ways. They can now also anchor negotiations where travel documents are missing. What makes this make-belief work is the manipulation of their importance. In the above example, because all the actors understand how important passports are for travel and stay with South Africa, they have created additional economies that build and capitalise on this perception. The woman needs the passport to gain enough days for her to do what she came to South Africa to do within the confines of legality. The immigration officer takes advantage of this need to extract monetary gain. The fixer, by connecting these two, affords the officer the money, the woman the days she needs and he gets a 'cut' from these transactions for himself.

This is one extended purpose of the passport these days. In other cases, passports appear over the same immigration counters without their holders. 'Ghost passports', as I have called them, can be decoupled from their owners to achieve the same purpose as in the above example. Disembodiment, a strategy that enables this make-belief, works to make border enforcement systems stutter. Practices such as those that drive the phenomenon of ghost passports reorientate the meanings of border enforcement by partially removing them from the realm of bureaucracy and infusing them with something of the social relations of opportunity and disempowerment. 
In historical perspective, it is not difficult to understand this attitude towards documents. They are often seen as instruments of coercion and domination and, apart from that principal function, have little else in terms of their substance in ordinary people's lives. Such an attitude, I have argued, represents political responsiveness not as conscious struggle, but as an internal dynamic of dispossession. Within their means, poor people attempting to string together livelihoods find that they have to exploit whatever cracks that appear in systems that stand for their dispossession. That immigration officers are likely to participate in these economies is often on account of their position in the landscape of relative dispossession, which posits them as sharing what Achille Mbembe and Janice Roitman (1995) call the same 'episteme' as undocumented travellers. In other words, they speak a more or less similar language in terms of where they come from, what they have and continue to experience in their social, political and economic lives, and what they aspire for. Their presence and interaction with the formal border enforcement systems make for a complex border space which defines Beitbridge as the particular third space that it is.

\section{One eats, the other starves}

The last inspection as one leaves the border gates into South Africa is a notorious piece of ground. This is where things can shape up for a successful entry into South Africa, or where they can very quickly unravel for ordinary travellers and their transporters. This is the same spot that has seen Mkhize, introduced in Chapter Three, come of age as an experienced undocumented traveller in his own right. The emptying of people's bags I noted represents the manner in which their disempowerment is tested to the very limit. Undocumented travellers and transporters often try to appear as regular travellers, but the system exposes them almost all of the time. 
Msholozi tried this strategy by stripping his minivan of any appearances of being a transporter, and yet that could not stop individuals being scrutinised to the minute detail.

Nevertheless, a few things were still possible. Away from this inspection, transporters were busy negotiating for their own passage and that of the undocumented man that was in the bus. They exited individually on foot, and many of them rejoined the bus at the same time as the trailer, at the petrol station outside the gates. If Msholozi had hoped to pronounce hunger on inspecting officials at the inspection by the exit, then those officials ate indeed. But that means some among the transporters, such as the man whose three passports were confiscated, starved in equal measure. There he stood, at the end, borrowing money to get his documents back.

It needs to be stressed that this business of eating binds hyenas and the official enforcement apparatus in a single tangle. In fact, through acts of letting undocumented travellers pass through the enforcement mechanism directly, the two economies, or systems, appear to anticipate each other. Transporters and undocumented travellers seek to legitimise their presence by submitting to inspections (Bolt, 2012). By 'allowing' this to happen, the enforcement mechanism legitimises them and itself in the process, although in ways that make its mechanisms appear partially compromised. This has significant implications for border subjectivities.

Border actors tend to appear as constantly changing figures or identities, suggesting that their subjectivities are hard to pinpoint. To reiterate, through these practices, they appear unhinged from predictable conceptions of social space and its relations. I have argued that the subject-constituting social practices of enforcement appear themselves implicated in producing ambivalent subjects. As much as their splintered identities are tested by the dominion, they themselves test 
the border enforcement mechanism, and indeed find ways to continuously restyle its rigid edifice. This mutability between domination and resistance offers grounds for the reimagination of the limits to the possible forms of movement. If this succeeds in reshaping the social landscape of undocumented movement, then such acts of redoing social processes represent unfinished business.

\section{Towards a new conception of the politics of undocumented movement}

This thesis joins other works that, increasingly take crossborder movement in Southern Africa and its associated political, displacement, remittance and informal economies as their focus (Crush \& Tevera, 2010; Nyoni, 2012; Hammar, 2014, 2010; Crush et al., 2015; Tevera, Crush, \& Chikanda, 2010; Bracking \& Sachikonye, 2010). For a region of such historical as well as contemporary socio-economic significance as the Beitbridge border and the greater Limpopo Valley, as well as South and Southern Africa, this study will strengthen these already existing voices. The contribution of this study, I believe, partly lies with its methodological approach which connects a socioeconomic analysis of the labour-migrationborder nexus to an analysis of subjectivity, or the modes of experience and identity that are produced in the border struggles of the Limpopo. Such an approach is useful in that it helps to place mundane processes into their broader context. This is important, because it can help emphasise the wider significance of local experiences and practices, or alternatively, illustrate how broader structural processes are likely to pan out on the ground.

The Beitbridge border, by the sheer volumes of the people crossing there, and the intensity of the struggles that characterise the negotiation of movement, is a particularly important case 
from which to illustrate, for Southern African, the articulation between movement, irregularity, informality, precarity and neoliberal capital accumulation strategies. As a sub-regional economic power that attracts both capital and cheap labour, South Africa furnishes a ready example of how these processes interact. By example of assisted border crossings, we are therefore in a position to describe how borders play a critical role in their co-articulation.

In terms of migration studies in general, this thesis offers a comparative perspective from a region that is undergoing rapid social changes but often escapes wider interest. Both in terms of what borders are and what they do, and in terms of informalisation processes, this study provides reason for a reflection on popular pronouncements that occupy political, media and policy discourses. For instance, moral panics about a human invasion by migrants that do not take into account the role of political economy or structural processes of bordering appear misplaced. Alternatively, debates on informality that, as Slavnic (2010) and Theron (2010) have suggested, miss the role of 'formal' players in their initiation and sustenance may also be only partially helpful. The Limpopo Valley demonstrates how this has been unfolding for quite a while.

Finally, the context of relative rapid changes or crises that this study has focused on, and the practices of assisted border crossings that emerge within such contexts, help us to think about the kind of human subject the migrant is or becomes. The kind of subjectivities that are rooted in crisis and ambivalence, as this thesis has shown, help contextualise the uncertainties and dislocations that accompany the meanings of being a crossborder precarious migrant. Nevertheless, the tenacity and ingenuities of these unassuming political actors in situating their practices and subjectivities in this context poses new questions on novel forms of subject formation for the people who are involved in border crossings. 
As a kind of re-imagination of the narrative of Africa's present and future (Gikandi, 2011), the practices and experiences that I have observed, reported and analysed in this thesis relate not only to the ways in which states and private actors interact in Southern Africa, but also to forms of social collaboration that are not merely rooted in specific local geographies, but are also transcended by them. At the same time, the crises that define the subject position of the actors at the Beitbridge border engender new ways of relating to space and self. This has significant implications for the continuing evolution of the nation-state and conceptions of subjectivity in post-colonial African countries. 


\section{REFERENCES}

\section{Archival Material}

F137/Vol V1, Secretary for Native Affairs, South Africa, to

Secretary for Native Affairs, Southern Rhodesia, 13 January 1950

NAZ S2239. Labour Monthly: 1953 October to 1960 October.

Southern Rhodesia Department of Labour Monthly Report: July 1960

NAZ, S138/40. Superintendent of Natives, Fort Victoria, to Herbert Taylor, CNC, Salisbury, 10 June 1927. In Murray, M. (1995). 'Blackbirding' at 'Crook's Corner', p 395.

NAZ S428/469/1939 Draft letter from The Chief Native Commissioner to the South African Secretary for Native Affairs, 15 May 1918

NAZ S2239. Labour Monthly: 1953 October to 1960 October. Southern Rhodesia Department of Labour Monthly Report: July 1960

NAZ S4821224/39, Commissioner of Native Labour to CNC, 26 August 1946.

NAZ S482/20B/46, RNLSC: Minutes of Second Meeting, 18 November 1948.

NAZ NB3/2/2 Rhodesia Native Labour, Stuart Erskine versus H.

A. Key, 22 November 1918.

NAZ S1226, Lieutenant W. H. D. Walker, Assistant Superintendent of Police, Bulawayo South, to Chief Superintendent, BSA Police, Bulawayo, 24 July 1939 
NAZ S1226, Chief Superintendent, CID, to staff officer, BSA Police, Salisbury, 15 June 1939

NAZ S1226, Chief Superintendent, CID, to staff officer, BSA Police, Salisbury, 15 June 1939

NAZ S1226, Assistant Commissioner, CID Bulawayo, Minute, 20 June 1942

NAZ S482/509/39, "Clandestine Migration of Natives to the Union": General Assembly, Sub Insp Robotham, 5 January 1945

NAZ NB3/2/2 Rhodesia Native Labour, Stuart Erskine versus H. A. Key, 22 November 1918;

NAZ NB3/2/2 2513/18 Chief Native Commissioner, to the Secretary of the Administrator, 6 December 1918

NAZ NB3/2/2 Rhodesian Native Labour, Letter from Acting Secretary of Native Affairs of the Union of South Africa, to the Rhodesian Native Affairs Department, 13 May 1923

NAZ NB3/2/2 93/280 Letter to the Chief Native Commissioner, Salisbury, from the Acting Secretary of Native Affairs, Union of South Africa, 26 July 1923

NAZ S482/52/44, Memorandum by the Secretary for Native Affairs, 13 April 1944

NAZ S482/509/39, “Clandestine Migration of Natives to the Union”: General Assembly, Sub Insp Robotham, 5 January 1945

NAZ S1226, “Native Labour", circular letter to all CID stations, 28 February 1939. The letter, at one point, makes an explicit connection between the South African Chamber of Mines and recruiters of the Limpopo. 
NAZ S1226, Minute by Assistant Commissioner, CID, Bulawayo, 20 June 1942. From my experience and research, this 'trick' was still in use as late as 2003, when I myself used it to get a visa to travel to South Africa on holiday.

NAZ S1226, NCO i/c, Kezi BSA Police to Assistant Commissioner, BSA Police, Bulawayo, 10 July 1942

NAZ S1226, Report to the Native Detective, Musimane, 27 October 1939; S482/509/39, “Clindestine Migration of Natives to the Union": general Summary, Sub Inspector Robotham, 5/1/45, 3 January 1945

NAZ S1226, Chief Native Commissioner to the Commissioner, BSA Police, 17 March 1934

NAZ S1226, Chief Superintendent, BSA Police, Bulawayo District to Staff Officer, BSA Police, 11 October 1937

SANA TAB GNLB 43984 'Suggestion that the District around Messina mine be closed for Recruiting'. Acting Secretary to local Board, Messina, to Director of Native Affairs, Johannesburg, 13 March 1912

SAB NTS 2025 26/80 2598/14/473. Acting Director of Native Labour to Secretary for Native Affairs, $18^{\text {th }}$ August 1921.

SAB NTS 2025 26/80 2598/14/473. Director of Native Labour to Native Sub-Commissioner, Louis Trichardt, 29 October 1924.

SANA TAB HKN 1/1/52 17N3/20/2 Southpansberg Farmers Union to Native Commissioner, Louis Trichardt, 25 February 1948

SANA SAB NTS 2025 26/80 2598/14/473. Director of Native Labour to Secretary for Native Affairs, 13 December 1922 
SANA SAB NTS 2025 26/80 2598/14/473. Director of Native Labour to Secretary for Native Affairs, 1 February 1923

SANA TAB HKN 1/1/52 17N3/20/2 ‘Foreign Farm Scheme Louis Trichardt Main File'

SAB NTS 2025 26/80 2598/14/473. Report no. 56/13/405, submitted to the Native Commissioner, Pietersburg on 13 August 1913

TAB HKN 1/1/52 17N3/20/2 ‘Depots: Foreign Labour Recruiting Scheme'. Secretary of Native Affairs to Chief Native Officer, Pietersburg, 10 July 1947

TAB HKN 1/1/52 17N3/20/2 ‘Farm Labour Scheme: Special Instructions for the Native Commissioner, Louis Trichardt'. Secretary of Native Affairs to Chief Native Commissioner, Northern Areas, 3 March 1947

TAB HKN 1/1/51 17N3/20/2 ‘Foreign Labour Recruitment Scheme - Louis Trichardt.' Secretary for Native Affairs to Commissioner, South African police, 18 April 1953

\title{
Published material (printed and digital)
}

\begin{abstract}
Abraham, I., \& van Schendel, W. (2005). The Making of Illicitness. In I. Abraham \& W. van Schendel (Eds.), Illict Flows and Criminal Things: States, Borders and the Other Side of Globalization. Bloomington: Indiana University Press.
\end{abstract}

Abrahams, R. D. (1985). Afro-American Folktales: Stories From Black Traditions in the New World. New York: Pantheon Books.

Abrahams, R. D. (1988). Eating in the Belly of the Elephant. In A. Jabbour \& J. Hardin (Eds.), Folklore Annual 1987. Washington, D.C.: Library of Congress. 
Abrams, P. (1988). Notes on the Difficulty of Studying the State. Journal of Historical Sociology, 1(1), 58-89.

Addison, L. (2006). Frontier Farm Labour: The Neoliberal Restructuring of Agriculture and Zimbabwean Migrant Farm Workers in Limpopo Province, South Africa. (M.A. Thesis), Carleton University, Ottawa.

Addison, L. (2013). Labour, Sex and Spirituality on a South African Border Farm. (Doctor of Philosophy), The State University of New Jersey, New Brunswick Rutgers.

Adepoju, A. (2002). Issues and Recent Trends in International Migration in Sub-Saharan Africa. International Social Science Journal, 52(165), 383 - 394.

Alexander, J., \& McGregor, J. (2001). Elections, Land and the Politics of Opposition in Matabeleland. Journal of Agrarian Change, 1(4), 510-533.

Alexander, J., McGregor, J., \& Ranger, T. (2000). Violence and Memory: One Hundred Years in the 'Dark Forests' of Matabeleland. Oxford: James Currey.

Alexander, P. (2001). Zimbabwean Workers, the MDC and the 2000 Elections. Review of African Political Economy, 27(85), 385 - 406.

Ally, R. (1993). South Africa's Path to Industrialization, c1850-1925. Paper presented at the Work, Class and Culture symposium, African Studies Seminar Series, on 28-30 June, 1993, University of the Witwatersrand, Johannesburg. Available online at: http:/ wiredspace.wits.ac.za/handle/10539/8405. [Accessed on 12 Oct., 2017].

Amin, S. (1976). Unequal Development: An Essay on the Social Formations of Peripheral Capitalism. Hassocks: Harvester Press. 
Amit, R. (2015). Queue here for corruption: measuring irregularities in South Africa's asylum ststem. Pretoria \& Johannesburg: LHR and ACMS.

Andersson, R. (2014). Illegality, Inc: Clandestine Migration and the Business of Bordering Europe. Los Angeles: University of California Press.

Andrijasevic, R. (2009). Sex on the move: gender subjectivity and defferential inclusion. Subjectivity, 29(1), 389-406.

Anjaria, J. (2011). Ordinary states: Everyday Corruption and the politics of space in Mumbai. American Ethnologist, 38(1), 58 - 72.

Appadurai, A. (1986). Introduction: Commodities and the Politics of Value. In A. Appadurai (Ed.), The Social Life of Things. Cambridge: Cambridge University Press.

Araghi, F. (2009). The Invisible Hand and the Visible Foot: Peasants, Dispossession and Globalization. In C. Kay \& H. Akram-Lodhi (Eds.), Peasants and Globalization: Political Economy, Rural Transformation and the Agrarian Question. London: Routledge.

Araia, B. B. (2006). Citizenship, Constitutional Legitimacy and Identity in Post-colonial African Nation-states. (PhD Thesis), University of North Carolina, Chapel Hill.

Archer, M. S. (1982). Morphogenesis versus structuration: on combining structure and action. British Journal of Sociology, 33(4), $455-483$.

Archer, M. S. (1995). Realist Social Theory: The Morphogenic Approach. Cambridge: Cambridge University press.

Arrighi, G. (1968). The Political Economy of Rhodesia. New York: Humanities Press. 
Arrighi, G. (1970). Labour Supplies in Historical Perspective: A Study of the Proletarianization of the African Peasantry in Rhodesia. Journal of Development Studies, 6(3), 197 - 234.

Association for Concerned African Scholars (ACAS). (2008a). Special Issue on the 2008 Zimbabwe Elections. Bulletin No. 79, Spring 2008. Available online at: http://concernedafricascholars. org/docs/acasbulletin79.pdf. [Accessed 16 Oct., 2017].

Association for Concerned African Scholars (ACAS). (2008b). Special Issue on Zimbabwe (II). Concerned Africa Scholars, Buletting No. 80, Winter 2008. Available online at: http:// concernedafricascholars.org/docs/acasbulletin80.pdf. [Accessed 16 Oct., 2017].

Association for Concerned African Scholars (ACAS). (2009). Reflections on Mahmood Mamdani's 'Lessons of Zimbabwe'. Concerned Africa Scholars, Buletting No.82, Summer 2009. Available online at: http://concernedafricascholars.org/docs/ acasbulletin82.pdf. [Accessed 16 Oct. 2017].

Ayimpam, S. (2015). Informal Trade, Cross Border Networks and Contraband of Asian Textiles from Brazzaville to Kinshasa. Journal of Borderlands Studies, 30(3) 395-403.

Bakewell, O. (2010). Some Reflections on Structure and Agency in Migration Theory. Journal of Ethnic and Migration Studies, 36(10), 1689-1708.

Barber, K. (1987). Popular Arts in Africa. African Studies Review, 3(30), 1- 78.

Bayart, J.-F., Ellis, S., \& Hibou, B. (1999). The Criminalization of the State in Africa. Oxford and Bloomington: James Currey and Indiana University Press. 
Bayat, A. (1977). Un-civil society: the politics of 'informal people'. Third World Quarterly, 18(1), 53 - 72.

BBC (British Broadcasting Corporation). (2016). 'Malawian 'hyena man' arrested for having sex with children', BBC News, 26 July. Available online at: http://www.bbc.com/news/worldafrica-36892963 [Accessed 1 Oct. 2017].

BBC (British Broadcasting Corporation). (2016). 'Stealing Innocence' in Malawi, BBC Assignment Magazine, 25 July 25. Available online at: http://www.bbc.co.uk/programmes/p041dlfb, [Accessed 12 Oct., 2017].

Beinart, W. (2001). Twentieth Century South Africa. Oxford: Oxford University Press.

Bell, K. (2015). 'Abandoning Informed Consent?' AAA Ethics $B \log$, Available online at: http://ethics.aaanet.org/category/ informed -consent/. [Accessed 13 May 2015].

Berg, U. D. (2008). Practical Challenges of Multi-sited Ethnogphaphy. Anthropology News, 49(5), 15-15.

Berstein, H. (1996). South Africa's Agrarian Question: Extreme or Exceptional? The Journal of Peasant Studies, 23(2-3), 1-52.

Bezuidenhout, A., \& Kenny, B. (2000). The Language of Flexibility and the Flexibility of Language: Post-Apartheid South African Labour Market Debates. Johannesburg: University of the Witwatersrand.

Bezuidenhout, A., Godfrey, S., \& Theron, J. (2004). Nonstandard Employment and its Policy Implications. Johaneesburg and Cape Town: University of the Witwatersrand and Univerity of Cape Town. 
Bhabha, H. (1994). The Location of Culture. New York: Routledge.

Bjanersen, J. (2017). Comment on Thomas Nail's (2015) political theory of the migrant. February 2017. Personal communication.

Blundo, G., \& Olivier de Sardan, J.-P. (2006). Everyday

Corruption and the State: Citizens and Public Officials in Africa. Cape Town: David Philip.

Boissevain, J. (1996). Patronage in Sicily. Man, 1, 18 - 33.

Bolt, M. (2011). Rooting Production: Life and Labour on the Settler Farms of the Zimbabwean-South African Border. (PhD Thesis), London School of Economics and Political Science, London.

Bolt, M. (2012). Waged Entrepreneurs: Policed Informality: Work, the Regulation of Space and the Economy of the Zimbabwe South Africa Border. Africa, 82(1), 111-130.

Bolt, M. (2015). Zimbabwe's Migrants, South Africa's Border Farms: The Roots of Impermanence. Cambridge: Cambridge University Press.

Bond. P. (2014). 'Talk left, walk right' in South African social policy: Tokenistic extension of state welfare versus bottom up commoning of services. Available online at: sds.ukzn. ac.za/files/2014-02-19\%20Bond\%20SA\%20social\%20policy.pdf. [Accessed 12 Oct., 2017].

Bond, P., \& Sauders, R. (2005). Labour, the State, and the Struggle for a Democratic Zimbabwe. Monthly Review, 57(7). Available online at: monthlyreview.org/2005/12/01/labor-thestate-and-the-struggle-for-a-democratic-zimbabwe/. [Accessed 12 Oct., 2017]. 
Bonner, P. (2003). Introduction. In P. Bonner \& E. J. Carruthers (Eds.), The Recent History of the Mapungubwe Area. South African Department of Enviromental Affairs and Tourism: Mapungubwe Cultural Heritage Resources Survey.

Bonner, P., Hyslop, J., \& van der Walt, L. (2007). Rethinking Worlds of Labour: Southern African Labour History in the International Context. African Studies, 66(2-3), 137-168.

Booi, M. (2016). 8 July. 'Zimbabwe revises import regulations', eNews Channel Africa (eNCA). Available online at: https:// www.enca.com /africa/zimbabwe-revises-import-reregulations. [Accessed 28 Sept., 2017].

Bourdieu, P. (1977). Outline of a Theory of Practice. Cambridge: Cambridge University Press.

Bozzoli, B. (Ed.) (1987). Class, Community and Conflict: South African Perspectives. Johannesburg: Ravan Press.

Bradford, H. (1993). Getting Away with Murder: "Mealie Kings", the State, and Foreigners in the Eastern Transvaal, c1918-1950. In P. Bonner, P. Delius, \& D. Posel (Eds.), Apartheid's Genesis, 1935 1962. Johannesburg: Ravan Press.

Brambilla, C. (2015). Exploring the Critical Potential of the Borderscapes Concept. Geopolitics, 20(1), 14-34.

Brambilla, C., Liaine, J., Scott, J., \& Bocchi, G. (Eds.). (2015). Borderscaping: Imaginations and Practices of Bordermaking. Surrey: Ashgate.

Brenneis, D. (2006). Reforming Promise. In A. Riles (Ed.), Documents: Artifacts of Modern Knowledge. Ann Arbor: University of Michigan press. 
Brophy, S. (2016), 27 May, 'SA border-crossing corruption rooted out with DHA staff arrests'. Available online at: http://www. traveller24.com/News/sa-border-crossing-corruption-rooted-outwith-dha-staff-arrests-20160527, [Accessed 10 Oct., 2017].

Brunet-Jailly, E. (2007). Theorizing Borders: An Interdisciplinary Reflection. Geopolitics, 10(4), 633-649.

BSAC. (1936). The Story of Rhodesia: Told in Series of Historical Pictures. Historical Catalogue and Souvenir of Rhodesia. Johanneburg: Hectors Limited.

Buhlungu, S. (2010). The Paradox of Victory: COSATU and the Democratic Transformation in South Africa. Scottsville: University of KwaZulu-Natal Press.

Bulpin, T. V. (1954). The Ivory Trail. Cape Town: Howard Timmins.

Burawoy, M. (1998). The Extended Case Method. Sociological Theory, 16(3), 4-33.

Burawoy, M. (2003). Revisits: An Outline of a Theory of Reflexive Ethnography. American Sociological Review, 68, 645-679.

Buscher, M., \& Urry, J. (2009). Mobile Methods and the Empirical. European Journal of Social Theory, 12(1), 99-116.

Bush, R., \& Cliffe, L. (1984). Agrarian Policy in Labour Migrant Societies: Reform or Transformation in Zimbabwe? Review of African Political Economy, 29, 77-94.

Butler, E. (2016). 21 July. 'The man hired to have sex with children', BBC News Magazine. Available online at: http://www. bbc.com/news/magazine-36843769 [Accessed 1 Oct., 2017]. 
Butler, J., \& Athanasiou, A. (2013). Dispossession: The Performative in the Political. Cambridge: Polity.

Cabot, H. (2012). The Governance of Things: Documenting Limbo in the Greek Asylum Process. PoLAR, 35(1), 11-29.

Callinicos, L. (1980). Gold and Workers: A People's History of South Africa. Ravan Press: Johannesburg.

Castles, S., \& Kosack, G. (1973). Immigrant Workers and Class Structure in Western Europe. London: Oxford University Press.

Chabal, P., \& Daloz, J.-P. (1999). Africa Works: Disorder as Political Instrument. Bloomington: Indiana University Press.

Chandavarkar, R. (2007). Customs of Governance: Colonialism and Democracy in Twentieth Century India. Modern Asian Studies, 41(3), 441-470.

Chatterjee, P. (2004). The Politcs of the Governed: Reflections on Popular Politics in Most of the World. New York: Columbia University Press.

Chávez, J. R. (2015). “Beyond Domestic Empire: Internal- and Post-colonial New Mexico". History Faculty Publications, 3. Available online at: http://scholar.smu.edu/hum_sci_historyresearch/3 [Accessed 12 Oct., 2017].

Cheal, D. (1988). The Gift Economy. London: Routledge.

Chikanda, A., \& Tawodzera, G. (2017). Informal Entrepreneurship and Cross-Border Trade between Zimbabwe and South Africa. SAMP Migration Policy Series No. 74. Waterloo, Canada: SAMP. 
Chiliya, N., Masocha, R., \& Zindiye, S. (2012). Challenges Facing Zimbabwean Cross Border Traders Trading in South Africa: A Review of the Literature. Chinese Business Review, 11(6), $564-570$.

Chiumia, S. \& van Wyk, A. (2014). 26 September. FACTSHEET: The new special dispensation permit \& what it means for Zimbabweans in SA. Africa Check. Available online at: https:// africacheck.org/factsheets/what-does-the-new-specialdispensation-permit-mean-for-zimbabweans-in-sa/. [Accessed 16 Oct., 2017].

Clarkson, N. L., \& Worher, W. H. (2013). South Africa: The Rise and Fall of. London: Routledge.

Cohen, R. (1987). The New Helots: Migrants in the International Division of Labour. Aldershot: Averbury.

Cohn, B. (1987). An Anthropologist among the Historians and Other Essays. New York: Oxford University Press.

Comaroff, J., \& Comaroff, J. (1991). Of Revelation and Revolution: Christianity, Colonialism, and Consciousness in South Africa.

Chicago: Chicago University Press.

Comaroff, J., \& Comaroff, J. (2012). Theory from the South: Or, how Euro-America is Evolving Toward Africa. Anthropological Forum, 22(2), 113 - 131.

Conlon, D. (2004). Productive Bodies, Performative Spaces: Everyday Life in Christopher Park. Sexualities, 7(4), 462 - 479.

Coplan, D. (2012). Border Show Business and Performing States. In T. M. Wilson \& H. Donnan (Eds.), A Companion to Border Studies. Oxford: Wiley-Blackwell. 
Crush, J. (2000a). Introduction: Making Hay with Foreign Farmworkers. In J. Crush (Ed.), Borderline Farming: Foreign Migrants in South African Commercial Agriculture (SAMP Migration Policy Series, No. 16). Cape Town: IDASA.

Crush, J. (Ed.). (2000b). Migrations past: A Historical Overview of Cross-border Movement in Southern Africa (Vol. 17). Cape Town: SAMP/Idasa.

Crush, J. (2008). South Africa: Policy in the Face of Xenophobia. From The Online Journal of the Migration Policy Institute. Available online at: https://www.migrationpolicy.org/article/ south-africa-policy-face-xenophobia. [Accessed 12, Oct., 2017].

Crush, J., Chikanda, A., \&Tawodzera, G. (2015). The third wave: mixed migration from Zimbabwe to South Africa. Canadian Journal of African Studies, 49(2), 363-382.

Crush, J., \& Pendleton, W. (2009). Remitting for Survival: Rethinking the Development Potential of Remittances in Southern Africa. Global Development Studies, 5(3-4), 53 - 84.

Crush, J., Skinner, C., \& Chikanda, A. (2015) Informal Migrant Entrepreneurship and Inclusive Growth in South Africa, Zimbabwe and Mozambique. SAMP Migration Policy Series No. 68. Waterloo: SAMP.

Crush, J., \& Tevera, D. (2010). Exiting Zimbabwe. In J. Crush \& D. Tevera (Eds.), Zimbabwe's Exodus: Crisis, Migration, Survival. Cape Town: SAMP.

Crush, J., \& Tevera, D. (Eds.). (2010). Zimbabwe's Exodus: Crisis, Migration, Survival. Cape Town: Kingston. 
Crush, J., \& Tshitekere, C. (2001). Contesting Migrancy: The Foreign Labour Debate in Post-1994 South Africa. Africa Today, 48(3), 49 - 70.

Das, V. (2004). Signature of the State: The Paradox of Illegibility. In V. Das \& D. Poole (Eds.), Anthropology at the Margins of the State. Santa Fe: SAR Press.

Das, V., \& Poole, D. (Eds.). (2004). Anthropology at the Margins of the State. Santa Fe: SAR Press.

Davidson, J.O.C. (2008). 'If No Means No, Does Yes Mean Yes? Consenting to Research Intimacies.' History of the Human Sciences, 21(4): 49 - 67.

Davies, R. (2004). Memories of Underdevelopment: A Personal Interpretation of Zimbabwe's Economic Decline. Souther African Regional Poverty Network. Pretoria.

De Genova, N. (2012). 'Border, Scene and Obscene'. In T. Wilson and H. Donnan (Eds.), A Companion to Border Studies. Oxford, UK and Malden, MA: Wiley-Blackwell

Delius, P., \& Trapido, S. (1983). Inboekselings and Oorlams: The Creation and Transformation of a Servile Class. In B. Bozzoli (Ed.), Town and Countryside in the Transvaal. Johannesburg: Ravan Press.

Derrida, J. (1972). Signature, Event, Context. Translated by Alan Bass. In, Margins of Philosophy. Chicago: Chicago University Press.

Dingwall, R. and E. Murphy. (2007). 'Informed Consent, Anticipatory Regulation and Ethnographic Practice.' Social Science and Medicine, 65(11): 2223 - 2234. 
Dirks, N. (2001). Castles of Mind: Colonialism and the Making of Modern India. Princeton: Princeton University Press.

Douglas, M. (1966). Purity and Danger: An Analysis of Concepts of Pollution and Taboo. London and New York.

Dube, P. (2014). The "Undesirable" Immigration Regulations 2014. Cape Town.

Eisenstadt, S. N., \& Roniger, L. (1980). Patron-Client Relations as a Model of Structuring Social Exchange. Comparative Studies in Society and History, 22(1), 42 - 77.

Ellis, S. (1994). Of Elephants and Men: Politics and Nature Conservation in South Africa. Journal of Southern African Studies, 20(1), 53 - 70.

Ellis, S. (1999). The New Frontiers of Crime in South Africa. In J.-F. Bayart, S. Ellis, \& B. Hibou (Eds.), The Criminalization of the State in Africa. Oxford and Bloomington: james Currey and Indiana University Press.

eNCA. (2016). 26 May, 'Hawks arrest corrupt SA officials in Beitbridge for document fraud'. Available online at: http://www. enca.com/south-africa/counterfeit-document-conspiratorsarrested-by-hawks, [Accessed 10 Oct., 2017].

Evans, H.-C. (2015). 24 November. 'Corruption, Smuggling, and Border Jumping: The Beitbridge Border Post'. Fair Planet. Available online at: http://www.fairplanet.org/story/corruptionsmuggling-and-border-jumping-the-beitbridge-border-post/. [Accessed on 10, Oct., 2017].

Fasin, D. (2011). Policing Borders, Policing Boundaries: The Governmentality of Immigration in Dark Times. Annual Review of Anthropology, 40, 213-226. 
Feinstein, C. (2005). An Economic History of South Africa: Conquest, Discrimination, and Development. Cambridge: Cambridge University Press.

Ferguson, P. (2015). Give a man a fish: reflections on the new politics of distribution. Durham: Duke University Press.

Fine, J. (2014). Migration and migrant workers in the postapartheid era. Global Labour Journal, 330-346.

Frayne, B., \& Pendleton, W. (2009). The Development Role of Remittances in the Urbanization Process in Southern Africa. Global Development Studies, 5 (85 - 132).

Frembgen, J. W. (1998). The Magicality of the Hyena: Beliefs and Practices in West and South Asia. Asian Folklore Studies, 57, 331 344.

Gaudet, M. (1992). Bouki, the Hyena, in Louisiana and African Tales. The Journal of American Folklore, 105(415), 66-72.

Gennep, A. v. (1960 [1908]). Rites of Passage. London: Routledge and Kegan Paul.

Giddens, A. (1984). The Construction of Society. Cambridge: Polity Press.

Gieryn, T.F. (1999). Cultural Boundaries of Science: Credibility on the Line. Chicago: University of Chicago Press.

Gikandi, S. (2011). Foreword: On Afropolitanism. In J. Warwrzinek \& J. K. S. Makokha (Eds.), Nagotiating Afropolitanism: Essays on Borders and Spaces in Contemporary African Literature and Folklore. New York and Amsterdam. 
Gluckman, M. (1940). Analysis of a Social Situaltion in Modern Zululand. Bantu Studies, 14(1), 1-30.

Gluckman, M. (1955). Order and Rebellion in Tribal Africa: Collected Essays. Oxford: Blackwell.

Green, S. (2013). Borders and the Relocation of Europe. Annual Review of Anthropology, 42, 345 - 361.

Gunaratnam, Y. (2003). Researching Race and Ethnicity: Methods, Knowledge and Power. London: Sage.

Gupta, A. (1995). Blurred Boundaries: The Discourse of Corruption, the Culture of Politics, and the Imagined State. American Ethnologist, 22(2), 375-402.

Gupta, A. (2005). Narratives of corruption: Anthropological and fictional accounts of the Indian state. Ethnography, 6(1), 5-34.

Hage, G. (2005). A not so multi-sited ethnography of a not so imagined community. Anthropological Theory, 5, 463-474.

Hammar, A. (2008). In the name of sovereignty: Displacement and state making in post-independence Zimbabwe. Journal of Contemporary African Studies, 26(4), 417 - 434.

Hammar, A. (2012). The Concept of Displacement. Audio File. Uppsala: Nordiska Afrikainstitutet.

Hammar, A. (Ed.) (2014). Displacement Economies in Africa: Paradoxies of Crisis and Creativity. London and New York: Zed Books.

Hansen, T. B., \& Stepputat, F. (Eds.). (2001). States of Imagination: Ethnographic Explorations of the Colonial State. Durham, N.C.: Duke University Press. 
Hardt, M., \& Negri, A. (2004). Multitude: War and Democracy in the Age of Empire. New York: The Penguin Press.

Harington, J. S., McGlashan, N. D., \& Chelkowska, E. Z. (2004). A Century of Migrant Labour in the Gold Mines of South Africa. The Journal of the South African Institute of Mining and Metallurgy, 65-71.

Hart, J. (2011). "Suffer to gain": citizenship, accumulation and motor transportation in late-colonial and postcolonial Ghana. (PhD Thesis), Indiana University, Bloomington.

Hart, K. (1973). Informal Income Opportunties and Urban Employment in Ghana. The Journal of Modern African Studies, 11(1), $61-89$.

Hart, K. (1985) The Informal Economy. The Cambridge Journal of Anthropology, 10(2), $54-58$.

Harvey, D. (2004). The 'New' Imperialism: Accumulation by Dispossession. Socialist Register, 40, 63-87.

Hasani, C. (2003). Land and Liberation: Lessons for the Creation of Effective Land Reform Policy in South Africa. Michigan Journal of Race and $L A W, 529$ - 560.

Hause, P. L. (1993). 'So who was Elias Khuzwayo?' In P. Bonner, P. Delius, \& D. Posel (Eds.), Apartheid's Genesis. Johannesburg: Ravan Press.

Hellman, E. (1949). Handbook on Race Relations in South Africa. Oxford: Oxford University Press.

Hemmings, C. (2002). Bisexual Spaces: A Geography of Sexuality and Gender. London: Routledge. 
Hemmingway, E. (1935). Green Hills of Africa. New York: Simon and Schuster.

Heyman, J. M. (1998). State Effects on Labor Exploitation: The INS and Undocumented Immigrants at the Mexico-United States Border. Critique of Anthropology, 18(2), 157-180.

Hoag, C. (2010). The Magic of the Populace: An Ethnography of Illegibility in the South African Immigration Bureaucracy. PoLAR, 33(2), 6-25.

Huni, S. (2015). 24 May. 'Two More Zim Buses Hijacked in SA'. The Sunday News. Available online at: http://www.sundaynews. co.zw/two-more-zim-buses-hijacked-in-sa/. [Accessed 13, Oct., 2017].

IRIN. (2011). 7 October. 'Deportations of Zimbabwean migrants set to resume'. IRIN. Available online at: http://www.irinnews. org/news/2011/10/07/deportations-zimbabwean-migrants-setresume. [Accessed 16, Oct., 2017].

James, D. (2011). The return of the broker: consensus, hierarchy and choice in South African land reform. Journal of the Royal Anthropological Institute, 17(2), 318-338.

Jansen, S. (2010). Anticipating 'hey you there'! Interpellation on the Road to the Border. Političke perspektive, 1(3), 7 - 28.

Jeeves, A. (1983). Over-reach: The South African Gold Mines and the Struggle for the Labour of Zambesia. Canadian Journal of African Studies, 17(3), 393 - 412.

Jeeves, A. (1985). Migrant Labour in South Africa's Mining Industry: The Struggle for the Gold Mines' Labour Supply. Kingston: McGillQueen's University Press. 
Jeeves, A. (1986). Migrant Labour and South African Explansion, 1920 - 1950. South African Historical Journal, 18, 73 - 92.

Johnson, D. (2000). World War II and the Scramble for Labour in Colonial Zimbabwe, 1939 - 1948. Harare: University of Zimbabwe Publications.

Johnson, D. (1990). Clandestine Migration in South Central Africa. Institute for Commonwealth Stidues, 40, 1-11.

Johnston, D. (2007). Who Needs Immigrant Farm Workers? A South African Case Study. Journal of Agrarian Change, 7(4), 228251.

Johnstone, F. A. (1976). Class, Race and Gold: A Study of Class Relations and Racial Discrimination in South Africa. London: Routledge.

Jones, J. L. (2010). 'Nothing is straight in Zimbabwe': The rise of the Kukiya-kiya economy, 2000-2008. Journal of Southern African Studies, 36(2), 285-299.

Jonsson, S. (2013). Crowds and Democracy: The Idea and Image of the Masses from Revolution to Facism. New York: Columbia University Press.

Kabwato, L. (2016), 01 August. We are all Hyenas, Opinion. Daily Times Malawi.

Kapferer, B. (2015). Introduction: In the Event - Toward an Anthropology of Generic Moments. In L. Meinert \& B. Kapferer (Eds.), In the Event: Toward an Anthropology of Generic Moments. New York and Oxford: Berghahn Books.

Kingdon, J. (1988). East African Mammals: An Atlas of Evolution in Africa, Volume 3, Part 1. Chicago: University of Chicago Press. 
Klaaren, J., \& Ramji, J. (2001). Inside Illegality: Migration Policing in South Africa after Apartheid. Africa Today, 48(3), 35 - 47.

Klaeger, G. (2013). Introduction: The Perils and Posibilities of African Roads. Africa, 83(3), 359-366.

Kolossov, V. (2005). Border Studies: Changing Perspectives and Theoretical Approaches. Geopolitics, 10(4), 606-632.

Kupe, T., Verryn, P., \& Worby, E. (2008). Go Home or Die Here: Violence, Xenophobia, and the Reinvention of Difference in South Africa. Johannesburg: Wits University Press.

Kusenbach, M. (2003). Street Phenomenology: The Go-Along as Ethnographic Research Tool. Ethnography, 4(3), 455-485.

Lamont, M., \& Molnár, V. (2002). The Study of Boundaries in the Social Sciences. Annual Review of Sociology, 28, 167-195.

Landau, L. (2010). Loving the Alien? Citizenship, Law, and the Future in South Africa's Demonic Society. African Affairs, 109(435), 1-19.

Larmont, M. (1992). Money, Morals, and Manners: The Culture of the French and American Upper-middle Classes. Chicago: University of Chicago Press.

Lawal, B. (1996). The gèlèdè spectacle: Art, gender, and social harmony in an African culture. London: University of Washington Press.

Lebowitz, M. A. (2003). Beyond Capital: Marx's Political Economy of the Working Class. New York: Palgrave Macmillan.

Lefebvre, H. (1991). The Production of Space (trans. Donald Nicholson-Smith). London: Blackwell. 
Legassick, M. (1974). South Africa: Capital Accumulation and Violence. Economy and Society, 3(3), 253 - 291.

Lewis, D., \& Mosse, D. (2006). Development Brokers and Translators. Bloomfield: Kumarian.

Li, T. M. (2009). To Make Live or Let Die? Rural Dispossession and the Protection of Surplus Populations. Antipode, 41(1), 66-93.

Likic-Brboric, B., Slavnic, Z., \& Woolfson, C. (2013). Labour Migration and Informalisation: East meets West. International Journal of Sociology and Social Policy, 11(12), 677-692.

Lincoln, D., \& Maririke, C. (2000). Southward Migrants in the Far North, Zimbabwean Farmworkers in the Northern Province. In J. Crush (Ed.), Borderline Farming: Foreign Migrants in South African Commercial Agriculture (Vol. Magration Policy Series 16, pp. 40 - 62). Cape Town: SAMP.

Lindberg, S. (2003). 'Its Our time to "Chop"': Do Elections in Africa Feed Neo-Patrimonialism rather than Counteract it? Democratization, 10(2), 121-140.

Lindell, I. (Ed.) (2010). Africa's Informal Workers: Collective Agency, Alliances and Transnational Organising in Urban Africa. London and Uppsala: Zed Books \& Nordic Africa Institute.

Long, N. (1968). Social Change and the Individual. Manchester: Manchester University Press.

Lourenco-Lindell, I. (2002). Walking the tight-rope: Informal livelihoods and social networks in a West African City. Stockholm: Acta Universitatis Stockholmiensis. 
Luebker, M. (2008). Employment, unemployment and informality in Zimbabwe: concepts and data for coherent policymaking. Issue paper No. 32 and Integration Working Paper No. 90. Harare: ILO Sub-Regional Office for Southern Africa (SRO_ Harare).

Luscombe, S. (2012). 19th Century Timeline. Available online at: http://www.britishempire.co.uk/timeline/19century.htm. [Accessed, 11 Oct., 2017].

Maddison, B. (2008). Labour Commodification and Classification: An Illustrative Case Study of the New South Wales Boilermaking Trades, 1860 - 1920. IRSH, 52, 235 - 260.

Magel, E. (1984). Folktales from the Gambia: Wolof Fictional Narratives. Washington, D. C.: Three Continents Press.

Mail \& Guardian. (2005). 2 October. 'Zim, SA travel visas 'to be scrapped". Available online at: https://mg.co.za/article/2005-10-13zim-sa-travel-visas-to-be-scrapped. [Accessed 2 Oct. 2017].

Makina, D. (2013). Migration and Characteristics of remittance Senders in South Africa. International Migration, 51, 148 - 158.

Mapokgole, R. B. (2014) There Is No Black In The Rainbow (Nation): A Bikoist and Fanonian Approach To Understanding "Xenophobic" Violence In South Africa, London \& Cape Town: Trinity College. Available online at: http://digitalrepository.trincoll.edu/cgi/ viewcontent.cgi?article=1437\&context=theses. [Accessed 18 Oct., 2017].

Malkki, L. (1992). National Geographic: The Rooting of Peoples and the Territorialization of National Identity among Scholars and Refugees. Cultural Anthropology, 7(1), 24-44. 
Mamdani, M. (1996). Citizen and Subject: Contemporary Africa and the Legacy of late Colonialism. Princeton: Princeton University Press.

Manheru, N. (2015). 'SA-loving, anti-Zim Mthwakazi rediscover love for home'. Available online at: http://www.newzimbabwe. com/news-22164-Pro-SA+Mthwakazians+knifed+too,+Manheru/ news.aspx. [Accessed 12 Oct., 2017].

Maphosa, F. (2010). Transnationalism and Undocumented Migration Between Rural Zimbabwe and South Africa. In J. Crush \& D. Tevera (Eds.), Zimbabwe's Exodus: Crisis, Migration and Survival. Cape town: SAMP.

Mapuva, J. (2015). Skewed rural development policies and economic malaise in Zimbabwe. African Journal of History and Culture, 7(7), 142 - 151.

Marcus, G. E. (1998). Ethnography Through Thick and Thin. Princeton: Princeton University Press.

Maré, G. (2014). Declassified: Moving Beyond the Dead-End of Race in South Africa. Johannesburg: Jacana Media.

Marx, K. (1976). Capital. Volume 1. Marx and Angels Collected Works (Vol. 35). London: Lawrence and Whishart.

Maseko, N. (2016). 30 September. 'Zimbabwe's import ban fuels smugglers'. Available online at: http://www.bbc.com/news/av/ business-37520164/zimbabwe-s-import-ban-fuels-smugglers. [Accessed 28, Sept., 2017].

Masquelier, A. (2002). Road Mythographies: Space, Mobilities and the Historical Imagination in Postcolonial Niger. American Ethnologist, 29(4), 829 - 855. 
Mate, R. (2005). Making Ends Meet at the Margins? Grappling with Economic Crisis and Belonging in Beitbridge Town, Zimbabwe. Dakar: CODESRIA Monograph Series.

Mauss, M. (1954). The Gift. Glencore: Free Press.

Mbembe, A., \& Roitman, J. (1995). Figures of the Subject in Times of Crisis. Public Culture, 7, 323 - 357.

McIntyre, M. (2011). Race, Surplus Population and the Marxist Theory of Imperialism. Antipode, 43(5), 1489 - 1515.

Mckenzie, J. (2001). Perform, or Else: From Discipline to Performance. London: Routledge.

Meagher, K. (2014). Smuggling Ideologies: From Criminalization to Hybrid Governance in African Clandestine Economies. African Affairs, 113(453), 497 - 517.

Medard, J.-P. (1982). The Underdeveloped State in Tropical Africa: Political Clientelism or Neo-Patrimonialism In C. Claphan (Ed.), Private Patronage and Public Power: Political Clientelism in the Modern State. London: Francis Printer.

Melly, C. (2013). Ethnography on the Road: Infrastructural Vision and the Unruly Present in Contemporary Dakar. Africa, 83(3), 385 - 402.

Mezzadra, S., \& Neilson, B. (2013). Border as method; or, the multiplication of labour. Durham and London: Duke University Press.

Miles, R. (1987). Capitalism and Unfree Labour: Anomaly or Necessity. London: Tavistock. 
Millen, D. R. (2000). Rapid Ethnography: Time Deepening Strategies for HCI field Research. Available online at: http://citeseerx.ist.psu.edu/viewdoc/ download?doi=10.1.1.595.9094\&rep=rep1\&type=pdf. [Accessed 13, Oct., 2017].

Mills, G. (2012). 'Backwards to beitbridge? A Strategy to revive Zimbabwe's Industry'. Available online at: http://www. thebrenthurstfoundation.org/Brenthurst_Commissioned_ Reports/Brenthurst-paper-201207-Backwards-to-Beitbridge.pdf. [Accessed on 10 Oct., 2017].

Mills, G., \& Hofer, H. (1998). Hyaenas: Status Survey and Conversation Action Plan. IUCN/SCC Hyaena Specialist Group. Available online at: http://www.carnivoreconservation.org/files/ actionplans/hyaenas.pdf. [Accessed 13, Oct., 2017].

Minaar, A., \& Hough, M. (1996). Who Goes There? Pespectives on Clindestine Migration and Illegal Aliens in Southern Africa. Pretoria: Human Sciences Research Council.

Mitchell, T. (1990). Everyday Metaphors of Power. Theory and Society, 19, 545 - 577.

Mlambo, A. S. (2010). 'A History of Zimbabwean Migration to 1990'. In J. Crush \& D. Tevera (Eds.), Zimbabwe's Exodus: Crisis, Migration, Survival. Cape Town: SAMP.

Mol, A., \& Law, J. (2005). Boundary variations: an introduction. Environment and Planning D: Society and Space, 23, 637-642.

Moore, J. (2013). 16 June. Anthropocene, capitalocene, and the myth of industrialization. Available online at: https:// jasonwmoore.wordpress.com/2013/06/16/anthropocenecapitalocene-the-myth-of-industrialization/. [Accessed 13, Oct., 2017]. 
Moore, J. (2014). Capitalism as frontier: On the nature and value of 'socially necessary' unpaid work. Available online at: https:// jasonwmoore.wordpress.com/2014/04/16/capitalism-as-frontieron-the-nature-and-value-of-socially-necessary-unpaid-work/. [Accessed on 13, Oct., 2017].

Morris-Jones, W. H. (Ed.). (1980). From Rhodesia to Zimbabwe: Behind and Beyond Lancaster House. London/New York: Routledge.

Moss, T. (2006). Zimbabwe's Two Land Tragedies That Must be Resolved. Available online at: http://www.cgdev.org/page/ zimbabwes-two-land-tragedies-must-be-resolved/ [Accessed 12, Oct., 2017].

Mountz, A., Wright, R., Miyares, I., \& Bailey, A. (2002). Lives in Limbo: Temporary Protected Status and Immigrant Identities. Global networks, 2(4), 335 - 356.

Moyo, S., \& Murisa, T. (2008). Civil Society: Public Action Towards a Transformative Agenda. In S. Moyo, K. Helliker, \& T. Murisa (Eds.), Contested Terrain: Land Reform and Civil Society in Contemporary Zimbabwe. Pietermaritzburg: S\&S Publishers.

Muleya, T. (2015). 13 February. 'Zim woman dies in bank heist'. The Chronicle. Available online at: http://www.chronicle.co.zw/ zim-woman-dies-in-sa-bank-heist/. [Accessed 15, Oct., 2017].

Muleya, T. (2015). 8 September. 'Corrupt Beitbridge Border Post cop fined'. The Herald. Available online at: http://www.herald. co.zw/corrupt-beitbridge-border-post-cop-fined/ [Accessed 10, Oct., 2017].

Muleya, T. (2016). 25 June. 'Another Zim Bus Robbed in SA'. The Chronicle. Available online at: http://www.chronicle.co.zw/ another-zim-bus-robbed-in-sa/. [Accessed 13, Oct., 2017]. 
Muleya, T. (2016). 15 August. ‘Bribes arrests... 2 SA officials nabbed for Beitbridge border corruption'. The Chronicle. Available online at: http://www.chronicle.co.zw/bribes-arrests-2-saofficials-nabbed-for-beitbridge-border-corruption/, [accessed 10, Oct. 2017].

Mundia, V. (2014). Anti-corruption Strategies of the Zimbabwe Revenue Authority (ZIMRA) Customs Department at Beitbridge Border Post: a case -based analysis. (MA Public Administration Thesis), Stellenbosch University, Stellenbosch.

Murray, M. (1995). 'Blackbirding' at 'Crooks' Corner': Illicit Labour Recruiting in the Northern Transvaal, 1910 - 1940. Journal of Southern African Studies, 21(3), 373 - 397.

Musemwa, M. (2006). Disciplining a 'dissident' City:

Hydropolitics in the City of Bulawayo, Matabeleland, Zimbabwe, 1980-1994. Journal of Southern African Studies, 32(2), 239-254.

Musoni, F. (2012). With An Apron in the Caboose: Illegal Migration across the Zimbabwe-South Africa Border. (PhD Thesis). Emory University, Atlanta.

Muzondidya, J., \& Ndlovu-Gatsheni, S. J. (2007). “Echoing silences": ethnicity in post-colonial Zimbabwe, 1980 - 2007. African Jourbnal of Conflict Resolution, 7(2), 275-297.

Muzvidziwa, V. (2012). Cross-border Traders: Emerging, Multiple and Shifting Identies. Alternation, 19(1), 217-238.

Mwenda, A. M., \& Tangri, R. (2005). Patronage politics, donor reforms, and regime consolidation in Uganda. African Affairs, 104(416), 449-467.

Nail, T. (2015). The Figure of the Migrant. Stanford, CA: Stanford University Press. 
Naum, M. (2010). Re-emerging Frontiers: Postcolonial Theory and Historical Archaeology of the Borderlands. Journal of Archaeological Method and Theory, 17(2), 101-131.

Ndlovu-Gatsheni, S. J. (2008). Nation Building in Zimbabwe and the Challenge of Ndebele Particularism. Journal of African Conflict Resolution, 8(1), 27-55.

Neocosmos, M. (2006). From 'foreign Natives' to 'native Foreigners': Explaining Xenophobia in Post-Apartheid South Africa. Citizenship, Nationalism, Identity and Politics. Dakar: CODESRIA.

Neocosmos, M. (2011). Transition, human rights, and violence: rethinking a liberal political relatioshiop in the African neocolony. Interface: a journal for and about social movements, 3(2), 359399.

Newman, D. (2005). Borders and Bordering: Towards and Interdisciplinary Dialogue. European Journal of Social Theory, 9(2), 171-186.

News24. (2006). 12 December. 'Zim runs out of passport ink'. News24 Archives. Available online at: http://www.news24.com/ Africa/Zimbabwe/Zim-runs-out-of-passport-ink-20061212. [Accessed 16, Oct., 2017].

News24. (2016). 2 July. 'Zim army deploys after protesters set Beitbridge warehouse on fire'. Available online at: http://www. news24.com/Africa/News/zim-army-deploys-after-protesters-setbeitbridge-warehouse-on-fire-20160702. [Accessed 28 Sept., 2017].

NewZimbabweVision. (2015). 11 October. 'Bulawayo-Joburg Intercape Bus Nearly Highjacked in South Africa on Sunday Morning'. Available online at: http://newzimbabwevision.com/ bulawayo-joburg-intercape-bus-nearly-hijacked-in-south-africaon-sunday-morning/. [Accessed 13, Oct., 2017]. 
NGOpulse. (2009). 5 August. 'So Near yet So Far: 90-day Zimbabwe Visa Waiver'. SAngoNet. Available online at: http:// www.ngopulse.org/article/so-near-and-yet-so-far-90-dayzimbabwe-visa-waiver. [Accessed 16, Oct., 2017].

Njoku, U. J. (2005). Colonial Political Re-Engineering and the Genesis of Modern Corruption in African Public Service: The Issue of the Warrant Chiefs of South Eastern Nigeria as a Case in Point. Nordic Journal of African Studies, 14(1), 99-116.

Nyamnjoh, F. B. (2006). Insiders and Outsiders: Citizenship and Xenophobia in Contemporary Southern Africa. Dakar: Codesria Books.

Nyamunda, T. (2014). Cross-border Couriers as Symbols of Regional Grievance? The Malayitsha Remittance System in Matabeleland, Zimbabwe. African Diaspora, 7, 38-62.

Nyathi, P. (2016). April 2016. The meaning of hyena as a metaphor for omalayitsha. Personal correspondance.

Nyers, P. (2011). No One is Illegal between City and Nation. Studies in Social Justice, 4(4), 127-143.

Nyers, P. (2015). Migrant Citizenships and Autonomous Mobilities. Migration, Mobility and Displacement, 1(1), 23-39.

Nyers, P., \& Rygiel, K. (2012). Citizenship, migrant activism, and the politics of movement. New York: Routledge.

Nyoni, P. (2011). Malayitsha as Informal Remittance Couriers: A Case Study of Zimbabwean Remittance Transporters (Malayishas) in Central Johannesburg. (MA in Anthropology), University of the witwatersrand, Johannesburg. 
Nyoni, P. (2012). New insights on trust, honour and networking in informal entrepreneurship: Zimbabwean malayishas as informal remittance couriers. Anthropology Southern Africa, 35(12), 1-11.

Ochonu, M. (2014). Africa in Fragments: Essays on Nigeria, Africa, and Global Africanity. New York: Diaspora Africa Press.

Ochonu, M. (2016). 08 September. 'Bring Back Corruption: A Critique of Neo-liberal Anti-corruption Rhetoric'. Pambazuka News: Voices for Freedom and Justice.

Ohmae, K. (Ed.) (1999). The Borderless World: Power and Strategy in the Interlinked World. New York: Harper Collins.

Olivier, d. S. (1999). A Moral Economy of Corruption in Africa. The Journal of Modern African Studies, 37(1), 25-52.

Onselen, C. v. (1976). Chibaro: African Mine Labour in Southern Africa, 1900 to 1933. London: Pluto Press.

Orosco-Mendoza, E. F. (2008). Borderlands Theory: Producing Border Epistemologies with Gloria Anzaldúa. (MA in Political Science), Virginia Polytechnic Institute and State University, Blacksburg.

Oucho, J. (2006). Cross-border Migration and Regional Initiatives in Managing Migration in Southern Africa. In P. Kok, D. Gelderblom, J. Oucho, \& J. van Zyl (Eds.), Migration in South and Southern Africa: Dynamics and Determinants. Pretoria: Human Sciences Research Council.

Oxlund, B. (2010) Responding to university reform in South Africa: student activism at the University of Limpopo. Social Anthropology, 18(1), $30-42$. 
Paasi, A. (1999). Boundaries as Social Process: Territoriality in the World of Flows. Geopolitics, 3(1), 69-88.

Palmer, R. (1977). Land and Racial Domination in Rhodesia. Berkeley and Los Angeles: University of California Press.

Papadopoulos, D., Stephenson, N., \& Tsianos, V. (2008). Escape Routes: Control and Subversion in the 21st Century. Ann Arbor, MI: Pluto Press.

Papadopoulos, D., \& Tsianos, V. (2012). After citizenship: autonomy of migration, organisational ontology and mobile commons. Citizenship Studies, 17(2), 178-196.

Parker, N., \& Alder-Nissen, R. (2012). Picking and Choosing the 'Sovereign Border': A Theory of Changing State Bordering Practices. Geopolitics, 17(4), 773-796.

Parker, N., \& Vaughan-Williams, N. (2012). Introduction: Critical Border Studies: Broadening and Deepening the 'Lines in the Sand' Agenda. Geopolitics, 17(4), 727-733.

Peace, C. C. f. J. a. (2009). Gukurahundi in Zimbabwe: a report on the disturbances in Matabeleland and the Midlands, 1980 - 1989. Johannesburg: Jacana.

Perera, S. (2007). A Pacific Zone? Insecurity, Sovereignty, and Stories of the Pacific Borderscape. In P. K. Rajaram \& C. Grundy-Warr (Eds.), Borderscapes: Hidden geographies and Politics and Territory's Edge. London and Minneapolis: University of Minesota Press.

Phimister, I. (1988). An Economic and Social History of Zimbabwe 1890 - 1948: Capital Accumulation and Class Struggle. Harlow: Longman. 
Pierce, S. (2016). Moral Economies of Corruption: State Formation and political Culture in Nigeria. Durham and London: Duke University Press.

Piper, L., \& von Lieres, B. (2011). Expert Advocacy for the Marginalised: How and Why Democratic Mediation Matters to Deepening Democracy in the South. IDS Working Paper 364. Brighton: Institute for Development Studies.

Piper, L., \& von Lieres, B. (2015). Mediating between States and Citizens: The Significance of the Informal Politics of Third-party Representation in the Global South. Citizenship Studies, 19(6-7), 696-713.

Polanyi, K. (2001 [1944]). The Great Transformation: The Political and Economic Origins of our Time. Boston: Beacon Press.

Polzer, T. (2010). Silence and Fragmentation: South African Responses to Zimbabwean Migration. In J. Crush \& D. Tevera (Eds.), Zimbabwe's Exodus: Crisis, Migration, Survival. Cape Town: SAMP.

Porter, B. (2014, 5th Edition). The Lion's Share: A Short History of British Imperialism, 1850 to the present. London and New York: Routledge.

Project, S. P. (1983). Forced Removals in South Africa: The SSP Reports, Volume 1. Also available online in a different form at: http://www.sahistory.org.za/article/forced-removals-south-africa. [Accessed 16 Oct., 2017].

Raimundo, I. \& Chikanda, A. (2016). Informal Entrepreneurship and Cross-Border Trade in Maputo, Mozambique. SAMP Migration Policy Series, No. 73. Cape Town and Waterloo: SAMP. 
Rajaram, P. K., \& Grundy-Warr, C. (2007). Borderscapes:

Hidden Geographies and Politics at Territory's Edge. Minneapolis: University of Minnesota Press.

Randeraad, N. (Ed.) (1998). Mediators between State and Society. Hilversum: Verloren.

Relph, E. (1976). Place and Placelessness. Pion Limited: London.

Riddell, R. (1980). Zimbabwe's Land Problem: The Central Issue. In W. H. Morris-Jones (Ed.), From Rhodesia to Zimbabwe: Behind and Beyond Lancaster House. London/New York: Routledge.

Riles, A. (Ed.) (2006). Documents: Artifacts of Modern Knowledge. Michigan: University of Michigan Press.

Rodriguez, N. (1996). The Battle for the Border: Notes on Autonomous Migration, Transnational Communities, and the State. Social Justice, 23(3), $21-37$.

Roitman, J. (1990). The Politics of Informal Markets in SubSaharan Africa. Journal of Modern African Studies, 28(4), 671-696.

Roitman, J. (2004). Productivity at the Margins: The Reconstruction of State Power in the Chad Basin. In V. Das \& D. Poole (Eds.), Anthropology at the Margins of the State. New Mexico: School of American Research Press.

Roitman, J. (2005). Fiscal Disobedience: An Anthropology of Economic Regulation. Princeton and Oxford: Princeton University Press.

Roitman, J. (2006). The Ethics of Illegality in the Chad Basin. In J. Comaroff \& J. Comaroff (Eds.), Law and Disorder in the Postcolony. Chicago: Chicago University Press. 
Ron, J. (2003). Frontiers and Ghettos: State Violence in Serbia and Israel. London, Berkeley and Los Angeles: University of Carlifonia Press.

Rosaldo, R. (1993). Culture and Truth: The Remaking of Social Analysis. Boston: Beacon Press.

Rutherford, B. (2008). An Unsettled Belonging: Zimbabwean Farm Workers in Limpopo Province. Journal of Contemporary African Studies, 26 (4), 401 - 415.

Rutherford, B. (2010). Zimbabwean Farm Workers in Limpopo Province, South Africa. In J. McGregor \& R. Primorac (Eds.), Zimbabwe's New Diaspora: Displacement and the Cultural Politics of Survival. Oxford: Berghahn.

Rygiel, K. (2011a). Border Solidarities: migrant activism and the politics of movement and camps at Calais. Citizenship Studies, 15(1), 1-19.

Rygiel, K. (2011b). Giverning border zones of mobility through e-borders: the politics of embodied mobility. In V. Squire (Ed.), The contested politics of mobility: borderzones and irregularity.

London: Routledge.

Sampson, A. (2005). Drum, the Making of a Magazine. Johannesburg: Jonathan Ball.

Sapir, D. J. (1981). Leper, Hyena, and the Blacksmith in Kujamaat Diola Thought. American Ethnologist, 8, 526 - 543.

Saunders, R. (2001). Striking Back: Industrial Action and Labour Movement Development in Zimbabwe. In B. Raftopoulos \& L. Sachikonye (Eds.), Striking Back: The Labour Movement and the Post-colonial State in Zimbabwe, 1980 - 2000. Harare: Weaver Press. 
Schechner, R. (2013). Performance Studies: An Introduction (3rd Edition). London and New York: Routledge.

Scheel, S. (2013). Studying embodied encounters: autonomy of migration beyond its romanticization. Postcolonial Studies, 16(3), 279-288.

Scheper-Huges, N. (2001). Commodity Fetishism in Organs Trafficking. Body and Society, 7(2-3), 31-62.

Schierup, C.-U., Munck, R., Brboric-Likic, B., \& Neergaard, A. (Eds.). (2015). Migration, Precarity and Global Governance: Challenges and Opportunities for Labour. Oxford: Oxford University Press.

Schierup, C. U. (2016). Under the Rainbow: Migration, Precarity and People Power in Post-Apartheid South Africa. Critical Sociology, 1-18.

Schierup, C.-U. (2017). Persornal Communication on the intersection of informalisation from above and informalisation from below. September 2017.

Scierup, C.-U., \& Jorgensen, M. B. (2017) (Eds.). From 'Social Eclusion' to 'Precarity' The Becoming of Labour: An Introduction. In, C.-U Schierup \& M. B. Jorgensen, Politics of Precarity: Migrant Conditions, Struggles and Experiences. Leiden: Brill

Schutz, A. (1962). Collected Papers, Vol. 1: The Problem of Social Reality. The Hague: Martinus Nijhoff Publishers.

Schutz, A., \& Luckman, T. (1973). The Structure of the Life-World, Vol.1. Evanston, IL: Northwest University Press.

Scott, J. (1985). Weapons of the Weak: Everyday Forms of Peasant Resistance. New Haven and London: Yale University Press. 
Scott, J. (1990). Domination and the Arts of Resistance: Hidden Transcripts. New Haven: Yale University Press.

Segatti, A. (2011). Reforming South African Immigration Policy in the Postapartheid Period (1990-2010). In A. Segatti \& L. B. Landau (Eds.), Contemporary Migration to South Africa: A Regional Development Issue. Washington D.C.: The International Bank for Reconstruction and Development / The World Bank.

Segatti, A. W. \& Landau, L. (2011). Contemporary Migration to South Africa: A Regional Development Issue. Washington, D.C.: The International Bank for Reconstruction and Development/ The World Bank.

Shah, A. (2009). Morality, Corruption, and the State: Insights from Jharkhand, East India. Journal of Development Studies, 45(3), 295-313.

Sharma, A., \& Gupta, A. (2006). The Anthropology of the State: A Reader. Oxford: Blackwell Publishers.

Sharma, N. (2009). Escape Artists: Migrants and the Politics of Naming. Subjectivity, 29(1), 467-476.

Sheller, M., \& Urry, J. (2006). The New Mobilities Paradigm. Environment and Planning A, 38(2), 207 - 226.

Sichone, O. (2003). Zimbabwe's Economic Policies, 1980 - 2002. DPMN Bulletin, 10(2).

Sidaway, J. (2011). The Return and Eclipse of Borders? Charting Agendas. Geopolitics, 16(4), 969-976.

Slavnic, Z. (2007). Informalization of the Economy and the Recommodification of Labour. in E. Berggren (Ed.) Irregular Migration, Informal Labour and Community in Europe. Maastricht: Shaker Publishing. 
Slavnic, Z. (2010). The Political Economy of Informalization. European Societies: A Journal of the European Sociological Association, 12(1), 3 - 23.

Slavnic, Z. (2011). Struggle for Survival in the Deregulated Market: Re-commodification and Informalisation of the Taxi Sector in Stockholm. Forum for Social Economics, 40(2), 233 - 251.

Slavnic, Z. (2016). The Informal Economy and the State. In S. Routh \& V. Borghi (Eds.), Workers and the Global Informal Economy: Interdisciplinary Perspectives. London and New York: Routledge.

Smart, A. (1993). Gifts, Bribes and Guanxi: A Reconsideration of Bourdieu's Social Capital. Cultural Anthropology, 8(3), 388 - 408.

Smith, D. (2007). A Culture of Corruption: Everyday Deception and Popular Discontent in Nigeria. Princeton: Princeton university Press.

Sørensen, E. (2008). A Multi-sited Comparison of ‘Doing Regulation'. Comparative Sociology, 7(3), 311-337.

Spener. D. (2009). Clandestine Crossings: Migrants and Coyotes on the Texas-Mexico Border. Ithaca and London: Cornell University Press.

Standing, G. (2011). The precariat: a new dangerous class. London: bloomsbury.

Steinberg, J. (2008). Thin Blue: The Unwritten Rules of Policing in South Africa. Johannesburg: Jonathan Ball.

Stewart, L. (1995). Bodies, Visions, and Spatial Politics: A Review essay on Henri Lefebvre's The Production of Space. Environment and Planning D: Society and Space, 13(5), 609 - 618. 
Stoneman, C., \& Cliffe, L. (1989). Zimbabwe's Political Economy and Society. London: Pinter.

Sutcliffe, J. (2013). 'The Labour Movement in Zimbabwe, 1980 - 2012'. E-International Relations Sudents. Available online at: http://www.e-ir.info/2013/03/07/the-labour-movement-inzimbabwe-1980-2012/. [Accessedm 18 Feb., 2016].

Tati, G. (2008). The Immigration Issues in the Post-Apartheid South Africa: Discourses, Policies and Social Repercussions. Géopolitique et populations, 3, 423-440.

Terreblanche, S. (2003). A History of Inequality in South Africa, 1652 - 2002 Durban: University of KwaZulu-Natal Press.

Tessier, K. (1995). The Challenge of Immigration Policy in the New South Africa. Indiana Journal of Global Legal Studies, 3(1), 225 -260 .

Tevera, D., Crush, J., \& Chikanda, A. (2010). Migrant Remittances and Household Survival in Zimbabwe. In J. Crush \& D. Tevera (Eds.), Zimbabwe's Exodus. Capw Town and Ottawa: SAMP and IDRC.

Thebe, V. (2011). From South Africa with love: The malayisha system and Ndebele households' quest for livelihood reconstruction in south-western Zimbabwe. Journal of Modern African Studies, 49(4), 647-670.

Theron, J. (2010). Informalization from Above, Informalization from Below: The Options for Organization. African Studies Quarterly, 29(7), 1323-1339.

Thomas, N. (1991). 'Sanitation and Seeing. the Creative State Power in Early Colonial Fiji'. Comparative Studies in History and Ethnography, 32, 149-170. 
Tobias, S. (2012). Neoliberal Globalization and the Politics of Migration in Sub-Saharan Africa. Journal of International and Global Studies, 4(1), 1-16.

Torpey, J. (1998). Coming and Going: On the State's Monopolization of the 'Legitimate Means of Movement'. Sociological Theory, 16(3), 239-259.

Torsello, D., \& Venard, B. (2016). The Anthropology of Corruption. Journal of Management Inquiry, 25(1), 34-54.

Trollip, D. C. (2013). Between Boundaries: A New Border Post at Beitbridge. (Master of Architecture (Professional)), University of the Witwatersrand, Johannesburg.

Trust, B. (n.d). History of the Trust. Available online at: http:// www.beittrust.org.uk/history.html. [Accessed 12, Oct., 2017].

Trust, F. (2012). SADC Remittance Flows Report. Available online at: https://www.finmark.org.za/sadc-remittances-flow-report/. [Accessed 12, Oct., 2017].

Tshabalala, X. (2017). Hyenas of the Limpopo: "Illicit Labour Recruiting", Assisted Border Crossings, and the Social Politics of Movement Across South Africa's Border with Zimbabwe, Journal of Borderlands Studies, DOI: 10.1080/08865655.2017.1348910.

Tshabalala, X. (2016). 'Brokerage Economies: Crisis, Cultural Acts and Contested Subjectivities at the Beitbridge Border of South Africa and Zimbabwe', Journal of Trafficking, Organised Crime and Human Security, 2 (2), pp. 141-156.

Tsianos, V., \& Karakayali, S. (2010). Transnational Migration and the Emergence of the European Border Regime: An Ethnographic Analysis. European Journal of Social Theory, 13(3), 373-387. 
Turner, V. (1969). The Ritual Process. London: Routledge.

Turner, V. (1982). Liminal to Liminoid, in Play, Flow, Ritual: An Essay in Comperative Symbology. In V. Turner (Ed.), From Ritual to Theatre: The Human Seriousness of Play. New York: Performing Arts Journal Publications.

van Hear, N. (2011). Mixed Migration: Policy Primer. Oxford: Oxford Migration Observatory.

van Houtum, H. (2005). The Geopolitics of Borders and Boundaries. Geopolitics, 10(4), 672-679.

van Houtum, H., \& van Naerssen, T. (2002). Bordering, Ordering, and Othering. Journal of Economic and Social Geography, 93(2), 125-136.

Vannini, P. (2008). Snacking as Ritual: Eating Behaviour in Public Places. In L. C. Rubin (Ed.), Food for Thought: Essays on Eating and Culture. Jefferson, N.C.: McFarland.

Vigneswaran, D. (2007). Free Movement and the Movement's Forgotten Freedoms: South African Representations of Undocumented Migrants. Oxford: Refugee Studes Centre (RSC Working paper, 41). Available online at: www.rsc.ox.ac.uk/PDFs/ RSCworkingpaper41.pdf. [Accessed 12, Oct. 2017].

Vigneswaran, D., Araia, T., Hoag, C., \& Tshabalala, X. (2010). Criminality or Monopoly: Informal Immigration Enforcement in South Africa. Journal of Southern African Studies, 36(2), 465-481.

Visvanathan, S. (2008). The Necessity of Corruption. Available online at: http://www.india-seminar.com/2008/590/590_shiv_ visvanathan.htm. [Accessed 1 Sept., 2016]. 
VOA (Voice of America). 2010. 10 November. 'Zimbabweans Without Passports in South Africa Running Out of Time'. Available online at: https://www.voanews.com/a/taylor-zimchaos-11nov10-107250998/156809.html. [Accessed 16 Oct., 2017].

Walker, C. (2014). Critical Reflections on South Africa's 1913 Natives Land Act and its Legacies: Introduction. Journal of Southern African Studies, 40(4), 655 - 665.

Walters, W. (2008). Acts of demonstration: mapping the territory of (non-)citizenship. In E. Isin \& G. Nielson (Eds.), Acts of Citzenship. London: Zed Books.

Wentzel, M., \& Tlabela, K. (2006). Historical Backgrounds to Southern African Migration. In P. Kok, D. Gelderblom, J. Oucho, \& J. van Zyl (Eds.), Migration in South and Southern Africa: Dynamics and Determinants. Cape Town: Human Sciences Research Council.

Weber, D. (1995). From Limen to Border: A Meditation on the Legacy of Victor Turner for American Cultural Studies. American Quarterly, 47(3), 525-536.

Weick, E. (1995). What theory is not, theorizing is. Administrative Science Quarterly, 40(3), 385-390.

Werbner, R. (1991). Tears of the Dead: the social biography of an African Family. Edinburgh: Edinburgh University Press.

White, T. H. (1954). The Book of Beasts: Being a Translation from a Latin Bestiary of the Twelfth Century. London: Jonathan Cape.

Wilson, F. (1972). Labour in the South African Gold Mines, 1911 1969. Cambridge: Cambridge University Press. 
Wolf, E. R. (1959). Sons of the Shaking Earth: The People of Mexico and Guatemala, Their Land, History and Cultures. Chicago: University of Chicago Press.

Wolpe, H. (1972). Capitalism and Cheap-labour Power in South Africa: From Segregation to Apartheid. Economy and Society, 1(4), 425-456.

Wolpe, H. (1988). Race, Class, and the Apartheid State. Paris: Unesco Press.

Woolfson, C., \& Likic, B. (2008). Migrants and the unequal burdening of 'toxic' risk: towards a new governance regime. Debatte: Journal of Contemporary Central and Eastern Europe, 16(3), 291-308.

Wotela, K., \& Letsiri, C. (2015). International movements, postapartheid dispensations and illegal immigration into South Africa. The Journal of Transdisciplinary Research in Southern Africa, 11(4), 99 - 117.

Xiang, B., \& Lindquist, J. (2014). Migration Infrustructure. International Migration Review, 48(1), 122 - 148.

Zaroulia, M. (2015). At the Gates of Europe: Sacred Objects, Other Spaces and Performances of Dispossession. In M. Zaroulia \& P. Hager (Eds.), Performances of Capitalism, Crisis and Resistance: Inside/Outside Europe. Hampshire: Palgrave Macmillan.

Zeilig, L. (2002). Crisis in Zimbabwe. International Socialism, 2(93), $75-96$.

Zinyama, L. M. (1990). International Migrations to and from Zimbabwe and the Influence of Political Changes on Population Movements, 1965-1987. International Migration Review, 24(4), 748767. doi:10.2307/2546206 
Zinyama, L. M. (2000). 'Who, what, when and why: crossborder movement from Zimbabwe to South Africa'. In D.

McDonald (Ed.), On Borders: perspectives on international migration in Southern Africa. New York: St. Martins's Press. 
